

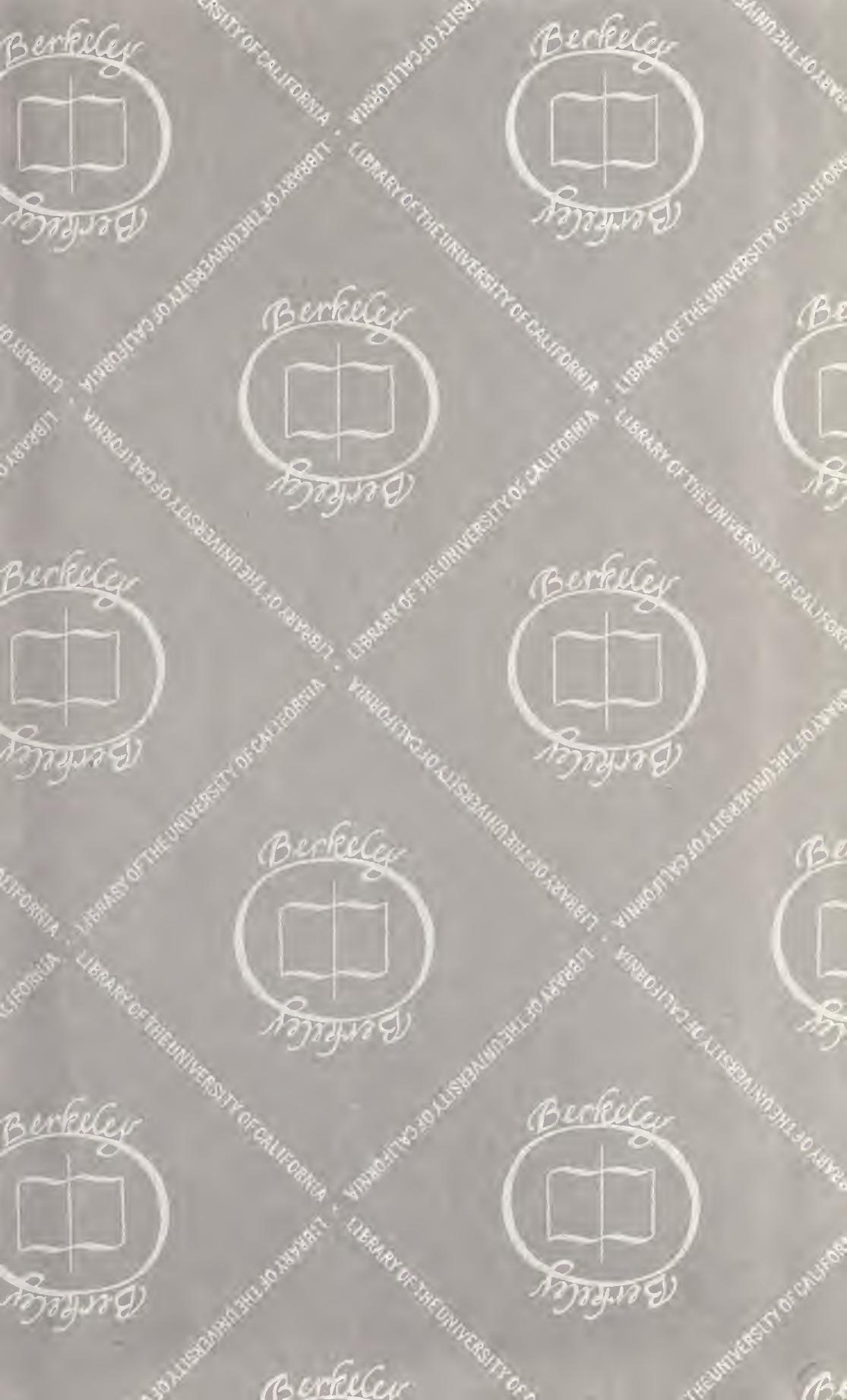




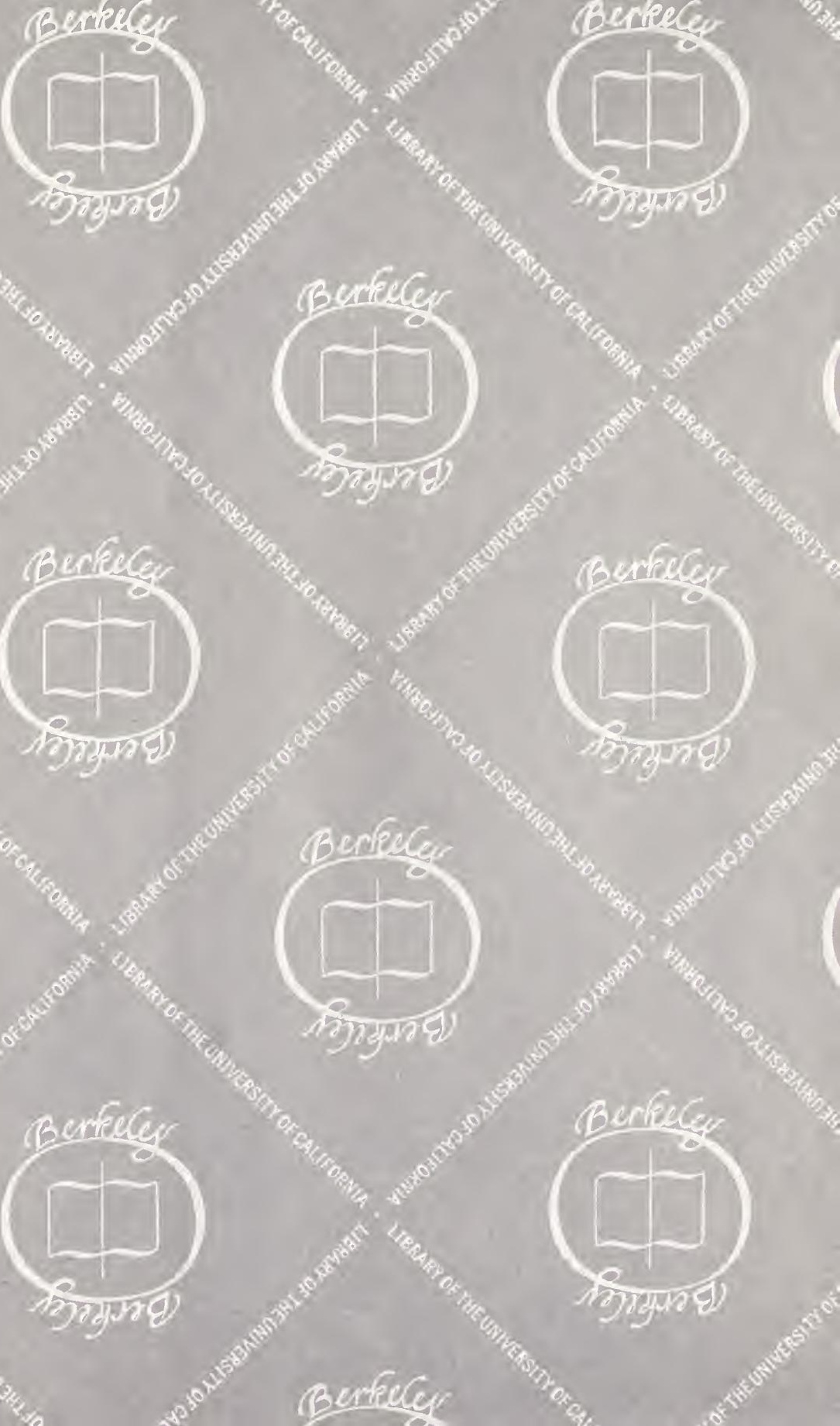







\section{THE UNHEATED}

G R E E N H O U S E

\section{DEPT: OF AGRICULTURE} DIV. OF AGR'L EDVCATION 



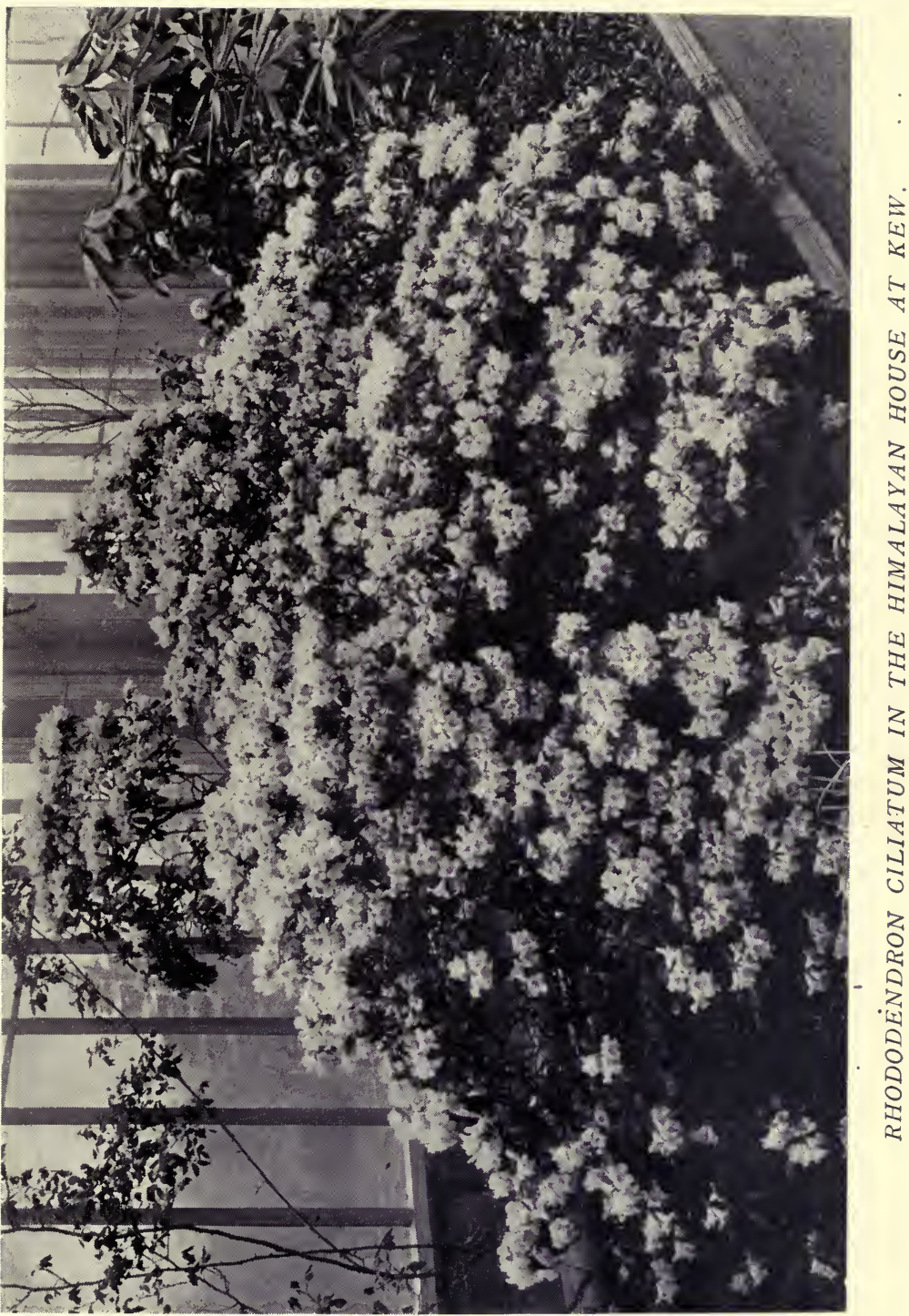


THE "COUNTRY LIFE"

LIBRARY

\section{THE UNHEATED \\ G R E N HO U S E}

BY

K. L. DAVIDSON

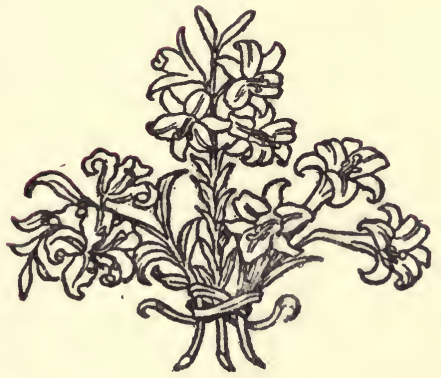

PUBLISHED BY

"COUNTRY LIFE," Ltd. GEORGE NEWNES, Ltd. 20, TAVISTOCK STREET 3-12, SOUTHAMPTON ST. COVENT GARDEN, W.C. COVENT GARDEN, w.C. 



\section{CONTENTS}

CHAP.

YAGE

I. Its Advantages . . . . . . . . I

II. On Typical Cold Greenhouses . . . 8

III. Some Hints on Construction . . . . 15

IV. Regulation of Temperature . . . . 23

V. Plants Suitable and Unsuitable . 30

VI. The Alpine House . . . . . . . 38

VII. Foliage Plants for Grouping • . . . 43

VIII. Bulbs and Tubers-I. Hardy Species • • 49

IX. Bulbs and Tubers-II. Half-Hardy Species 57

X. Lilies . . . . . . . . . . 66

XI. Flowering SHRUBS . $\quad . \quad$ • $\quad . \quad 73$

XII. Some Hard-Wooded Plants . . . . $8 I$

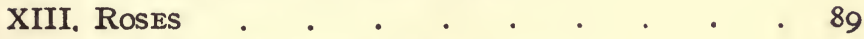

XIV. Hardy Perennials for Spring • • • 94

XV. Autumn Perennials Under Glass . • . IoI

XVI. Annuals and Brennials . . . . . 107

XVII. HARDY ORCHIDS . . . . . . II6

XVIII. Succulent Plants . . . . . . 121

XIX. The Potting Shed-Summer Quarters . . 128

XX. ROUtine Work . . . . . . . . I33

APPENDIX . . . . . . . . . 143

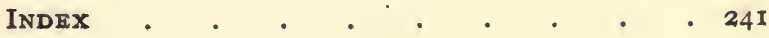




\section{LIST OF ILLUSTRATIONS}

Rhododendron Ciliatum in the Himalayan House at Kew . $\begin{gathered}\text { To face } \\ \text { page }\end{gathered}$

Frontispiece

Campanula Pyramidalis in conservatory . . . . 10

View of the East Corridor in the Botanic Garden, Edinburgh • • • • • • • • • • I I

The Alpine House in Royal Gardens, Kew • . . . 38

Interior of the Alpine House, Kew . 39

Lysimachia Crispidens . • . • . • . 42

Thalictrum Anemonoides . . . . . . 43

Lilium Longiflorum in pots . . . . . . 44

Simple Grouping of Summer Plants . • . . . 45

The Stag's Horn Fern . • . . . . . . 46

A Hardy Fernery - • . . . . . . . . 47

Asparagus Sprengeri . • . . . . . . 48

Chionodoxa (Glory of the Snow) and Iris Rosenbachiana . 49

Fontin's Lily of the Valley . . . . . . 52

A Winter Flowering Iris (I. Stylosa Alba) . . . $\quad 53$

Lachenalias. . . . . . . . . 62

A Rare White Nerine . . . . . . . . 63

Funkia Tardiflora . . . . . . . . . 64

Arthropodium Cirratum . . . . . . . 65

Best Form of Madonna Lily (Lilium Candidum) . 66

Yucca Guaternalensis in the Temperate House at Kew . 67

Lilies Grown in Tub . . . . . . . 68

Hoheria Populnea. . . . . . . . 78

Rhododendron Prœcox in the Temperate House at Kew . 79 
Eriostemon Myoporoides pags Glory Pea (Clianthus Puniceus) . . . . . $\quad 85$ Rose Niphetos as a Pot Plant . . . . . 92 Rose Jersey Beauty as a Pot Plant . . . . . 93 Broad-leaved Siberian Saxifrage (Megasea Ligulata) . $\quad$. 96 Shortia Galacifolia • • . • . . . 97 Primula Marginata. . . . . . . . $\quad$. 98 Auriculas . . . . . . . . . . 99 Symphyandra Wanneri . . . . . . . . 100 Campanula Isophylla Alba . . . . . . . Ior Campanula Fergusoni . . . . . . . . 104 Salvia Azurea Grandiflora . . . . . . . 105 Hybrid Cineraria, Kew . $\quad . \quad$. $\quad . \quad$. $\quad . \quad$. 108 Marguerite Carnations . . . . . . . . 109 Cypripedium Acaule $\quad . \quad$. $\quad . \quad$. $\quad . \quad$. . . 116 Orchis Latifolia . $\quad$. $\quad$. . . . . . II7

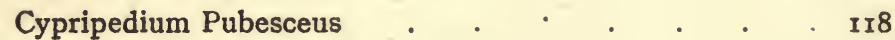
Group of Sarracenias . . . . . . . . II9

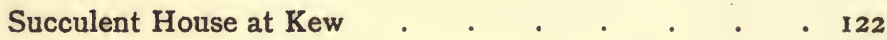
Cereus Triangularis . $\quad . \quad$. $\quad . \quad$. $\quad . \quad$. $\quad$. 123 Mesembryanthemum Roseum in South Devon ${ }^{-}$. . . 124 Sedum Ternatum . $\quad$. $\quad$ • . . . . 125 


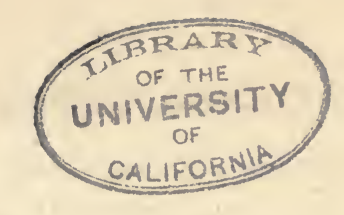

\section{THE UNHEATED GREENHOUSE}

\section{CHAPTER I}

\section{ITS ADVANTAGES}

IT is a strange fact that while every other branch of gardening has made giant strides during recent years the unheated greenhouse still remains neglected and unhonoured. The outdoor border of hardy perennials has its votaries by the thousand, and well it may. The heated glass-house is to be found in most gardens, but it is a question whether a tenth part of the pleasure can be obtained from it all the year round that may be found in the successful management of an unheated greenhouse by the skilful amateur who, whether he rejoices in the aid of a gardener or no, prefers to keep a corner where he may "potter about" at his own sweet will amongst his plants, and work with his own hands on their behalf. This is mainly due to the vicissitudes of our changeful English climate, which for practically half the year makes outdoor gardening impossible for most people, and the heated house dangerous. But both the joys of the open garden and, in a measure, even those of the hot-house may be combined and enhanced under the sheltering roof of the unheated greenhouse, as I hope to be able to show in the following notes, which are faithful records of many years of practical experience.

It is well from the starting-point to have a clear under- 
standing of what is meant by a cold greenhouse. It is one in which it is neither convenient nor desirable to have a fixed heating apparatus, and in which it is only intended to prevent the temperature from falling below $35^{\circ}$ or, in other words, simply to keep out frost. The term "fixed" is used advisedly, for though there may be cases of glass corridors or of a larger glass-garden in which an ordinary fixed flow-andreturn pipe might answer better than a removable apparatus, it must be borne in mind that the main principle of the unheated greenhouse-except during the few dead and dark weeks which precede and follow the shortest day, or on the occasion of a sudden fall of temperature or of damping fogis to keep it cool enough for the plants of temperate regions, which alone are suitable to be grown in it. It goes without saying that the mere shelter of glass will not keep out severe frost. Therefore some means of raising the temperature under certain conditions of weather, to be considered later, are not forbidden to the cold greenhouse; but artificial heat being, in a general way, not only needless but undesirable, it should be on all accounts as temporary in its character as possible. Heating power of even the most temporary character may be entirely dispensed with, as in the case of an alpinery, which is one of the most delightful forms of the cold greenhouse, but, of necessity, it limits in some degree the choice of plants.

It must be confessed that such unheated glass-houses are by no means in favour. The professional gardener, as a rule, pins his faith to the boiler and pipes, and looks askance at the plants which will thrive in a temperature lower than from $60^{\circ}$ to $80^{\circ}$. Tinctured with the hurry and impatience of slow results characteristic of the age, he rejoices in the quick development of fine showy plants, and it is not to be denied that splendid success follows his skilful culture. Much of the success is ephemeral, however, not to say stereotyped. One 
may go into greenhouse after greenhouse and find beautiful and well-grown foliage and flowers, undoubtedly, but all of the same stamp. It is seldom that a new and distinct plant arrests one's steps and arouses one's enthusiasm, and how rarely does one see nowadays the grand specimens of hardwooded plants which were the pride and glory of a past generation, but which took both time and patience to build up. To-day the gardener's art consists in turning out plants wholesale, and it is not too often that he has any incentive from his employers to rise above it, and truly enough it saves a "power of trouble." The amateur, on the other hand, longs to move out of the common groove, and grudges no trouble, but he taxes the capabilities of his unheated house beyond its reasonable limits, and it fails. Midwinter finds him mourning over half-frozen flowers, which, in the quaint phrase of our forefathers, refuse to "blow," and will scarcely even exist. He also, therefore, denounces his cold greenhouse as a fraud, because he has grown plants in it which cannot thrive in a low temperature, and either practically gives it up or orders a furnace. Thus both professional gardener and untutored amateur agree in condemning the cold greenhouse, though from different points of view.

Now my plea is not for unheated greenhouses as against hot-houses. We cannot do without the lovely flowers of the tropics-the Allamandas and Dipladenias, the Palms, and the Orchids, which are such a delight to all flower-lovers. Let us have these by all means, but all the same we need not overlook the numberless hardier plants, not inferior to them in beauty, which are grateful for the simple shelter of glass, and will give us of their best without the expense and labour involved by an elaborate heating apparatus. Believe me, the gardener's - and more especially the amateur gardener'stroubles are not at an end when his greenhouse is fully equipped with boiler and quadruple rows of pipes. Let us, 
then, consider chiefly the advantages and disadvantages, or rather limitations, of the unheated greenhouse for the practical gardener.

\section{HEALTHFULNESS}

There are hundreds of delicate people who dare not venture to stand about out of doors on a chill autumn or winter's day to superintend garden operations who yet, of all recreations, best enjoy the tending and environment of plants. The relaxing heat of a stove is equally insupportable for any length of time, and abrupt transitions from the moist warmth, even of an intermediate house, into the freezing outer air, or a sudden grappling with a keen easterly blast, is more than even the strongest can stand without risk. It is no small boon, then, on a dreary winter's day to have a place of shelter, neither too cold nor too hot, and a possible occupation where an hour or two may be safely spent in the company of the plants we love. It is a melancholy fact that the glass-house, seen from outside as a garden adjunct, is not itself, in an artistic sense, a thing of beauty. It is even worse than a mere negative, and sometimes becomes a positive eyesore. All the more reason, therefore, that the inner aspect should atone for the outer, that when we enter it we may be tempted by a genial atmosphere to linger long to enjoy the loveliness of leaf and flower, without a vague dread of an evil genius of bronchitis or rheumatism hovering about us with shadowing wing. If we have the true gardening spirit there will always be some work to do, some new interest to discover. Outside, the rain may patter on the glass or the bare boughs toss in the whistling wind, and only the pale Hellebore or perhaps a belated China Rose ventures to brave the inclement season before the Snowdrops come; but within, while we run no risks, we may have greenery and tender spring tints and scents of early Hyacinth and Iris, of Violet and Crocus, and a host of flowers which 
only ask the gentle coaxing of a little shelter to bless us for our courtesy by stealing, with innocent guile, a few hours from the "winter of our discontent."

\section{MODERATE COST}

"Who loves a garden loves a greenhouse too," and if this were true in Cowper's day, it is no less true in ours. We are becoming every day more and more a nation of gardeners, and no sooner does the passion for growing plants seize upon us than the necessity of some shelter for them in severe weather makes itself felt. The fine crop of glass-houses which has sprung up over the length and breadth of the land during the last half-century took its origin, probably, from the urgent need of saving through the winter the bedding plants which were to fill the garden beds in summer. Cheap as glass and woodwork may be now, the greenhouse was formerly in many cases the outcome of much cogitation and self-denial in small luxuries, to end after all, not seldom, in disappointment, for the heating, through ignorance of its need, had been overlooked, and the very considerable expense of a boiler and pipes. had never entered into the calculation. Bedding plants are not quite so much in vogue as of yore, but still the wail goes up-scarcely a week passes but it may be heard in country home, in rectory, or in suburban villa- "We can't save our Geraniums "- geranium being a generic term handy for daily use- " because we have no heat in the greenhouse." And it is very true, for here we come to the limitations of the coldhouse. In it we must not expect to grow the plants which require heat in winter to bring them to perfection. Pelargoniums, it is true, will exist in a temperature that never falls below $35^{\circ}$, and some will even stand a slight frost, as is seen by the vigorous specimens to be seen occasionally against a wall under the sheltering eaves of a cottage in Devon or 
Cornwall, but they are not the type of plant best suited for the unheated greenhouse. Generally, in these cases, it is a question of expense. Either there is no means of heating or no efficient member of the household to discharge the duty of attending to the greenhouse fire, or it may be the cost of fuel which must be considered-with the usual result of a useless greenhouse. Expense may be of little consequence in some gardens, but these are in the minority. Even to those who are ready to spare no expense the coal bill in these days of exorbitant prices becomes a question of some moment, and it is astonishing what a capacious maw is possessed by the monster called a greenhouse furnace. On the score, then, both of initial cost of a permanent heating apparatus and a constantly recurring expense for fuel, I rest a second plea for the cold greenhouse, in spite of its limitations with regard to certain classes of tender plants.

\section{SIMPLICITY OF MANAGEMENT}

The garden-lover who has no experienced helper-perhaps also some who professedly have--knows full well the wretched trick the furnace is apt to play of going out on the very night of the hardest frost of the year, of pipes bursting at inconvenient seasons, and the misery of finding plants ruined and the work of many a happy though arduous day lost for ever. Needless to descant on the daily and nightly joys of the stokehole, even when all goes well. But if there be risks and impediments such as these when the thermometer falls below freezing-point, there are difficulties more insidious, but none the less real, in regulating a high temperature. Plants grow with amazing rapidity in heat, and the novice is delighted with his early success; but, alas! they also lengthen, and before long his plants, like the unfortunates celebrated by Tennyson 
which were "by squares of tropic summer shut and warmed in crystal cases," are apt to meet the same fate, or-

"These, though fed with careful dirt,

Are neither green nor sappy;

Half-conscious of the garden squirt,

The spindlings look unhappy."

Unhappily, too, other things grow as fast as the spindlings. Aphis is but a feeble foe, comparatively speaking, and easily to be overcome; but the horror of a visitation of mealy bug -the plague of the hothouse-is not to be described, and scale is nearly as noxious. In the unheated greenhouse the annoyance of such direful insect pests is greatly lessened, and the careful gardener need have none of them. On the score, then, of simplicity of management, I rest my third plea.

To sum up, therefore: For health of enjoyment, for minimum of expense, and for easy handling, the unheated greenhouse presents certain advantages not heedlessly to be overlooked by the lover of plants who makes a hobby of cultivating them for his own pleasure. Add to these somewhat prosaic advantages the great charm of seeking out and making friends with rare and unusual plants, of persuading them to grow and do well under unwonted conditions, of bringing fragments from far distant lands to remind us of happy hours spent under sunnier skies, or of raising seedlings sent from furthest corners of the Empire to show the diverse flora of the environment of new homes. In such manifold ways the cold greenhouse at all times of the year never fails the intelligent gardener. It is subject to no great extremes of temperature, it may be large or small as means or strength will permit, it may be planted out to form a garden under glass, or it may be used exclusively for pot plants. It steps in midway between garden and hothouse, sharing and prolonging the pleasures of the one and giving a safe haven to the refugees of the other. 


\section{CHAPTER II}

\section{ON TYPICAL COLD GREENHOUSES}

THE unheated greenhouse may be represented by four distinct types, which can be classed as follows : I. The glass-garden. 2. The garden corridor. 3. The conservatory. 4. The ordinary span, or lean-to greenhouse. Under each of these heads a few remarks will be necessary.

\section{THE GLASS-GARDEN}

Under the somewhat clumsy name-for want of a betterof the glass-garden it is intended to express the greenhouse adapted for the permanent planting of shrubs and climbers. It is, in fact, a garden in miniature, covered by glass, but requiring no interior furnishing, as of stands or stages, other than the plants themselves. The laying out of the beds, borders, and pathways must be controlled by the size of the structure and the kind of plants, be they shrubs or be they alpines, to be grown in it ; but while the main planting is permanent, it can and should be so arranged as to leave ample room for the introduction of successional plants. This, in outline, is the idea of the glass-garden; and while it may be the most ambitious, it is, perhaps, also the most delightful, type of the cold greenhouse. Such a house may be of grand dimensions-an annexe, possibly, of one of the long ranges of glass-houses to be found in many a stately garden, constructed 
chiefly for the winter protection of flowering shrubs and bulbs, and for the purpose of giving interest and enjoyment, together with a certain amount of exercise, to those who are debarred from taking an active share in the more vigorous pursuits of healthy outdoor English life.

It stands to reason, to begin with, that the construction, as well as the planting, of such a winter garden requires both judgment and good taste, and will give ample scope for the exercise of a thorough knowledge of suitable subjects. Here, too, is a case in point, where a cold greenhouse may reasonably be fitted with a single or even double flow-and-return pipe, as required by the size of the building, in connection with the main boiler, but so furnished with valves as to shut off all heat, except when absolutely needful to keep out frost or to put the air in circulation to prevent stagnant damp. It is not hard to picture a grand glass-garden of this kind, large enough to give a permanent home to the flowering Acacias, Himalayan Rhododendrons, Boronias, Correas, and the like, which, though tender, live and flower profusely out of doors in sheltered positions in the favoured climate-for example, of the Isles of Scilly. It may be taken for granted that all shrubs and plants -and their name is legion-that will live happily in the open air in our southernmost counties are fit subjects to thrive well under the shelter of glass, assisted, in the hardest weather only, by just so much artificial heat as will suffice to prevent the thermometer falling below $35^{\circ}$. Any of us who have had experience of the difference in well-doing between plants grown in pots and those which receive the more generous treatment of the greenhouse border will readily understand the advantages offered on this point by the glass-garden. Such a house should be under the charge of an exceptionally intelligent gardener, well instructed and interested in the cultivation of hardy and half-hardy plants, who will take a pride in making use of the heating apparatus as sparingly as possible. The idea, 
however, of a coalition between hardy plants and a glass shelter has hardly as yet permeated the minds of any but a few garden enthusiasts; but this slur will not long be cast upon English gardens. Kew has taken the initiative in the costly and splendid new wing which has been added within the last few years to the Temperate range of glass-houses, and it is there we must go to learn what may be done on the grandest scale in the glass-garden. It is true that ample provision is there made for raising the temperature, but it is used only in case of need, and we come upon frequent mention of the "big unheated greenhouse" in notices of plants in flower in the Gardens. This covered-in garden, with its rare and lovely shrubs and exquisite Lilies, forms one of the most delightful attractions of Kew, which has so worthily earned, especially of late years, the appreciation and gratitude of all true garden lovers.

But we need not despair if, on the other hand, our winter garden must be of very modest character, and if our wish is to do without heating at all, even of the most temporary and removable kind. So be it. There is plenty of material at hand if one chooses without trespassing an inch upon dubitable ground, and quite as much pleasure and happiness to be gained in the use of it. I remember well the description of such a winter garden given in the pages of the Garden perhaps twenty years ago. In it there were neither hot-water pipes nor heating of any sort to get out of order and worry the contented owner, who was, nevertheless, under no great concern for his plants even in the midst of the hardest of black frosts, for he took care to grow only such as could pass through it unscathed, and who revelled in the fairest of spring bulbs and early flowers long before the open garden could boast of more than a chance blossom here and there. Very tew-more's the pity -have been found to follow so good a lead and attain as great a reward. 
$y^{3}$

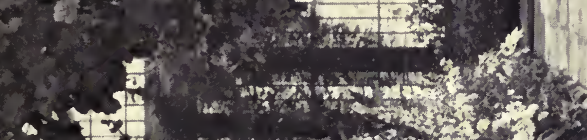

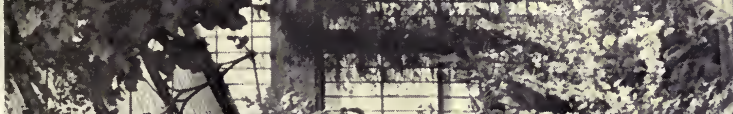

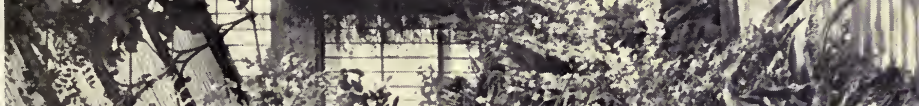

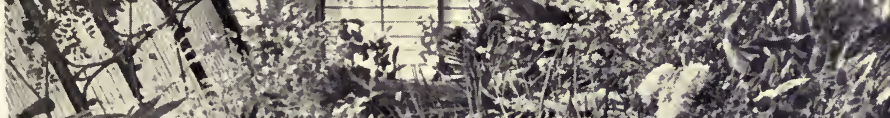

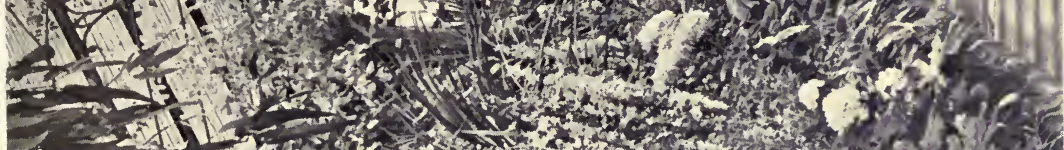

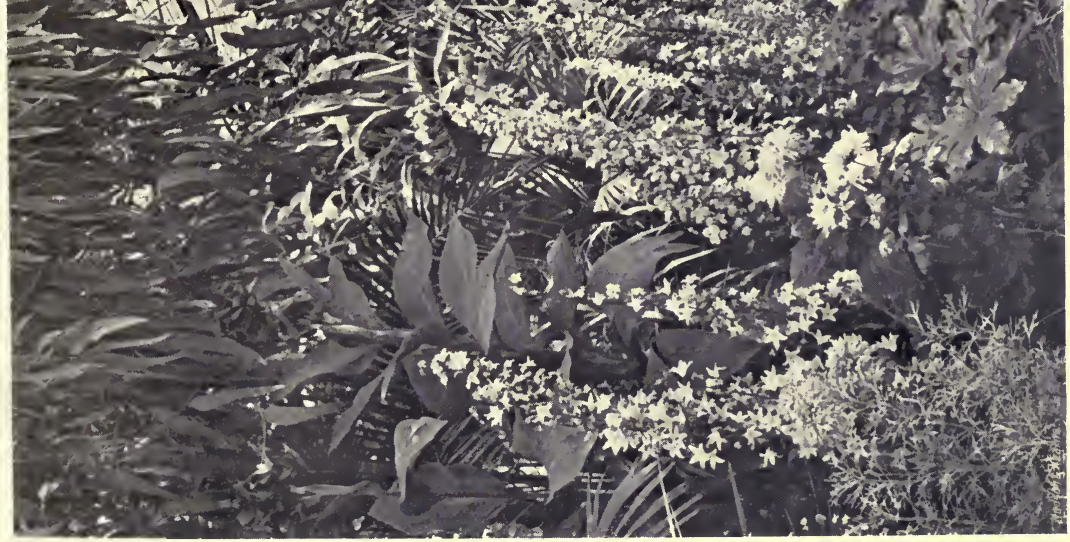




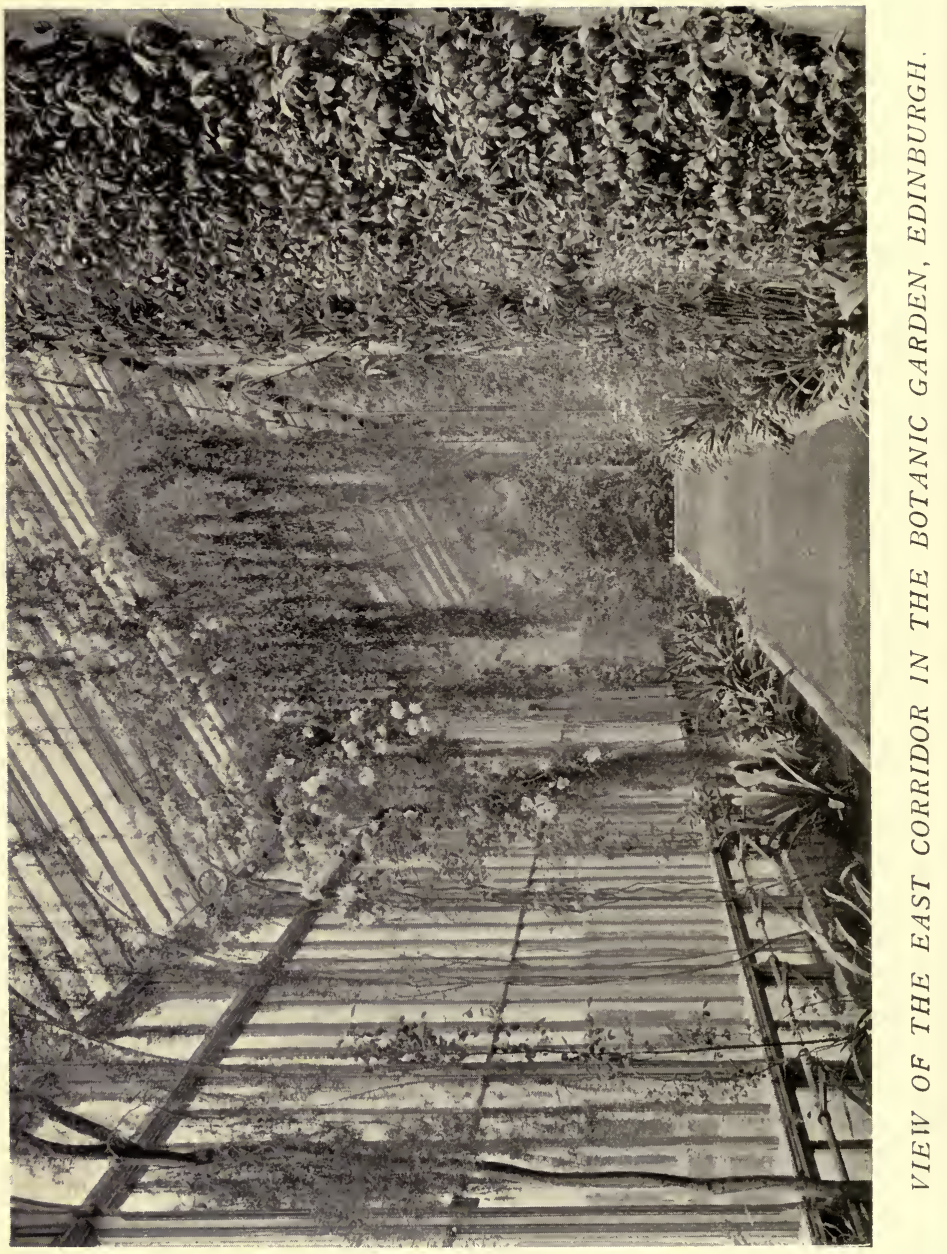




\section{THE GARDEN CORRIDOR}

The unheated greenhouse may take on occasion the form of a glass corridor, and when this happens to be a lean-to passageway connecting garden structures, or it may be outlying rooms of a dwelling, it is the place of all others in which to grow specimens of the rarer flowering shrubs, such as Carpenteria californica, which succeed best when trained against a wall, and which are all the better for having their root-room restricted by a narrow border. Sometimes a glass corridor may more conveniently have a span roof, as, for example, in cases where there is no carriage-way to the entrance of the house, and more or less distance has to be crossed in bad weather before reaching shelter. A covered way, under such circumstances, though not in itself beautiful, is a boon to guests, and some method of making a simple glass-passage of the kind presentable at small expense is no less a boon sometimes to the host. There are plenty of hardy climbers of which use may be made, like the finer kinds of Clematis and Jasmines, of Ivy and of Vine, not to speak of Tea Roses, which are the glory of the cold-house gardener, while a corridor is a most fitting place for Agapanthus or Crinum Moorei, or any such grand but unwieldy plants, which are best grown in tubs or in Italian pottery of the massive sort. The only wonder is, with such wealth of fine and easily grown plants of every kind and habit at command, that our glass-houses should, even at this date, be so indifferently furnished as to variety, which the majority of them undoubtedly are.

But further discussion of suitable subjects for cold greenhouse treatment must be set aside for the present, and we must turn to the less ambitious types of glass-house, to be found in everybody's garden, which are mainly under the personal control of the owner, with or without the help of a gardener. 


\section{THE CONSERVATORY}

There are two forms of glass-house common to the gardens of most country homes : the conservatory, which adjoins the dwelling, and into which one or more of the sitting-rooms generally open; and the greenhouse, which finds its separate place, with more or less aptitude for its purpose, in the garden. Now, "conservatory" is a pretentious name, and it might be wished that one more modest could be coined to replace it; but it would seem as if few folk were alive to the fact that conservatory and greenhouse are not convertible terms. Yet the difference between them is plain and well marked-a conservatory being a shelter where plants in flower may be shown and admired, while the greenhouse is the home and, at times, the hospital of plants in growth. Where only one of these exists, doubtless there must be some adaptation to circumstances; but it can scarcely be too much insisted on that the conservatory is not intended to be turned into a working greenhouse, as is too often done. If it must be, then I venture to urge that it is better to draw a curtain between sitting-room and the inevitable dishevelment of the garden workshop, and to let a cheerful bay-window, a glass porch, or any other convenient position receive the plants we have cherished, when they are ready to be displayed in their beauty. The conservatory, being, in fact, an ante-chamber or vestibule to the living-rooms of the house, should be, equally with these, always in good order. One of the first considerations, therefore, is to keep it clean.

This very trite assertion may provoke a jeer, but only those who have held the reins of management in their own hands can have any idea of the way in which debris of withered leaves and fallen flowers accumulate, to say nothing of evil pests in the shape of slugs and caterpillars, woodlice and centipedes, which stray in and hide under stages and in odd 
corners; and how important it is to keep clear of the unavoidable mustiness which comes of more or less perpetual damp. For this reason it is strongly to be recommended that a conservatory be used strictly for pot plants, that there should be no heavy fixed stages and no inside border for permanent planting of shrubs or climbers, in order that, at short intervals, the house may be emptied and thoroughly cleaned and rearranged. Stands or stages should be used mainly as aids in the grouping of plants, and the lighter and more unobtrusive and easily movable they are the better. These points are touched upon lightly here, for they must be reverted to later, and will very likely be regarded as fads; but experience teaches. Cleanliness and good order, with fresh, healthy plants, well grouped and not always in the same stereotyped position, go far to make even a small conservatory not only the joy and pride of its owner but a pleasure to all who see it. A conservatory of this kind, however, necessitates some sort of separate and extra resource to act as feeder to it, and this may be found in cold frames or pits, or in a working greenhouse, from whence plants may be brought, and to which they can be returned when their flowering is over.

\section{THE WORKING GREENHOUSE}

The ordinary span or lean-to greenhouse usually finds its place in some corner of the garden, and generally is-and ought to be-furnished with a front bench and some sort of stage. Dampness and a certain amount of " undress " here is not out of place. One's plants are in their nursery, or, it may be, recruiting; pans of seedlings may stand about ; Ferns may be tucked away under the stage; a Maréchal Niel, with its roots in an inside border, or any other climbers one may desire, can be trained up the rafters or on the back-wall; and pruned back-plants, however shabby-looking, need not hide 
their diminished heads. What would be incongruous and unsightly in the conservatory is here natural and right. There is little, perhaps, to be said on so well-worn a theme for the present; but certain points of construction, important to be considered in putting up any of the types of unheated glasshouses here spoken of, remain to be suggested. Only this let me add. It is the working greenhouse that is the best of all - the sanctum sanctorum of the gardener. Who but those who know it can fathom the peace, the rest, the depth of happiness to be found within its hallowed precincts. What marvels of plant life open out there to the patient observer, what strange vagaries of the germination of seeds, what mysterious processes in the germination of Ferns; what rare loveliness in the silent building up, leaf by leaf, of even the commonest plant; what exquisite art in the gradual laying on of colours and moulding of buds and flowers! Aye! but treasures such as these are only unfolded to the vision of the devout lover who thinks no toil too great that will unlock the cabinet of Nature's secrets; whose hand is not afraid to risk the roughness of daily tending; whose ear is awake to whispers so low that they are unheeded by idle passers-by; whose eye is quick to note the changes of an hour. Such reverent students learn to worship while they work, and to them, in the uplifting symbolism of Eastern speech, plants and flowers become, in very truth, as "the fringes of the garment of God." 


\section{CHAPTER III}

\section{SOME HINTS ON CONSTRUCTION}

Too often it happens that we are the victims of circumstance and have to make the best of what falls to our lot, but when we can be the architects of our own fortunes in greenhouse matters it is well to know beforehand exactly what we want. Without pretending to enter too much into details, which must be regulated by individual cases, let me set down a few points of construction of special importance to the well-doing of the unheated greenhouse which have come under my own notice.

\section{ASPECT}

To begin with, a few words on aspect, which, though they may apply equally well to all plant-houses, may not be out of place here. It is generally admitted that for the successful culture of plants a span house, wherever it is possible, is far and away the best form of glass structure. It is warmer and lighter, and in it a genial atmosphere can be more easily maintained. An open position, away from high walls and trees, should be chosen for its site, with a run, by preference, from east to west which, on the whole, gives the best results. But a lean-to house is often a necessity, and, in such circumstances, should be placed, if possible, against a south wall, especially when it is required for the bringing on of early flowering shrubs or bulbs, and general working 
purposes. For a conservatory the case is different, and east, west, or even north, should be chosen rather than a southern aspect, which is generally far too scorching in spring and summer for the well being of plants in flower, though necessarily colder in winter. It has happened to me to enter into possession of a conservatory so badly planned at the outset, though intended to be imposing, and such a veritable suntrap, that it was hopeless to try to keep it well arranged with fresh-looking foliage or flowers. Ultimately it was turned into an abode for Cacti and succulent plants, for which it was passably well adapted. For strictly decorative purposes, therefore, a north aspect may be not without its advantages. Otherwise it is to be avoided, as it can only be used successfully for certain shade-loving plants, of which Lapageria may be given as a notable example.

It is well to remember that under any aspect-favourable or otherwise-something in the way of plant life may be found to which the special circumstances are exactly suited, and so, when these are adverse, to take courage. It sometimes happens that a most unpromising greenhouse may turn out to be a blessing in disguise. A lean-to house in a north aspect, for example, has been found before now to be specially well adapted for the culture of certain fine Orchids, such as Disas, and for New Zealand Filmy Ferns.

Site and aspect being chosen, the special needs of the unheated greenhouse must be considered. These are dryness, ventilation, and shading.

\section{DRYNESS}

It may seem absurd to insist upon dryness as an essential point in a plant-house, which, from its very purpose, must be more or less damp; but there is always a point when a blessing may become a curse, and of all worries and annoy- 
ances in a cold greenhouse there are none greater than drip. The evil is not so urgent in summer, though even then there are bulbs put aside to ripen, or succulent plants on no account to be over-watered, which the drip is sure to visit in preference to the moisture-loving plant a foot or two distant; but in winter, when heavy rain is often speedily followed by hard frost, to have pot plants soaked with water and then frozen is simple ruin, and means many a heart-break. It is by no means a very easy matter to avoid this trouble, and carpenters inexperienced in horticultural building have sometimes to be employed, especially in the country, and they are apt to make mistakes. It is probably safer to put all such work into the hands of some well-known and established firm, but it is a very general practice in these days to obtain woodwork and glass all ready to put together and to do the fitting on the spot with such assistance as is at hand. When this is done care should be taken to insist on well-seasoned wood, the lack of which is a fruitful source of mischief. Forewarned is forearmed, and a few hints to those who have to overlook an inexpert workman or to do the fitting themselves may be helpful. The slope of the roof, the quality and lap of the glass, and the shooting to carry off the surplus rainfall, are all matters of moment which cannot be provided for at haphazard with impunity. It is an axiom well understood by gardeners, but not so well by amateurs, that a plant-house should be no higher than is actually necessary for the plants grown in it, allowing, of course, comfortable head-room for the cultivator. In other words, the plants should be as near the light as possible, a lofty house in most cases being positively detrimental to them. On the other hand, a low-pitched house will, as gardeners say, "keep the moisture down," which means a damp-laden atmosphere. Now this is just what is wanted in some cases-e.g., in a Cucumber pitwhere strong heat and heavy moisture are essential factors in 
successful culture; but in an unheated house moist air, which in winter is liable to be stagnant and must be chill, is exactly what we have to avoid. To put it more accurately, we must have it in our power to regulate the degree of atmospheric damp, supplying moisture when required in hot, dry weather, but keeping mostly on the side of moderate dryness both in summer and winter. Where the roof is steep, however, hot sunshine will cause a rapid upward current, which dries the air so thoroughly that plants will quickly droop, and unless constantly refreshed they will soon hang out signals of supreme distress in the way of blight. Not only so, but a steep roof takes more glass and presents a greater surface to frost. A happy mean must therefore be struck, and it lies between the two extremes of $25^{\circ}$ and $35^{\circ}$, or at most $40^{\circ}$, with the proviso that the house be kept as low as it reasonably can be in accordance with its proposed purpose, whether it be for dwarf-growing alpines or flowering shrubs or Roses. For a small house $20 \mathrm{ft}$. by $\mathrm{I} 2 \mathrm{ft}$., a good average slope would be $37^{\circ}$, for if the width be narrow a higher pitch is required to give standing room; but in planning a house it is much better to allow for as much breadth as possible, as it will be found more convenient in every way.

Careful glazing is essential. Glass of $2 \mathbf{~ o z}$. quality should always be used, to save breakage amongst other reasons, and a good average size for the panes is 22 in. by 14 in.

It was pleaded not long ago in a monthly serial of high artistic authority that greenhouses should be built "as of old, with small sheets of glass laid thickly overlapping, and more proof against scorching and freezing than the neat, bigsheeted, modern kinds," and from an artistic point of view this advice cannot be gainsaid. There is truth, too, in the argument that thick overlapping may give more shade in summer and greater protection in winter, though it does not counterbalance other disadvantages; but greenhouses, un- 
happily, are not picturesque, and we must be content meanwhile with the practical side of the question. So let the gardener court all the light that is so essential a factor in the wellbeing of plants. An overlap of half an inch is quite enough. When it is broader green mould collects, which is not even picturesque in its ugliness, while in hard frosts the moisture which lodges becomes frozen, and very often cracks the glass. Smoothly ground edges to fit closely without any lap are sometimes recommended, but the panes are liable to slip and occasion needless trouble. In any case this plan is better left unattempted by unskilled hands. As a hint to an inexperienced glazier, and to ensure a water-tight roof, the squares should be well bedded in putty, which must be neatly trimmed off within and without-no outside putty being required-and it is well to use, besides, four brass-tacks to keep each pane in place. If these small details are not overlooked, and the woodwork kept at all times thoroughly well painted inside and out, there ought to be no fear of annoyance from drip. An excellent method adopted by a thoroughly practical horticultural architect is slightly to round off the lower edge of each pane of glass, which attracts the wet to the middle point and greatly lessens the risk of drip.

No less important is it to avoid ground-damp, and a good brick or concrete path in a working greenhouse is a great boon. In a conservatory opening out of rooms a flooring of tiles that are non-porous is very desirable. Flags are commonly used for this purpose, especially in the country, and perhaps look better, but they "hold the wet," and if quite plain tiles are chosen there need be nothing to offend the eye, while the gain is great. In hot weather the floor can be sprinkled several times a day, and the moisture will quickly find its way into the air and leave no puddles behind it. Borders are not to be recommended, as has been said before, or any kind of planting out in a conservatory, 
especially in a small one, partly, though not wholly, on account of ground-damp, but this must be a matter for individual taste to decide.

Delightful as it is to look out upon a garden picture of bright flowers close at hand when all beyond is shrouded in fog or iron-bound in frost, it must be granted that a good deal of damp, very undesirable but easily communicated to a sitting-room, is a not infrequent sequence of the privilege, especially when the conservatory is unheated. It can be mitigated, however, if not altogether avoided, overhead by the thoroughly sufficient system of glazing that has been here recommended for the prevention of drip, and under foot by a floor tiled throughout, which effectually precludes the rising of moisture from the ground.

\section{SHOOTING}

An abundant supply of rain-water close at hand is important, no less for the convenience of the cultivator than for the welfare of his plants, and no working greenhouse should be built without a tank of some sort to hold the rainfall from the roof and proper gutters to convey it into the right receptacle. The waste of water in this land of ours is enormous, and it is a subject which calls for much more serious consideration by experts than has hitherto been given to it. In a small way-e.g., from the roofs of glass-houses in private gardens-much good, pure water is allowed to run away for want of proper shooting, soaking into the ground, where it makes a swamp and doing harm where it should be an unmixed good. A well-cemented covered tank below the ground level with a pump is perhaps the most convenient form of reservoir, as its holding capacity may be as great, in reason, as space and circumstance will permit, and certainly greater than that of any cistern that can be placed in the 
greenhouse itself. An open tank possesses this advantage, however, that the water it contains is tempered and never so cold as that which is drawn from below; but it takes up room, and, unless very well planned, is ugly. For some positions a barrel half-hidden by Ivy answers very well, and may be made a pretty feature; but, in truth, standing water in an open tank is better outside than within an unheated greenhouse, so long as there is a supply close at hand. The shooting in most general use is 3 in. "half round" iron guttering, held up by brackets; but 3 in. "three-quarter round" spouting is better for heavy rainfall, as it is a great nuisance to have an overflow running down the glass and finding its way into the greenhouse instead of into the tank. In fixing the gutters a fall of from 3 in. to 4 in. should be allowed in a length of $50 \mathrm{ft}$.

Before passing on to other conditions of temperature dependent on ventilation and shading, it may be well to suggest here that much vexation and trouble will, generally speaking, be saved if the plan of the greenhouse or conservatory be made on the simplest lines. As far as my experience goes most round or octagonal houses with a lantern-shaped addition at the top are less adapted to answer the needs of the average amateur, as they certainly are of the professional gardener, than the more usual straight-lined forms, which also have the advantage of being less costly.

One more item. It is becoming more and more the custom to add coloured glass in some shape or form to planthouses. Sometimes it is intended as an embellishment, sometimes as a screen from too neighbouring houses. Be that as it may, it can scarcely be too forcibly stated that the plant-grower who is content with plain, clear panes will find himself the happier man in the long run. The question of 
taste is another matter. Here we are only concerned with the best methods of growing plants under certain conditions and enjoying them to the utmost, and my earnest advice to any one who has it in his mind to build a greenhouse is to eschew all and every sort of stained glass in its construction. 


\section{CHAPTER IV}

\section{REGULATION OF TEMPERATURE}

Ir must be always borne in mind that shelter, not coddling, is the aim and end of the unheated greenhouse, and the grand difficulty in face of cold-house gardening is how to maintain a fairly equable temperature. When the selection is limited to strictly hardy plants, the regulation of cold is, probably, of less importance than that of heat, but when half-hardy plants and bulbs come within the range of our desires (and it is well that they should) the greenhouse thermometer in winter must not be allowed at any time to fall below $35^{\circ}$ Fahr., which is the lowest temperature at which frost can safely be kept at bay. But the owner of an unheated plant-house aims at reaching a point beyond mere safety. $\mathrm{He}$ is ambitious enough to hope that his winter conservatory may rival, if it may not in some degree even surpass, the hot-house devoted to tropical plants, in its wealth of flower and greenery gathered together from distant quarters of the temperate zone. Emulation, it is true, strikes but a low note in the scale of ethics, but human nature needs a healthy stimulus to rouse it into action, and so we are none the worse for a friendly contest with a neighbour. But there does come a time when winter is at its darkest and coldest, from the shortest day onwards for a few, though only a few, hard weeks, when it must be confessed that it is almost impossible to keep up a bright display of flowers in a greenhouse that is totally unheated. Not quite impossible, however, for we are by no 
means at the end, but rather at the beginning of our possibilities in this direction; yet even very hardy plants have a trick of looking self-conscious and rueful in a black frost, and it is the very motive of the cold greenhouse to make hardy plants comfortable and to coax them into earlier flowering.

Personally I have always been quite content with a small, portable apparatus, called a Heat Radiator, the invention of an exceedingly able mechanician, Mr. Gillingham, of Chard, and constructed on scientific principles. This has been found to answer well in unheated greenhouses of moderate dimensions - say from $15 \mathrm{ft}$. to $25 \mathrm{ft}$. in length.

The special advantage of the little brass or copper cylinder which goes by the above name, in addition to its neat appearance, is its portability. When it is out of use, it need take up no room in the greenhouse, but may stand in any convenient hall or passage. Should a change of weather give warning of danger, which sometimes happens very suddenly, five minutes will suffice to place it in position and light the lamp, when a rise of several degrees of temperature will very speedily be shown on the thermometer, which should be in every plant-house. On rare occasions it may smoke, but this calamity-for calamity it is-is generally due to want of care in trimming the wick, and can be avoided by the most ordinary attention. Few things are absolutely perfect, but the principle of the Heat Radiator is excellent-it is not unsightly, and as far as I know, though by no means a new invention, has never been surpassed for simplicity and efficiency, as a temporary means of keeping out frost.

During those few dreary weeks to which reference has been made it was always a simple matter to keep the air in circulation on chill, foggy days, or a night temperature, according to weather, of between $35^{\circ}$ and $40^{\circ}$, which was all that was wanted to make Daffodils and winter Iris and a host 
of charming spring flowers hold up their heads in happy contrast to their fellows in the garden outside.

There are several other inventions for the purpose, none of them perhaps without some drawback, and every season sees new additions to the list. A demand seriously maintained for a perfect removable apparatus of sufficient power to keep out frost will surely call forth exactly what is required.

It may be worth while to make a note of a very roughand-ready contrivance which has been successfully extemporised on occasion for keeping out frost. An ordinary lamp is lighted and placed on the floor, with a pillar of bricks on each side to form a support for a very large flower-pot, which is inverted over the chimney. Upon this a pyramid of inverted pots, each a little smaller than the last, is built up, and the hot air rising through the holes of the pots heats them through and through, and thus a stove may be devised on the spur of the moment which will diffuse an atmosphere genial enough to keep the enemy, for the nonce, out of a house of moderate dimensions.

\section{VENTILATION}

By some strange perversity the proper ventilation of the amateur's greenhouse is often one of the last details of construction to be considered, which would never happen if experience could only be bought ready-made. Plenty of air is as necessary to plant life as to human beings, and it would seem to be as unreasonable to plan a greenhouse without ventilation as to build a cottage with windows not made to open; yet it is by no means an unheard of case for a greenhouse (mostly of the smaller sort) to have no other means of ventilation than the door, while, even in more important structures, roof ventilation is the exception rather than the rule. For perfect efficiency there should be not ventilators 
merely but a system of ventilation. Free circulation of air is indispensable, but it is not always recognised on the other hand that draught is most injurious to plant growth. The shrivelling of tender foliage, especially of Fern fronds, generally set down to want of water, is due, more often than is suspected, to exposure for a few hours to cross-currents of air. It should be possible, therefore, in all greenhouses to "put on" and "take off" air, in gardening phrase, according to the way of the wind, and in order that this may be done effectively ventilators fitting closely and firmly must be provided both at the top and at the sides of a plant-house. A span roof $20 \mathrm{ft}$. in length should have four ventilators placed alternately at each side, and over these, upon the ridge, it is well to have a wooden cap as an additional safeguard against drip. Strong hinges of the kind called "water joints" are to be recommended, as being more durable than the ordinary make. In a long house it is a great saving of labour to be able to open and shut these top ventilators simultaneously by an iron winch. Side ventilation is provided for, either by having the lights made to open or by wooden shutters let into the brick walls. The latter alternative is in use, mainly, when the span roof rests upon the wall-plate-a form of glass-house rarely seen in any but professional gardens, though such " pits" are admirably adapted for plant culture.

It is difficult to lay down precise rules for ventilation, but as a general principle it must be understood that the treatment of plants in an unheated greenhouse is in strong contrast to that given in the stove, where a close humid atmosphere does no harm. There are not many days in the year, even in heavy fog, when at least a chink may not be left open to allow free circulation of air, for though it is a common practice to keep greenhouses closely shut in foggy weather, a little dampness from outside is actually less harmful than stagnant damp within. In winter it is always safer 
to open the upper ventilators rather than those at the side. The chief trouble comes in the early days of spring, especially if we are ill-provided with blinds. Then the thermometer is apt to rush up to $80^{\circ}$ or so, on the slighest hint of bright sunshine on the glass, while a keen wind may be blowing from north and east. It is often hard enough, under circumstances like these, to know how to regulate the temperature. The temptation is to open side-lights as well as roof ventilators and to let in all the air we can, for scorching heat is as bad for hardy plants as frost for those that are half-hardy, yet even hardy plants under artificial treatment easily "catch a chill" at the roots in this way, from which they may never recover. At such a moment we find ourselves on the horns of a dilemma, and very much inclined to sympathise with the pitiable case, near akin to our own, of the gardener of whom Mr. E. V. Lucas tells us, who wrote to his employer: "I'm varry sorry to tell you that I cant do enaything with the greenhouse. I think he will kill every plant I have sometimes he will get varry hot and another time I cant get enay heat in him and we cant stope him from smoking so I doant know what to do with him "! Happily the troubles of the cold-house gardener are in great measure simplified, and if the ample provision which is so essential be made for ventilation, experience will soon teach the necessity of avoiding draught. Only let it be remembered at the same time that a stuffy stagnant atmosphere, persisted in for a few days only, will surely set up an invasion of that very infectious complaint "damping off."

For eight months of the year it is scarcely possible to give too much air, and where it may chance that a glasshouse is chiefly used for the shelter during winter of halfhardy shrubs, or Roses planted out, it is an excellent plan to have it so built that the lights can be altogether removed when required. Of late, portable houses on rails for forcing 
Lily-of-the-Valley and other temporary crops have come somewhat into vogue, and some adaptation of the idea might be of value for the glass-garden. In any case spare lights can always be used to good purpose in various wayse.g., for Tomatoes during the summer-and need not lie idle.

\section{SHADING}

It is from February onwards that shading, no less than the ventilation, of the unheated greenhouse becomes a serious question. The shelter of glass from storm and stress is heartily welcome, as we know, to hardy and half-hardy plants which flower at inclement seasons, yet no sooner does the sun begin to shine in his strength than the glazed roof is apt to become a funeral pall. If the scorching rays are not by some means tempered, a sudden farewell will have to be taken of faded and withered flowers. Tulips open wide and pale, beneath the ardent sunbeams. Narcissi lie prostrate and can never more be persuaded to lift their languid heads. Rhododendrons and Azaleas hopelessly cast off their flowers and dangle them in an aggravating way by their long pistils. Camellias put on brown edges in token of mourning, and every flower seems to pant out a feeble protest against the cruel fate that took them away from the fresh open air and consigned them to a furnace-so soon are benefits forgotten when times are changed! But blinds of tiffany or thin strong netting-materials which give sufficient but not too dense shade-fixed on rollers, so that they may be raised or lowered at pleasure, will save all this disaster. Sometimes the sunshine lasts but an hour or two, yet every gardener knows that more mischief can be done by an hour of neglect than can be repaired in a season, for it is not only the flowers that suffer, but serious and lasting injury is done by 
the scorching and scalding of tender leaves, which are in truth the lungs of the plants.

Permanent shading is sometimes given by washing over the inner surface of the glass in spring with "Summer Cloud" or some similar composition, and not removing it until the autumn, but it is only rarely expedient. Plants subjected to constant shade soon get drawn up in a vain attempt to reach the light, and their leaves grow pale and sickly. Occasionally, however, shading of this kind may be used with advantage in a Fern-house or for a conservatory built in the eye of the sun, the tenants of which are continually shifting their quarters. In such cases permanent shading-i.e., for the summer-may be an actual gain, but no clouding of the glass looks well, and it is at best but a poor makeshift. For many years, during the bright months, I used fixed blinds with the best success in a sunny conservatory which had no established occupants. These were made of very thin strips of wood painted green, through which the light passed freely but with a softened shade as of sunshine in a Hazel coppice, full of restful harmony. I never saw such as these elsewhere, but in some positions nothing could serve the purpose better, and many comments of approval were bestowed upon them. In most planthouses of the kind under consideration, however, rollerblinds are undoubtedly the best. Where these cannot for any reason conveniently be fixed, tiffany may be fastened to the rafters by hooks and rings, though at the expense of a good deal of time and trouble in putting up and taking down. It should be hooked to the rafters rather than to the sash bars, to allow the hot air to circulate freely between the shading and the glass. 


\section{CHAPTER V}

\section{PLANTS SUITABLE AND UNSUITABLE}

IT is natural enough for those who are young in gardening matters to be disappointed when they are warned that plants from the hardy and half-hardy classes only must be reckoned upon for cold greenhouse culture. What is the use of a greenhouse at all, they are ready to ask, if only common, everyday flowers can be grown in it ?

Let me try to expound both its use and its charm. The craving for flowers is universal, but in winter we want them in our rooms rather than out of doors. The garden has a winter beauty of its own, and we know and love it well, but it is not the beauty of flowers. The tracery of bare boughs against the sky, the glow of scarlet Holly berries midst polished leaves, the quiet grey tones of Rosemary and Lavender-all these in their various ways give a sense of restful waiting for the coming activities of spring, and they are very dear to us. But all the same we want flowers, for, lacking two things, books and flowers, no home looks home-like. We can buy them, doubtless, but "boughten" flowers do not satisfy the craving that will not be still, and we wander out into the garden ready to welcome the homeliest floweret which has dared to brave the winter storms. What are we likely in most localities to find? Christmas Roses maybe, but besmirched; Snowdrops, not always snow-white, unless, haply, a carpet of turf lies spread beneath them; Laurustinus - except in the milder South-hopeful-looking at a distance, 
but sear and brown on closer view; the earlier Crocus buds and Primroses wantonly nipped off by saucy sparrows; the rest, as yet, awaiting their awakening. A handful of purplebrown Mahonia leaves, a few battered flowers from the China Rose in some sheltered corner, some clustering Ivy or a spray or two of variegated Box-these form the sum total of what many a garden gay enough in summer is able to produce. Whether we will or no-rare cases excepted-for our winter posy we must needs go to the greenhouse. Call to mind the most common everyday flowers that we know-Daffodils, Hyacinths, Wallflowers, Stocks, Crocus, Forget-me-not, Violetsand think whether a greenhouse filled with such as these would not be an enviable possession from Christmas onwards?

And then, again, if we are not flower-lovers merely, but plant-lovers-a very different cult-how keen is the disappointment when, after months of patient tending of one and another of the lovely green things upon the earth which are to us as priceless gems, we are robbed of the full fruition of our labours by treacheries of weather or hungry bandits in the shape of slugs and snails! The open ground is no safe place to which we dare trust our rarest treasures, and a sheltering frame becomes a necessity, and sooner or later the frame will need expansion into larger space, where we may group and make pictures of our plants and enjoy them to our heart's content.

Yet it is a mistake to think that hardy flowers need be common. The finer varieties are always worthy if we take the pains to seek for them; and it is their earlier flowering under shelter, no less than their own beauty and sweetness, that gives them their claim to the greenhouse. A greater mistake still would be to think that even such everyday things will bless us with a grace so early, unless we lay our plans with intention and remember cheerless winter days to come when summer yet holds her lap full of flowers. 


\section{HARDY PLANTS}

Let us try to define the distinction between hardy and half-hardy plants from the point of view of the unheated greenhouse. Hardy plants, as we know, are those which need no protection to enable them to withstand the frequent changes of our climate in all parts of the United Kingdom, but for greenhouse purposes we must gather out of these such as can be made decorative either for foliage or for flower during the flowerless season. Roughly speaking, this season extends from October, when the first keen frost sweeps its sharp scythe over the autumn garden, until March-in some years later still-when swelling buds and the blackbird's mellow pipe begin to tell us that spring is here. Before Christmas, Chrysanthemums, late Tea and China Roses, a few annuals especially prepared, like Cosmos, the crimson spikes of Schizostylis, Carnations of the Margherita type, late purple Asters too tardy to open out of doors, and many another bright flower will come to our aid. With the new year, and before if we try, we can have Roman Hyacinths, paper, and the early Scilly White Narcissus, scarlet Van Thol Tulips, and Christmas Roses, while the cheerful gleam of Coronilla and Winter Jasmine and the lovely cream-white flowers and buds of the Box-leaved Myrtle and of Laurustinus will not leave us forlorn even at that pitiless season. Then will follow a long procession of spring bulbs, herbaceous perennials, and shrubs, which it is our business to coax into flower to fill in the remainder of the weeks until the greenhouse needs no longer to take the place of the outer air. So much as this, and, indeed, much more, may be done without any firing at all, for these are all hardy plants, but not without some extra care when the weather is specially severe, and maybe, on occasion, at the cost of a little drooping, not very harmful, of the more tender flowers. Not without energy, and 
perseverance and forethought besides, for the winter campaign must be prepared for in two ways-( $\mathrm{r}$ ) by retarding such summer flowers as can be kept back to bloom in the latest autumn, and (2) by bringing spring plants into flower before their due season. Midway between these two comes another class, of which early Rhododendrons and Azaleas are a type, which flower naturally almost at midwinter, but seldom escape unhurt if they remain unsheltered. A limit, indeed, can scarcely be put upon the hardy spring flowers-Anemones, alpine Primulas, Orobus, Saxifrages, Cyclamen vernum, and Doronicums - to name but a few out of a host which lend themselves with gratitude, and enjoy such gentle forcing as the shelter of glass can give them. They come from many lands, and often from climates much more rigorous than our own, but where they are neither puzzled by the wiles nor entrapped by the cruel ogre of the weather, who entices them with smiles one day-to gobble them up on the next.

There is but one hardy plant which for this purpose, perhaps for its very hardiness, I, for my own part, would not choose-the low-growing herbaceous Heath (Erica carnea). Be the winter what it may it never loses heart of grace, but bides its time. It may blush into perfect beauty a little sooner or a little later, as the season lets it, but no storm seems to harm, no stress to change it; all hurtful creatures pass it by, only the bees murmur over it their first happy thanksgiving as they sip the nectar from its tiny flasks. Most flowers we love to gather and bring indoors, but not this one. True child of the mountains and the moor, it asks no shelter; let us leave it to its liberty, for, as it seems to me, it is happier so. 


\section{HALF-HARDY PLANTS}

It is customary to count as half-hardy many of the softwooded plants which are used for summer bedding, such as Pelargoniums, Heliotrope, Ageratum, Cupheas, and the like, but it is a misleading term as far as the unheated greenhouse is concerned, for in no part of the British Isles will these survive a winter out of doors, and they might perhaps be more accurately described as sub-tropical. It is true that Pelargoniums of certain sorts thrive all the year round in sheltered spots in the Isles of Scilly, but whole hedges of them were cut down to the ground-line in a disastrous winter some years ago when there was a most unusual visitation of $10^{\circ}$ of frost. It is also true that they will exist under glass in a low temperature, but it must always be above $40^{\circ} \mathrm{Fahr}$., for they quickly damp off unless there is enough warmth to keep them in a growing state, while to have zonal Pelargoniums in bloom during the winter requires not only a season of special preparation beforehand, but a temperature equal to summer heat; hence it is plain that they cannot be recom. mended for the cold greenhouse.

Ordinary greenhouse plants, again, such as Libonia floribunda, Bouvardia, Chinese Primula, and even Persian Cyclamen must be put out of our thoughts, though the last two do excellently well in the windows of light warm rooms. It must therefore be clearly understood that by "half-hardy" in these pages it is intended to express the degree of hardiness which will pass safely through an ordinary winter in the Isle of Wight or in Devon and Cornwall, and which is able to endure a trifle of frost for a short time in a dry, still atmosphere without permanent injury. But even for half-hardy plants like these the mere shelter of glass will not suffice, because the advantages of climate afforded by the South Coast are exceptional, and therefore if we decide to grow the more 
tender amongst them we must make up our minds to provide some temporary means of raising the temperature in severe weather. Amongst the half-hardy plants that are suitable under these conditions we may include some of the Heaths and handsome South African Crassulas and Mesembryanthemums, as well as Gladioli, Lachenalias, Crinums, and other bulbs from the same regions, the Disas and some terrestrial Orchids of Table Mountain; Acacias, Boronias, Correas, and other hard-wooded plants from Australia and New Zealand; strange Cacti and Mamillarias from the arid plains of the southern United States; Rhododendrons from the Himalayas, verily a goodly company, with infinite variety from which to choose.

It may be added that the two classes of hardy plants and half-hardy plants overlap each other, and that some things reckoned tender will survive when hardier ones fail, but the reason is probably found to be some accident of individual constitution rather than in any question of temperature. Many of the plants here mentioned require special treatment and are not altogether easy to succeed with, e.g., the hardwooded Australasians, which are, nevertheless, well worthy of all the pains and care that can be bestowed upon them. Others, again, like the Cape bulbs, present no difficulty of culture when once their management is understood, as in the case of Nerines, while succulent plants are the most longsuffering of all green things, living and often even thriving under positive neglect, yet rewarding, many of them, the most moderate understanding of their wants with largest interest of brilliant and sometimes gorgeous flower.

It is very needful that the distinctions which $I$ have tried to make clear between plants suitable and unsuitable for the unheated greenhouse should be carefully noted, for nothing but disappointment can follow an attempt to make a simple glass shelter do duty for a house capable of being heated up 
to Orchid or even Pelargonium pitch. No less important is it clearly to define our intentions to ourselves as to whether we grow hardy plants only or whether we wish to include the less hardy, for which a certain amount of heating power is required, though not enough to render the term "unheated greenhouse" a contradiction, inasmuch as it need be in most cases merely a transient encumbrance and not a permanent one. In either case some knowledge of plants and a hearty desire to know more is inseparable from the true enjoyment of this, or, indeed, any other branch of gardening. With regard to culture, nothing teaches so much as practice, and when the true gardening instinct exists the early stage of helpless ignorance soon gives place to greater assurance, as we take advantage day by day of every hint, spoken and written, that comes in our way. Then as experience grows we begin to make experiments on our own account, for there is no doubt whatever that many plants may be educated and made to adapt themselves to environments other than those that are natural to them, and herein lies one of the many interesting features of advanced work in a cold greenhouse. A generation since, numbers of plants now commonly to be found in our garden borders were grown under glass and reckoned too tender to be trusted out of doors. The result of experiments during many years in testing the capabilities of unheated houses in my own garden proved to demonstration that a fair proportion of plants will succeed admirably under good management, and are less subject to blight and disease in a much lower temperature than is usually supposed to be indispensable to them.

The same effects, it is true, may be traced as the result of the different modes of treatment, as may be noticed in Switzerland between the plants of the valley and those of the bleaker mountain-side-the growth is not so rapid, and luxuriance is restricted. But what is lost in these respects is made up in 
added vigour of constitution and greater power of resistance to the attacks of insect pests, and even in more abundant flower. Therefore, in choosing plants for the unheated greenhouse we may lay aside all misgivings, so long as we make no mistakes between plants suitable and unsuitable to be grown in it. 


\section{CHAPTER VI}

\section{THE ALPINE HOUSE}

A GOOD example of the simplest form of the unheated greenhouse is to be found in the Alpine House at Kew. It is nothing more than a low span-roofed glass-house, $40 \mathrm{ft}$. long by $9 \mathrm{ft}$. wide, with flat stages on each side of a narrow gangway, and has no heating apparatus of any kind. It is provided, however, with shading to temper sun-heat, should it prove too powerful, as it often does, in early spring. Here, throughout the winter and spring months, a succession of lowgrowing plants and bulbs indigenous to the alpine districts of all parts of the globe may be seen in happier circumstances and in better flower than would be possible out of doors in our changeful climate. A large proportion of such plants perfect their growth rapidly during the short but strong summer heat of their native habitats, and are almost ready to burst into flower again when their progress is arrested, sometimes quite early in autumn, by a thick fall of snow which tucks them up safely for their long winter sleep. Months later, when the snows melt and there is no more danger to fear, they have little more to do than to open their bright eyes upon the world new-clad in greenery. Any one who has had experience, for example, of a Canadian spring, will understand the sudden transformation from the winter shroud of snow to gay, green woods and plains enamelled with flowers. Transplant the denizens of such climates to our seagirt Britain and, so far from being happier, they are sore bewildered and tried beyond 


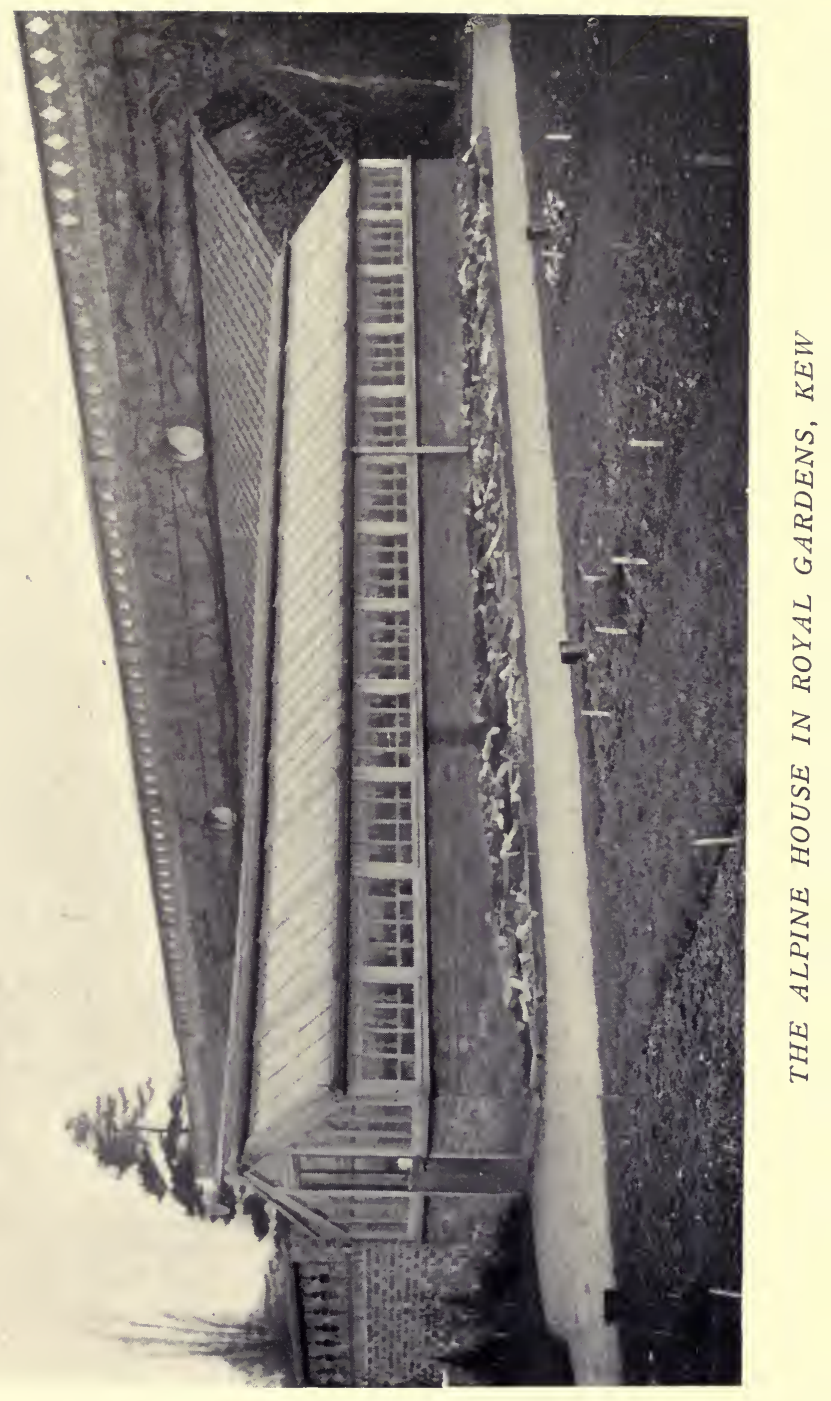




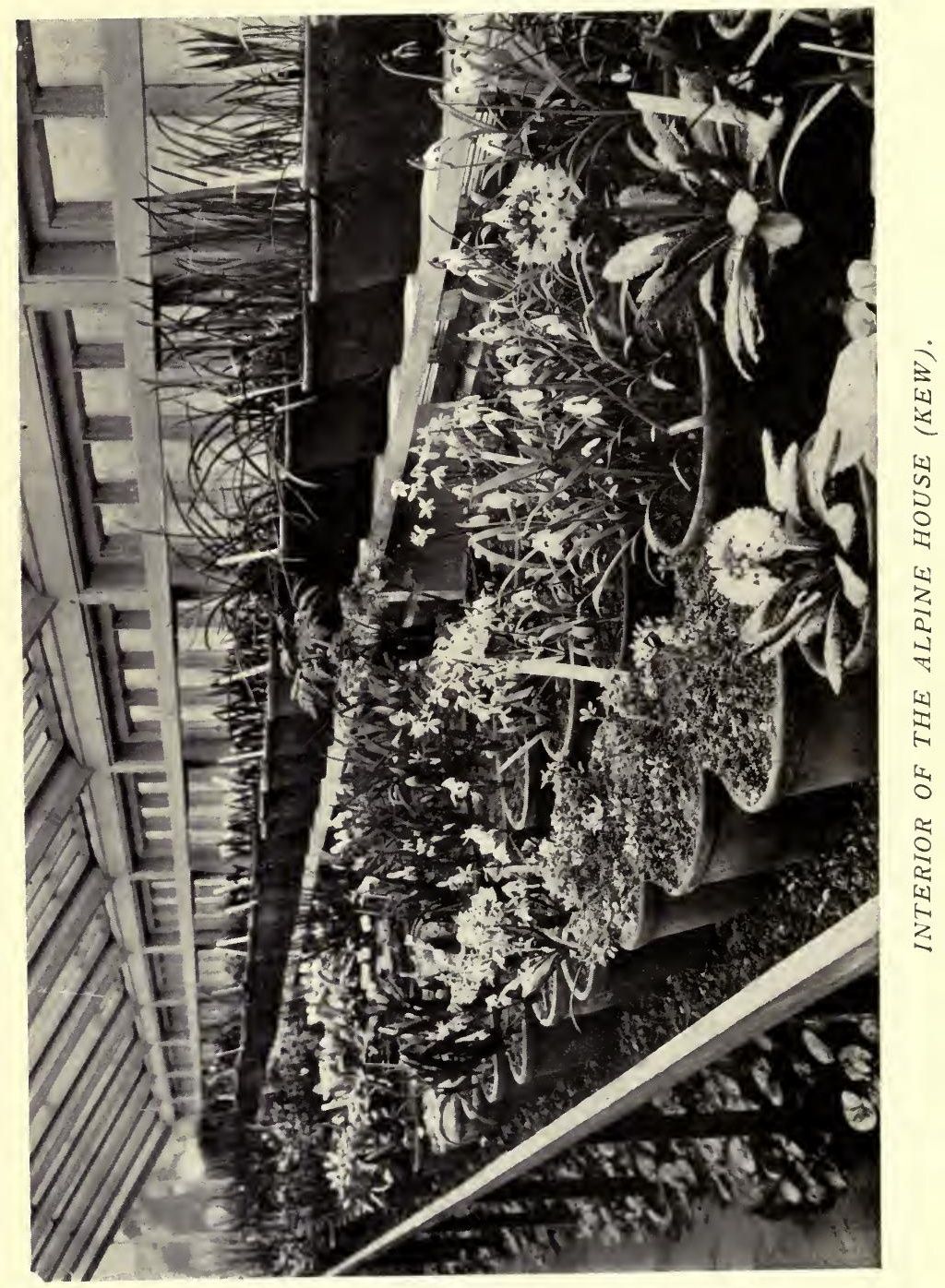


endurance by the alternations of mildness and rigour to which they are subjected, and we who try to cultivate rare and beautiful species under these altered conditions too often meet with disappointment. Under the protection of a simple glass roof, however, the want of the snow coverlet is not so much felt, and such plants can go on, without check from wind or weather, to perfect their pure, stainless flowers. At the same time, they do not give us that sense of unnatural forcing which is inseparable from the hardy spring-flowering shrubs, like Lilac or Wistaria, when, as is often done, they are brought on quickly into bloom in a heated atmosphere. True alpine plants will not stand artificial heat, and the Saxifrages, Soldanellas, Cyclamens, Irises, and other mountain plants shown in the Alpine House at Kew are grown out of doors during the summer and autumn, either in prepared beds or in cold frames where they can be planted or plunged according to their requirements, and are brought inside to open their flowers. They are mainly grown in pans and pots which can be easily returned to their growing-quarters as soon as their beauty is past. Ice has been standing on several occasions on a small glass tank containing Azolla filiculoides in the Alpine House when I have seen Saxifraga burseriana major, Corbularia monophylla, Primula megaseæfolia, \&c., in flower, and many other plants in bud without showing the least sign of distress.

Saxifrages are typical plants for the alpine house. The earliest of them all to open is S. burseriana major, and any one may be proud of having, early in January, a well-established pan of so lovely a plant in bloom, for it takes some time to build up and some care to preserve in good condition. Few gardens possess a superabundance of this fine variety or even of the typical species with smaller flowers which open a little later. Saxifrages, and especially these slow-growing, densely tufted species, do well grown in pans from 6 in. to 8 in. 
across, in light sharp soil freely intermingled with nodules of stone-some of the larger pieces being only half-sunk beneath the surface, against which the little tufts can nestle. A very pretty specimen may be grown in such a miniature rockery. To increase the stock, when a plant has gone out of flower, a rosette may be snipped off here and there wherever it will be least missed, pressing it gently into a pinch of sharp sand on the surface of the soil. These will soon root, and each will become the nucleus of a healthy tuft. Saxifrages of this section will live in the same pan for a length of time, the bare worn-out pieces being carefully cut away and fresh soil of the nature of pulverised granite added as a surface dressing, but much disturbance of the roots is to be avoided. Very many species of these minute silvery rock-foils may be grown in this way. The mossy kinds, represented by S. camposi, grow much more quickly into good specimens. Amongst the alpine Saxifrages may be found golden-yellow, pale primrose, purple, and pink flowered species, as well as white. S. cotyledon -S. pyramidalis and $\mathrm{S}$. nepalensis being only fine varieties of the same-which belongs to the encrusted section, makes a noble pot plant in late spring, though few people, for some reason, succeed in growing it well. To form a good specimen, perfect rosettes of the strap-shaped leaves must be chosen for potting singly in three-inch pots_- "perfect" being said advisedly, as an ill-shaped rosette never produces a fine spike of bloom. These must be kept entirely free from the numberless offsets by which, in its native home, it creeps along the fissures of the rocks. By giving frequent and gradual shifts into larger pots, the plants are encouraged to grow as large as possible betore the flowering stems are produced. This may happen either in the second or third season, but if a succession of young plants be kept up by putting in sufficient offsets every year, some are sure to flower every spring, and the tall pyramid of multitudes of milk-white flowers, sometimes 
two and even three feet in height, is extremely ornamental. By planting several of the rosettes in a pan, thus restricting root-room, and taking care still to remove all offsets, a dwart specimen may be grown, carrying several feathery white plumes instead of the single pyramid.

No more truly alpine plant can be named than that child of the snowdrift, Soldanella. Its cultivation is not altogether easy, and a hint given by M. Correvon, years ago, having proved of great value, may be passed on to others. Soldanellas enjoy nothing so much, under abnormal conditions, as growing in living sphagnum, in full sunshine. Living sphagnum must, of course, be constantly moist, and requires a thin layer of sandy bog-soil at the bottom of the pan. The tiny plants of Soldanella inserted over the surface of the moss send down their roots among the cool spongy stems and thrive apace. This method provides as good a substitute for the melting snow as can be devised under cultivation, but they are successfully flowered at Kew under ordinary treatment in pans of suitable soil.

To turn to an entirely different class of plant. Amongst the luxuries of the alpine house, at present, must be counted the newer species, increasing in number year by year, of dwarf bulbous Iris. Some of these are far from new, since I. persica, nearly related to some of these more recent introductions, is the very first plant figured in the old series of the Botanical Magazine (A.D. 1793). But of late years, collectors in various parts of Asia Minor have turned their attention to this beautiful genus, and our gardens will be richer in future by their labours. Very many of these new species are tempting items for the Iris connoisseur. I. Heldreichi, with large grey-blue flowers and deep violet falls, is one of the most attractive of plants to grow for an alpine house. Not quite so striking, perhaps, in flower, but more so as a plant, with its abundant channelled leaves, is I. sindjarensis, a Mesopotamian species, 
which blooms in February and March, when its tender slateblue flowers shading off to creamy white are both pretty and fragrant. In the same category with these rare species are I. Hausknechtii, I. Tawei, I. bolleana, and others. Their culture is scarcely to be taken in hand by a novice, because they are both scarce and dear, and their requirements may not as yet be entirely understood, but there are others, like I. alata, I. orchioides, I. Danfordioc, I. bakeriana, \&c., which are more easily procured, and are charming additions to the alpine house. Better known still is I. reticulata in its many delightful forms.

No more fascinating branch of garden work could, in fact, be taken up by the enthusiastic amateur than the furnishing of an alpine house for six months of the year from November till May, providing occupation for the summer and enjoyment for the winter. The form of it, besides, may be varied, for another arrangement which can be adopted for the alpine house is a permanent rock garden under glass - the lights being so put together that they may be entirely removed during the summer. Evergreen ferns of low stature, some of the dwarf vacciniums and gaultheria, and other suitable greenery might here be grouped-intervening spaces being left with a view to the introduction of plants in flower in their season from the outside frames. Such an alpine house, which may be larger or smaller according to circumstances, would make as charming a winter garden as could well be devised.

Alpine plants are legion, and it is impossible here to do more than indicate the lines upon which they may be used under glass, but a list will be found of the best and most suitable species, including many of the smaller bulbs and tubers which have been successfully grown at $\mathrm{Kew}$ and elsewhere for this purpose. 


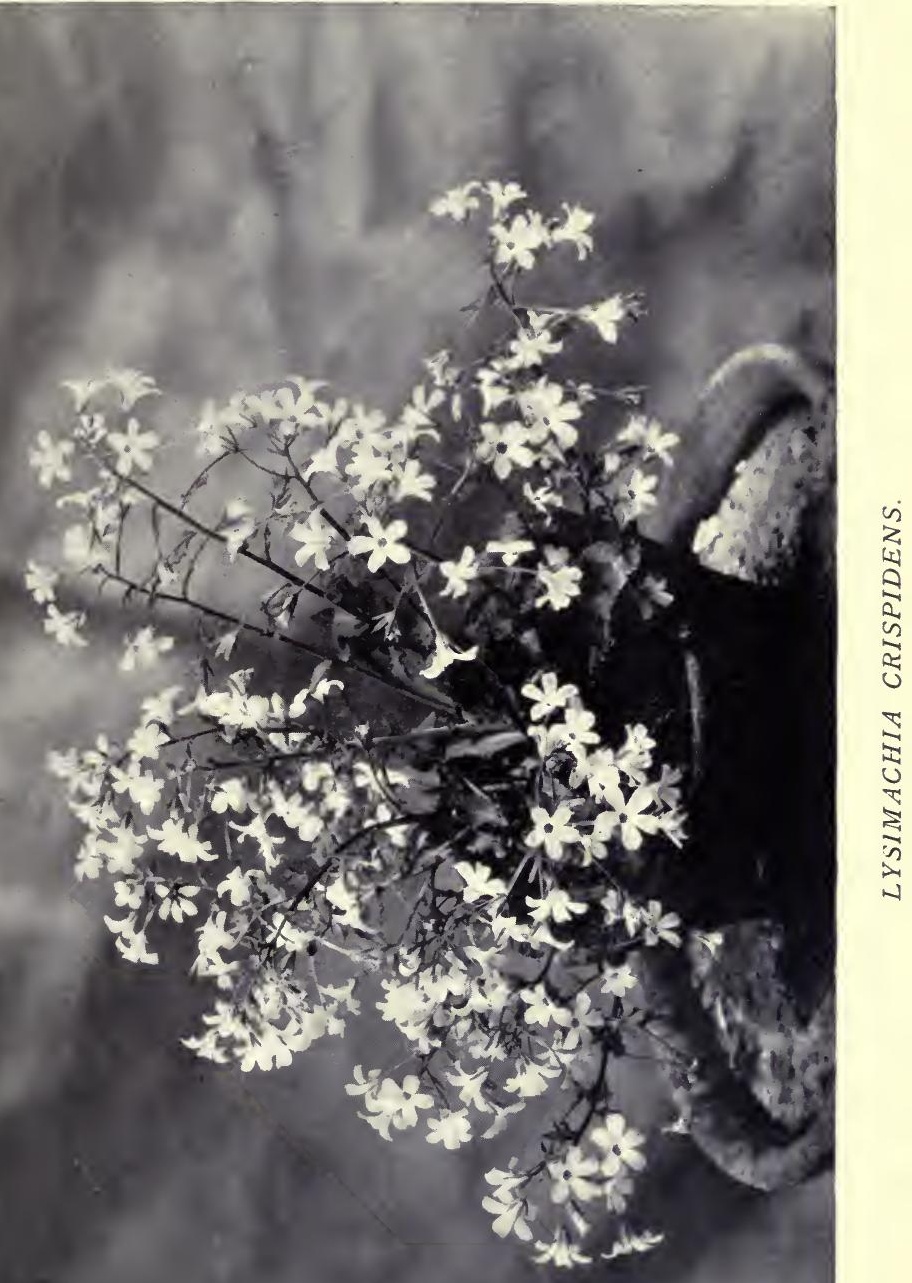




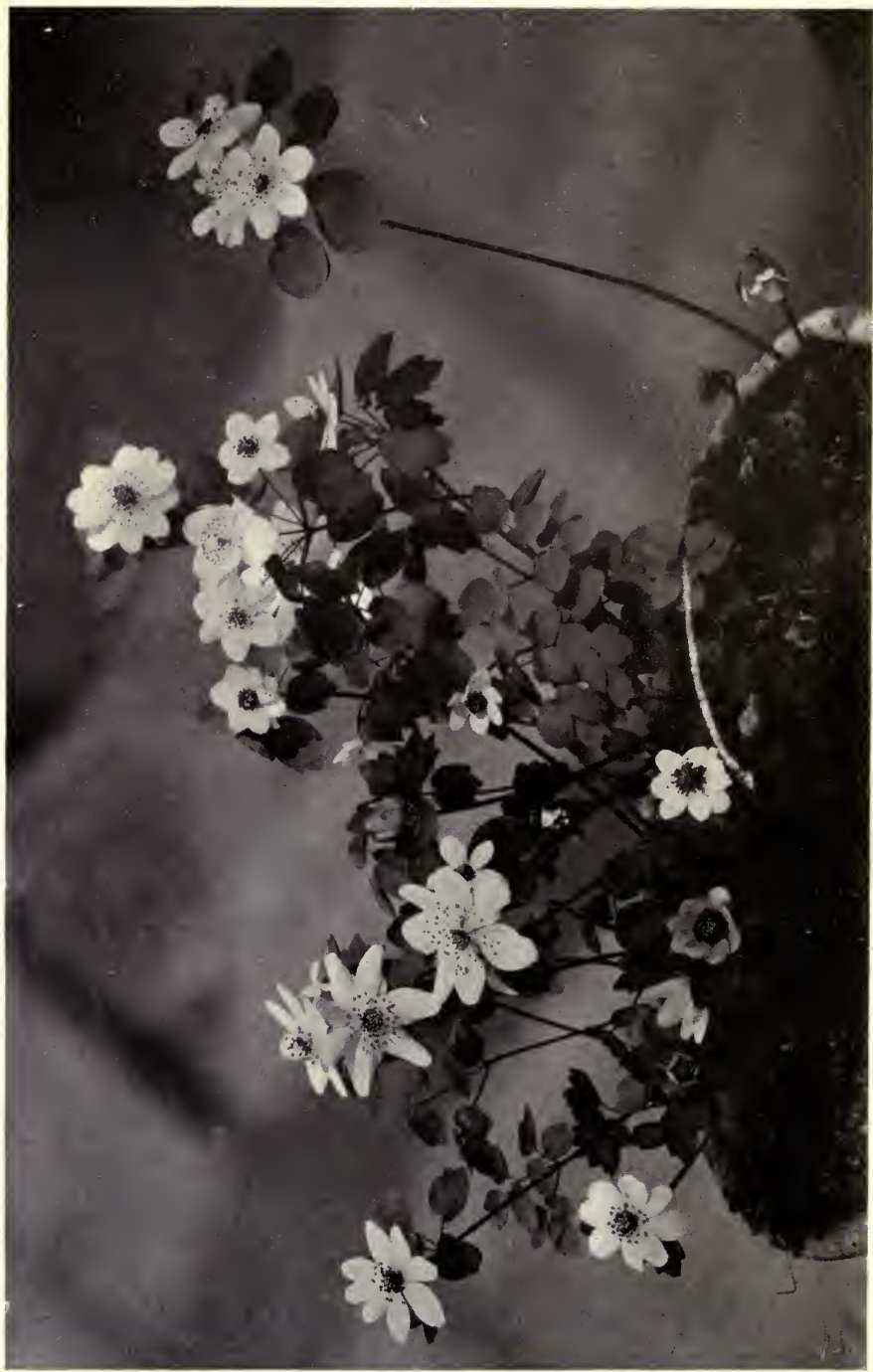

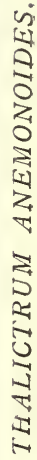




\section{CHAPTER VII}

\section{FOLIAGE PLANTS FOR GROUPING}

THE tasteful arrangement of cut flowers is a fine art in which most people now have some training, but how few ever think of undertaking the same kind office for growing plants. Harmony of form and colour in the grouping of plants is no less important, however, and when it is attained gives just the touch of difference between mere routine and the cultured sense of fitness.

To the amateur who finds himself in possession of an unfurnished cold greenhouse the advice of an "old hand" would be to think first of foliage plants. The value of greenery for all decorative purposes is recognised in these days as perhaps never before. This is proved by the myriads of fine-leaved plants distributed from the great plant factories of our day; but it is doubtful whether the modern tendency towards regarding these as so much furniture is altogether wholesome. The cool greenhouse may be said to cut at the root of the evil, for in it plants are grown and not manufactured, and long may it be before we give up the oldfashioned love for tending and training our favourites, until they become living friends, associated with all the joys and sorrows of our homes. Most people find out by bitter experience that plants grown at high-pressure speed in strong heat are unsuited to the conditions of a mere glass shelter, but, nevertheless, many of the same species, or their close allies, succeed admirably when brought up 
under more natural treatment, and are indispensable for pictorial grouping.

There is no question that in large conservatories detached from the dwelling, permanent planting of certain evergreen trees and shrubs is most advisable-a method already suggested on a small scale for one form of alpine house. These may be associated with well-planned rockwork, or fern-edged pool, so that the main features of the house may remain unaltered, while flowering plants can be brought in from the working-quarters according to season. The Himalayan House at $\mathrm{Kew}$ is a noble example, on a grand scale, of a cold conservatory of this character. For such purposes, there is abundance of material in the way of fine-leaved shrubs of larger or smaller growth to suit all positions. Planting for continuance, however, must be done with the utmost care and good taste, or it will be disappointing. But this kind of planting is not always possible, nor even desirable, and many people, whether they will or no, have to content themselves with pot plants. In any case, a small space soon becomes overcrowded and untidy, and no plant is always at its besttwo good reasons why, under limited conditions, permanent borders are better avoided, and every facility allowed for frequent rearrangement. This is more particularly the case when the ordinary small conservatory, which is seldom absent from the rectory or country home, or even the suburban villa, adjoins the sitting-rooms. To this end, and for other reasons given in a former chapter, it is well also to dispense with fixed stages, using only such simple removable contrivances for the raising and arrangement of pots as may best lend themselves to the natural grouping of the plants at disposal. In this way the whole mise en scène of the conservatory can be altered at will, but it will be understood that this is intended merely as a practical suggestion to those who do not begrudge a little time and trouble to give a fresh setting of ordered beauty to 


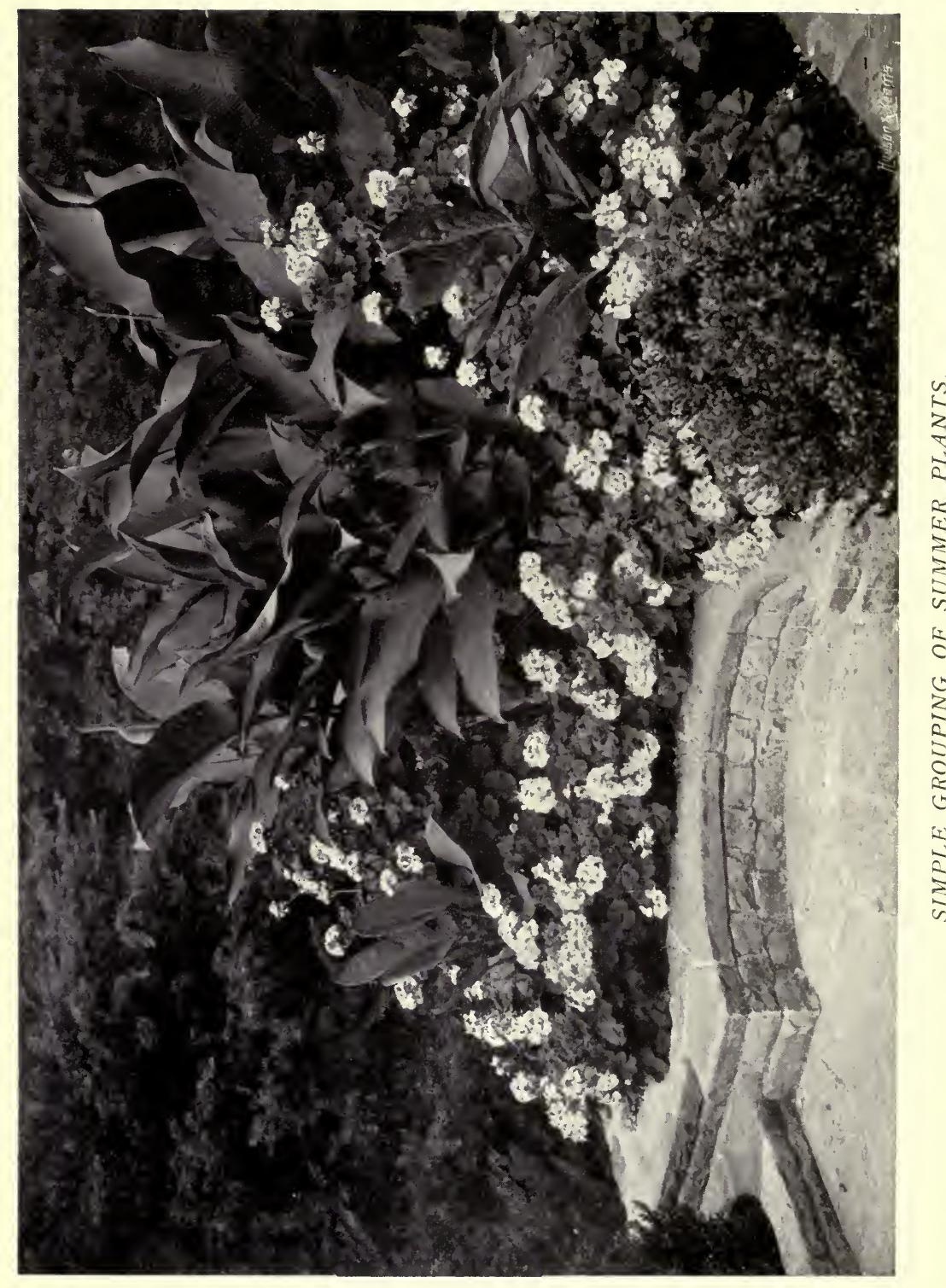


the too rigid commonplace of ordinary daily life, and applies only to the drawing-room annexe, which is always in evidence. The refreshment to mind and eye given by the varied plant pictures which a skilful hand is able to arrange can scarcely be told in words, but if one thinks of the ordinary greenhouse stage, with its serried ranks of flowering plants, flanked by brilliantly coloured Coleus and other variegated leafage, with here and there an Asparagus or Fern by way of foil, the difference may very readily be imagined. It has been said with reason that two-thirds of the available space in a greenhouse might well be allotted to flowerless plants. But even with greenery the art of harmonious grouping depends in a great measure on the quick discrimination between concord and contrast. Sometimes the one, sometimes the other will give the best effect; but it is a mistake to think that foliage of any kind will accord with every flower. The trained eye will detect in a moment the want of harmony, and hence the importance of having a good stock of the most varied greenery to choose from. It may be said in passing that one distinct advantage of the cold house system is that a much greater variety can be grown, as foliage plants not in use or any that are out of flower can be transferred to outdoor quarters or simple garden frames instead of either taking up precious room or perishing outright for lack of suitable accommodation.

For all purposes of grouping, then, greenery being indispensable, it will be well to make a note under the two heads lately defined of hardy and half-hardy plants of some of the most suitable for cold house culture.

The fashion of the day being to employ Palms of many kinds for decorative purposes, it is as well, perhaps, that we can, with confidence, place the two Fan Palms, Chamærops excelsa and C. humilis, on the hardy list. They are much alike in general appearance, but the first-named is perhaps the best. It is a Chinese species, and is often met with 
under the alias of C. Fortunei, a fact to be noted. The European Fan Palm (C. humilis) may be distinguished from it by the thorny projections on the leaf-stalks, the narrower plaits of its leaves, and by the offsets, which are thrown from the base of the stem. It is also somewhat dwarfer in growth. Both are good stand-by plants, doing well out of doors during summer, but needing shelter from wind and draughts even more than frost in winter, as the broad leaves are easily torn and disfigured. Acanthus, so much more grown in pots as room- and basket-plants on the Continent than with us, should never be omitted. A. latifolius and A. spinosus are two distinct and useful species. Aralia sieboldi, another wellknown evergreen, may be set down as indispensable. Small plants of Muhlenbeckia, with foliage recalling the Maiden-hair Spleenwort, is desirable for many purposes. All sprays of it that have been used with cut flowers may be kept, and if they have not already begun to root in the water, may be given the benefit of a fresh jug to themselves, where they can complete the operation at their leisure. In due time several of the rooted sprays may be potted together and make pretty basketplants. Perhaps others may have found no difficulty, but until the above method of striking cuttings of this graceful evergreen was accidentally discovered, I never once succeeded in rooting a plant of it by ordinary means. The jug, which provides darkness for the rooting stems, is a point to be noted. Such minute details are very amateurish, but like an old cottage friend who always planted her cuttings of Lemon plant, in firm faith, under a Gooseberry bush, "I do believe there be sum'at in it!"

For mixing with spring bulbs, Solomon's Seal is one of the most charming of foliage plants. There should be a well. prepared bed in some spare corner of the garden from which in the autumn the best roots can be taken for potting, the smaller tubers being replanted for the following year that they 


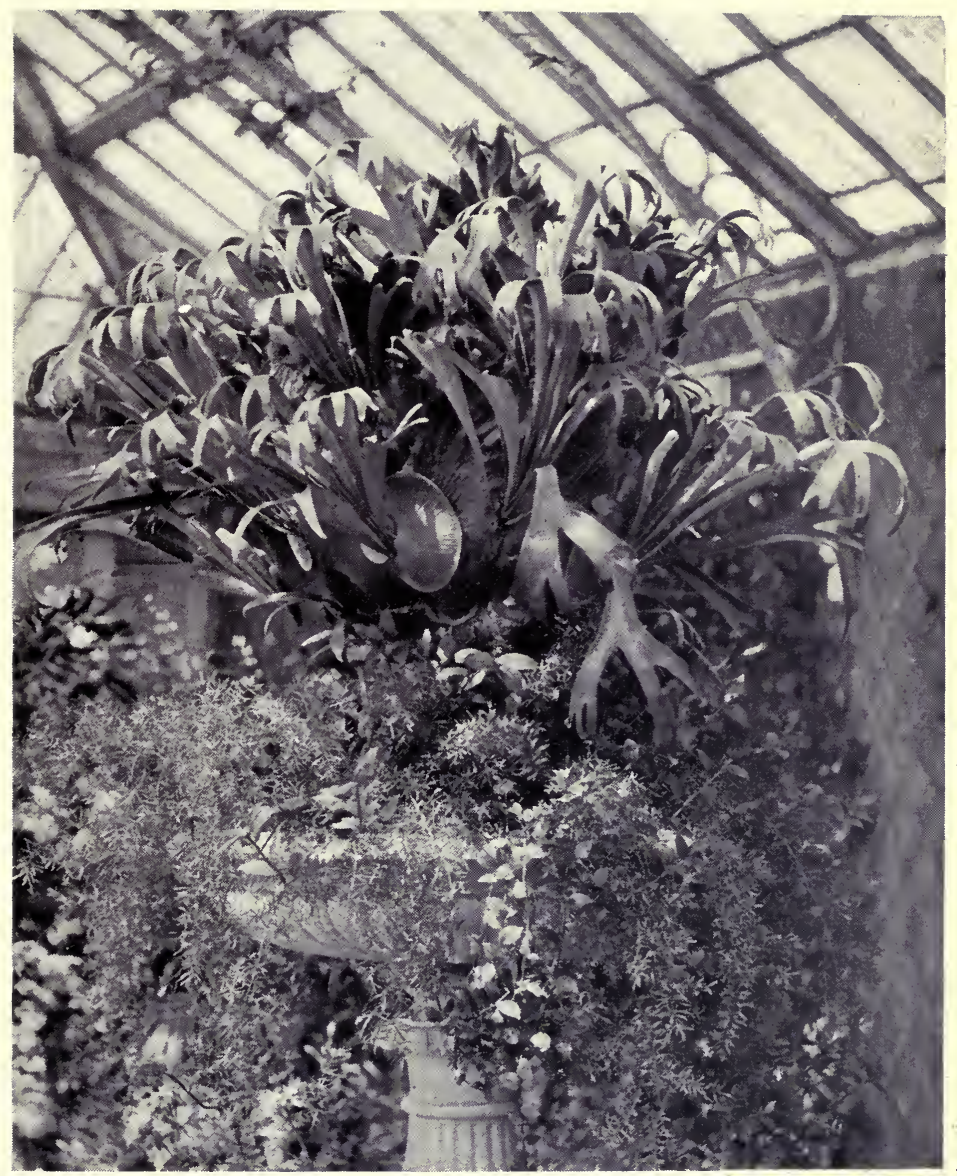

THE STAG'S HORN FERN 


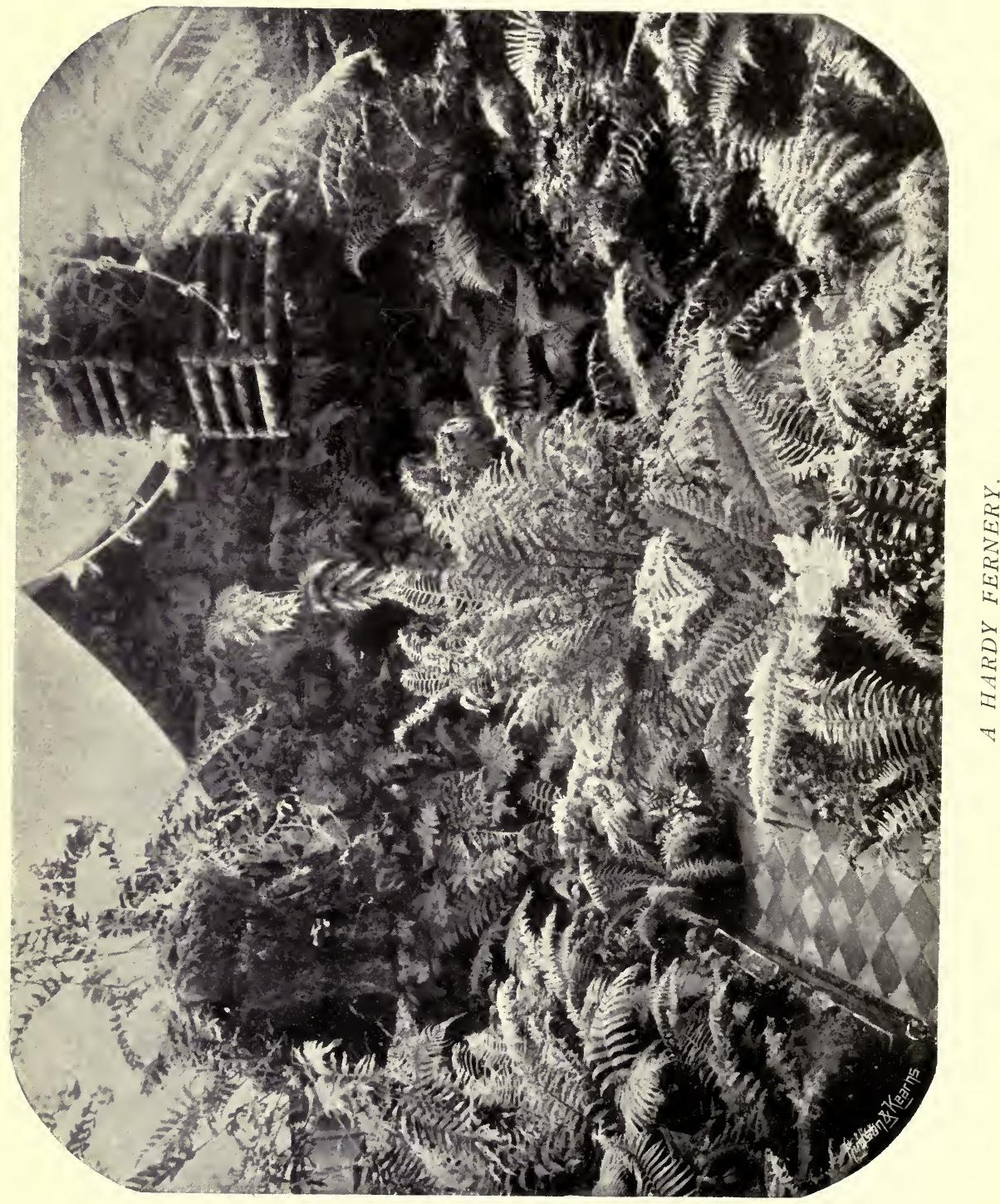


may have a season for recruiting. The same advice may apply to most plants which have served their turn in the conservatory. Myrtles, large and small-leaved, and Eugenia buxifolia, provide good greenery of a different character. Eugenia will also bear its delicious fruit abundantly in a small-sized pot, making the greenhouse fragrant with its peculiar aromatic scent. Small-leaved Ivies can be used in various ways, and Senecio mikanoides, the Ivy-leaved Cape Groundsel, which may often be seen trailing half-wild over bushes in Cornwall, is by no means to be despised where a quick growing climber is desired. Amongst herbaceous plants, and therefore only of use during summer and autumn, Funkia grandiflora and Funkia sieboldiana are very ornamental, and particularly well adapted for grouping with various kinds of Lilies in flower.

Nothing of course can be more valuable than a well-grown stock of hardy evergreen Ferns, both native and foreign. Of these the British species of Maiden-hair (Adiantum CapillusVeneris), of which there are several remarkable varieties; Polypody, especially the Welsh form; Hart's-tongue; Polystichum, with its proliferous forms; and Asplenium Adiantum-nigrum ("French Fern"), may be mentioned. Of exotic species, Woodwardia radicans, with its massive drooping fronds, each carrying a bulblet at its point, is invaluable for large spaces. The Ostrich-plume Fern (Struthiopteris germanica), and Lomaria chilensis, and L. magellanica are also large-growing, handsome, and quite hardy. Smaller species are Lastræa marginata and Polystichum acrostichoides. Amongst deciduous species, the very beautiful plumose varieties of the lady Fern (Athyrium Filix-fœmina) are well worth growing, and the fine Canadian Maiden-hair (Adiantum pedatum) should not be overlooked. If variegated foliage be desired, the small Euonymus radicans and Aucubas are useful, and small tufts of the old-fashioned Ribbon grass, grown in pots, 
go well with various kinds of white Narcissi, and make a fair substitute for Eulalia zebrina and the variegated Carex japonica when these are not at hand, though both are good "grasses" for pot culture. Centaurea ragusina and Cineraria maritima will supply silvery foliage and come in well for lighting up a dark corner. 


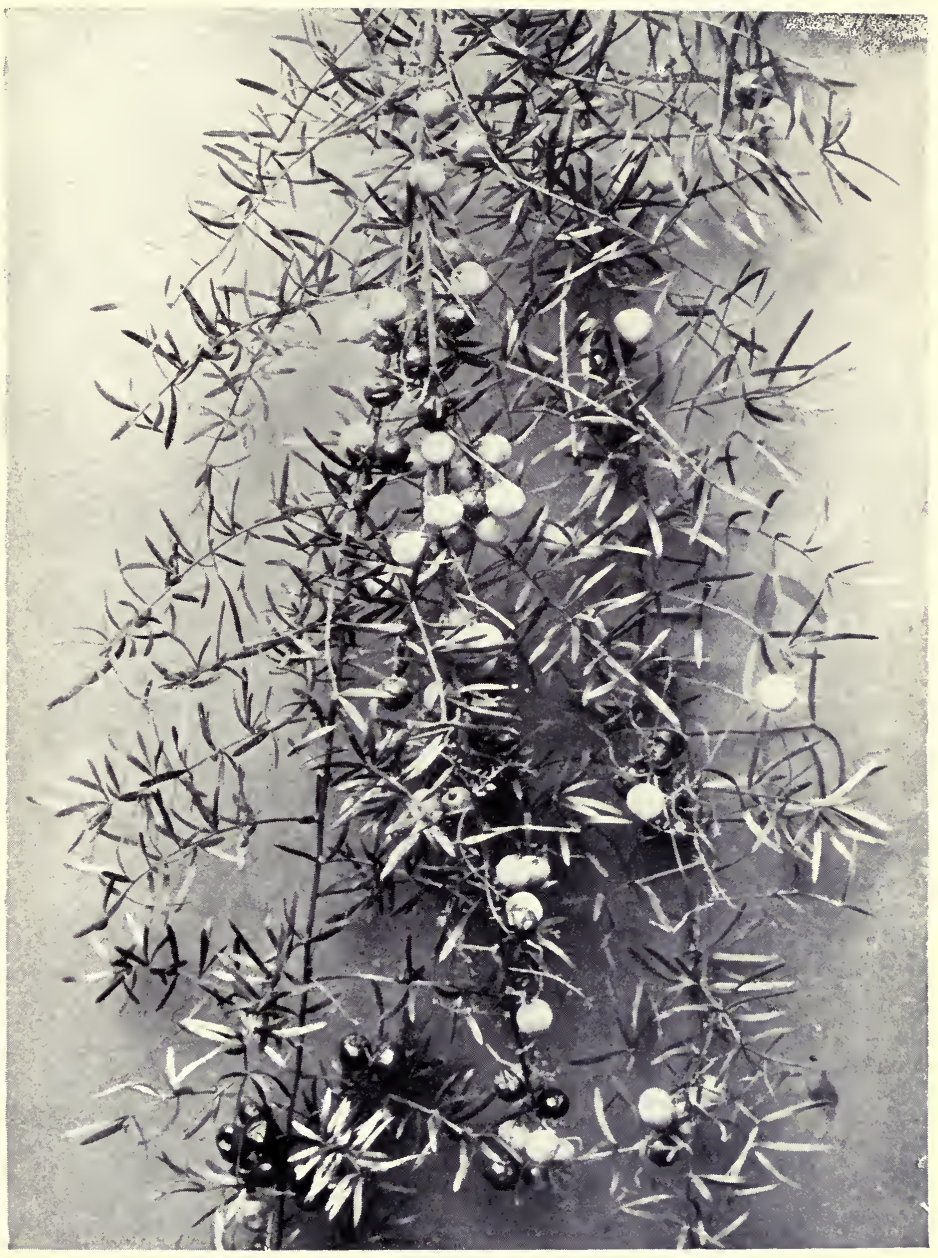

ASPARAGUS SPRENGERI. 


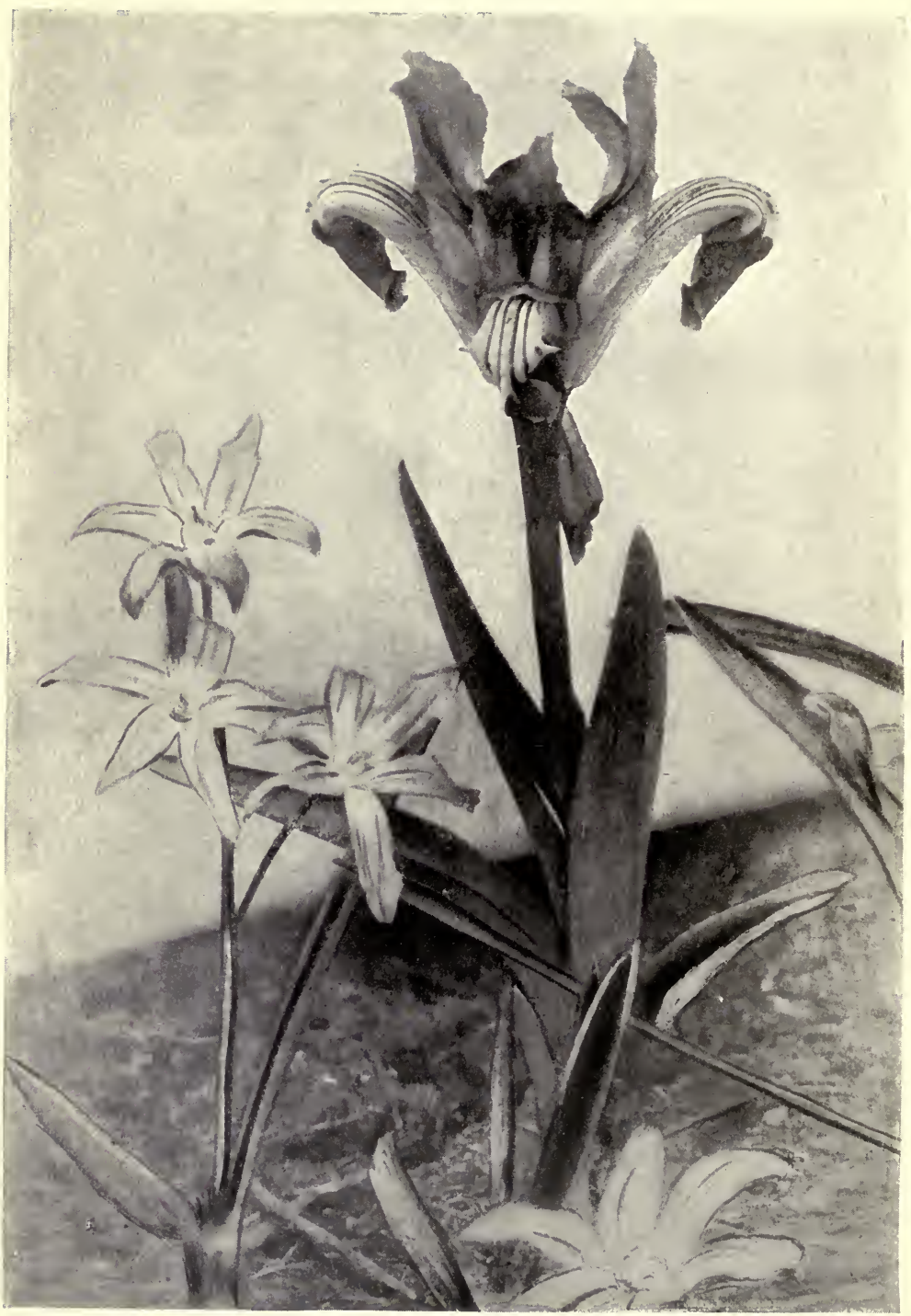

CHIONODOXA (GLORY OF THE SNOW) AND IRIS ROSENBACHIANA. 


\section{CHAPTER VIII}

\section{BULBS AND TUBERS.-I. HARDY SPECIES}

THE question of greenery apart, the cold house gardener would not fare badly if he were restricted to bulbs alone. For simplicity of management, for exceeding charm of flower, and for the comparatively small space required for stowage when they are at rest, there is no class of plant that will give, year in year out, a better return for good cultivation. With tuberous-rooted plants added to the list, he may do well indeed. For the earlier winter flowers in the unheated greenhouse, hardy bulbs must, in fact, be our mainstay. Nothing else will take their place, but to have them in perfection we must take time by the forelock. Herein, be it well understood, lies the main secret of success, for time, under these conditions, must take the place of boiler and pipes. The right moment past, we cannot hope to make it up by rushing our bulbs in a forcing-house. Midsummer-day might, with advantage, be taken as a signal that it is time to begin to lay our plans for our winter campaign. Instead of this, as a rule, the catalogues, which the bulb merchants never fail to send us, are laid by until, perhaps, some chill November day wakes us, all too late, to the fact that our greenhouse begins to look ragged and forlorn.

To a certain extent, both the experienced gardener and the novice must depend on Dutch bulbs for a bright display of early spring flowers, and it is better to reckon upon an annual outlay for such things as Hyacinths, Tulips, and Florist's 
Crocus, because they cannot be grown to perfection, year after year, in pots. Even the bi-yearly system, which answers well for many plants, will not in all cases give the best success with these. At the same time, with a rotation of three or four years, we may grow our own bulbs, of most sorts, if there be any reason for doing so.

It is safe to reckon that from twelve to fourteen weeks at least, according to the season, will be required to bring such quick-growing bulbs as Roman Hyacinths and dwarf Tulips into flower. It is evident, therefore, that, if we want a breath of the spring-tide to reach us when flowers are fewest and most precious, the end of August will be none too soon to find the earliest batch potted of these, and also of some other bulbs to be named presently, followed by more at intervals of a fortnight until the end of October. It is seldom that Dutch bulbs can be obtained quite so early, but the order should be sent with as little delay as may be after the receipt of the catalogue -a plan which serves the double purpose of securing the finest bulbs and of receiving them at the earliest moment.

The first three or four weeks will be profitably spent by the newly potted bulbs in some retired corner of the garden under a coverlet, 2 or 3 in. thick, of cocoa-fibre, or sifted ashes, which answer the purpose quite as well. This is the best substitute we can give for mother earth, and provides darkness, even temperature, and moisture for the development of the root fibres-a matter of the first importance if we want good flowers.

At the end of that time the pots may be removed, according to the date when they are wanted-for it will not hurt some of them to remain in darkness even for a week or two longer -either to a sheltered spot still in the open where they can be given a little protection, or, better still, to a cold frame. In either case they must be shaded for a day or two to inure the pushing leaves gradually to the light. In due time they will 
be ready for their last move to blooming-quarters, and for early spring flowers such as these a greenhouse with a south aspect will naturally give the best results.

This kind of bulb-growing, of which the general outline is here given, is very simple. A few easy rules and careful watering must not be neglected, and then they will take care of themselves; for good cultivation in the bulb grounds and the summer sunshine have done most of the work, and the flowers already lie folded in their hearts before the bulbs reach us. It would be needless to give such familiar directions were it not that every day one meets with new-fledged gardeners trying their first flight who thankfully accept the plainest hints. As soon as the flowering is over the buibs may be planted in the borders, where they will give very acceptable, if smaller, blooms for years to come; but if they should not be wanted for this purpose, let them not be wasted. Be sure that there is some poor neighbour who cannot afford such luxuries to whom they will be a veritable mine of pleasure.

Narcissus, in its many and varied groups, is perhaps the most charming of all hardy bulbs, and in one form or other will carry us from the dark December days to the end of March, and longer if we wish. Paper White-one of the least satisfactory to grow, and with a somewhat evil smell-is generally reckoned the earliest. The equally early Scilly White is not grown so much as it deserves, though it is familiar enough in its cut state. It belongs to the Tazetta or bunchflowered group, and, though it cannot boast the pure white of the South European N. papyraceus, it has a sweeter scent, and the pale lemon of the cup fades by degrees to the creamy tint of the rest of the flower. This species, said to be a native, if I am not mistaken, of St. Michael's Mount, on the Cornish Coast, or at any rate naturalised there, comes into bloom about Christmas in favourable seasons. On that account it is too tender for the gardens of the mainland, but may be had in per- 
fection under glass during December. This and some others of the earlier Daffodils may be potted with the first batch of Van Thols and Roman Hyacinths, or even before. Next in order and in quick succession will come such kinds as the paletinted N. præcox and the deeper-toned single varieties of $\mathbf{N}$. pseudo-narcissus and Double Telamonius, the great bosses of which, familiar as they are, can never be out of favour. Then will follow the splendid trumpets of Emperor; the golden chalice-cups of Sir Watkin; Ornatus, the earliest of the Pheasant Eyes ; the lovely bicolors, Empress, Horsfieldi, and Grandee, treading on each other's steps; and the modest drooping heads of the ivory-white N. cernuus. Or, if we like, we can have double flowers-Butter and Eggs, Bacon and Eggs, and, loveliest of the group, Codlins and Cream-the dear old-fashioned names given them by our forefathers, before even the new-born craze for Daffadowndillies set in. These are all delightful, and can scarcely be surpassed for bold grouping, and are cheap as they are good. The sweet-scented Jonquils must not be forgotten, nor the lovely little double Queen Anne's Favourite (N. capax), nor again that extremely elegant and recent introduction of Mr. Peter Barr's, Queen of Spain.

But we may indulge in rarer kinds if we will, and revel in the lovely forms given to us by that patient and skilful hybridist, the Rev. G. H. Engleheart. Or if miniature kinds are more alluring, there are the three charming species of Hoop-petticoat (Corbularia), yellow, citron, and white, and the dainty $N$. cyclamineus with its upturned petals. Unlike the so-called "Dutch" bulbs, Narcissus possesses the advantage of being a good garden investment. Most kinds increase so liberally by offsets that by good management we can grow our own bulbs yearly and have enough and to spare. One point in strong favour of the unheated greenhouse with regard to these and other hardy bulbs must not be passed over without 


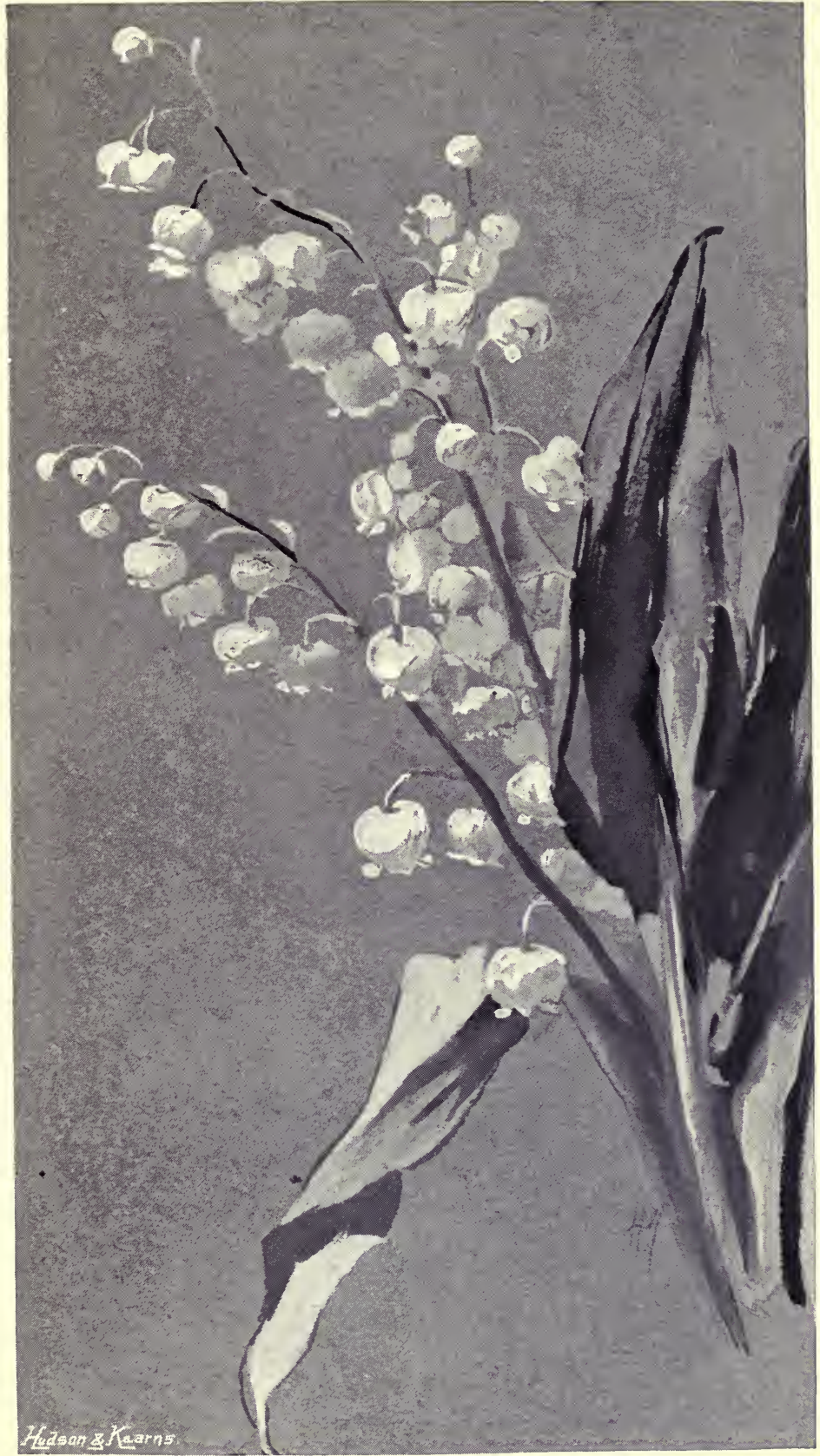

FONTIN'S LILY OF THE VALLEY. 


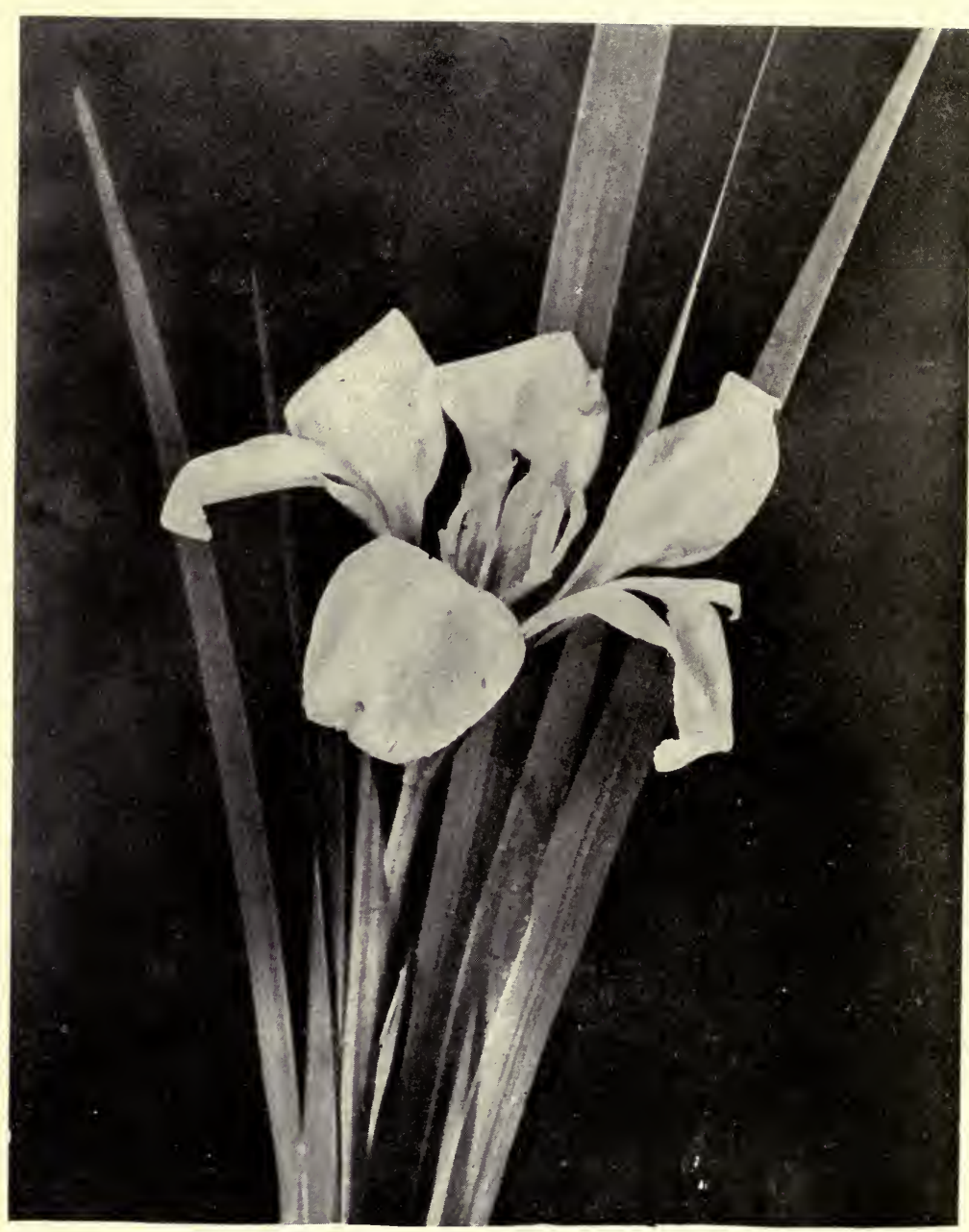

A WINTER FLOWERING IRIS (I. STYLOS 1 ALBA). 
a word. Narcissus is so essentially a hardy genus that many of the most beautiful varieties resent heat and will not give of their best under hard forcing, by which also the bulbs are so much weakened that they are afterwards practically worthless. The gentle forwarding which is all that hardy plants of this class get under the mere shelter of glass does no harm either to bulb or bloom, while we reap the advantage of the earlier enjoyment of flowers, pure and untarnished by wind or weather.

A cultural hint may be added. Bulbs have a sorry trick of "going blind," i.e., the flowers wither away when beginning to develop. This is mainly due to lack of water. Narcissus, in most cases; Hyacinths; Tulips notably, and in fact the greater number of bulbs are greedy of moisture during the rising of the flower scape. After flowering, water should be gradually withheld.

Iris represents another and most precious genus of hardy bulbs and tubers. It has but one failing-the short-lived flowers; but this is in some degree and in some species atoned for by their long succession. One of the most beautiful of hardy winter flowers, beginning in late November and continuing until early spring in favoured spots, is Iris stylosa, the pencilled blue flowers of which have also a lovely white counterpart. Though a native of Algeria, it may be safely given a place under the present heading; but, unfortunately, it is not one of the most easy to flower in pots. This can be done nevertheless, and an established group in a broad deep pan, for it dislikes disturbance at the root, will last for years, and is worth any amount of trouble to attain. The different forms of I. reticulata, with their sweet scent and rich livery of purple and gold, must find a place in every unheated greenhouse, and will sometimes take us by surprise there on a January day. It is seldom that the different varieties of I. pumila, I. germanica, and similar species are pressed into 
the service for early flowering under glass, yet they respond so readily to such gentle persuasion that where they have been tried the result has given much satisfaction. Careful cultivation in a prepared garden bed and lifting for potting in alternate years is a good plan to adopt.

The beautiful Spanish and so-called "English" Irises, though somewhat "leggy," are not the less useful on that account for grouping with suitable greenery. Nor must the tiny Iris cristata be forgotten, a perfect gem, with its delicate pale-blue falls and feathery crests. The slugs have such an unfailing instinct for this dainty morsel that $I$ have found the only safe place at flowering time to be some quiet haven under glass. It succeeds well in a deep pan with sunken bits of stone, or planted on a bit of permanent rockwork. A topdressing of some good light soil now and then helps the rooting stems, and the lovely little flowers lift themselves up at intervals from the leafy points. It is not a showy plant, but one that every lover of flowers must delight in. Another very distinct hardy species is I. tuberosa, whose quaint green flowers with dark velvety blotches will serve as a natural foil to some of the more brightly coloured kinds. Iris-growing has its deeps as well as its shallows, but we need not fear to get beyond our depth with those named above, or to be without some representative of this lovely tribe for several months of the year. Other species, more delicate, range themselves better under the half-hardy list.

In turning over a parcel of bulbs and tubers, perhaps none look so utterly unpromising as the brown flaps and sticks of different kinds of Anemone and the little dried-up claws of Ranunculus, yet to both of these we are indebted for some of the most brilliant of our spring flowers. In the very early weeks of the year we shall find the splendid colouring of Anemone fulgens and of the best forms of $A$. coronaria, single and double, added to the lasting quality of the flowers, invaluable for the cold greenhouse. The last gives us, as well as scarlet and 
good purple, all manner of delicate middle tints. The working up of a good strain of these most delightful Anemones from seed and by a rigid selection is a most pleasant and interesting task. But some smaller and less showy species must not be overlooked. The hardy Greek Windflower (A. blanda) and the Italian A. apennina raised from seed will give in succession quantities of their starry flowers of clearest porcelain to deepest azure, and, though we may see them at their best, nestling in mossy glades under the shelter of the budding Chestnut-trees of their native woodlands, yet nothing can be sweeter than the way they open their blue eyes on a sunny morning upon very different surroundings in a strange land. Another species, A. stellata, which is rosy-purple in its primary form, but ranges from pure white with dark stamens to cherryred under cultivation, also deserves a place.

Probably most people would think of trying Anemones for an unheated greenhouse without any suggestion. It is much more rare to find Persian Ranunculus grown in pots for the same purpose, yet these are well worth a trial. Years ago beds of Ranunculus were the pride and glory of many an oldfashioned garden, and the slender claw-like tubers were increased and preserved, year after year, with the utmost skill, and laid by in paper bags with loving care until planting time; but now we should probably do better to buy our stock yearly. In a warm greenhouse Ranunculus fails utterly in pots, but in a cold frame there should be no difficulty, and a September potting ought to give most acceptable flowers in April, when we begin to want a change from Narcissus and Hyacinths.

Of miscellaneous hardy bulbs and tubers, what a long list might be given. Let a few be named by way of reminder. To begin with, there are large Snowdrops of sorts which coaxing will seldom bring into flower before their appointed time, but which open pure and free from stain under glass; and Winter Aconite, not amiss upon a wintry day and almost 
as happy in a moss-surfaced pan as in a furrow of its native olive-yard on the Italian hills. There is the lovely Crocus Imperati, in pencilled lilac and buff, and other delicate winter-flowering species, beloved of many far above their more robust Dutch brethren, which flower a little later. Sisyrinchium grandiflorum, too, craves for shelter from the January blast for its fragile bells, purple or white; while Chionodoxa and Scilla, able to brave the hardest frosts, are yet very willing to take life more easily. Cyclamen Coum and C. vernum, too, with their allies, rosy or pure white with marbled foliage, are ready to give us beautiful leaf forms when the flowers are gone. Another lovely thing, too much beloved of slugs in the open, and well worthy of shelter, is Ornithogalum nutans, which decks itself daintily in green and silver, while the peculiar sheen of its spikes of drooping flowers under artificial light makes it a dinner-table decoration quite unique in its effect.

As spring advances, there is Lily-of-the-Valley, welcome early or late; and English Fritillaries, chequered like some bit of old-world chintz, or white, or palest lemon, with nodding heads; and exotic forms like F. aurea, not slender and fragile like the others, but hanging its large golden flowers upon stems only three or four inches high. The various species of Tulip, again-which must not be confused with the garden varieties-give us a wide range of choice, from the strikingly fine T. Kaufmanniana to the dainty little rose-and-white T. Clusii. These are but a few, and every one of these, and many more that might be added to the number, can be grown in the open border, most of them without much trouble, whilst it is not to be denied that good cultivation in pots entails a considerable amount of labour and care; but it has its reward when flowers are rare and cold damp days forbid much lingering in the garden in search of the few that may happen to be there. 


\section{CHAPTER IX}

\section{BULBS AND TUBERS.-II. HALF-HARDY SPECIES}

A LARGE number of bulbs are available for the unheated greenhouse which are somewhat difficult to place, because they are suited neither to the warm house nor to the open garden. Many of these can resist even a few degrees of frost on occasion, but the rapid changes of our climate are more than they can endure. For such the greenhouse that can be kept just above freezing-point by temporary means is admirably adapted. Planting time in some cases coincides with that of the earliest hardy bulbs, and, as they require to begin with much the same treatment, August is generally a busy month in the potting shed.

Lachenalias and Freesias, two well-known groups of halfhardy bulbs, belong to this section. L. pendula flowers naturally in November; consequently, it ripens its bulbs first in order, and to have its welcome spikes of bright lightcrimson in due season-July is not too soon to pot this particular species. L. pendula is far too seldom grown, for it is one of the most precious flowers of early winter. The genus includes a number of most charming species and hybrids which have been gradually coming more and more to the front, and the varied shades of colour in the flowers of different species are somewhat remarkable. L. pendula is, I believe, the only species of its peculiar shade of rose-red. The greater number are brilliant yellow, either self-coloured 
or touched with scarlet, and with more or less distinct purple blotches. One species, generally called L. tricolor, but more correctly L. luteola, has a good deal of green in the drooping bells, while another, L. cœrulea purpurea, shows a peculiar metallic blue on the spike of grey-white flowers, and in its best variety is very ornamental.

The most familiar of all hybrid forms is L. Nelsoni, raised now many years ago. It will always hold its own, but of late years these lovely Cape Cowslips, as they are sometimes called, have been skilfully taken in hand by Mr. F. W. Moore, the able curator of the Glasnevin Botanical Gardens, Dublin, and others, and have been brought to a high degree of perfection.

Lachenalias should be grown with as little artificial heat as possible, and nothing injures the flowering quality of these, or in fact of most bulbs, more than to let them start into root growth before they are potted. The routine of cultivation may be said to begin as they go out of flower. Water should then be given them sparingly, and after the leaves die down it must be withheld altogether. The pots may then be laid on their side on a warm shelf, where they will not be dripped upon, that the bulbs may ripen, for to be kept absolutely dry during their period of rest is essential. The least moisture at this stage will start the ring of little white root-points into growth, in which case, it is better to re-pot them immediately. August is, however, the right month for re-potting all the kinds, L. pendula excepted, when they should be shaken out of the dry soil, sorted into three sizes and placed in their flowering pots without delay. On this point, it is well to remember that any disturbance of the roots after potting and growth has once begun will seriously cripple the flowering power of the bulbs. The larger bulbs will give the finest spikes for pots; the second size may be "boxed" and will give useful flowers for cutting; the smallest, if the sort be valuable, will be worth 
saving for stock, but in any case they must be separated from the large bulbs. Three weeks under ashes will generally suffice, and then a cold frame, open day and night, except in drenching rain, will be the best position until the frost, which seldom fails to come during the first week in October; then an additional thick mat will be needed, and the frame must be closed in the evening, but as much air as possible should be given during the day. It often happens that weeks of mild weather follow that first early frost, but let the leaves get once badly frosted, all the hopes of the year are lost as far as flowers are concerned. This open-air treatment, as far as it can be carried out, gives far better results with Lachenalias than coddling, and with many other half-hardy bulbs as well. Several species of Lachenalia may be used with good effect as basket-plants.

Freesias may be grown on the same lines, and stand up firmly on their wiry stems under cool treatment, instead of flopping about in the tiresome way they often do in heat. Never shall I forget a March day in a garden on the Aventine at Rome where Freesias reigned supreme. Under the Palms, bordering the shrubberies, indeed, everywhere, they reared their pretty heads and filled the air with sweetness. With plenty of moisture at the root, dry air above, and with as much sun as our wintry skies will allow, they will do almost as well under a glass shelter, only frost must not touch them.

Somewhat in the same category come Ixias-so exquisite when they open wide their filmy, many-coloured tissues to the sunbeams. The taller Sparaxis pulcherrima, too, not often seen, but very beautiful, is a gem tor the cold greenhouse. For hanging-pots or baskets the sulphur-coloured Oxalis cernua, sold now as the Bermuda Buttercup-on the principle that it comes from Madeira and is no Buttercup-is most ornamental. Six of the bulbs, not very large at best, 
are quite enough for a good-sized basket, while three will be ample for a six-inch pot. Scarcely any plant plays more pranks with its roots than this species of Oxalis. The bulbs must be planted a good two inches or more below the rim of the pot to allow of earthing-up, otherwise the silvery white coils of tubers will shoulder themselves out in the oddest way, especially if, by chance, they are a little cramped for room. Turn out a pot a few weeks later and not a trace of these fleshy coils remain; instead, if one looks closely, the rudimentary bulbs may be detected clinging to some of the fibrous roots. Later on, these will develop into shining brown "nuts," beloved of mice, for they will travel any distance to get them.

With the single exception of Lachenalia pendula, the halfhardy bulbs and tubers above detailed may be expected to bloom in March and April, and are, strictly speaking, springflowering, though with all such plants grown under shelter of glass a little experience teaches that they may be advanced or retarded with a little change of treatment-educated, in fact, to our wishes.

A little later, but in quick succession, to these come the early flowering Gladioli-G. ramosus and its congeners-from the dainty "Bride" (G. Colvillei albus), through a whole series of varieties with pink and scarlet flowers, prettily blotched with white. These are followed by the fine cherry-coloured spikes of G. Saundersi, which have only one failing - that their stems are too slender for the large flowers, and need support. Lemoine's hybrid strain has also many varieties, with flowers of cream and purple, which provide a useful change of colour. In southern countries, these Gladioli are hardy, and may be left in the open border during the winter, but for the present purpose they are placed more appropriately on the half-hardy list.

Alströmerias are now favourite border plants, but one of 
the most beautiful of them all, A. pelegrina alba, is more tender, requiring shelter, and is perhaps the only one suitable for pot culture. Alströmerias do best grown from seed, for the long thong-like roots are easily injured, and dislike removal. For this reason it is well to sow the seeds of this species in what is called a "Lily pot," deep and narrow in proportionthree or four seeds at most being enough for a 7 -in. pot. This lovely plant, with its heads of white Lily-like flowers, freckled with palest green, will disappoint no one. It starts early into growth, and, like Lachenalias and other half-hardy bulbs, must not be frosted, but it is a typical plant for the cold greenhouse, as it invariably shows signs of distress in too great warmth by losing its leaves.

Probably most people would wish to grow Callas, but they are somewhat more tender than might be supposed, for the leaves are disfigured by the slightest touch of frost. They are quite safe, however, in a low temperature, provided it does not touch $35^{\circ}$.

The dainty little climbing Tropæolums, not always recognised as tuberous plants, should not be overlooked, as they also add an entirely distinct feature to the greenhouse in early spring. T. tricolorum Jarratti is the best known species, and is often grown upon a balloon trellis. In a small unheated conservatory $I$ once had a narrow piece of wired wall between two windows which every spring was draped with its brilliant scarlet and black flowers, and was the admiration of all beholders. T. brachyceras, with small butterfly-like yellow flowers, has the same habit, and trains itself to upright wires in much the same fashion, both of them hanging out many slender branchlets in natural festoons. Almost any form of trellis, or even a support of slight twigs, is better than the stiff artificial wire balloon so beloved of some gardeners. T. azureum, with its slender blue flowers, is only seldom met with, but it is a very gem 
of its kind, and quite as easy to grow as the others, and the three are so entirely distinct that it is well to grow them all. The tubers increase quickly. Two or three new ones will generally be found on turning out the pots, and the original tuber will exist for years, growing larger and larger. A cultural hint may be found of use. It is better to shake the tubers out of the soil very soon after the foliage and stems are dead and dry and to pot at once. for the next year's flowering. The usual plan is to put them carefully away until the autumn, but they have a habit of taking their owner unawares and sending out a long, straggling wire-like shoot, difficult to disentangle and easily brokenan injury irreparable for the season. If kept quite dry they will not start any the sooner for being potted, but a watchful eye must be kept upon their movements in early autumn, so that a support of some kind may be supplied in good time.

The greenhouse must not be left tenantless in summer, however, and an infinity of miscellaneous kinds remain to be mentioned, like Arthropodium paniculatum, charming both in flower and leafage, Veltheimia viridifolia, some of the Ornithogalums, Watsonias, and Lilies-one of the most important groups of all, which must presently be taken into consideration by themselves. Iris fimbriata, not much grown and of unusual type, may here be recommended. The pale, drooping, evergreen leaves resemble a broad-leaved grass, and are at all times graceful, and the pale-blue crested flowers which appear in May and June might be some delicately tinted Orchid. Full exposure to sun and air and generous treatment during the summer will probably overcome the shyness to flower of which this beautiful Chinese species is sometimes accused. Later in the year we may have Nerines, another genus of Cape bulbs, represented by the wellknown Guernsey Lily, which, being autumn flowering, require 


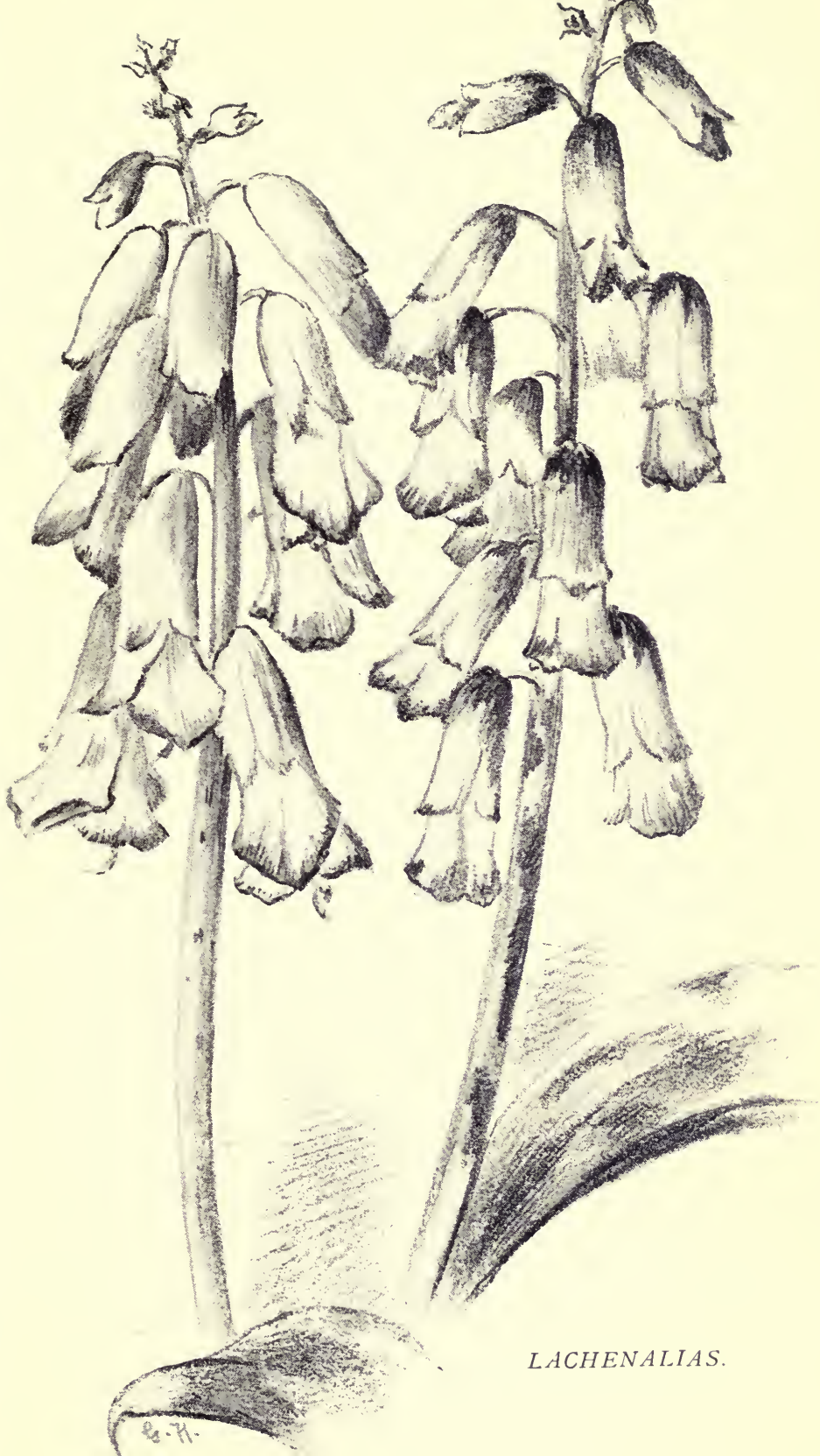




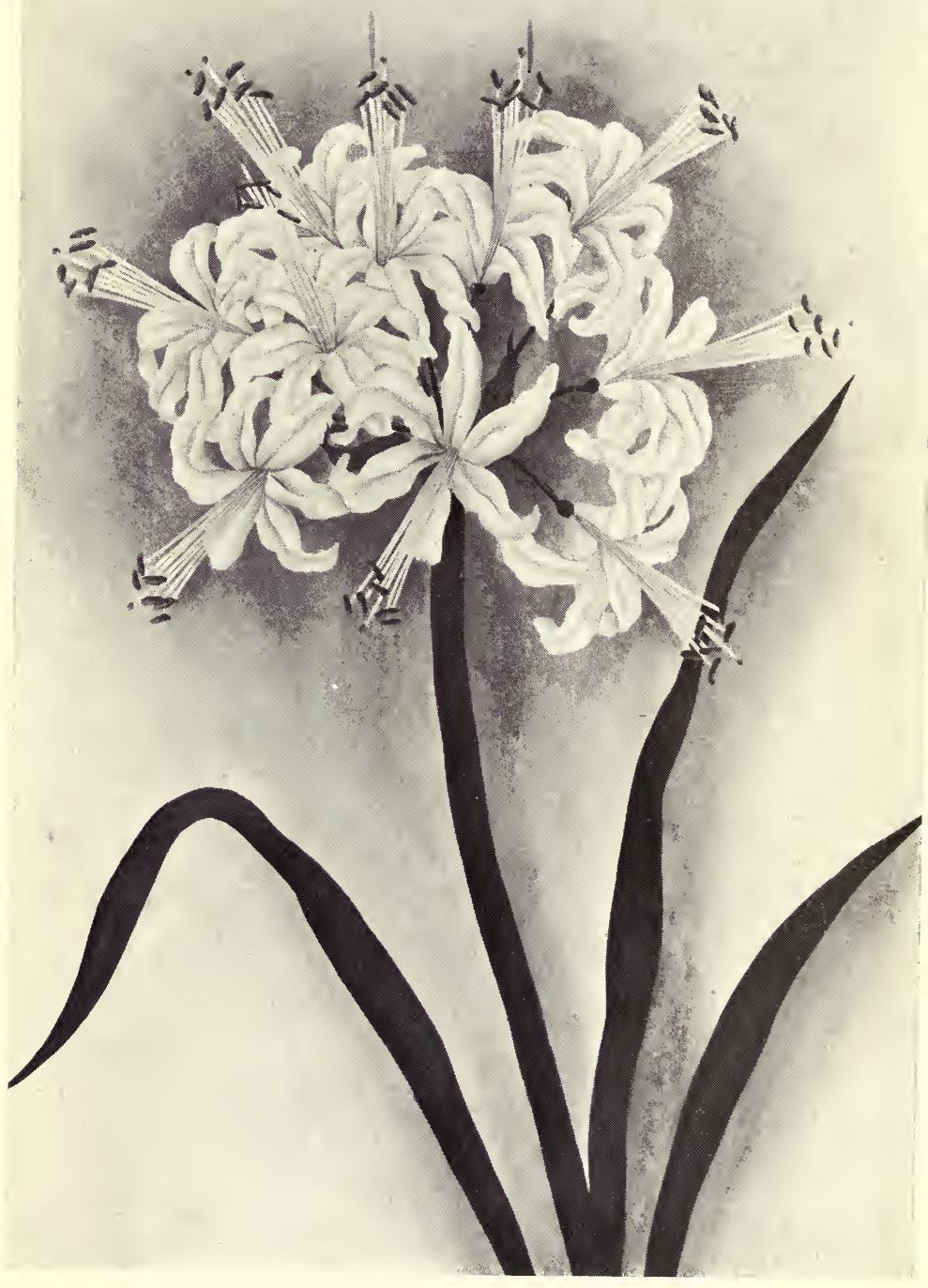

A RARE WHITE NERINE 
rather different treatment. The essential point with these is the summer roasting while the bulbs are at rest. A hot shelf near the glass, where they will not get a drop of water, is the most suitable position as soon as the leaves have died down. At the end of August or in September, for they are somewhat uncertain, the flower scapes begin to show, coming before the leaves, therefore one must be prepared with good greenery to group with them. These gorgeous Amaryllids, crimson, scarlet, and cherry-pink, according to their species, are amongst the most valuable of autumn flowers for the greenhouse. The pretty little N. undulata, with pale-pink crimped petals, though not showy, is very attractive, and the flower-heads of all the kinds are longlasting. The flowering, however, depends not only on the care taken of the bulbs in summer, but of the foliage, and herein lies the difficulty of growing Nerines without a good working greenhouse or frame devoted to such things as must be kept from frost. Out of flower, they are not particularly ornamental, but leaf growth must then be encouraged, and they must be kept growing all through the winter.

One difference between the treatment of Nerines and most other bulbs is that they resent re-potting. It is better to leave them alone until by natural increase the bulbs burst their pots. A good top-dressing in early autumn is all that they ask for. One of my most pitiful garden experiences is connected with Nerines, of which I happened to have a good store of finest species. They were left during my absence from home in a vinery at rest in which were some broken panes of glass. The pots were first soaked with rainthen came a severe frost and then bulbs were hard frozentreatment from which they never recovered, and the whole batch was lost. This is mentioned as a warning that where Nerines are grown-and they are worth growing-suitable winter quarters, safe from frost, must be found for them, but 
a window in a warm room will answer perfectly, as it also does for the better known Scarborough Lily (Vallota purpurea). Belladonna Lilies, on the other hand, will so rarely flower in pots that they cannot be recommended for the smaller sort of unheated greenhouse, but planted out in rather poor gravelly soil, they are admirable for the narrow borders close to the wall which are found in some conservatories and corridors.

For such positions also - though it also flowers very well in pots-the handsome Crinum Moorei is very suitable, especially when associated with such plants as Funkia Sieboldi and F. grandiflora (good both in foliage and flower) which will serve to hide the somewhat ungainly length of stem of the Crinum. A note should also be made of another Funkia recently introduced-F. lancifolia tardiflora-which on account of its late flowering should prove valuable under glass.

Kniphofias-the Red-hot Pokers of our gardens-may not seem exactly suitable to rank as pot plants, yet there are some species which do well and are extremely useful grown in this way for autumn flowering. The very dwarf $K$. Macowani and the more robust $K$. corallina are kinds in point. For these a cold frame with sunny exposure is the most suitable position in order that the flower scapes may attain their full rich colour. The new taller growing species, $\mathrm{K}$. longicollis, though hardy, produces its clear yellow flowers too late to open well out of doors, but succeeds admirably planted out under glass, where there is space for it. It would be worth trying, when it becomes better known, grown in a pail or tub for smaller structures where only pot plants can be accommodated, as it flowers naturally from late autumn onwards into winter.

The new Anoiganthus breviflorus, which opens its umbel of golden-yellow flowers in December, may also find a place in the greenhouse with temporary warming power. But 


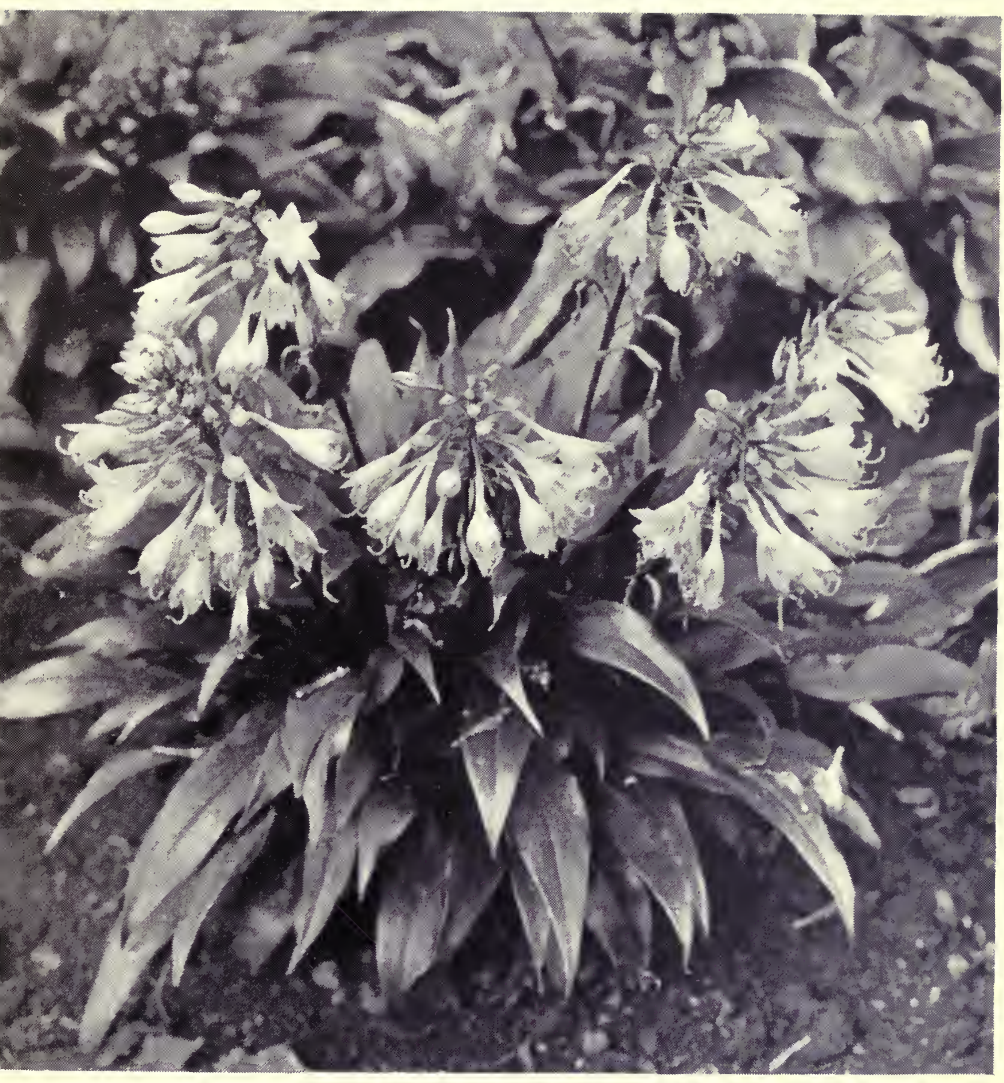

FUNKIA TARDIFLORA. 


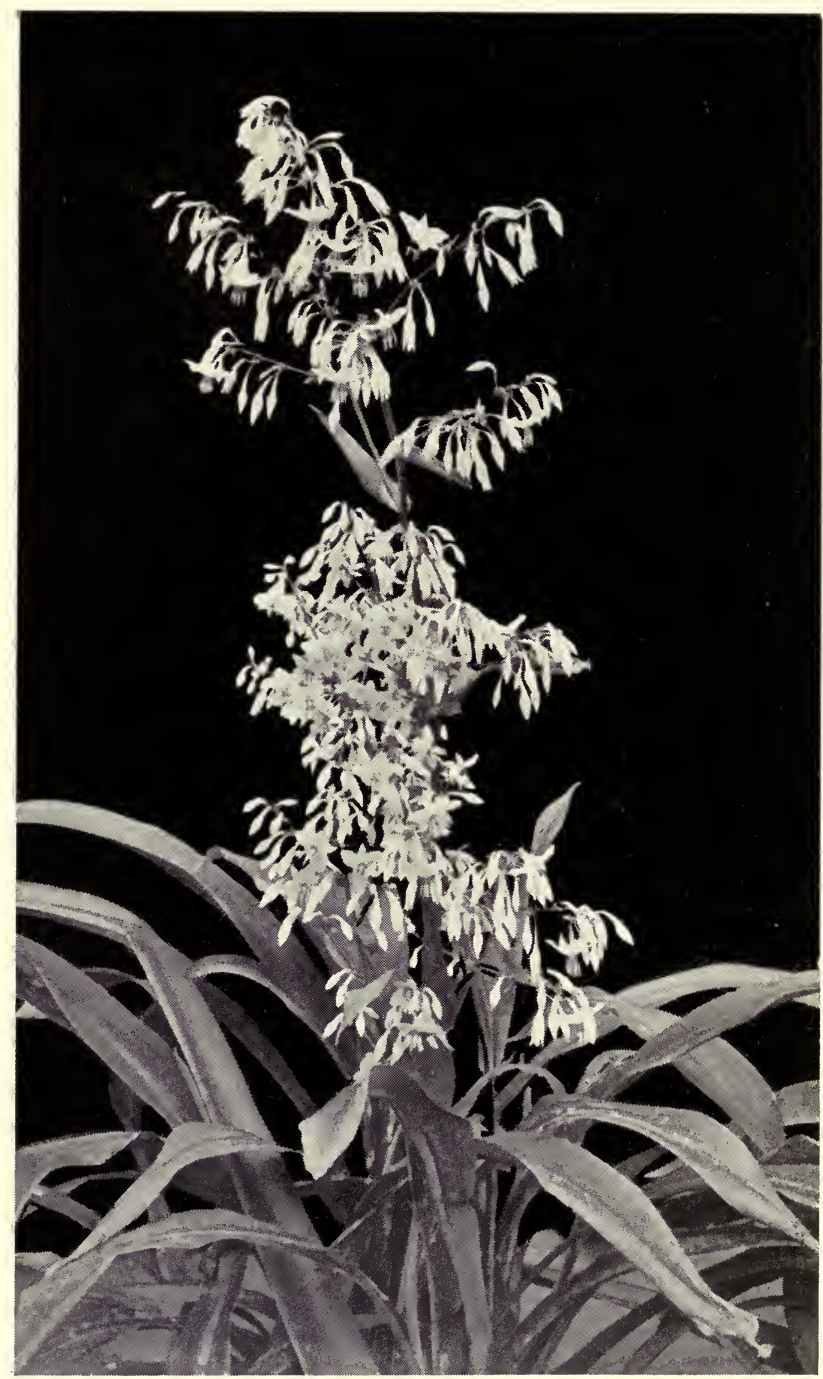

ARTHROPODIUM CIRRATUM. 


\section{BULBS AND TUBERS-HALF-HARDY SPECIES 65}

enough of these interesting and highly decorative plants have been suggested to bear out the statement that with bulbs and tubers alone-though the half has not been told-we may find material enough to make the cool greenhouse a source of interest from year's end to year's end. 


\section{CHAPTER X}

\section{LILIES}

Hitherto Lilies, apart from Amaryllids, have been left out of consideration, because the subject is too large to be dismissed with a mere paragraph. It is obvious, however, that they are almost the most important amongst flowering bulbs for the unheated greenhouse in late spring and summer, not only on account of their intrinsic beauty, but from their adaptability to varied circumstances. Certain kinds, like $\mathrm{L}$. giganteum, and perhaps, on account of its' overpowering scent except in the open air, L. auratum, are only suited for outdoor culture. Others are admirably adapted for planting out, where the structure is large and airy. Probably no more lovely greenhouse picture could be devised than a wellplanned Lily garden under glass, with, perhaps, by a counterfeit of nature, a streamlet running through it into a rocky pool, where groups of Lilies might grow amidst and out of fitting foliage, screened the while from all the dangers, alike of sun and storm. But such arrangements, though far from impossible, are scarcely within the scope of all, and perhaps the topic most generally useful relates to Lilies suitable for pots.

Only a few, in proportion, out of the many beautiful Lilies now grown can be considered well adapted for this purpose. Some, like L. szovitzianum and L. excelsum ( $=$ L. testaceum), are too tall, others will not submit to being cramped at the roots, like some of the North American swamp Lilies, and 


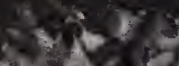

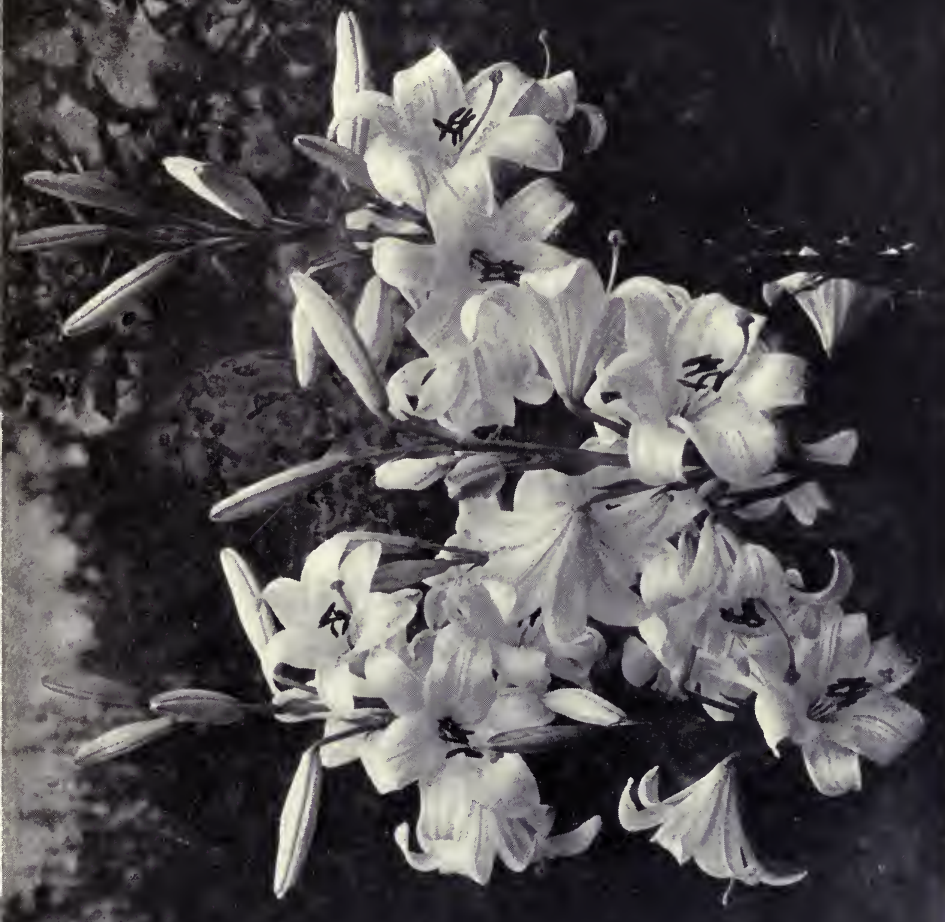

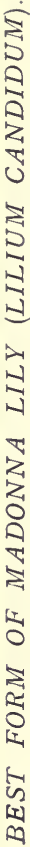




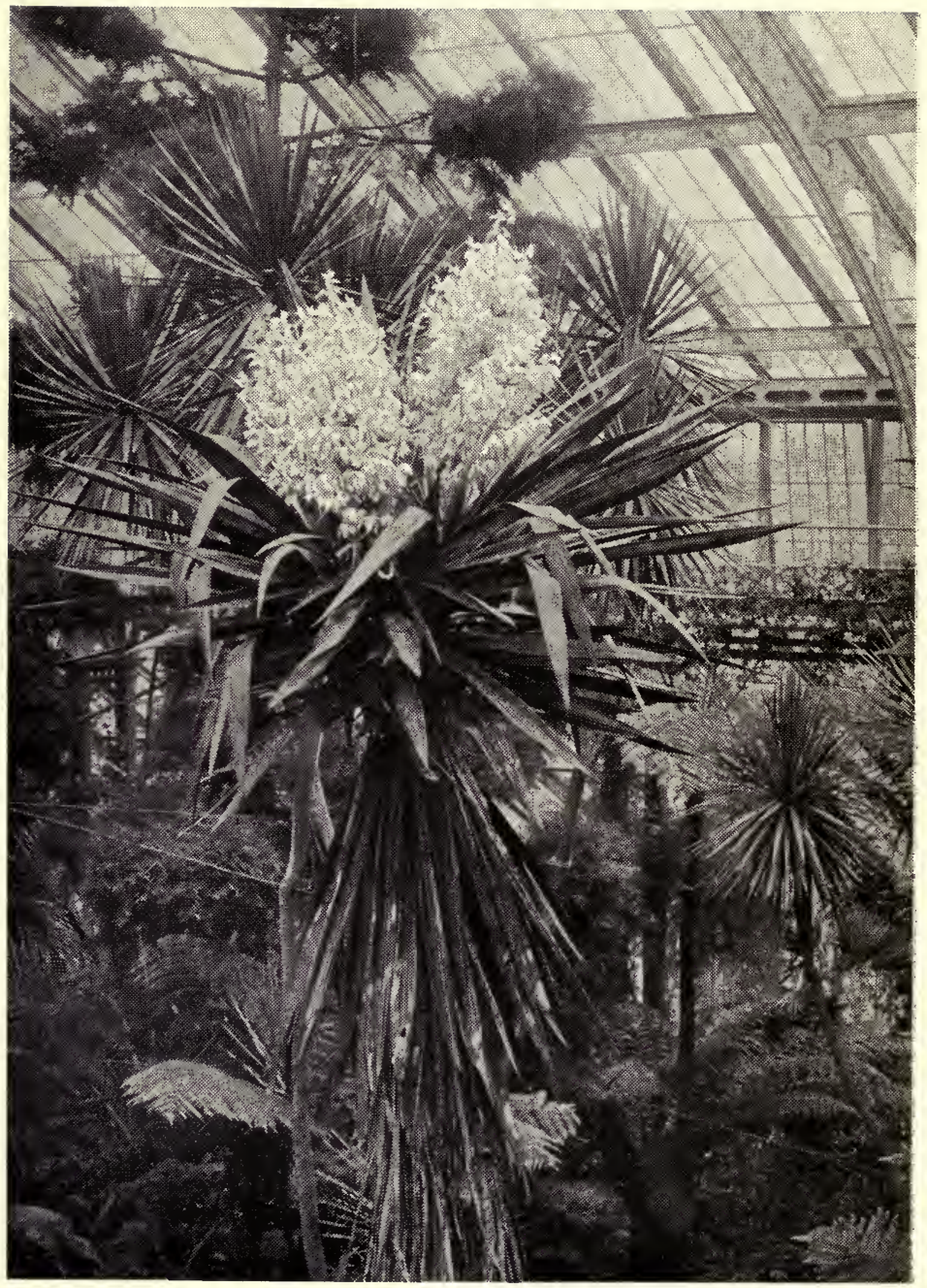

YUCCA GUATERNALENSIS IN THE TEMPERATE HOUSE AT KEW. 
some require treatment or soil difficult to give, but a few hints as to those which are most likely to succeed in a general way may not be out of place. Amongst early kinds-i.e., flowering in June and July - may be reckoned the different varieties of $L$. thunbergianum, also called $L$. elegans. This is a dwarf-growing species, of which many varieties have been raised. They belong to the group with erect heads of cupshaped flowers, of which the well-known Orange Lily (L. croceum) of our borders is a type, and are very handsome in their varied shades of colour from lemon and yellow to orange-red. Some are so dwarf in habit that they actually flower at little more than $6 \mathrm{in}$. high. Such an one is the buff-coloured variety, $\mathrm{L}$. alutaceum, which is also one of the earliest. A nearly allied species, L. umbellatum ( $=\mathrm{L}$. davuricum), fairly common in our gardens, is rather larger in all its parts, and the flowers are mostly of shades of dark orange-red. Both species are frequently grown in pots, but care should be taken to give shade in bright weather, when they are flowering under glass, otherwise they quickly lose their rich colouring and turn brown.

A pretty little early Lily, of a different type, is the slendergrowing $\mathbf{L}$. tenuifolium, a miniature turn-cap, with bright-red flowers, and quite at home in a pot. This is one of the Lilies most easily raised from seed, which is fortunate, as the bulbs are not very long-lived.

Amongst white Lilies, the best known, yet one of the fairest of them all, is the Madonna Lily (L. candidum), a wilful beauty, not always kind, for, strange to say, it will not everywhere succeed. As we all know, this Lily is much in demand for church decoration, and huge cases containing thousands of bulbs are sent over from Holland every autumn for forcing purposes. These bulbs are, for the most part, finer than any I have ever seen of English growth. They are cultivated, presumably, in the same enriched soil of the sand 
dunes in which other Dutch bulbs thrive so marvellously, and are lifted at the exact moment when the leaves are almost dead and root action arrested. A good many weeks must necessarily elapse before they are replanted, and the point I should like to make clear is, that in all the hundreds of these bulbs of which, as it so happens, I have had experience, never a trace of disease has appeared, and the flower spikes, unless they have had too much attention in the way of heat, have been as good as they can be. Whether this is due to the dry nature of the sand in which they are grown or the drying-off process-which certainly does no harm-to which they are subjected on being lifted, I will not venture to assert, but those who want Madonna Lilies either for pots in a cold greenhouse or for church decoration in May cannot do better than to procure some of these splendid bulbs from Holland. They cannot be induced to flower so soon as Easter without forcing, but if obtained as early as possible in the season, given protection from frost in a cold frame during the severest weather, and brought into an unheated greenhouse with a south aspect in March, they ought to be ready for Whitsun. tide, or even earlier sometimes, according to the date upon which it falls. Five bulbs in a deep, broad pan 15 in. by 8 in. will make a good clump, and the noble spires prove very acceptable several weeks earlier than they can be looked for in the garden, whether for church or corridor, or even for grouping in the shady angle of a courtyard or verandah, with suitable background and undergrowth of greenery, where, as sometimes happens, garden-room is denied. Of white Lilies for pots one of the earliest and best is L. longiflorum. The trumpet is not so long as in the variety known as L. Harrisi, which is imported in large numbers from Bermuda, but it is much more hardy and satisfactory to grow. It comes to us from Japan and is a well-known favourite. Amongst newer and less familiar species is L. Alexandræ, also from Japan, and 


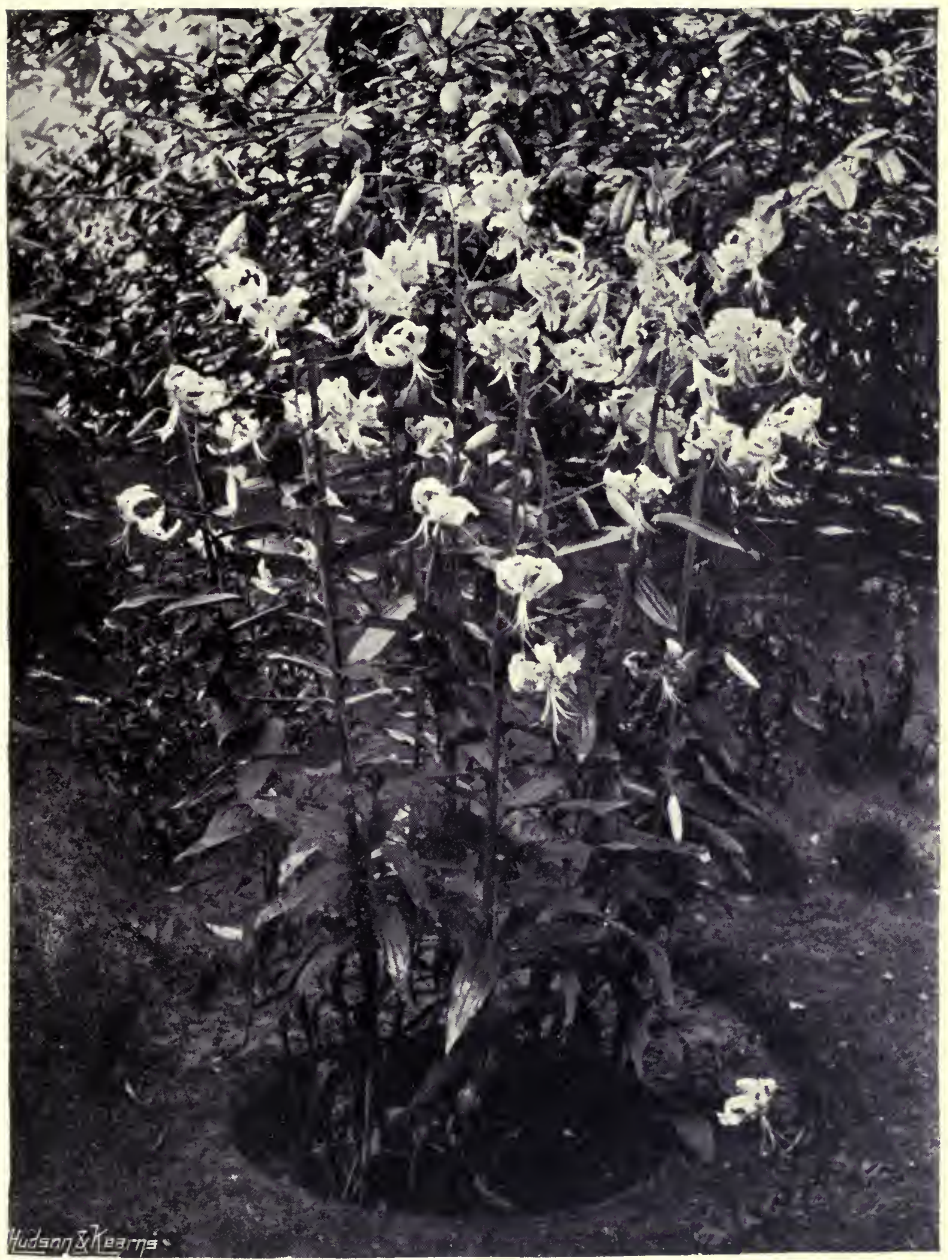

LILIES GROWN IN TUB. 

supposed to be a hybrid between L. auratum and L. speciosum, though this may be doubtful. The flowers, which are pure white, are less trumpet-shaped than L. longiflorum, but more so than in L. auratum, and the thick waxy petals last well, while the scent is less oppressive than in L. auratum. When better known and less costly this Lily is sure to become popular, as it succeeds admirably under pot culture and flowers at a height of about 18 in.

But many hues may be looked for amongst the Lilies, and another charming species, also well suited for pots, is the new L. rubellum, with clear pink- or rose-coloured flowers. It is too soon, perhaps, to speak positively of its good behaviour, but those who have had most experience have testified to its strong constitution and to the early flowering of established bulbs.

It is, of course, quite possible to grow in pots the lovely orange-yellow L. Henryi, discovered and sent home from China some years since by Dr. Henry. Its great height, however, points rather to its suitability for planting out, where its magnificent proportions can have full scope, but in whatever way it is grown it has proved itself to be one of the most valuable Lilies of recent introduction. At Kew in the open air it has reached a height of $8 \mathrm{ft}$., and a single stem has carried as many as thirty flowers.

I have grown two small North American Lilies sent across to me by the kindness of a friend, which are extremely pretty for the unheated greenhouse. One of these, L. Grayi, is nearly allied to $\mathrm{L}$. canadense, and has the same kind of creeping bulbs. The flower is orange-red with reflexed spotted petals. The other, L. philadelphicum, is quite distinct, having open-cupped flowers of even more brilliant colouring. They are both worth growing in this way by a Lily collector, though not very easy to keep, and both love a peat soil. 
Of the later flowering Lilies L. tigrinum, though one of the oldest garden species, is still one of the most beautiful, but the variety called Superbum is the only one well adapted for pot culture. Its very distinct shade of deep apricot, however, makes this variety valuable for the purpose, as well as its intermediate season of flowering.

But our greatest standby for autumn is the Japanese L. speciosum, in its different varieties, flowering naturally as it does in August and September. This Lily, which used to be known as L. lancifolium, is not always recognised under the newer name, but it is too familiar to need description. The three forms are represented by $L$. speciosum roseum, L. speciosum rubrum, and L. Krætzeri, which is the best of the white varieties, and may be distinguished by the pale green stripe down the centre of each petal. A deep red variety is known as Melpomene.

In growing these and other Lilies, it is well to know which species naturally throw out stem-roots and which do not, as it indicates a different system of potting. Of those which have been mentioned, L. Alexandræ, L. auratum, L. elegans, L. Henryi, L. longiflorum, L. speciosum, and L. tigrinum all have stem-roots, and should be potted low, leaving a space of 2 in. or 3 in. above the bulbs for a liberal top-dressing as soon as these stem-roots begin to push. Without this, they will wither away for lack of nourishment, and the flowers will greatly suffer. On the contrary, L. candidum and L. Grayi root from the base only, and should be potted with the top of the bulbs almost on a level with the soil, only taking care to leave a sufficient rim for proper watering-a necessity often overlooked when potting is done by an inexperienced hand. I have found the long pots recommended before for Alströmeria extremely useful for Lily culture, especially for the stem-rooting kinds. In buying new bulbs no time should be lost in potting them as soon as received. 
With home-grown bulbs, the moment to turn them out of their pots arrives when the leaves and stems have become quite yellow - a week too soon is better than a week too lateas root action is suspended for an incredibly short time. My practice has always been to separate the larger from the smaller bulbs, re-potting all immediately, and have found it answer much better than keeping them above ground, even for two or three weeks, in spite of the fact that the L. candidum bulbs sent over from Holland do not seem to suffer.

Two-thirds of turfy loam to one of leaf-mould, some welldecayed manure from a spent hot-bed, two or three double handfuls of road-grit or coarse sharp sand, and a sprinkling of soot, well mixed together, make an excellent compost which suits most Lilies, but there are a few, like L. Grayi and L. philadelphicum, which prefer peat. The pots must be well drained, and a handful of old hot-bed refuse well rammed down above the crocks is desirable. After potting a good watering should be given, and then a thick layer of cocoanut-fibre refuse will keep the Lily bulbs safe until they begin to push. The young growths must be protected from frost in the same way as other bulbs, but the more hardily Lilies can be grown, and the more they are in the open air (always, of course, according to the weather) the better. It is a melancholy sight to see such fine Lilies as L. speciosum, for example, spoilt by overmuch coddling, but they should be brought under glass as soon as the flower-buds are formed, and watch kept lest these should be crippled by green fly. They will require an abundance of water during the growing season, but after flowering this must be gradually withheld, as with other plants of the like nature, and the pots should stand in some sheltered place out of doors for the bulbs to ripen.

It is easy enough to flower Lilies well for one season, 
for they are as a general rule in good condition when bought from trustworthy dealers, but the test of a good Lily-grower is to keep the bulbs year after year, and probably most of us have a record of as many failures as successes. 


\section{CHAPTER XI}

\section{FLOWERING SHRUBS}

IN considering suitable plants for the unheated greenhouse, it is better-partly for the sake of easy reference and partly because their cultural treatment is, in most cases, likely to run on the same lines-to group them under specific headings. Flowering shrubs, both hardy and half-hardy, form a most important decorative class, whether from the standpoint of the spacious winter garden, or of the modest conservatory for which plants in 5 -in. to ro-in. pots are the most suitable and convenient. The winter garden is pre-eminently fitted for the permanent planting of some of the countless grand shrubs and rafter plants, such as the Himalayan Rhododendrons, Acacias, Magnolias, and others, which flower naturally during the earliest part of the year, for it is likely enough to stand idle, as far as show purposes are concerned, during the summer months-not for lack of material to make it delightful, but for lack of interest at that season on the part of the owners of it. For late autumn, a season when the winter garden begins once more to be attractive to the house party, such fine things as the deep-purple-flowered Desmodium penduliflorum and Asparagus umbellatus, which is charming in flower as well as graceful in greenery, may be cited as examples less familiar than they might be.

The glass corridor, being often a passage-way from the house to a billiard-room or to the gardens, might give suitable place to such mid-season subjects as, for example, Carpenteria 
californica, so impatient of fire heat, but so lovely with its great heads of wax-white flowers, though this fine shrub is even now not very well known. The finest specimen I have ever seen was one which had to be planted, for want of a better place at the moment, at the end of a centre-border in a large Rose house, and there it remained till it had to be removed for want of room. It was a wonderful sight when in bloom, with every branch weighed down with lustrous flowers. It is easy enough, however, to keep it within due bounds by judicious pruning, therefore it can be safely recommended.

There are many shrubs of this almost hardy class which refuse to flower in pots, because they require a certain amount of undisturbed, if somewhat restricted, root-room. They are so eminently beautiful that a wide corridor devoted to their culture would be a grand feature. To name a few, there is Fremontia californica, craving shade during the hottest sunshine. Another is the South American Poinciana Gilliesi, graceful in its pinnate foliage, and with golden-hued flowers glorified by their flowing crimson stamens. There is Abutilon vitifolium, with its grey-green, mealy looking leaves and bunches of exquisite pale mauve (or white) recurved flowers, so distinct in every way from other Abutilons that it would scarcely be recognised as such, but quite intractable for pot culture. Buddleia Colvillei, too, said by Sir Joseph Hooker to be one of the handsomest of Himalayan shrubs, would be suitable for such a position. Its flowers are not rolled up into Orange balls like the B. globosa of our gardens, but hang in clusters of white-throated crimson Pentstemon-like flowers from the ends of the branches. At Kew this fine plant is found to be better fitted for the cold house than for any other method of culture. To these may be added Veronica hulkeana, scarcely hardy in the open, but one of the very best of the New Zealand Veronicas, growing from $3 \mathrm{ft}$. to $4 \mathrm{ft}$. high, and giving a mass of its pretty light mauve spikes during late 
April and May. Another suitable shrub is Weigela hortensis nivea, somewhat unsatisfactory out of doors in most gardens, but worthy to take high rank both for its pretty netted leafage and its bouquets of delicate white flowers. For winter and early spring flowering, Daphne indica is a useful shrub, content with a back-wall so long as it can be undisturbed at the root and can have room to develop. Cantua buxifolia, a fine Peruvian evergreen, bearing red pendulous flowers at the ends of the branches in early summer, is suitable for clothing a supporting pillar. For this purpose Cestrum (= Habrothamnus) elegans is also invaluable, flowering later in the year. All these, and many others, will thrive in a light, airy glass shelter in a good aspect with a minimum winter tem perature kept just above freezing-point. Most of them are hardy enough to live out of doors in favourable positions, but the severe strain upon their endurance prevents such freeflowering as we may fully expect under glass.

It is impossible to do more than suggest plants likely to succeed under cool treatment, but there are enough of all kinds to suit any and every purpose-the choice must be in accordance with individual tastes and requirements. Three shrubs, to use a comprehensive term, which may be found in flower in many a Devonshire garden in November and December, occur to mind as being well worth growing in less propitious climates for the absolutely cold greenhouse. Young plants of the Box-leafed Myrtle flower at a very small size, and though they will grow into big bushes, are neat and compact at all times. Beginning to flower in September, they go on continuously, often till Christmas, out of doors, until compelled to give up by stress of weather. Their creamy-white flowers and pearly buds are welcome indeed in a pot at that dull season. About November the homely little Coronilla glauca, brave and bright, begins to set about its winter work, and though it cannot boast the beauty of the less known South 
European species, C. Emerus, which blooms in the spring, yet its fresh, blue-green leaves and numerous heads of pale yellow flowers for six dull weeks are not to be despised. To complete the trio, we have the winter-flowering Jasmine (J. nudiflorum), so often cut off by unkind frosts in the midst of its bloom. Grown in a ro-in. pot and fastened not too strictly to a pillar or rafter to allow scope for its pendent branches, it is very effective under glass. It may be used also as a fountain plant for a corner and made to droop over a low trellis-like contrivance, which suits its habit better than being treated as an upright semi-climber. It must be carefully cut back, however, soon after flowering. Laurestinus-of which Viburnum lucidum is the best species-is also very welcome. For this season, too, a curiosity may be grown in the Glastonbury Thorn (Cratægus monogyna præcox), for though it might be risky to predict that it would actually open its blossoms on Christmas Eve, according to tradition, yet it is, in truth, a winter-flowering Hawthorn, and might very probably keep up its reputation. Many kinds of hardy springflowering shrubs, such as Hawthorns, Wistaria, Malus floribunda, Prunus, and others, may be educated to flower in pots, year after year, at a very early season. The main secrets are to keep such things in compact form by skilful pruning and to ripen the wood thoroughly in open-air quarters during the summer. Any amateur can try his hand at the cultivation of such shrubs for this purpose, for they are all worthy in their way and not difficult to manage, but they are mainly grown by professional gardeners who have large conservatories to "furnish"-a term not congenial to the true lover of plants. Prunus japonica fl. pl., however, with double white flowers, is a very charming shrub, adapted for either a small or large greenhouse, for, by frequent transplanting when young to keep it within due limits, it may be flowered in a 6-in. pot. It is naturally of low-growing, bushy habit, and will, after pruning, 
which should be done as soon as flowering is over, send up many strong shoots from the base during the summer; these will flower their whole length the following season to a height of from $2 \mathrm{ft}$. to $3 \mathrm{ft}$. Being perfectly hardy, flowering shrubs of this latter class take up no room under glass when their purpose is accomplished, but they must receive kindly shelter in good time to bring them into bloom before their normal season.

More than one kind of Cytisus is well adapted for the cold greenhouse, besides the well-known C. racemosus. A beautiful weeping standard may be grown by grafting the Teneriffe broom (C. filipes) upon a laburnum stock, when the drooping branches will be covered with pure white flowers in early spring. This elegant species may also be grown from seed in pyramid form by leading up the main stem and leaving the rest of the branches to themselves.

Several of the shrubby Spiræas are popular as pot plants, notably the fine S. Van Houttei, which produces masses of white flowers in early spring under glass. Amongst such smaller-growing shrubs, Deutzia gracilis is an old favourite which we cannot do without, one of the most graceful of any when in flower, blooming well in a $4 \frac{1}{2}$-in. pot if desired, and only asking to be cut back immediately after flowering to do better every spring-how it would be prized did we not know it so well! Hybrid forms of these beautiful shrubs are being raised by M. Lemoine of Nancy, who has taken them in hand. One of these, called D. Kalmixflora from a fancied resemblance, may prove to be an acquisition, as it has flowers of pale pink, edged wlth a deeper blush.

Hardy Rhododendrons of the very early flowering section deserve the protection of glass, for in two seasons out of three their flowers are apt to be spoilt by snow and inclement weather. One of the first to bloom is the crimson-flowered R. nobleanum. For planting out in large conservatories, this 
and many still more decorative species may be grown, and in early spring are of course amongst the most splendid of flowering shrubs, but most kinds can also be made amenable to pot culture. There are two or three early flowering and smaller-growing species, however, which may be noted as being especially valuable for the unheated greenhouse of moderate size. The little Siberian R. dauricum opens its lilac flowers naturally in January and February, therefore it is thankful for protection at that uncertain season. A little larger in growth and later to bloom is R. ciliatum, a fine Himalayan species, with pink buds which expand into white flowers. Between these two comes a useful hybrid form, R. præcox, with rosy-purple flowers. $R$. racemosum, which should not be overlooked, is a little-known but very charming dwarf species from China, of quite different character, as its pale pink flowers are produced in spikes. It is astonishing how spreading shrubs like Rhododendrons can flower and flourish in so small a space, but they may often be seen with several fine trusses, quite happy in 5 -in. pots. It is better, however, to flower them one year and rest them the next by planting out in a reserve-bed in the open air, though the very slight amount of forcing which they receive in the cold greenhouse does no harm, and if they set their buds well there is no reason why they should not be lifted and potted every season.

Of miscellaneous shrubs coming under no special class there are many which might be suggested: Choisya ternata, though found in most gardens out of doors, may yet be given a place for early flowering under glass. The hardy Abelia rupestris, with its pendulous mauve-white flowers imbedded in red-brown bracts, is charming either in a large basket, or, if planted out in a greenhouse border, will make a handsome autumn-flowering shrub, good enough to join the choicest company. Nerium Oleander, though more tender, is worth 


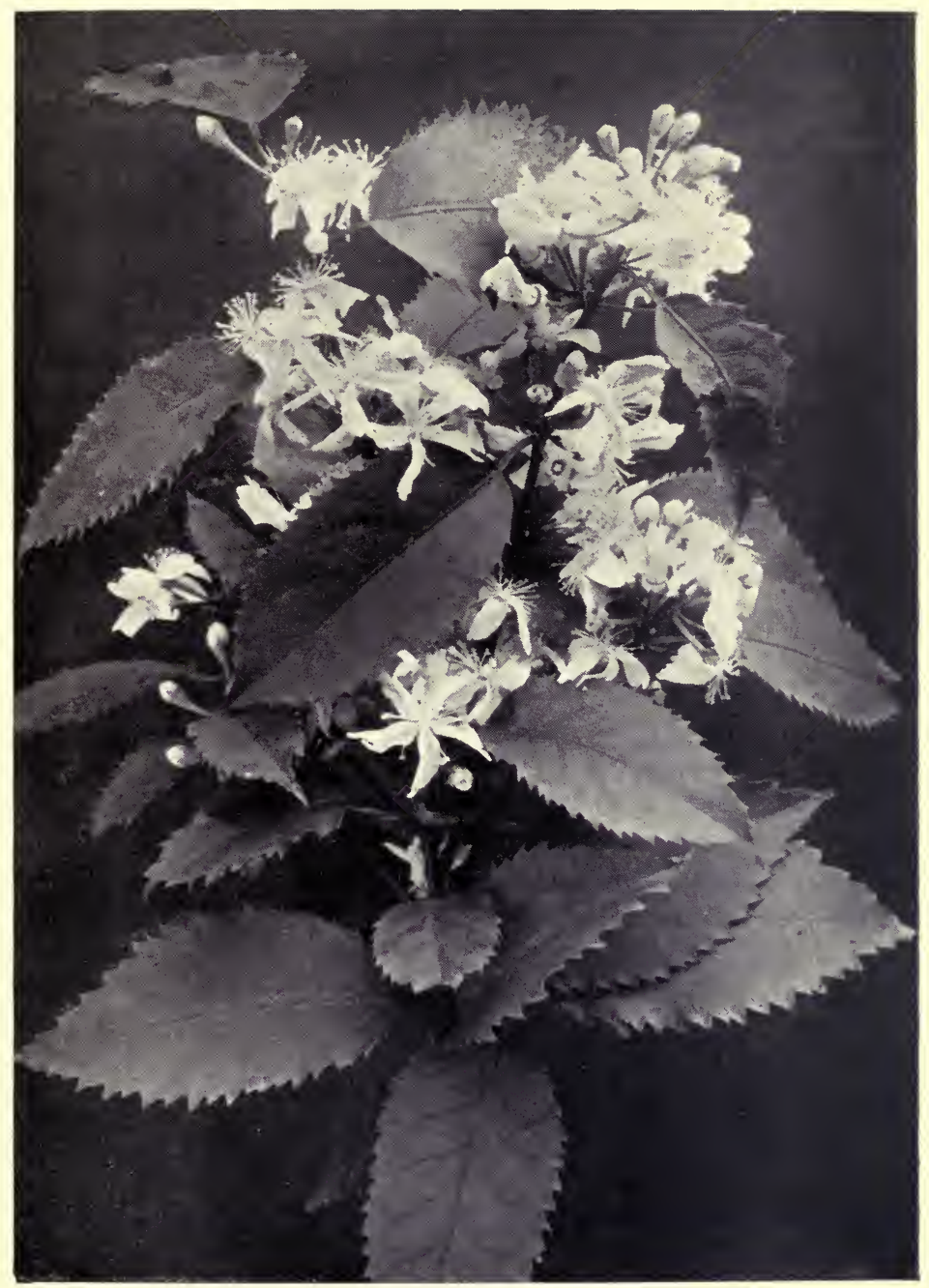

HOHERIA POPULNEA 
growing, especially in some of its less common single white or pale yellow and buff forms. It flowers freely, whether in small pots or in large tubs, but requires protection from actual frost and abundance of water in the growing season. For late summer, both the Brugmansias are good and not very commonplace half-hardy plants, either for a greenhouse border or for large pots or tubs. In fact, $B$. sanguinea, with long orange-mouthed tubes, treated as a herbaceous plant, succeeds well out of doors up to a point, but beyond that it will not go. It springs up strongly from the stool in the spring, and in the course of the summer the robust branchlets cover themselves with fine buds, which just begin to open when frost cuts them off. Under glass they are safe, but the same plan of cutting down ruthlessly to the ground-level after blooming, even for pot plants, may be recommended, as it keeps them in better shape. They may, however, be preferred as standards-a form which often comes in very usefully for grouping purposes. The flowers of B. suaveolens are white and trumpet-shaped, and though it is perhaps a trifle more tender, it requires much the same cultural treatment.

Two little-grown plants must close the list, which might be much prolonged. How seldom do we see the Pomegranate (Punica granata) in English gardens, except occasionally on a warm wall in the southern counties, yet there is no shrub more worthy of planting out, if there be a fitting position for it in corridor or glass-covered verandah, or for growing in a tub, as we may see it so frequently abroad. The dwarf variety may be seen in Germany flowering well even in 5-in. pots. The brilliant scarlet flowers, whether single or double, are suggestive more than any others of warmth and sunshine, while the shining foliage, red-tinted in the young spring shoots, is always beautiful.

The other plant of very different character is Echium 
fastuosum, little known and less grown. It may be called a shrub by courtesy, since it is not herbaceous. This remarkable bushy Bugloss was figured in a coloured plate in one of the earlier volumes of The Garden. Falling in love with its portrait, I obtained seed and raised it, and in due time reaped a rich reward for my pains in its magnificent heads, some 8 in. or 9 in. long, of deep gentian-blue flowers. A very similar species, E. callithyrsum, is equally handsome, and only a trifle paler in hue. They come from the Canary Islands, and are by no means hard to grow. The foliage, as in all Echiums, is rough and shaggy, and the bush grows large and spreading, but any one who has seen its uncommon beauty would consider it worthy of some trouble to grow well. Whether as a fine specimen in a 10 -in. pot, or planted out in a wide border, few things are more striking in their way than these two species of half-hardy Bugloss for the decoration in April and May of the unheated greenhouse. 


\section{CHAPTER XII}

\section{SOME HARD-WOODED PLANTS}

IT is so generally recognised that hard-wooded plants are more difficult to grow than those that are called, by way of distinction, soft-wooded, of which Pelargoniums may be taken as a type, that, with the few notable exceptions, they have well-nigh disappeared from our greenhouses. They are slow-growing, but, on the other hand, under proper treatment, they are long-lasting, for one difference between the two classes is this, that while soft-wooded plants seldom flower well when they are old and have therefore to be constantly renewed, the others, well grown, flower better and better in their age than in their immature youth. Probably many old gardeners can well remember some enormous specimens of the yellow-flowered Heath (Erica Cavendishi), of Hederoma tulipifera, studded all over with waxy pink and white bells, of Aphelexis macrantha, a sort of pink everlasting from New Holland, and others, all typical hard-wooded plants and the pride of their grower's heart, which used to travel to town from Staffordshire in their own comfortable van, year after year, to win their annual prizes at the metropolitan shows. Splendid examples they were, of which the like are seldom seen now, and though we may not wish to own such leviathans of their race, yet it would be a great pity to let such fine things be forgotten.

Perhaps when we remember that Azaleas and Camellias may both be included in the ranks of hard-wooded plants, the 
cultivation of which most possessors of a greenhouse have attempted, an effort to grow others may not appear quite so formidable. At any rate, some of them are so well adapted to the cold greenhouse that they are worth any pains that can be taken with them. By way of parenthesis it may be as well to remind the unbotanical reader that Azaleas are now ranged under the generic name of Rhododendron, a change which is rather puzzling until one gets used to it, for writers in garden literature are now taking into use the more accurate term; but for gardening purposes the old name of Azalea is too firmly fixed in popular speech to be easily discarded and therefore is retained here.

To begin with, the well-known Azalea indica, which always suggests a hot-house, is by no means greatly addicted to heat. Large bushes in perfect health and flowering freely may be found growing in the open air in many parts of the country; yet they must be set down-with most of the other plants which come under this heading-as belonging to the halfhardy class that are grateful for protection from actual frost, chiefly because their fragile flowers are easily spoilt by bad weather, and besides, for the greenhouse we want flowers before their due season. To induce them, therefore, to open their buds during winter or spring, as the case may be, they must be specially treated. Azaleas set their flowers so early in the autumn that we can safely predict the amount of flower to be expected from them. This process once accomplished, for which it is necessary that the wood be well ripened in the open air during the summer, it is mainly a question of bringing the plants into snugger quarters, earlier or later, according to the time they will be required.

The greater number of the Azaleas we see in our greenhouses have been reared in Belgium, where the process of grafting is carried on systematically on a large scale. I gained a great deal of practical information a year or two ago through 
the courtesy of Mr. F. Sander, who spent some time in taking me over the very interesting nursery belonging to the firm at Bruges. The small standards when they have reached sufficient maturity are planted out in prepared beds every season, where they make sturdy growth and ripen their wood. Those that are strong enough set buds on every branchlet during the summer, and are lifted in September, with as little disturbance of the balls of roots as possible, to be sent away to other nurseries. The smaller plants are placed again under glass close together upon stages and packed in with fresh soil. Here they grow on slowly but steadily through the winter until planting-out time returns once more. Why should we not adopt some modification of the same system, even though we may have but half a dozen plants of the kind to care for ? A small space of prepared ground in suitable position is all that is needed, and after planting, but little attention would be required beyond watering in dry weather. I am convinced that many small greenhouse shrubs would be much safer, and the new roots would get more feeding and consequently, give better results than if kept starving in pots all the year round. At any rate all kinds of Azaleas-A. indica, A. sinensis (=A. mollis) and the Ghent hybrids may be so treated to their great advantage. Firm potting is essential, and not over much pot-room, a point on which most novices make a mistake.

It may be a little doubtful whether the same treatment would answer with Camellias, on account of a tiresome trick of dropping their flower-buds, which usually happens just after they are brought under glass from their summer quarters. Camellias are, in reality, hardier than the common Laurel, yet they are generally reckoned as greenhouse plants, probably for the reason that their early flowers do not stand either frost or wet. They succeed best, undoubtedly, where they can be planted out under glass, for 
which their evergreen habit peculiarly fits them, as they are never unsightly. The single and semi-double kinds are by far the most interesting as well as ornamental, and there is a charming little white species (C. Sasanqua alba) which is well worth growing.

When grown in pots, after they have made their new leaves-not before-they should be plunged out of doors in a semi-shaded position, which in their case is better than full exposure to the summer sun, and they must be carefully attended to with regard to watering. When it is time to take them in, about October $r$, a gradual transition from open air to frame, and from frame to greenhouse, will generally overcome the dropping tendency.

It is perhaps a little difficult to define the exact limits of a hard-wooded plant, but speaking generally, it is one with woody stem and somewhat wiry branches, and with fine hairlike roots, which delight in a fibrous, peaty soil mixed with sand. Of such plants a Cape Heath, or, for that matter, our common Heather, may be taken as a type. There are a good many shrubby subjects which may be said to take an intermediate place, the successful management of which may lead up to the more difficult New Holland and Cape plants. Amongst these easier plants to grow, which are content with good loam instead of peat, may be mentioned the Shrubby Mimulus (M. glutinosus) with pretty salmon-buff blossoms of the Monkey-flower type, of which there is also a noteworthy crimson-red variety. One of the daintiest of the Calceolarias (C. violacea) may also for convenience sake be placed in this section. It may be grown out of doors; in fact, in a Dorsetshire garden under the shelter of a wall it grew into a good sized bush, $2 \mathrm{ft}$. at least in height, and flowered abundantly every season until an unusually severe winter killed it. Neither its foliage nor woody habit, nor its pale-mauve helmetshaped flowers, are the least suggessive of any ordinary form 


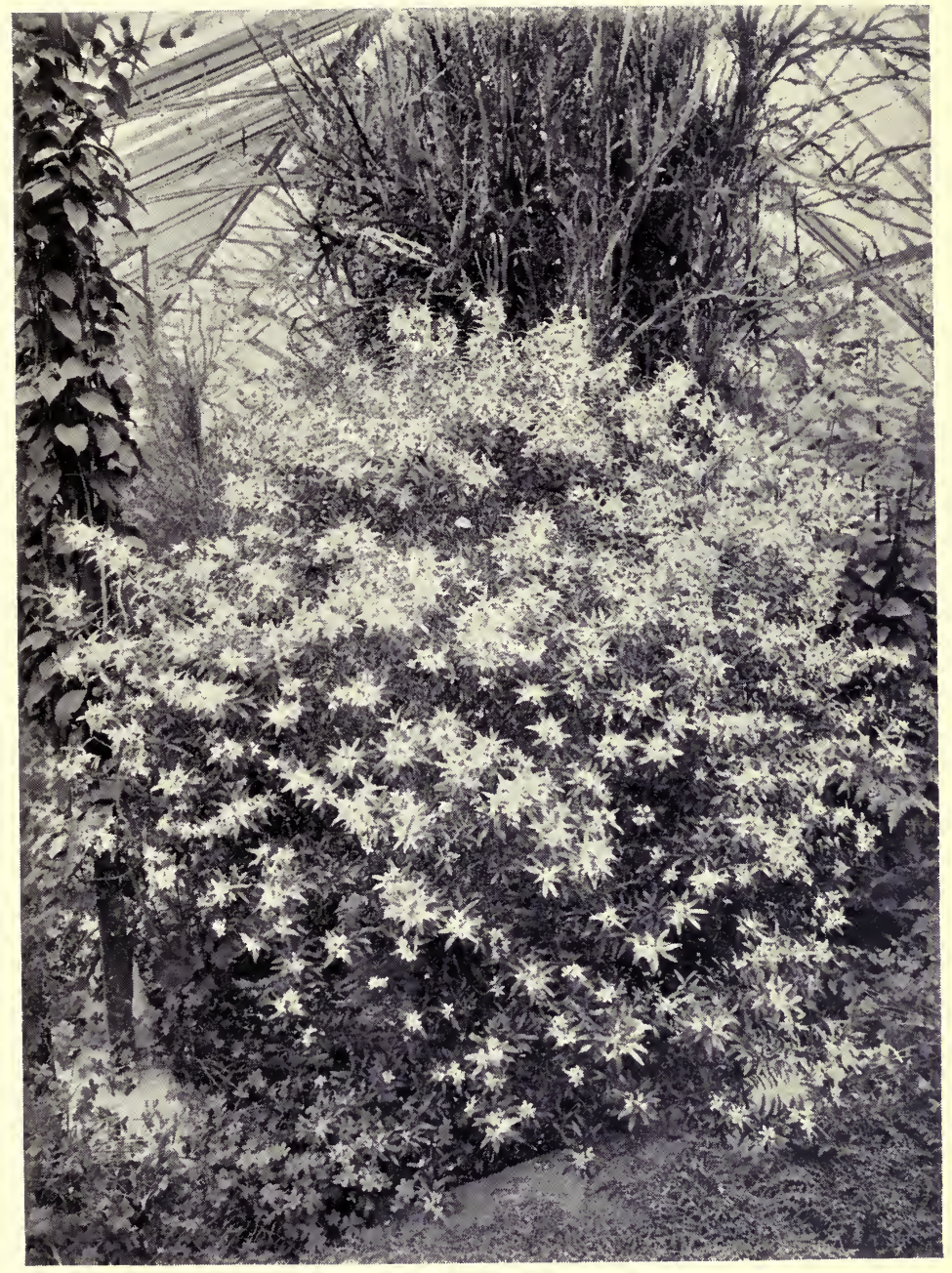

ERIOSTEMON MYOPOROIDES. 

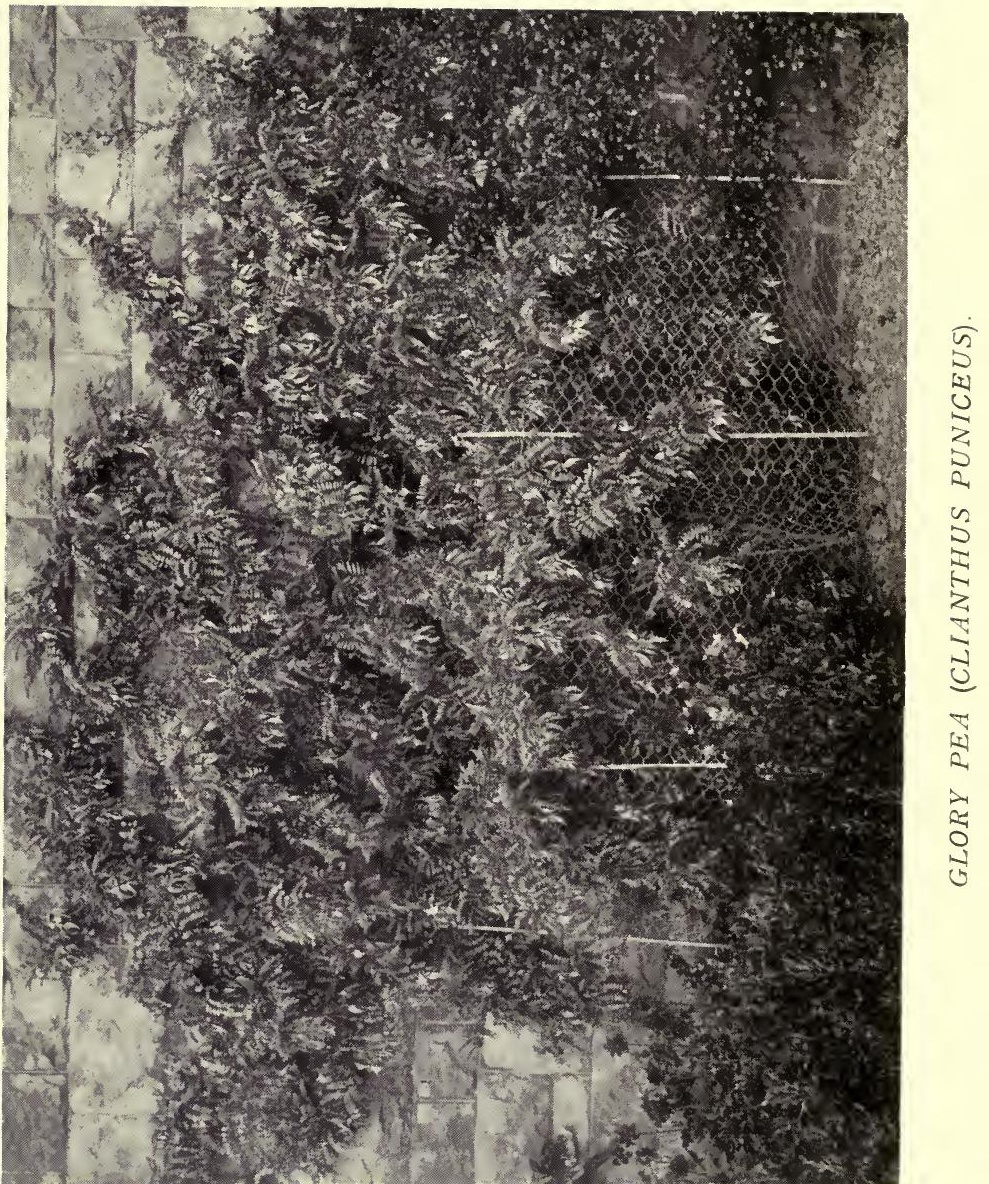
of Calceolaria, and it is always noticeable in a greenhouse, as it is by no means well known.

Hypericum chinense is another twiggy, low-growing shrub which is almost hardy, and will do well either in a pot or, better still perhaps, in a basket, which would suit its somewhat trailing habit. The large yellow flowers nearly equal in size those of the well-known St. John's-wort (H. calycinum) of our shrubberies, but are much more elegant from a peculiar Catherine-wheel-like twist of petals and stamens, and it may be reckoned a specially fine species of an interesting genus. The more familiar Polygala dalmaisiana, the purple flowers of which, with quaint little brushes of protruding stamens, is an old favourite, presents no difficulties of culture, needing nothing more than kindly pruning to keep it in shape. Another charming Australian Pea-flower is Swainsonia galegifolia alba, now well known and popular; it has been found to be hardy against a wall in a sheltered Cornish garden. This may be propagated best by cuttings, as the seed which it produces freely is apt to revert to the purple-flowered type.

All these sub-shrubs are more or less easily grown, and we will now take an example of one that will give more trouble. One of the most gorgeous of Australasian leguminous plants, Clianthus puniceus, is sometimes called the Glory Pea of New Zealand. Those who have seen some of the cottages near Porlock on the Somersetshire coast, with plants in full flower climbing almost to the eaves, will not be inclined to dispute the title. But it will not grow everywhere out of doors, and in that case must needs be considered a greenhouse shrub. Except for red spider, there is no special difficulty in its culture, but for a long time a finer species still, C. Dampieri, with black blotches on its scarlet flowers-which is not, like the other, an evergreen, semi-climbing shrub, but a herbaceous perennial-puzzled even experienced growers. The secret, however, has been discovered, and a very fine specimen in a 
large basket hanging in the Himalayan House at Kew attracts much attention as well as admiration during its season. Success depends upon the grafting of the delicate C. Dampieri upon a more robust stock, either C. puniceus or, preferably, upon the nearly allied Colutea arborescens, a perfectly hardy shrub, more common abroad than in English gardens. The result of this grafting is to change the intractable C. Dampieri into a sturdy and easily managed plant, peculiarly well suited to the unbeated greenhouse, as in a cool temperature it flowers for a length of time during the early months of the year. An account of a most resourceful method, adopted in some Continental gardens, has been published, and deserves to be quoted.

Seed of both stock and scion are sown in February; when the cotyledons of the young plants are sufficiently developed to handle, the terminal bud of the stock is removed, and that of C. Dampieri-the scion-is inserted instead. The union is not hard to effect under a bell-glass, but it is, necessarily, a delicate operation. The after-culture is similar to that of other plants of like nature. The pot or basket in which this fine species is grown must be well drained, however, and more than usual care is needed in watering, as it is stated that the foliage must not be wetted. Probably, also, as in the case of C. puniceus, the less the knife is used the better. This plan of growing C. Dampieri is worth attention, and I give it here, though I have not yet had an opportunity of testing it myself, as any gardener, amateur or otherwise, might be proud of rearing and flowering a good specimen of so grand a plant. It is not impossible that many cases of failure may have been due to over-kindness in the way of coddling, as the other species does so well in the open air in a genial climate.

To come to hard-wooded plants, more strictly speaking, some of the Heaths, such as Erica hyemalis, the later-flowering but fine and distinct E. propendens, and others, Correa bicolor and C. cardinalis, Bauera rubioides, Epacris miniata 
splendens, Hovea Celsii, Leschenaultia biloba major, Pimelia decussata, and Tremandra verticillata are all suitable subjects, and likely, under careful treatment, to do well in the half-hardy house. Not long ago, in a somewhat shallow frame under a wall, I saw a batch of strong seedling Heaths, looking like a forest of sturdy young Spruce Firs in miniature, getting ready for a shift into their first pots. This was in the garden of a keen amateur, who had only taken up gardening a year or two previously, and was a bold venture ; but in gardening there is everything to be gained by making such experiments for ourselves. All such plants as the above require a compost of good fibrous peat mixed with sharp sand, and the potting must be very firm-a point which cannot be too strongly urgedas the hair-like fibres prefer a hard soil into which to root. Above all the soil must never be allowed to become very dry, yet the drainage must be good, as stagnant moisture is equally hurtful. The winter atmosphere of the house must be dry and buoyant, for which reason a very modest amount of warmth is necessary in time of severe frost or, more especially, in continued damp and still weather. Another important point in the treatment of hard-wooded plants is the judicious cutting back of the main shoots immediately after flowering. After this has been done, and as soon as a new growth has fairly started, the plants can be plunged up to the rim of the pots in cocoa-nut fibre or ashes out of doors to rest and ripen their wood for the next season's campaign. An annual re-potting is not necessary, but it should be given when required, just when the new growth has begun. Most of the plants named I have seen doing well out of doors in very sheltered Cornish gardens, therefore there is little fear that they will not do well in a low winter temperature under glass. Good cold frames or deep pits, however, as well as a conservatory, are indispensable in most gardens where the culture of plants of delicate nature such as these is attempted. 
It may be useful to give the cultural details of Hovea Celsii, a very ornamental hard-wooded plant which has long been a favourite, though now not often met with, and of which the clusters of rich purple-blue Pea-shaped flowers are extremely attractive. This plant is more easily raised from seed than from cuttings, and the seedlings begin to make strong growth at once. As soon as they are large enough they should be potted singly in $2 \frac{1}{2}$-in. pots, and given a shift into a larger size as the roots touch the sides and require more room, care being taken not to allow them to become pot-bound. Hovea has naturally rather a loose habit of growth, and may be trained either as a standard or as a bush. If the standard form be preferred, the young plant may be allowed to grow as a single stem to a height of 18 in. (or more if desired) before the top is pinched out, when it will break into many shoots. If a bush be wanted, free pinching must be carefully attended to from the first to lay the foundation of a shapely plant. The soil and treatment otherwise are just the same as that of halfhardy hard-wooded plants in general, for which it will stand as a good object-lesson. It is to the disadvantage of this fine Hovea that it needs a large-sized pot before it comes to flowering size, but it is then very ornamental. Leschenaultia biloba major, with still more brilliant blue flowers, is another hard-wooded plant, better known, which has not the same drawback, as it will flower in a comparatively small pot.

To sum up the requirements of these somewhat exacting plants : A compost of sandy fibrous peat, pots well drained, plants firmly potted, protection given from actual frost, a cool, dry, airy house in winter, careful cutting back after flowering, open-air summer quarters where the pots can be plunged to their rims, and careful watering at all seasons. Where these directions can be carried out the growing of the finest hard-wooded half-hardy plants need present no insuperable difficulty. 


\section{CHAPTER XIII}

\section{ROSES}

ONE form of usefulness, and a very desirable one, for which a cold greenhouse is well adapted, is for the growing of winter and spring-flowering Roses. The delight of having Roses, whether growing or for cutting, during the dull months of the year can scarcely be overrated, and it is astonishing how much may be done with a cold greenhouse in this direction. There are Roses both tender and hardy, and all are not suitable for the purpose, but, fortunately, some of the very best may be grown under good management, and will flower well out of season, without any forcing by artificial means other than the protection of covering glass. No doubt it does require good management to have pot roses in bloom in early winter, but we all know how, in favourable seasons, some of the very best of the Hybrid Perpetual section and Tea Roses will go on flowering in the open till nearly Christmas, and how in the warmer parts of our British Isles we may sometimes gather a handful of pink or crimson China Roses from some cosy nook in January, which are even more fresh and beautiful than during the heat of summer. Such late Roses, however, are apt to get sadly battered, nor can we always safely reckon upon them. It is a happy thing, then, for the mere Roselover that very many of the most beautiful Roses can be grown on their own roots, and cuttings may be struck which will make satisfactory plants by those who know nothing of the intricacies of budding, grafting, and the like delicate opera- 
tions. Catherine Mermet, for example, one of the most charming of Tea Roses, will grow very easily from a slip taken off with a "heel," and inserted in sandy soil under a bell-glass; or it will even put forth roots in a small jug of water, into which a bit of charcoal has been dropped to keep it fresh.

The main secret is to take the slip or cutting in the right condition. Generally speaking, the end of the branch from which a flower has been cut, slipped off at the juncture with the stem, will be in exactly the half-ripened state most promising for successful rooting. It is true that own-root Roses take some time to grow into large plants, but an established bush is a precious possession and will go on for years. Cuttings may be put in out of doors from June to October-the earlier ones rooting the same season, while the later will break away in the spring. Such rooted cuttings make a good foundation for pot plants, and will give flowers, if properly cared for, during six months, more or less, of the year when the garden outside is bare.

The routine of Rose culture is a large subject, and cannot, of course, be fully entered upon in a short chapter the chief object of which is to be suggestive. One main point in the preparation of pot roses for winter flowering must, however, be in the unheated greenhouse-referred to here-the removal of every bud which forms during August and September, when the second flowering of both Tea Roses and hybrid Perpetuals may be naturally looked for out of doors. During the summer all pot Roses that have flowered in the cold greenhouse should be plunged in suitable quarters outside, so that they may make new growth and ripen their wood, and it is during the latter part of this period that they must be watched in respect of disbudding. In fact, our winter Roses will be in proportion to the judicious care and attention bestowed upon them, in watering, mulching, and so forth during this important restingtime. When they are brought under shelter again, in October, 
there will then be strength to produce some welcome winter flowers, and though these may open somewhat slowly from want of sunlight during November and December, they will increase as the days grow longer and brighter. One way of getting extra vigorous plants from young-rooted cuttings is to shift them at once-either from the open ground or from pots-into those in which they are to flower, and which may be from 6 in. to 8 in. in size, plunging them during the summer in a gentle hot-bed made up of leaves and stable manure, giving at the same time a liberal top-dressing to each, but leaving the stems and foliage in full exposure to light and sun. After some weeks the heating material may be renewed, if the object be to obtain strong specimen plants quickly. The pots must not be removed too suddenly from the plunging material, as the roots will suffer if they are not gradually hardened off. I have tried a similar plan with other plants besides Roses, and have found it answer extremely well.

There is no doubt that for the highest success in Rosegrowing for winter- and spring-flowering they should have a house to themselves, however small it may be. The construction of an unheated Rose house is a matter of importance, and depends upon the mode of culture decided upon, for Roses may be grown either entirely in pots or planted out in borders. In the latter case the lights should be removable, so that they may be taken off entirely during the summerotherwise the Roses cannot thrive. A span-roofed house with an aspect from north to south, and resting on low walls, is the best form to adopt, whether for Roses in pots or in beds. When there is a border at each side it is a great temptation to plant some of the delightful Noisettes and climbing Roses in order to make use of the roof-space, but my own experience and that of others agree in condemning this plan, as it makes the centre of the house practically useless by over-shading. It is, nevertheless, not impossible to have climbing Roses, 
even of vigorous sorts, where there is house-room, for they can be grown and will flower well in pots or tubs, and these can be turned out into summer quarters when the proper time arrives. On the whole, it is more satisfactory in a general way to grow Roses in pots, because they can be brought into the conservatory when in flower or placed in any other position where they can best be appreciated; while the Rose house during the summer may be utilised, if need be, for the production of tomatoes.

But a Rose-house, after all, is a luxury by no means indispensable, and we may do very well without one. Yet it is advisable to grow a good many plants-and by striking our own cuttings we can increase our stock without any limit save that of convenience-so that by slight variations of treatment the different batches may come into flower in succession. Some may be plunged in their pots; others, again, may be planted out in a sunny reserve-bed, and lifted and re-potted in October, which will retard them slightly, and disbudding may be stopped earlier or later. In this way there will be no difficulty in having Gloire de Dijon, or Souvenir de la Malmaison, or Mrs. Bosanquet, and some of the China Roses in flower from November to March, without any forcing, with others to follow in April and May.

It is not every Rose that will do well on its own roots, but the most suitable for growing in pots to flower in the cold greenhouse will be found mostly amongst the China and Tea Roses and their hybrids. The old pink Monthly Rose and the crimson Cramoisie Supérieure are never de trop, and will help to bridge over the darkest winter days. Catherine Mermet and her somewhat numerous progeny-the Bride, Bridesmaid, \&c. -are all admirable (though not over vigorous) and deserve all the pains we can take with them. Maréchal Niel, of course, cannot be omitted, and roots very easily. It is generally grown as a climber, but this method has its disadvantages, and 


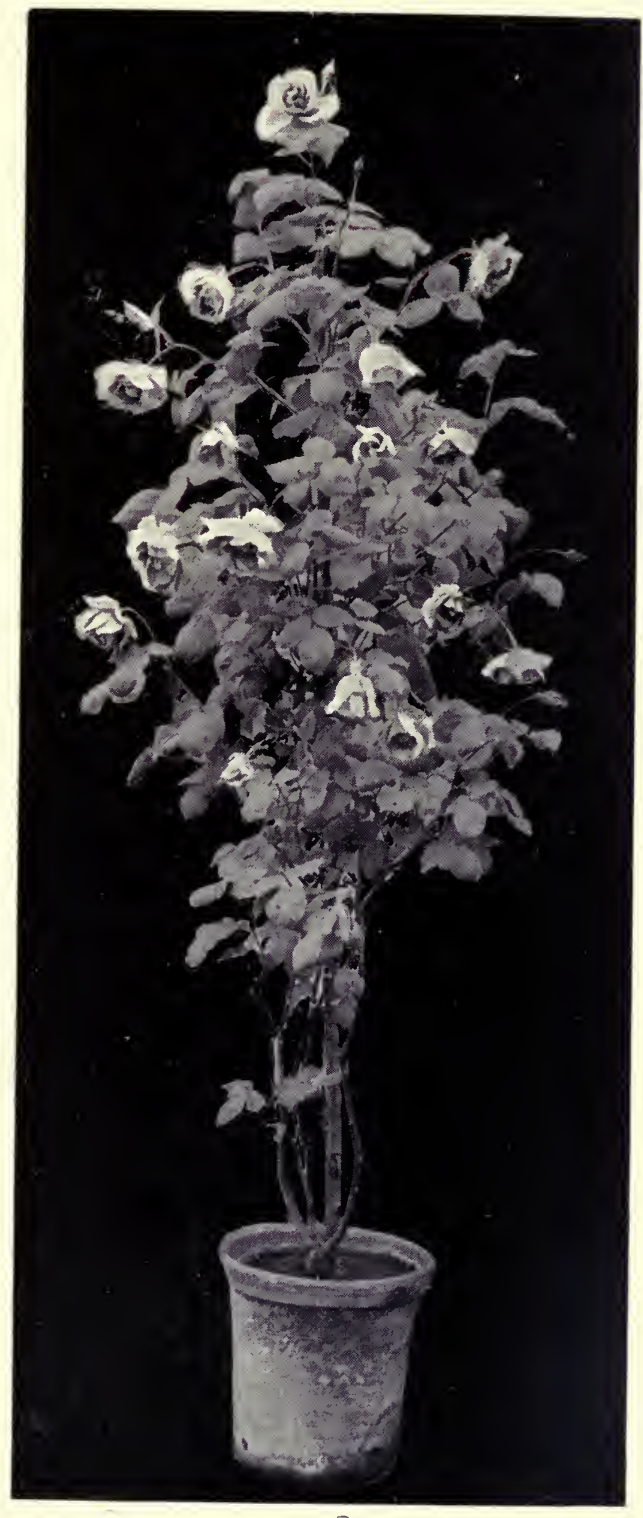

ROSE NIPHETOS AS A POT PLANT. 


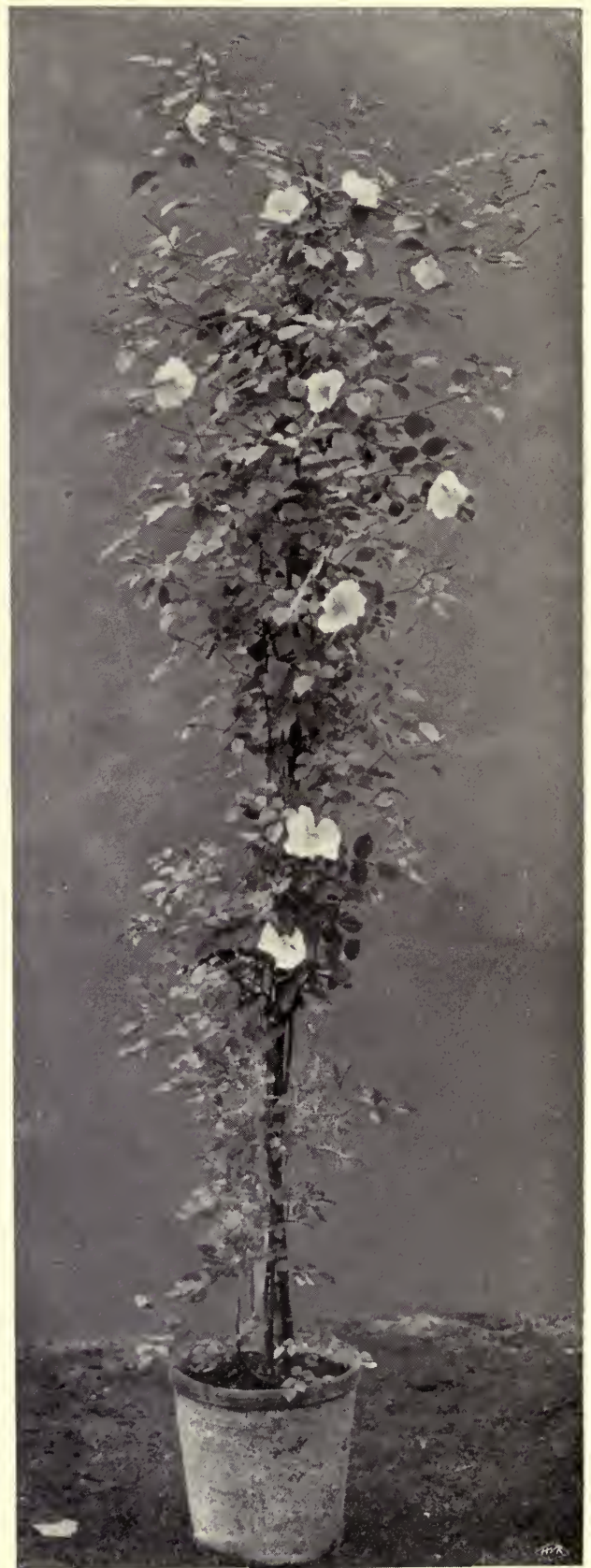

ROSE JERSEY BEAUTY AS A POT PLANT. 
unless there should be a house devoted to climbing Roses, which is delightful when it can be done, it may be just as well to try other ways.

Besides these already named, a few of the best Roses for the purpose are Niphetos, La France, Mme. Lambard, Marie van Houtte and Anna Olivier. Général Jacqueminot, however, cannot be omitted, and Ulrich Brunner and Mrs. John Laing, all Hybrid Perpetuals, should do well. These may find a place in the most modest greenhouse, and will give untold pleasure. I had some Roses early in April which were lifted, as an experiment, from the cutting-bed as late as February 12, and brought into an unheated but sheltered greenhouse. These, without any previous preparation, made wonderful growth and are well set with buds already showing colour. They are planted for a special purpose in painted margarine-tubs, which I may commend to the notice of other gardeners as being useful and handy for many like purposes. This little bit of experience tends to show that fewer difficulties exist in growing pot Roses than we might suppose. In fact, it is no use waiting until everything we read of in books as essential is ready to hand. Now and then, and more often indeed than is supposed, a great success will reward very scanty opportunities, and my advice to a novice is to make a beginning by striking as many cuttings as possible. By so doing, we shall soon find out the best varieties to grow and the best method of cultivating those which we find will adapt themselves best to our own special circumstances. 


\section{CHAPTER XIV}

\section{HARDY PERENNIALS FOR SPRING}

THERE are two seasons when a few good herbaceous perennials may be used with advantage for the decoration of the unheated greenhouse. In the earliest months of the year, while winter still lingers, they are wanted, not only for the sake of variety, but that we may forestall the tardy spring. Again, towards the end of September, when the first frosts may come any day to rob us of our border flowers, it is well to be able to prove that the plant world is not peopled solely with Chrysanthemums. In the one case, they must be gently forwarded by all means at command; in the other, with some exceptions, they must receive special treatment to retard their flowering. In a greenhouse in which absolutely no means of heating exists, the gentle persuasion of hardy plants to earlier flowering afforded by a glass shelter is of special value. Another phase of the same practice, namely, the protection of plants which flower naturally during winter, has already been considered under the head of the Alpine House; but a good many perennials of larger growth than most alpines, suitable for an ordinary greenhouse, may be mentioned here. Adonis amurensis, a somewhat recent introduction, is one of these, and differs but little from the better known $A$. vernalis, though it is scarcely so fine a plant, but its bright yellow flowers are amongst the earliest of the year.

Christmas Roses (Helleborus niger) can fairly claim a foremost place in the winter list. These are not always easy to 
manage as pot plants. One of the most successful growers I ever knew was a farmer's wife, whose Christmas Roses were always to be envied. These used to divide their yearly cycle between a deep earthenware washing-pan, in which they flowered, and a shady border under a north wall, to which they were banished as soon as the flowers were past their best, but not neglected, for they received a generous mulch of farmyard manure and an occasional drenching with rain-water, not wholly free from soapsuds, during hot and dry summer weather. When the buds had gained some size in the late autumn, the clump was carefully lifted without disturbing the roots and reinstated in the brown pan, whose winter station was on the broad windowsill of the best parlour.

Here, sheltered from wind and rain, the flowers opened, pure and fresh, in due season. No better system than that adopted by my old friend can be followed, though a broad, deep garden-pan, with drainage-holes complete, may be substituted as more fitting for the greenhouse, though it is doubtful whether it would prove an actual gain. To prepare such a plant the root-stock of an old clump must be carefully broken up into pieces, each with growing buds and some of the black fibrous roots attached, from which the species derives its name. The only right moment to do this is just when the greening sepals show that the flowering time is over and active root growth is setting in, and these flower-stems should be cut away to prevent an effort to seed. After planting the pieces, not too thickly, the pan should be plunged, preferably in a border shaded from midsummer sun, and the surface mulched to keep the roots moist and good. It is very possible that there will be no flowers the first season, as Hellebores dislike root disturbance. After the first year the plant should be turned bodily out of the pan into the border during the summer and replaced in autumn, which can be done with very little meddling with the roots. 
Astilbe japonica, popularly known as Spiræa, is a true garden perennial, which flowers out of doors early in summer, and is valuable from doing well in shady places, but it is so universally grown as a greenhouse plant that this fact is generally forgotten. A. chinensis, which is quite distinct from the Japanese species, with which it must not be confused, flowers rather later in the open air, but answers well under pot culture. Its taller growth and branching, feathery flowerspikes make it a most desirable addition to the greenhouse. The handsome but tender foliage, as well as the pretty delicate flowers of the various species of Epimedium also, are never seen to better advantage than under glass, where they are secure from rough weather.

There are a good many well-known garden plants which may usefully be employed in the same way for the cold greenhouse. Orobus vernus is valuable for pots early in the year, when its clusters of blue-purple Pea-flowers are very spring-like and welcome. Several varieties of it exist, and it is easily raised from seed. O. variegatus, which flowers later, may also be tried.

The large-flowered Forget-me-not (Myosotis dissitiflora) is a gem of the first water, and may very successfully be grown in pots or in zinc troughs about 4 in. wide as an edging for groups of plants to hide unsightly pots. These troughs may be made of any size and shape, and have been found extremely useful filled with growing plants of this Forget-me-not or of white Rock-cress (Arabis albida) in church decoration, especially for windows, being less perishable as well as less formal than many of the designs used for the purpose. Shelter in early spring is peculiarly acceptable to this Forgetme-not, as the first flowers are often injured by frost. It is a good plan to grow some spare plants in an outside border, that they may scatter their seeds, and to use these strong self-sown seedlings, which answer far better than cuttings, for 


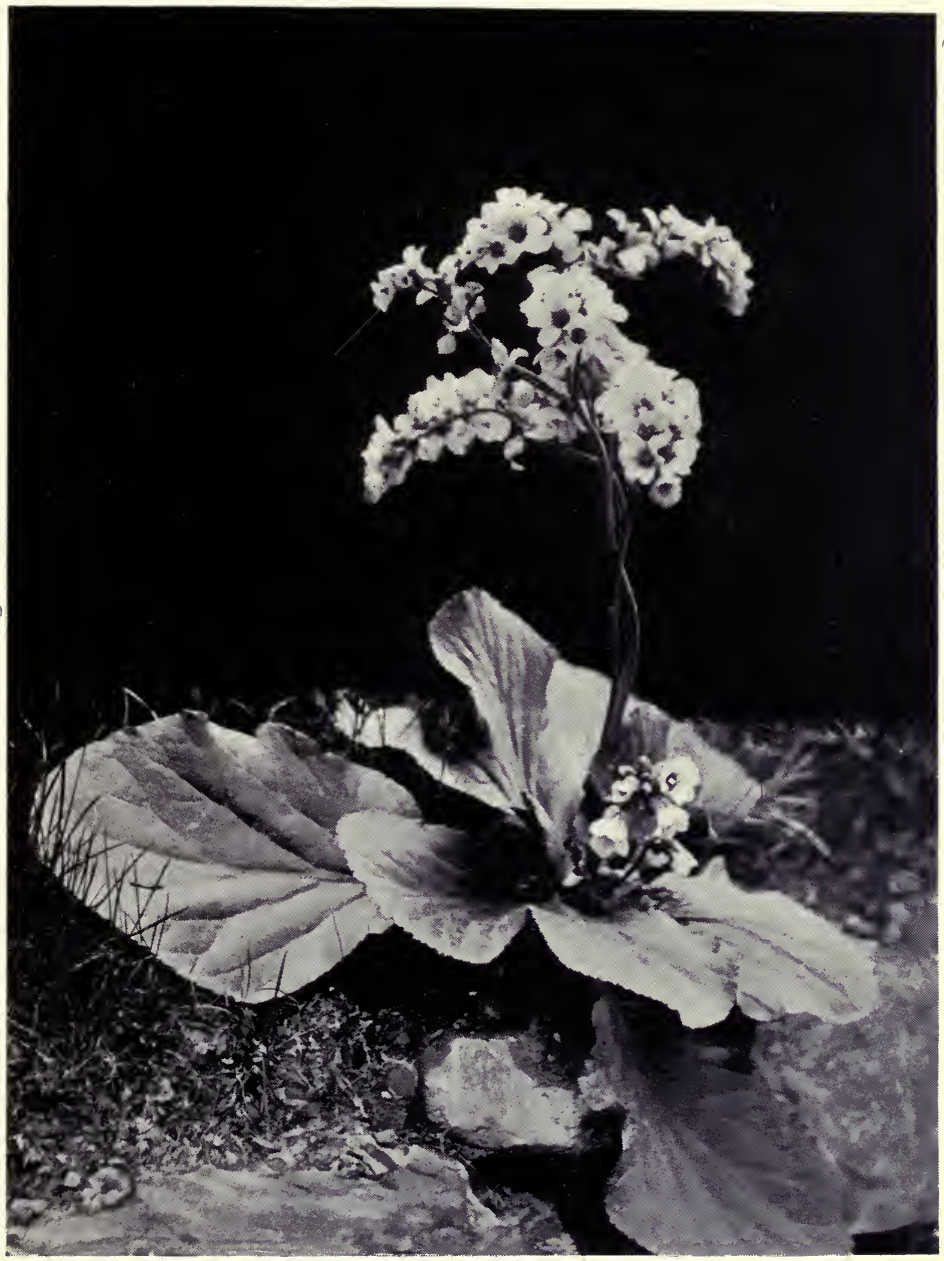

BROAD-LEAVED SIBERIAN SAXIFRAGE (MEGASEA LIGULATA). 
$-13$

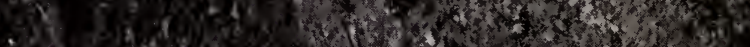

- in

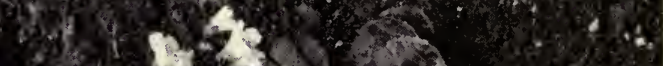

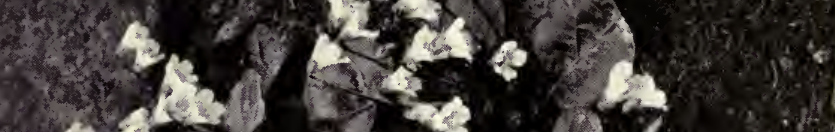

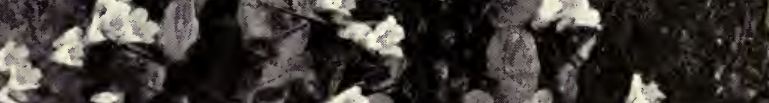

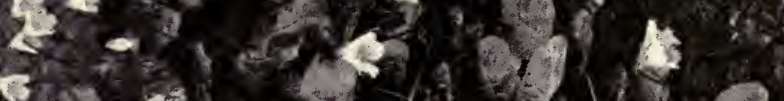

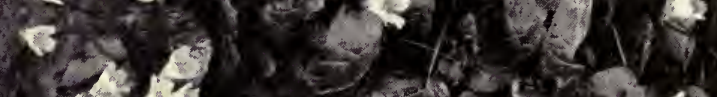

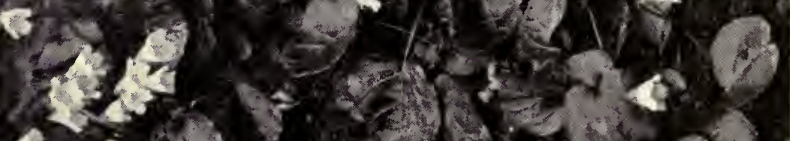

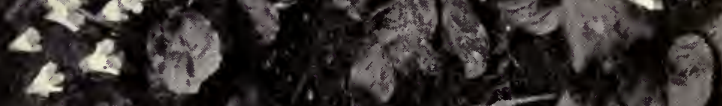

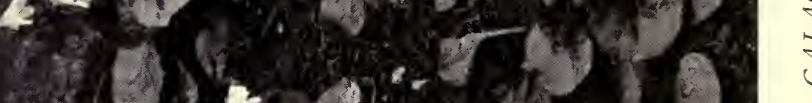

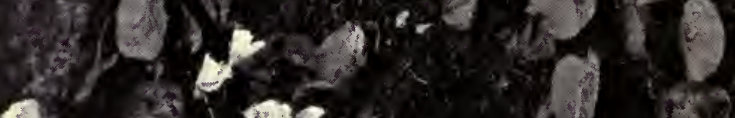

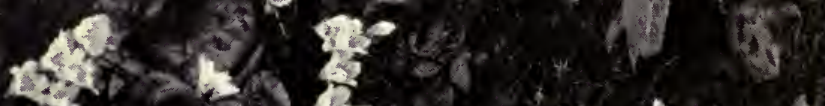

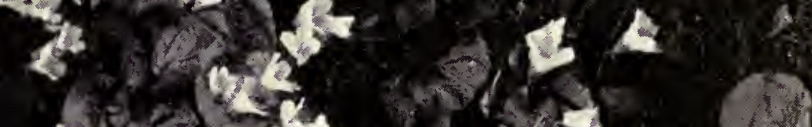

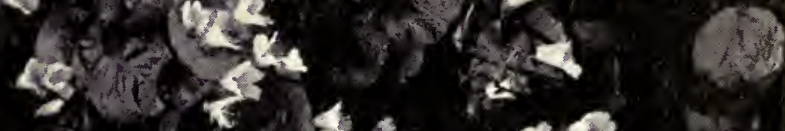

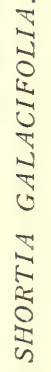

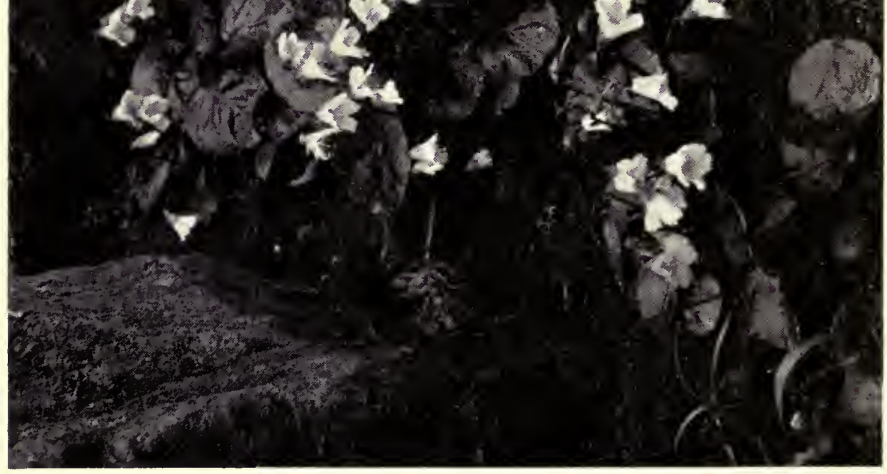


potting in the autumn. In Italy the large-leaved Saxifrage (S. crassifolia) is used as a pot plant in all sorts of positionson terrace-walls, on the balustrade of a sunny loggia, sometimes even in the half-shadow of an over-springing archway. The pink clusters of flowers rise well above the thick oval leaves, and the good effect of the old-fashioned plant thus grown takes one by surprise. To get the ruddy flush of leafage which they will put on in full exposure, the plants must live out of doors, and be brought into the greenhouse only in the depth of winter. There is a charming white variety of this species very little known, and both should be noted.

Some of the Doronicums are bright and sunny-looking. The dwarf $D$. caucasicum responds quickly to kindly shelter, and opens its big yellow Daisy-like flowers very early in the year. The tall $\mathrm{D}$. excelsum comes into bloom a little later. It is apt to flag in the hot spring sunshine, and must be kept as cool as possible.

Another favourite and good plant is our old friend Dielytra, now called Dicentra spectabilis. It is a hardy perennial, but in some parts of the country the succulent stems and sprays of graceful pink flowers are often damaged by late spring frosts.

Another very charming hardy perennial is the white form of the Peach-leaved Bell-flower (Campanula persicifolia). To get it to flower in early spring requires considerable forethought, as the foundation for the next season must be laid in the previous April, but the way to manage it is as follows : Good side-pieces must be chosen which show no sign of sending up flowering stems, or the plant will be in bloom before it is wanted. These should be potted firmly in good loam, in 7 -in. pots, and plunged at once in an outside border. In the autumn the pots must be transferred to a cold frame, like most other plants which are being brought on gently for 
early flowering, and later be removed to the greenhouse, where the spikes of pure white flowers will be very acceptable. There are many garden forms, single and double, of this Bellflower, of which the type is blue, but a very good one for the purpose in view is that known as the large white Cambridge variety.

The preparatory process thus sketched will be found useful for other herbaceous plants, and may be tried with modifications for any perennial which seems in the grower's fancy to be suitable and desirable. Heuchera sanguinea with its spikes of carmine-red, Tiarella cordifolia, the feathery white plumes of which are never out of place, though never so lovely as in their native woods, the long-spurred Rocky Mountain Columbines (Aquilegia corulea and A. chrysantha) are all wild flowers of the New World, well known now in our best gardens, but they may be pressed into the service of the cold greenhouse should circumstances suggest their use. It is a well-known fact that plants can be educated, so to speak, to change their time of flowering. A species, for example, which flowers naturally in June, by an alteration of treatment and temperature may be induced to bloom in April. The following season, in all probability, with the same treatment, the flowers will appear a month earlier, until, instead of midsummer, that particular specimen gradually becomes accustomed to open its flowers in spring. This tendency to change of habit is a very useful one, and should be turned to the best advantage by the cold-house gardener.

Primroses of several different types are valuable in the earlier months of the year, and follow each other in obliging succession. Dean's hybrid forms of the common Primrose (P. acaulis) make pretty groups of many shades-pure white, lilac, and deep crimson being found amongst them, as well as the normal Primrose colour. In arranging these in a greenhouse it is well to group them in gradations of one colour, 


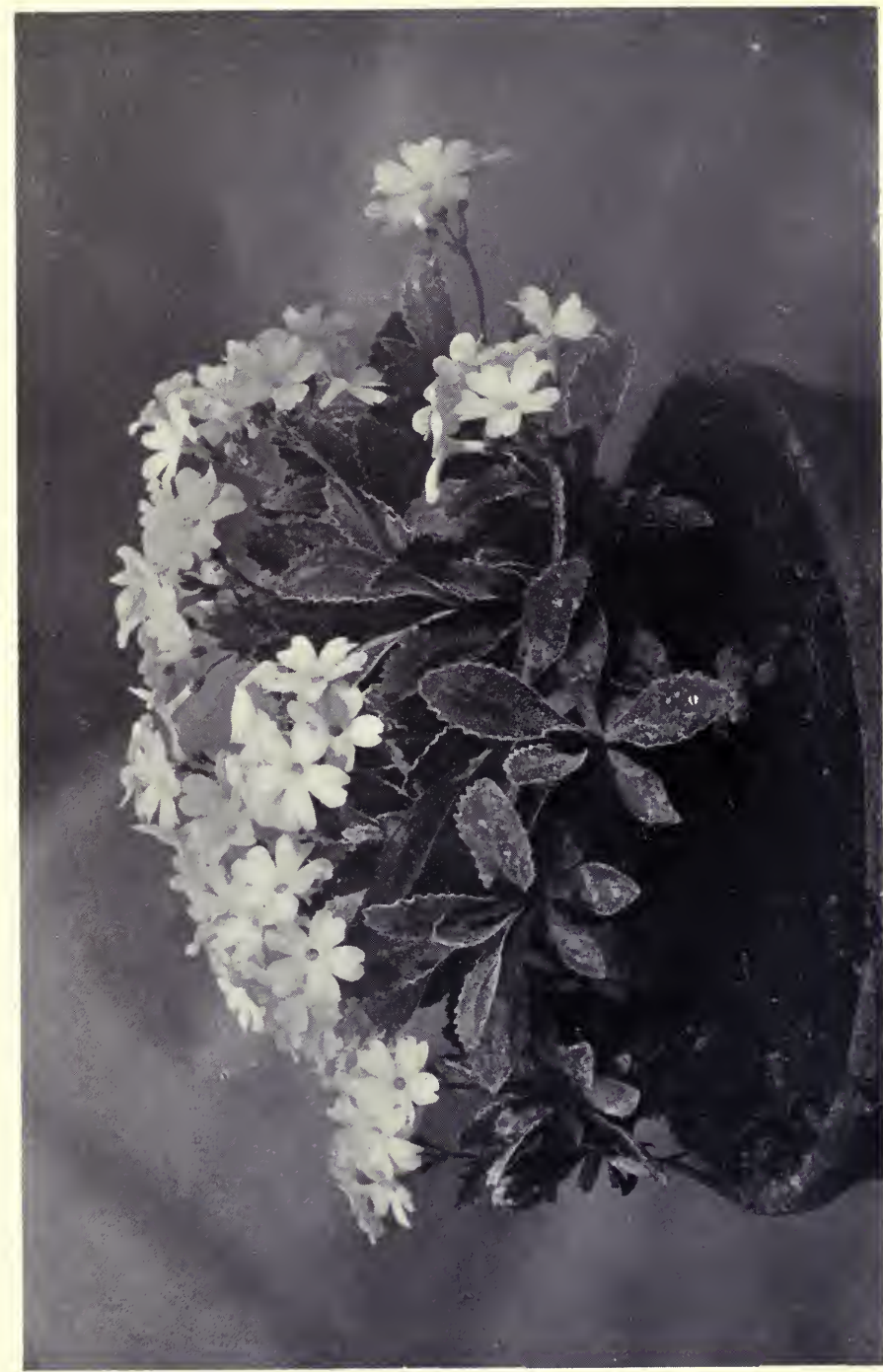




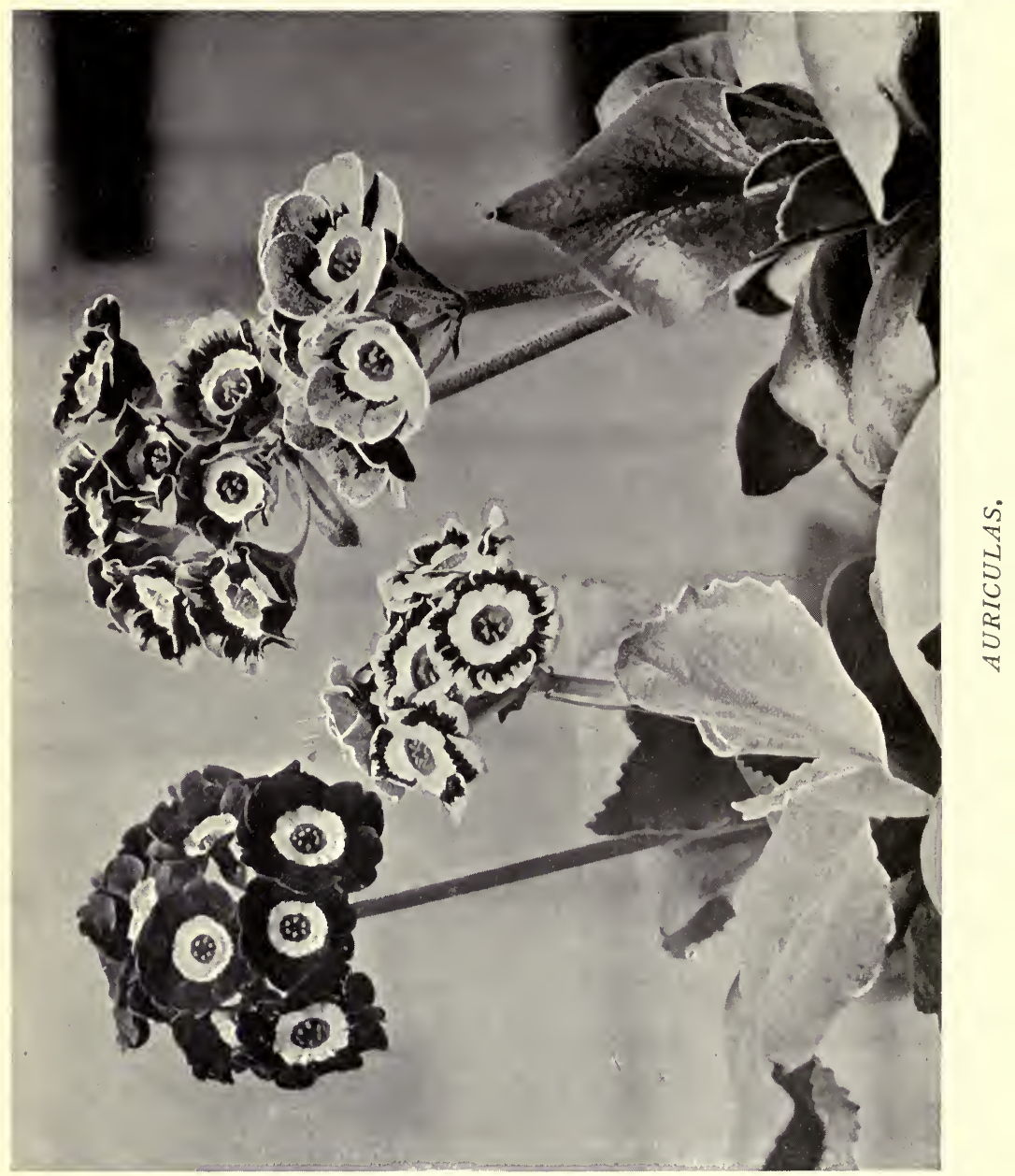


otherwise the variety is so great that they are apt to lose their refinement of character, which is never the case when care is taken in the juxtaposition of tones. The fine race of Polyanthus Primrose may be used in the same way, and if there be no wild garden or bit of mossy woodland where they can be grown as Nature would have them, it is a moot question whether the next best way of enjoying these beautiful plants is not in the cold greenhouse, coaxed into flower a little in advance of their kith and kin out of doors.

Primula Sieboldi, of very different character to either of the above, is another elegant species, especially when the best hybrid forms are chosen, as the type unfortunately has flowers of rather an ugly shade of rose-purple, but this has been much improved upon by careful selection and inter-crossing. This Primrose throws up its tall slender stems and clusters of six to ten large flowers well above the pale green leaves, and is very distinct. It is also better suited for pot culture than for the garden on account of the thin fragile nature of both flowers and leaves, which are, moreover, deciduous. The creeping rhizomes, which are slender and not very noticeable, are apt to be dug up and lost in the open border, and therefore it is a good practice to divide and re-pot the plants as soon as the leaves show signs of dying down. The pansfor these are best for this Primrose-can be plunged in a shady place to take care of themselves until the time arrives in the autumn to remove them to the frame or greenhouse, when they will need nothing more than a little top-dressing. Auriculas, too, of the so-called alpine section, are very good, and it is interesting to raise seedlings both of Primroses and Auriculas, taking care in the first instance to buy seed of a thoroughly reliable strain, and afterwards, by rigorous selection and casting away of all doubtful and mixed colours, to work up a first-rate stock of one's own choosing. All these are common, everyday plants, yet a most effective greenhouse 
display can be made in early winter and spring out of materials such as these, with a few bulbs and hardy greenery to match.

It is more interesting still to grow uncommon plants. One such, not to wander from the Primrose, is a Javan species, which has been known for perhaps half a century to explorers by the name of the Royal Cowslip, but is, nevertheless, comparatively new to cultivation, and is still rarely met with. The climate of Java is tropical, but it has lofty mountains, whereon, at an elevation of some $9000 \mathrm{ft}$., Primula imperialis is found in company with Buttercups, Violets, Honeysuckle, and other familiar English plants, choosing, however, only to grow in moist, cool spots, under the shade of bushes or in thickets. As far as is known, this particular species is to be found in no other part of the world. To give some idea of this giant of its race, it may be said that it sends up a stout flower-stem some $3 \mathrm{ft}$. high, from a rosette of very large and long, Primrose-like leaves. The flowers, which are borne in whorls-in this respect resembling some other Asiatic Primulas-are of a shade of yellow, deepening into orange, peculiar to itself, and it is in all ways, when well grown, a fine and striking plant. The difficulty has been to get foreign seed to germinate, but ripe seed has now been perfected by home-grown plants, and probably it only needs, like so many of the Primrose family, to be sown as soon as ripe to sprout quickly and freely. The Royal Cowslip may be given as a type of many another rare and beautiful plant which will adapt itself, under loving culture, to the cold greenhouse. Nevertheless, it takes some enthusiasm, no less than painstaking, to enable us to get off the beaten track of everyday garden routine and seek out for ourselves the far-off treasures of distant lands. 


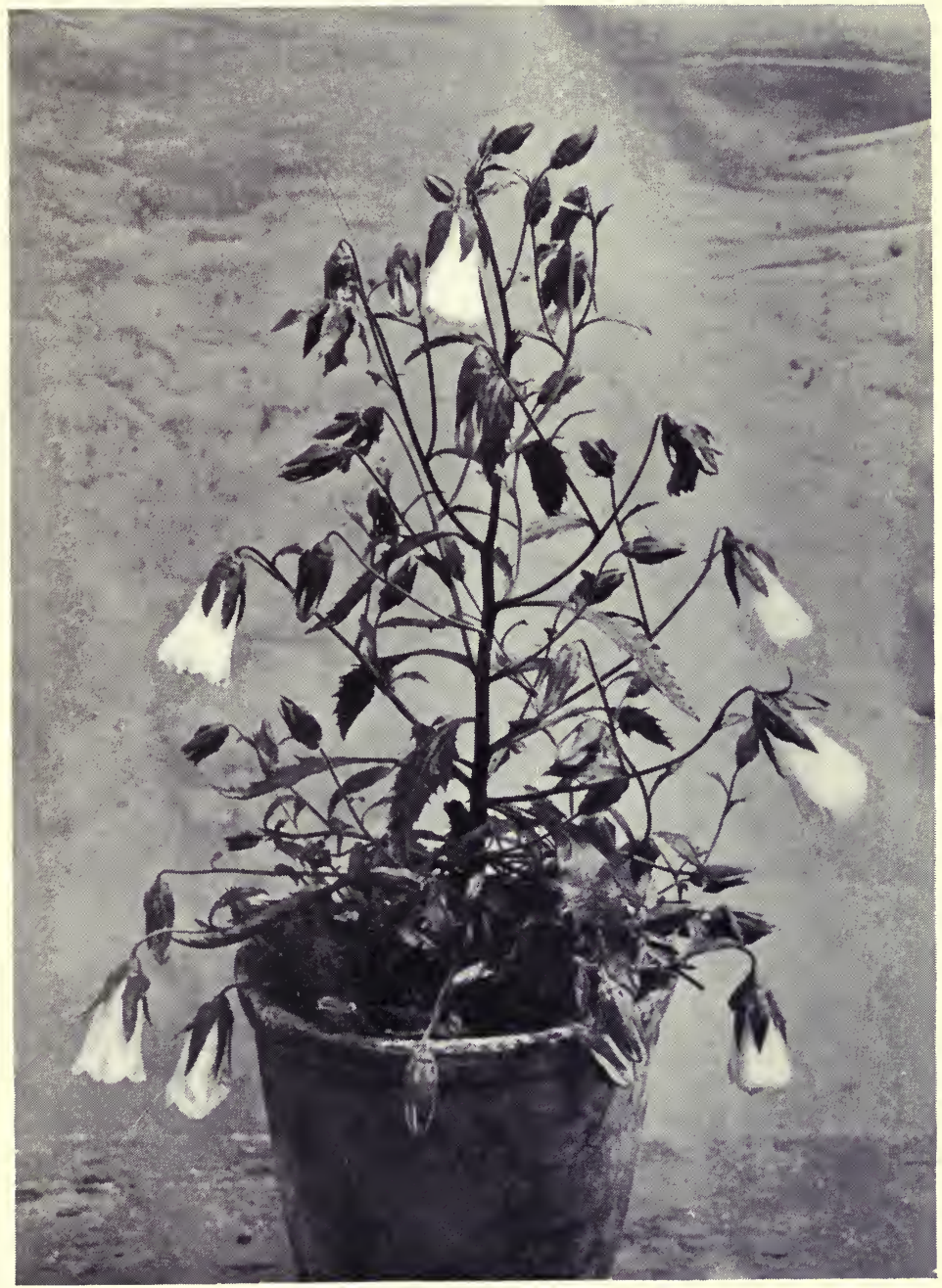

SYMPHYANDRA IVANNERI. 


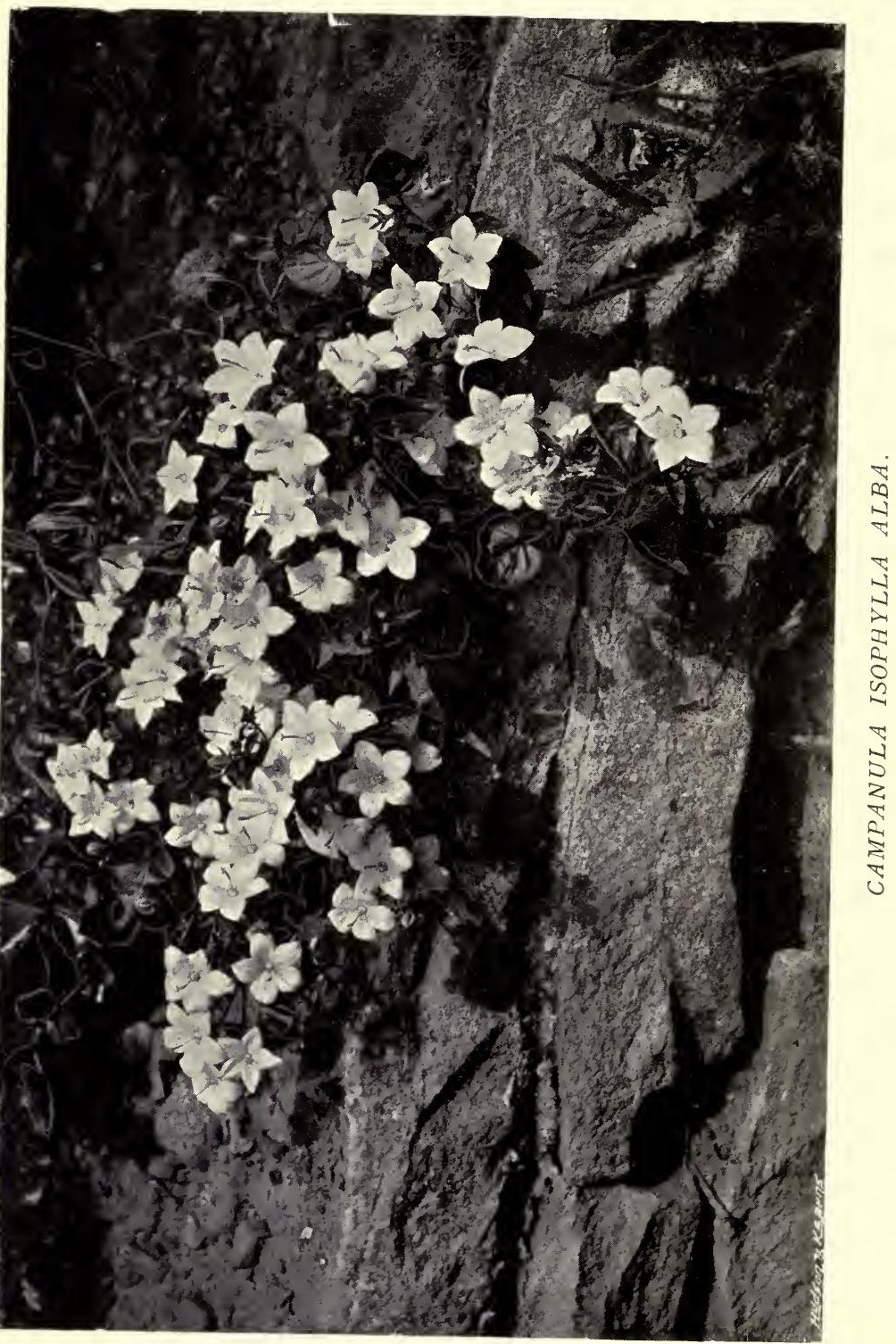




\section{CHAPTER XV}

\section{AUTUMN PERENNIALS UNDER GLASS}

IT is easy enough to have plenty of bright flowers under glass in late autumn where an average temperature of $50^{\circ}$ to $60^{\circ} \mathrm{Fahr}$. can be maintained, but when there is no heating apparatus or merely a portable one, plants must be chosen warily. Chrysanthemums, no doubt, are the mainstay of all gardeners for conservatory decoration at this season, and are as available, being hardy perennials, for unheated as for heated houses, though the flowers have a tendency to damp off in chill, foggy weather. No one would wish to be without such old but fine stand-by varieties as Mme. Desgranges and its bright-coloured sports, Source d'Or, Mlle. Lacroix, Bouquet Fait, Cullingfordii, and others, not forgetting some of the delightful single forms, grown naturally as free-flowering bushes. For our special purpose, early, and mid-season varieties are more to be recommended than late ones. It is true that nothing else can quite take the place of chrysanthemums in greenhouse decoration. They are so universally grown, however, and it is so easy to get information on all points with regard to them, that it will be more profitable to inquire what other flowering plants are attainable from Michaelmas to the end of the year.

Naturally, we think first of the few late-blooming perennials which, though quite hardy, are likely out of doors to have their flowers either crippled or wholly destroyed by early frosts. One such, often grown in pots on this account for 
the greenhouse, is Stokesia cyanea, a fine composite, with blue Thistle-like flowers. There are two varieties-a fact which has only recently been made known-and as one of these is summer-flowering, care should be taken to get the right sort for late work. Aster grandiflorus, the latest of the Michaelmas Daisies, is sometimes treated in the same way, as it seldom perfects its large blue flowers in the open border. Senecio pulcher is a good late-blooming Groundsel, with redpurple flowers, which may be put into the same list. It is interesting to grow it from inch-long root-cuttings in early autumn, like Seakale, thus securing fresh plants every year, and the best effect is made when several plants occupy a broad, deep pan to form a clump. The colour of the flowers, unfortunately, is one that contrasts badly with most others, which is a drawback. A very good low-growing plant belonging to the same genus, Senecio Kæmpferi, may be mentioned here, though it is somewhat more tender. It has broad, handsome foliage, splashed with white and a touch of pink, and is worth growing both for its leaves and flowers. It bears a loose cluster of large yellow Daisy-like flowers, and is more often seen in Belgium and elsewhere on the Continent as a window plant than with us. This is not to be confused with Farfugium grande, with round yellow spots on its green Coltsfoot-like leaves, which is, perhaps, a greater favourite with English folk than it need be.

Chrysanthemum serotinum, better known amongst herbaceous perennials as Pyrethrum uliginosum, rears its great height and holds up its flowers high above our heads in the autumn garden, unless the precaution is taken of heading down the plants in early June. These tops may be put in as cuttings and make excellent little pot plants, proving very useful in the greenhouse during October and November. The Winter Cherry, Physalis Franchetti, is striking and handsome for late autumn when grown with several stems 
and hung with its vivid orange-scarlet capsules. It is much finer in every way than the old P. Alkekengi. The first frost makes the leaves drop when the plant is out of doors, but with the protection of glass we get foliage with the brilliant lanterns, which is a great gain. Another hardy Japanese perennial - Tricyrtis hirta-which is, strictly speaking, a miniature Lily, with a short, creeping root-stock, makes an admirable late cold greenhouse plant. Its pretty mauvewhite flowers, spotted with lilac or purple, are very Orchidlike in their effect, and are borne pretty freely.

Carnations of the self-coloured Grenadin type, which are chiefly white and scarlet of various shades, are invaluable for autumn flowering. If the object is to ensure really good flowers it is a good plan in the first instance to raise a batch of seedlings from reliable seed of the best strain, which should be allowed to flower the first season in the open ground. Many variations will occur amongst them, and a strict selection of the finest must be made for future stock. Any tendency to throw up flower-stems in the spring must be kept in check, and layers should be laid early in the season, before midsummer if possible. When thoroughly rooted, which will be in about six or eight weeks from the time of layering, they should be transferred to 5 -in. pots, and it must be borne in mind that Carnations, of all plants, like very firm potting to ensure good flowering. If all goes well flower-stems will soon begin to appear, and a cold frame will be sufficient to bring them on until they are ready for the greenhouse.

For hanging-baskets or pans raised to a position near the eye, a creeping Himalayan perennial, familiarly known as the Shamrock Pea (Parochetus communis), which flowers naturally in October and November, is extremely pretty, both in its twin Pea-flowers of pale stone-blue and its large trifoliate leaves. It is also more satisfactory to flower under glass than out of doors, even on the most sheltered rockery. For the 
same purpose two Italian Bell-flowers, Campanula fragilis and C. isophylla alba, are invaluable, the latter being the more easy of the two to grow into a fine specimen. A little early pinching-back of the shoots will help to retard their flowers till late autumn, when they are very welcome. Though these are both natives of sunny Italy, they prefer partial shade when under glass. A fine blue variety, C. isophylla Mayi, named after its raiser, has recently been introduced.

So far, mostly quite hardy plants have been under consideration, but there are a good many half-hardy perennials which may be used, with a little careful preparation beforehand, for the autumn greenhouse. Two or three dwarf species-not varieties - of Dahlia, for example, come in very well to fill up a gap at this late season. D. gracilis, a slender-growing Mexican plant, with bright scarlet single flowers and finely cut leaves, is good and showy, only care must be taken to secure the true species, and not some coarse-growing seedling masquerading under the name. D. glabrata (syn. D. Merckii) has smaller lilac or white flowers, but produced very freely; while the Black Dahlia, so-called (which is not really a Dahlia at all, but Cosmos diversifolius), makes a good foil with its dark brown, velvety petals. These can be raised from seed, and answer best if they are grown in pots plunged out of doors during the summer, and all the strength thrown into the growth by the removal of all buds until the plants are wanted to flower. Arctotis arborescens, a very beautiful, but rather tender, perennial, often used for summer bedding, comes under this class. It is somewhat bushy in habit, and likes plenty of room, but it is well worth taking any pains to get its large creamy-white flowers in autumn. These are tinged with pink on the under-side of the petals, and the fine grey-green foliage sets them off to great advantage. How true it is that no greenery goes better with any flower than its own leaves. Another species, A. aureola, has glowing orange flowers, which 


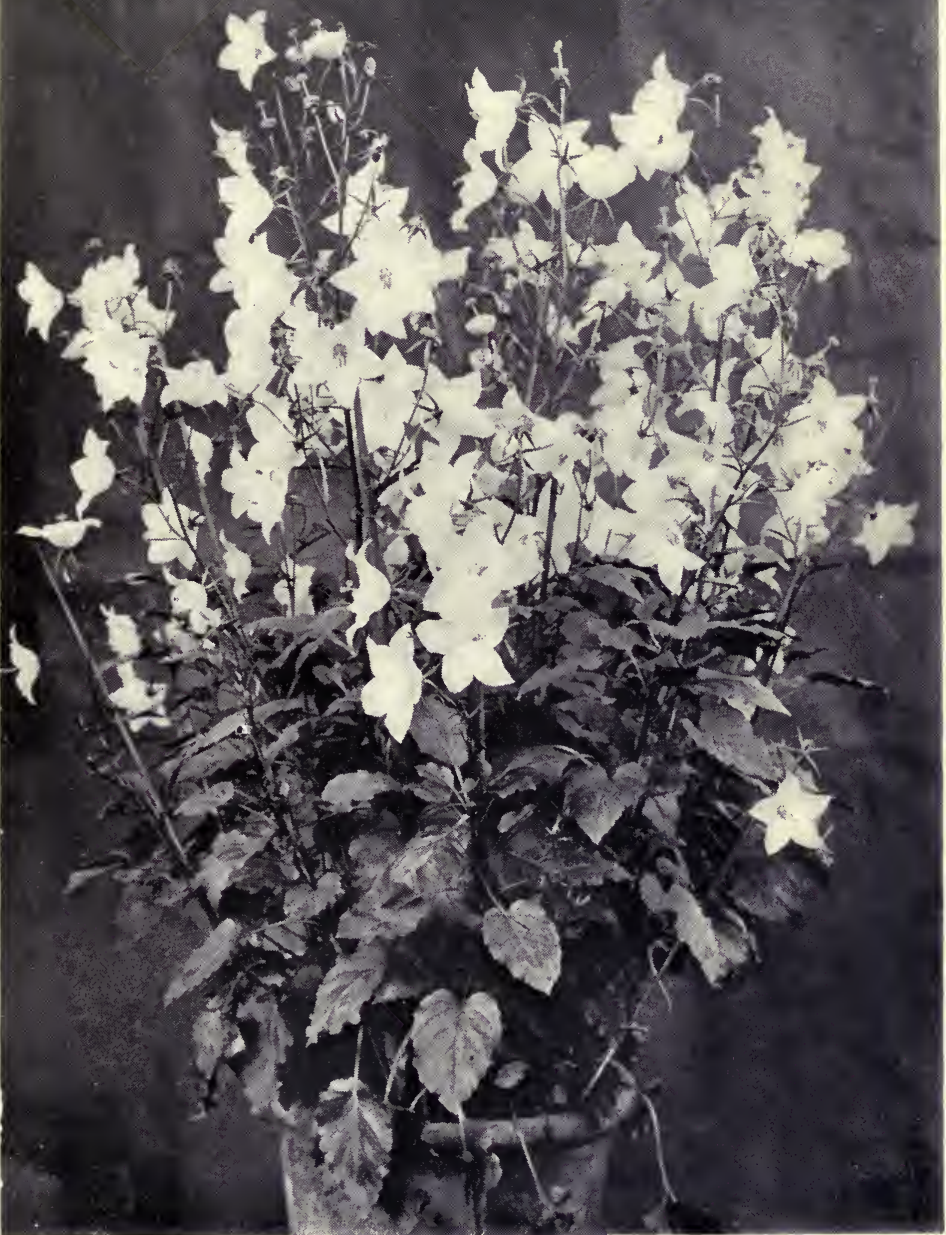

•

CAMPA ULA HYBRID FERGUSONI. 


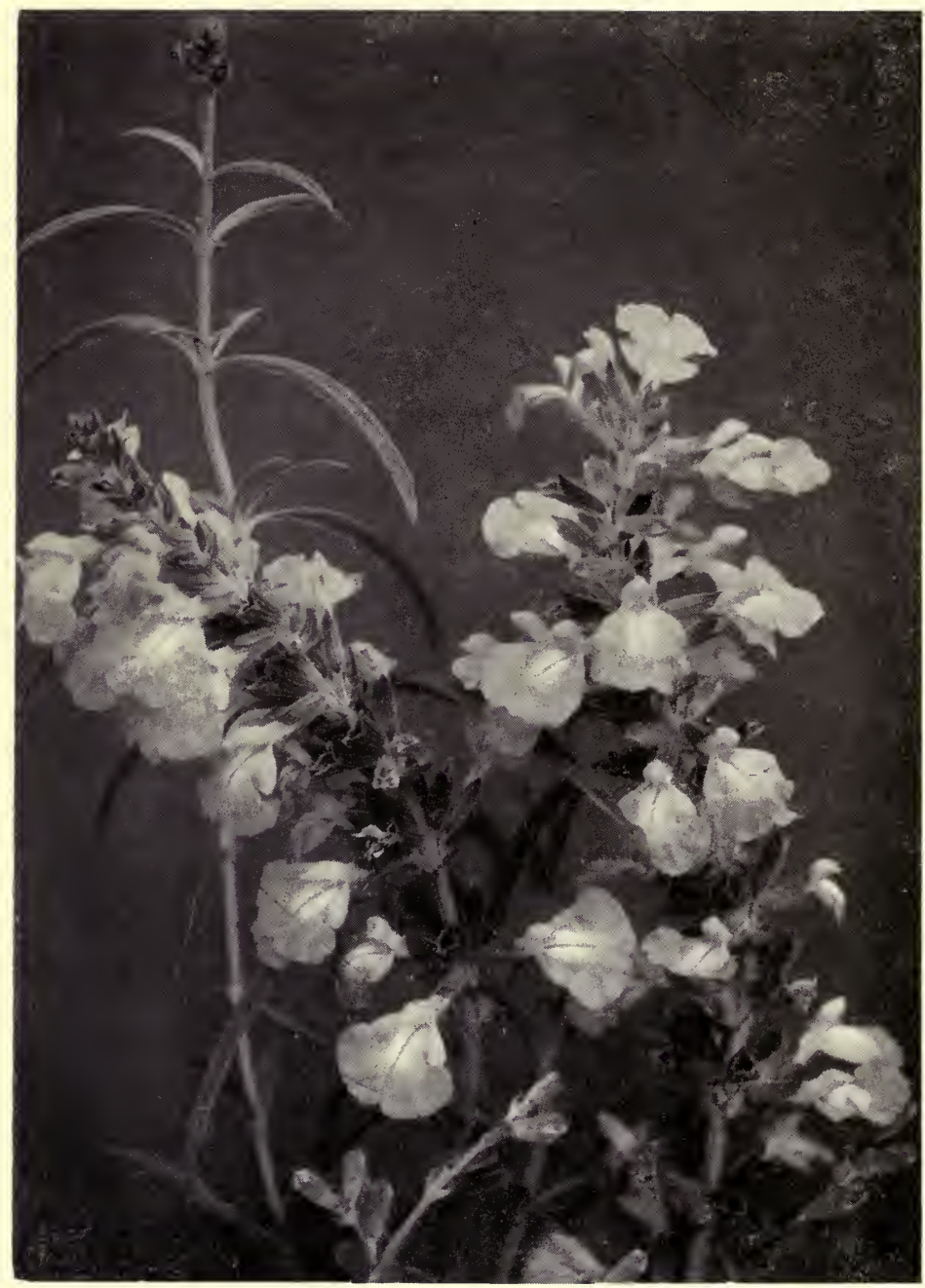

SALVIA AZUREA GRANDIFLORA. 
it produces till quite the end of the year out of doors in the Isles of Scilly, and would probably answer as well as the largergrowing A. arborescens. Alas! they have one fault, they close in dull weather.

Paris Daisies, both white and yellow, grown from springstruck cuttings, make delightful autumn plants when plunged out of doors during the summer, and the points of the shoots carefully pinched out to make them bushy. There is something so innately cheery about them that, common as they are, they may not be left out of our year-end programme.

Several of the hardier Salvias, treated in the same way, make fine and useful plants. They are so quick-growing, as a rule, that after the cutting stage is passed they require several shifts during the season, until finally they reach a 9-in. pot, in which size they should flower well. Severe pinching is also necessary to make them compact, but in any case they take up more room than most plants. For a strictly cold greenhouse it is better to be content with such species as S. Pitcheri (syn. S. azurea grandiflora), S. coccinea superba, S. Hians, purple with spotted lip, and S. patens, well known, with deep blue flowers, of which there is also a white form, rather than the more tender species. In a good season, however, and with the temporary help, on occasion, of a heat radiator, S. splendens, with its brilliant scarlet spikes, S. gesneræfolia, and S. rutilans, but with Pineapple scented foliage, may be successfully grown, though they need a genial temperature of at least $50^{\circ}$ to develop their flowers satisfactorily. The cultural treatment of both hardier and more tender species during the summer is identical.

The subject of retarding flowering plants by refrigeration, which is coming so much into vogue, can hardly be passed over without some reference here. It is now quite possible to procure many different kinds-perennials (such as Astilbe japonica, better known as Spiræa), bulbs, represented by 
several species of Lily, and even hardy deciduous shrubs, like Azalea mollis-ready prepared to flower in the autumn greenhouse. These will, probably, require special care to bring them to perfection after the severe ordeal to which they have been subjected. But the amateur who loves his plants, and desires to know more of the unstinted variety which the garden of the world offers to the seeker, may do better than to hark back to spring when so great a wealth of autumn flower is within his reach. There is more show of reason for helping autumn and spring to clasp hands over the sleeping form of winter. 


\section{CHAPTER XVI}

\section{ANNUALS AND BIENNIALS}

Nothing is more dismal and ugly than a greenhouse left bare and empty of its proper occupants. Not seldom, indeed, it then becomes a storehouse for all sorts of garden lumber, the untidiness of which it fails, unluckily, to hide. Yet it is not an unlikely thing to happen that one finds one's self at some time or other with a greenhouse on one's hands, yet for a period too short to accomplish much in the way of plantgrowing. A year's tenancy of house and garden is, in truth, for gardening purposes, an awkward gap to fill. It is, of course, open to any such tenant to put the conservatory into the hands of some neighbouring florist should there be one within easy distance, and under some circumstances this is, doubtless, the best way out of the difficulty. If the greenhouse, however, happens to be unheated a professional gardener will probably shake his head in despair of doing himself any credit during the winter months, and, beyond supplying a few evergreens in pots, may even decline altogether to attempt any floral decoration until the spring. It is not to be denied that there are considerable obstacles in the way, and for the winter almost everything depends upon the time available for preparation; but a good deal may be done, at the cost of a few shillings and a little time and trouble, with annuals and biennials or certain other plants, possessing, strictly speaking, a longer term of life, but which may be treated as such. A few suggestive hints as to the most 
suitable may be useful, not only to those who mean to depend entirely upon such yearlings, but for others, who will find many of them exceedingly valuable, if not indispensable, additions to their flowering plants. Where time fails to raise these for ourselves it is generally possible to buy strong seedlings of ordinary sorts ready for potting, so that we need not wholly despair of procuring decorative material of this temporary nature, and with little outlay.

Annuals are often regarded with some contempt, but it may be traced in most cases to failure in growing them well, resulting mainly from the initial mistake of sowing the seed too thickly. Seed is often minute, marvellously so when one thinks of the germ of life and the earliest food for that germ which is, in one way or another, packed up in it. It does not at all follow, however, that the plant produced from a microscopic seed should require to be looked at through a magnifying glass when full-grown, and this we must always take into account. A single seedling of Nemophila or Limnanthes will make a grand free-flowering specimen if allowed proper scope, when a dozen cramped into the same space will be utterly worthless and disappointing.

Seeds, minute or otherwise, must not be sown too thickly, and with the larger kinds, like Tropæolum or Lupine, it is a good plan for indoor work to put them singly into the smallest pots and to shift them as required into larger sizes. Annuals, again, under these circumstances must never in the earlier stages be allowed to get pot-bound, needing constant attention from the first, until they get their final transfer into the flowering-pot. Hardy biennials may often, on the contrary, be planted outside with advantage to make their growth before being potted for the greenhouse, which is a great saving of time and labour. These require a somewhat longer time to bring them to the flowering stage, and are generally sown one year to flower the next. The time of their flowering depends 


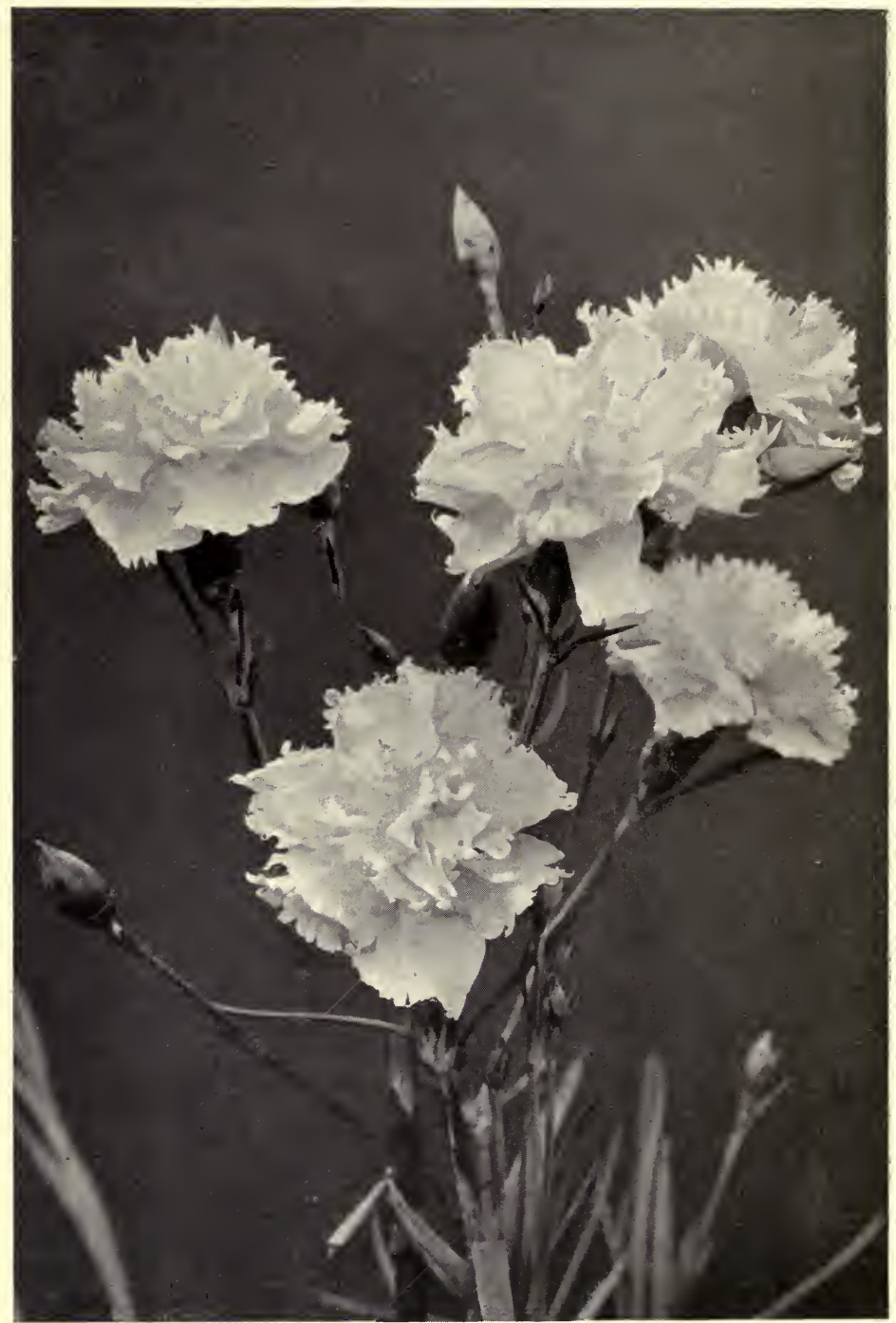

MARGUERITE CARNATIONS. 
in most cases on the time of sowing and subsequent culture-a statement not so obvious as it may seem at first sight, because they are sometimes contrary in their ways, and may, if they are in sulky mood, pass over a whole season.

A houseful of Wallflowers in midwinter, some in flower and some coming on, would be no mean success to attain. The full red-brown of Harbinger and the clear yellow of Belvoir Castle, which are amongst the earliest to bloom, are at all times beautiful, and other later well-known varieties, to be found in every seed list, will give intermediate shades never out of harmony with each other. Wallflowers are really perennial in duration, though not very long-lived, but as they flower within a few months of sowing, they are commonly treated as annuals. For very early winter the first sowing is best made in April, and a second may follow three weeks later. Where there is a bit of garden ground the young plants may be pricked out 3 in. apart in rows with not less than 6 in. between the rows. Later on, when they begin to require more room, every second plant may be transferred to a new row, allowing 6 in. between each of them. Here they may remain until October, when they can be potted in 5 -in. pots for flowering in the greenhouse. Where there is no garden, boxes or zinc trays may be made to serve the purpose. In either case care must be taken to keep the plants weeded and watered in dry weather. Wallfowers are hardy things-never more so than when grown on the scanty foot-hold of a crumbling wall, their natural home. Cultivation in rich soil tends to make them less hardy, and the shelter of glass, therefore, is very welcome in severe and especially in windy weather, and will also hasten the flowering time. Double German Wallflowers are very popular and handsome with their quaint purple and Primrose tints, but they are more tender and not so fragrant as the smaller-fiowered common 
sort. They come into flower later, and the seed need not be sown till May.

Stocks, which are mostly biennials, are neither so hardy nor so early as Wallflowers, but they are very useful, and if seed of the intermediate section be sown in June and treated much in the same way as recommended for Wallflowers they will flower quite early enough to take their place when the Wallflowers begin to grow shabby. Some experts prefer to grow them entirely in pots, giving them shifts into larger sizes as soon as the roots touch the sides. All-the-Year-Round is a very fine white variety, and there are crimson and purple shades in the same strain. For a later display the annual TenWeek Stocks may be sown as early as February under glass, and, with good cultivation, will be in fine flower long before any of their kind out of doors. The large, sweet-scented flowers of this section are very beautiful in the infinite variety of their delicate tints.

Scarcely any introduction of recent years has been more welcomed than that of the annual Margherita Carnations of Italian origin. Sown early under glass, planted outside as soon as the seedlings are strong enough, and allowed room enough to develop, they will grow during the summer into vigorous plants well set with buds in time to be potted with other things for winter flowering. If the season be favourable many buds will open before Christmas, and with a good strain of seed, which is always a most important factor in the case, a very large percentage of the plants will give fine doublefringed flowers of refined hues. The single "rogues" are also extremely pretty, and by no means to be despised as decorative plants. Few people realise how well the common white Pink, as well as its rose-coloured form, treated practically as biennials, respond to gentle forwarding under glass. Tufts of cuttings or divisions of old plants put out in new soil in rows in May can be lifted and potted in September. They 
may then stand out of doors with the pots plunged in ashes until Christmas or thereabouts, and will come into flower about nine weeks after being brought in. How welcome they are, filling the greenhouse with sweetness on an April day, none can tell but those who have tried them.

Sweet Peas are a great stand-by, but it is essential that they should be sown about midsummer to come in for very early blooming. Three seeds sown in a small pot, and transferred with as little disturbance of the roots as possible into larger sizes, and grown out of doors, will make beautiful specimen plants. They may be pinched back now and then to make them bushy, and will flower well in a ro-in. pot; but they should be brought under shelter before the first early frosts at the end of September or they may receive a check which will retard their blooming. Eckford's good varieties offer abundant choice of colour, and these should be kept distinct, as mixtures are seldom desirable or effective.

Any of the hardy annuals which are recommended in the seed lists for autumn sowing, which usually means August and onwards, may be tried with a fair chance of success, and should flower by relays from early spring. Mignonette will scarcely be overlooked. The old-fashioned kind, though not so large or handsome as Machet, Parson's White, and some of the Covent Garden strains, is the sweetest of all. Three seeds sown in a small pot, the strongest only to be retained, and re-potted as required in rich soil, will give very satisfactory results.

Tender annuals for summer and autumn blooming, such as Astors, Tropæolums, Mimulus, Nemesia strumosa, Salpiglossis, Celosias, Martynia fragrans, \&c., must be sown under glass in March, April, or May, according to circumstances, and require a good deal of care in pricking-out, potting, and in some cases pinching-back, with as much open air as possible to prevent their spindling. These may be so timed as to flower until 
late autumn. Greenery should not be forgotten, for which the Japanese Hop, Zea Mays, and some of the elegant annual grasses, will answer well. The biennial Fish-bone Thistles (Chamæpuce Casabonæ and C. diacantha) are also very useful for this purpose. Cosmos bipinnatus, with its finely cut leafage, makes an effective foliage plant while it is young, and a few out of a batch of seedlings might be reserved for this purpose, but the plants intended to flower will do better if summered out of doors. This, being one of the latest of autumn-blooming annuals, is not very satisfactory in the garden for our climate, but if grown under generous conditions it is exceedingly ornamental in the greenhouse during October and November, either in its white or light purple form.

I will transcribe a short extract from a book seldom to be met with in the present day-Mrs. Loudon's work on annuals, which is well illustrated with coloured plates. The hints there given have been very useful to myself, and they form a guide for the general culture of annuals in pots, whether autumn or spring sown. I quote the following passage verbatim, but it will be noticed that in the case of Rodanthe Manglesi, the plant in question, the time of sowing is stated to be April, Rodanthe being half-hardy, but the same cultural directions are applicable whether the seed be sown in autumn or in spring, i.e., whether the annuals be hardy or half-hardy.

"The seed was sown on April 5, in pots filled with three parts peat, or rather heath-mould, and one of loam. In the first week of May, when the plants were still in the seed-leaf, they were pricked out singly into small $2 \frac{1}{2}$-in. or 3 -in. pots. In a week's time they were shifted into rather larger pots, and this shifting was repeated six times, always into rather larger pots, till the middle of August, when the plants were in $9 \frac{1}{2}$-in. pots, and when they were first allowed to flower. On September I4, when one of these plants was sent to us by Captain Mangles, it was $1 \frac{1}{2}-\mathrm{ft}$. high about 
$4 \mathrm{ft}$. in circumference, and had a thousand expanded flowers upon it, besides innumerable buds, which have continued expanding ever since, and it is still (November $\mathrm{I}$ ) a blaze of beauty. It is watered every morning with a little warm water, and the dead flowers are cut off as they fade. 'The great art,' says Mr. Goode, in the manuscript directions sent us by Captain Mangles, ' is to prevent the plant from growing upwards, and to cause it to increase and expand in breadth instead of length.' To do this, all that is required is to watch it well, and the moment the roots have nearly filled the pot, to transplant it into a larger one. By constantly attending to this, the plants will grow thick and shrubby in their character, and while the shoots will grow strong and capable of bearing a most profuse floration, the beauty of the plants in shape will be greatly improved." This may be old-fashioned practice, but nevertheless the above passage is highly suggestive, and it proves that an annual plant may be grown into a fine specimen, even though it may live out its life in a succession of pots. The same routine of treatment will answer equally well for biennials.

One or two dwarf annuals of a succulent character are well adapted for summer flowering under glass-Portulacas, which enjoy the extra heat and are delightfully gay in their vivid colouring of crimson, yellow, and purple, and the free-flowering Mesembryanthemum tricolor, pink and white, with a dark eye. These should all be sown very sparingly, as they are apt to resent transplanting, and do better if they are thinned rather than pricked out, looking best when grown in shallow troughs or pans.

The different varieties-orange, yellow, and white-of Iceland Poppy ( $P$. nudicaule) do well treated as biennials, and, sown in autumn, make charming pot plants for early spring.

For those who like to travel out of the common track, two 
beautiful species of Pentstemon, not very often met with, may be added to the biennial list. P. Cobæa is a Texan plant which blooms naturally late in autumn and has long, shining, deep green leaves and spikes of bell-shaped lilac or white flowers. Being very viscid they attract insects to such a degree out of doors that their beauty is sometimes marred by the small victims which cannot get free from the sticky trap, but they make very fine pot plants. P. Murrayanus is quite distinct from the last, having glaucous leaves and bright scarlet tubular flowers, and there are garden varieties distinguished, as Grandiflora, of different shades of rose and violet. Both these species, which are quite different to the well-known border Pentstemons, do better sown in early autumn and protected during the winter either in a cold frame or greenhouse, as they are somewhat tender, but are well worth growing by those who do not begrudge time and trouble.

As a garden experiment, which probably has never been attempted, it would be interesting to prove what could be done in the way of cold greenhouse decoration by the use of annuals and biennials alone. To this end I will gather the hints given above into four distinct rules :

r. Pot off singly while still in the seed-leaf.

2. Shift several times into pots a size or two larger than the last, to encourage root-growth.

3. Use rich soil and water often with weak soot-water, which is a good and safe stimulant.

4. Pick off all early buds until the plant is sufficiently strong to support a luxuriant bloom, and remove all withered flowers as they fade, to prevent the formation of seed. Sometimes it may also be desirable to pinch out the point of the leading shoot, so that laterals may be thrown out below to make a shapely plant.

The successful cultivation of annuals is, in fact, a fine 
art, and may be summed up in the garden-lad's definition of gardening, "A-doing of things at the right time" - a maxim instilled into his understanding, no doubt, by a past-master of the craft, and which applies with double force in the case of this handsome but short-lived section of plants. 


\section{CHAPTER XVII}

\section{HARDY ORCHIDS}

To include Orchids in a series of plants eligible for an unheated greenhouse may seem, at first sight, to be out of the question. Nevertheless, in hardy terrestrial orchids, there is a tolerably wide field open for experiment, and for the sake of those who find in this special class the acme of all that is beautiful in plant life, it is well that it should not be omitted. Terrestrial Orchids include some very fine genera, in which many of the species are hardy, though others of the same genus inhabit the Tropics-a well-known example being found in Cypripedium. Besides the handsome Cape Disas-the purple-flowered Bletia hyacinthina (China), which was long grown in stove-heat until it was discovered to be quite hardy enough for out-door culture-and the hardy Cypripediumsthere are great numbers of ground-Orchids found in all parts of the Temperate Zone which may be ranged under the popular head of Orchis. The flowers of many of these are very fine, while others possess exceeding interest from their mimicry of various insects, like the Bee and Fly orchises of our own chalk downs and their fringing woodlands. A collection of some of the best of these is well worth growing, and quite sufficient in itself to take the shape of a very good hobby, including both hardy and half-hardy species, though all would need treatment differing from most ordinary plants. It would be well, therefore, for any one taking up their culture to make a speciality of them. To see these plants in their 


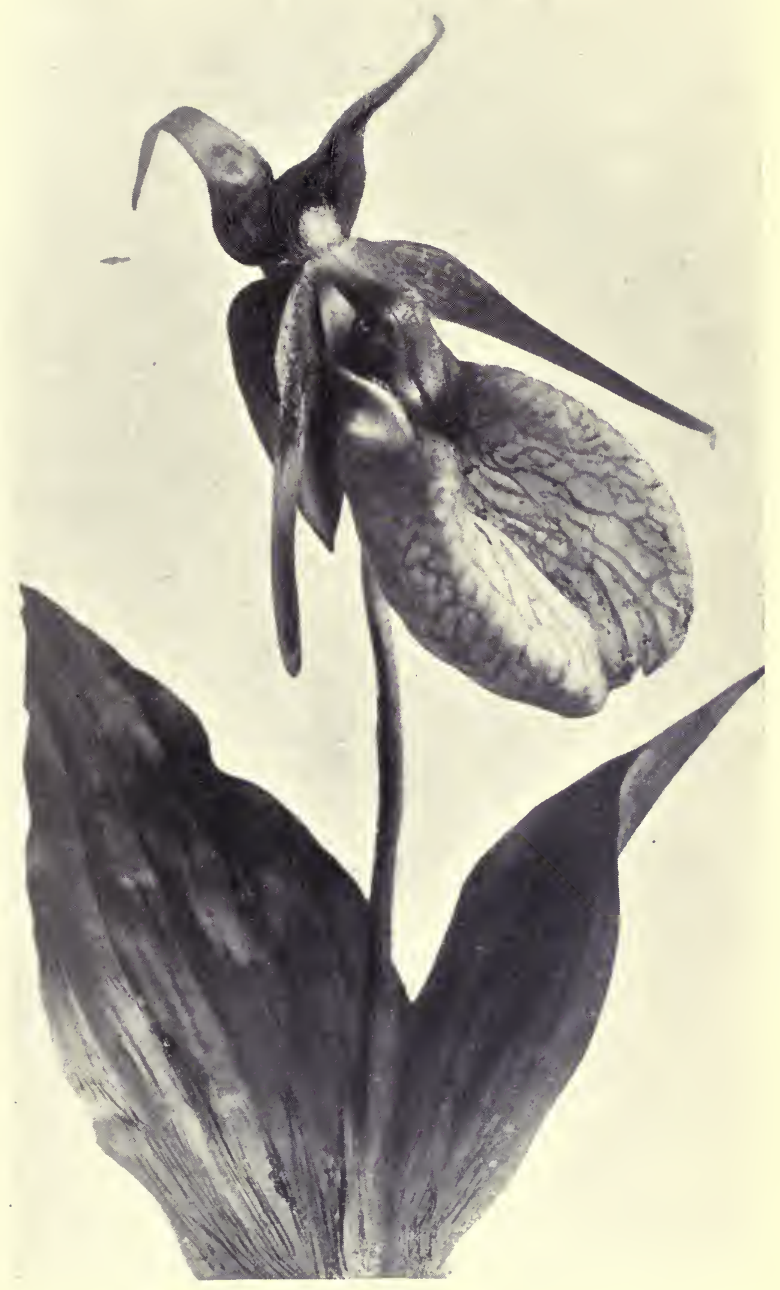

CYPRIPEDIUM ACAULE. 


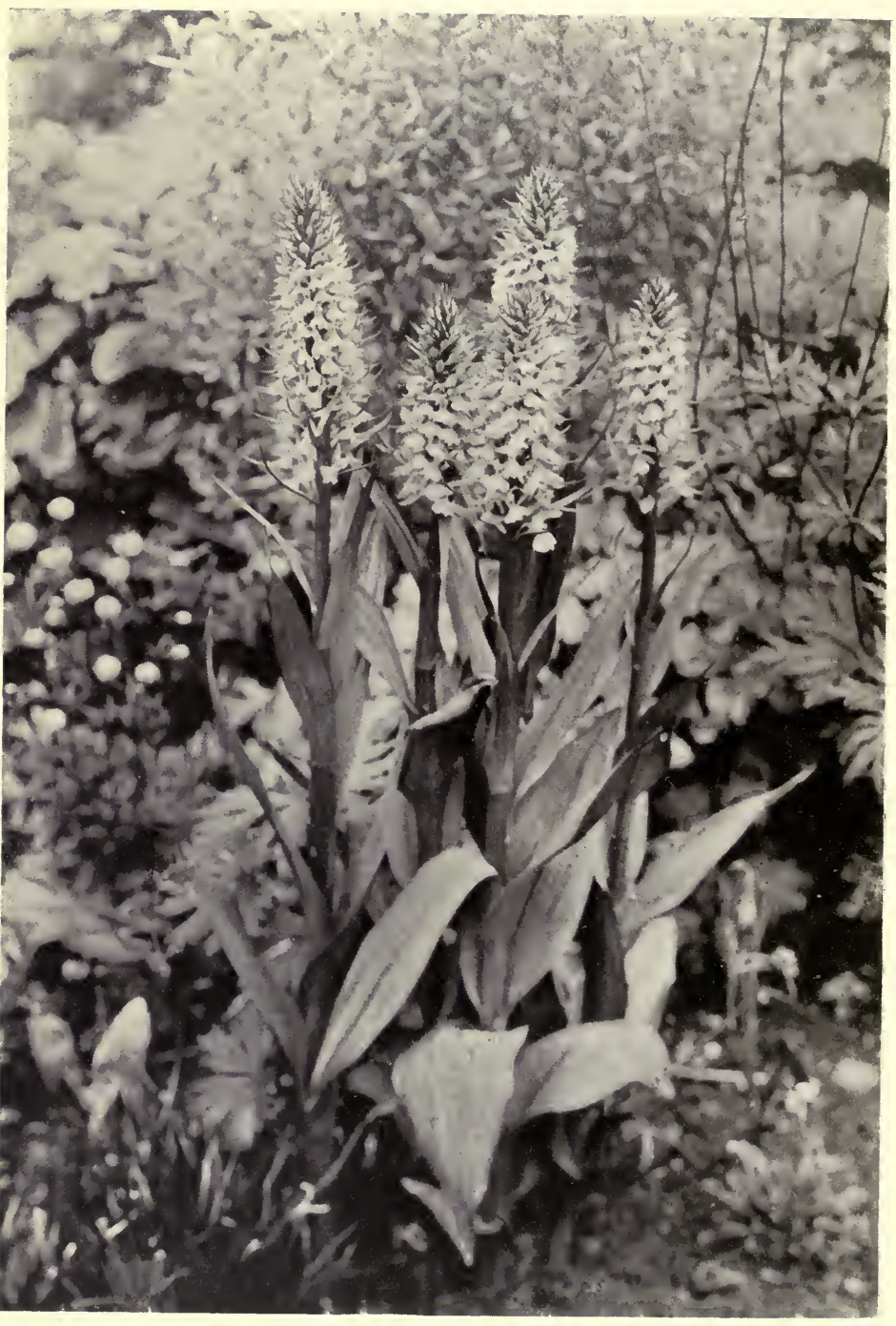

ORCHIS LATIFOLIA. 
native habitats, makes one long for a closer acquaintance with them. Never shall I forget one spring morning on the Appian Way, when the grassy borders of the wide Roman road were bright with patches of C. papilionacea-a painted beauty, not to be confounded with our modest white butterfly Habenaria -and bee-and-spider-like Ophrys of various species, and the delight of gathering new kinds amungst them. A mental note was registered on the spot that the next venture in cold house experiment, when opportunity offered, might well be on some of these quaint and lovely plants. For here I must confess that $I$ am about to trench on the cultural experience of others, rather than on my own; yet knowing, by ocular demonstration, how much may be done in this direction, it seems better not to leave out entirely so important a group.

It is quite possible to procure, both from foreign and English dealers, tubers and roots of the most desirable species of terrestrial Orchis, African and American as well as European. The chief difficulty is to make sure of their having been collected at the right season-a too frequent source of failure. Most of this class will do well in deep pans, in light, turfy loam, alternating as to quarters between a cold frame in summer, and a greenhouse in winter from which, for the half hardy kinds, frost is just excluded. One reason why the interesting South European Orchises are hard to cultivate satisfactorily in our climate out of doors seems to be the same that often arises with bulbous Iris and other alpine plantsgrowth begins too early, and they cannot stand the crippling alternations of frost and thaw. This trouble is overcome where such plants can be given the shelter of a cold house.

The fine Madeiran Orchis foliosa is well known, and is a robust and very ornamental plant for the unheated greenhouse. It grows to a height of 18 in. and upwards, and the handsome spikes vary in colour from a deep shade of purple to pale rosy-lilac. Being one of the easiest to manage, and 
increasing year by year under good treatment, it is one of the best upon which to try one's 'prentice hand. As an example of quite another type, Calypso borealis, a small but very choice bog species, may be quoted. It is scarcely 4 in. high, yet the plants in the Alpine House at Kew attract many a visitor who knows their rarity, and can admire beauty in miniature. Unlike $\mathrm{O}$. foliosa, and the Ophrys or insect-like section, which are mostly found in dry, open spots, this little North American gem delights in shade and bog-soil, like our own marsh Orchises, and will do well in a spongy compost of sandy peat and loam, to which some chopped sphagnum moss would be a good addition. The same treatment will suit Goodyera pubescens, with silver-veined leaves.

On the whole, the hardy bog-Orchids seem to be more easily managed than those of the insectiferous section. Most of them can be successfully grown in pots or pans in the compost already recommended and surfaced with living sphagnum, which keeps the soil moist and cool and is as near an approach as can be made to that of their native haunts.

Hardy Lady-slippers (Cypripediums), for example, would form a grand addition to the cold Orchid-house. C. spectabile, the pink and white Mocassin Flower of North American swamps, is one of the most vigorous and best known of these, and finds a place in all good English gardens provided with suitable positions for bog plants. Once upon a time, when crossing a long stretch of swamp in Canadian backwoods settlements, in a rough country waggon, bumping along as the creaking wheels rolled over the unsteady logs of a corduroy-road, I remember seeing this lovely Cypripedium, for the first time, growing in massive clumps with other ravishing bog plants, and being sternly forbidden to attempt to gather one of them at peril of sinking shoulder-deep in the ooze, if not risking life itself. It was a hard trial at the 


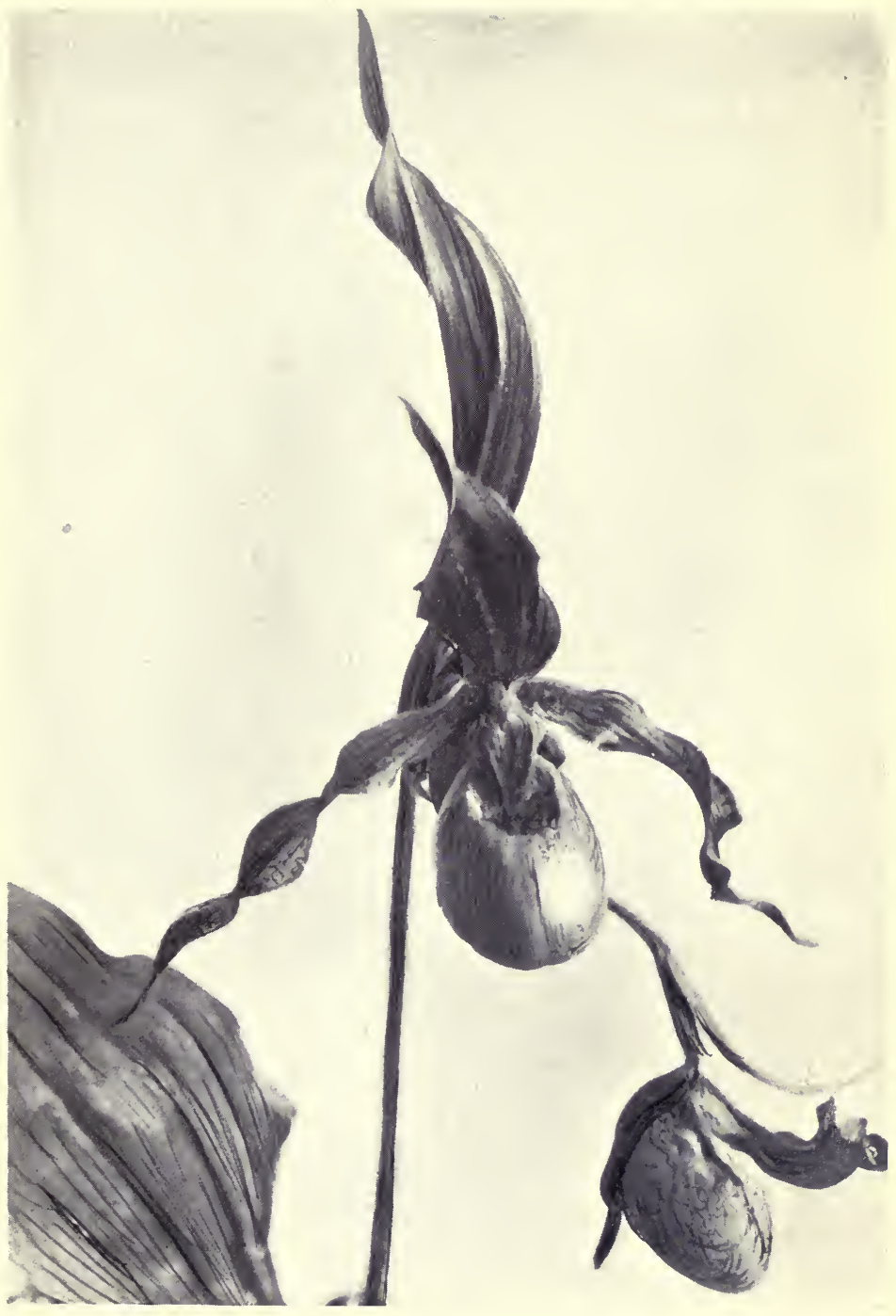

CYPRIPEDIUM PUBESCENS 


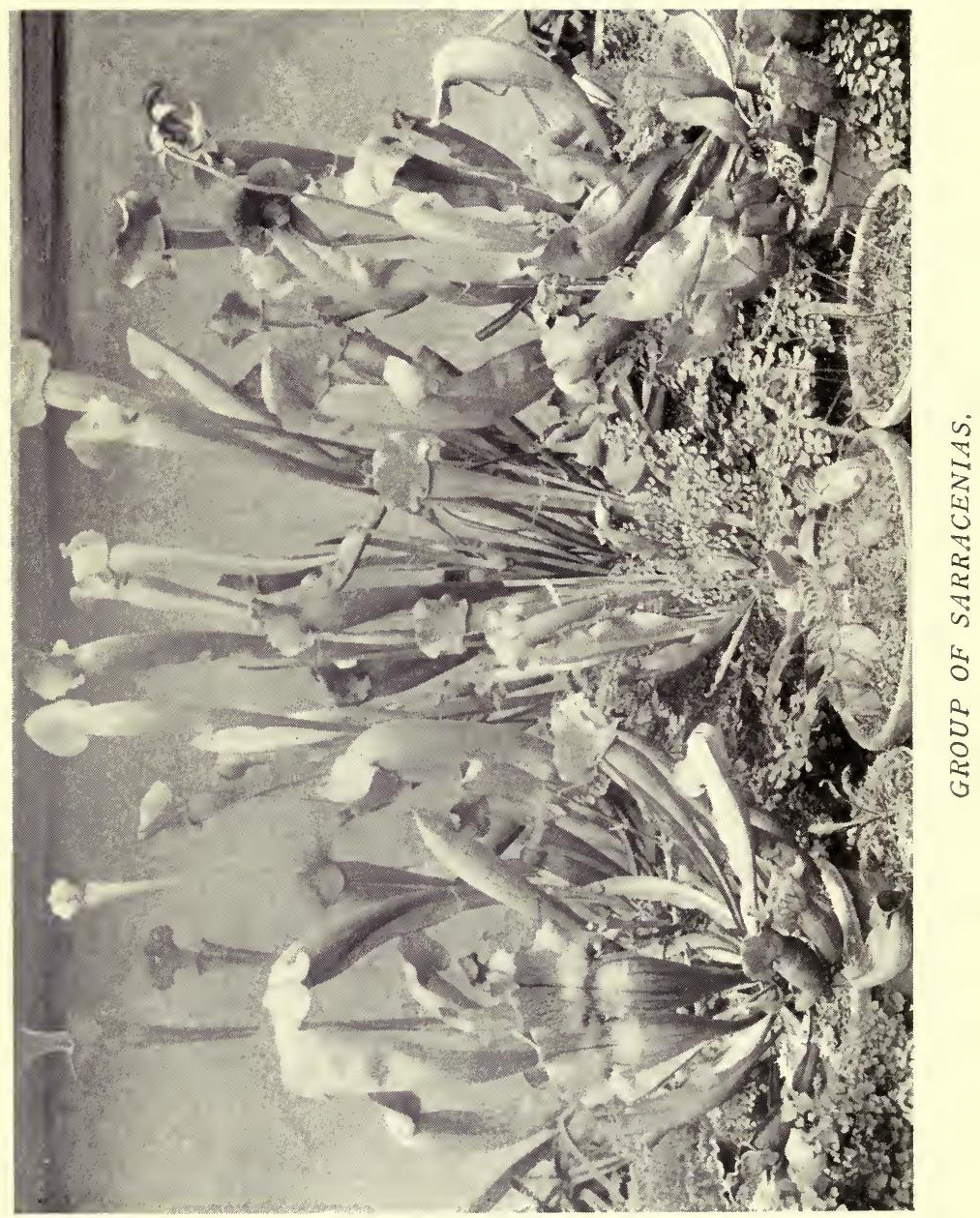


moment for a young and wilful enthusiast. In such a spot, Mocassin Flowers can be seen at home at their real best. But I am not sure-since we cannot in our English gardens emulate the wild luxuriance and tangle of the native bog, which is picturesque, but malarial withal-whether the most enjoyable way of growing such bog plants is not on the lines I have here ever so slightly suggested, so seldom is it that one sees them entirely at their ease in the bog-bed. Two or three species of these hardy Cypripediums have yellow and brown flowers, such as our own rare C. calceolus, reputed intractable under cultivation; C. parviflorum, smallerflowered, but elegant with its twisted petals and sepals; and C. pubescens, a stronger-grower than either, easier to manage, and fairly plentiful. A scarcer North American species, C. candidum, has a white lip, with sepals and petals of greenish brown. There are, besides, other hardy Cypripediums worth growing; for example, the somewhat uncannylooking Siberian C. macranthum, with its large purple pouch; and the stemless red-flowered $\mathrm{C}$. acaule.

Associated with these-for, though they are not Orchids, they company together by nature-one or two species of Sarracenia would be very fitting to cultivate, being seldom quite satisfactory in the open garden, as the pitcher-shaped leaves generally become torn and disfigured. S. purpurea, the typical Huntsman's Cup, and S. flava are two of the hardiest. This hardy section of Sarracenia would offer a field for hybridisation quite as interesting as the tender species which have already been taken in hand by experts with such gratifying results, as may be seen any spring day at Kew, in the annexe devoted to such plants.

The Disas, again, which take rank among the finest Orchids, are pre-eminently amenable to cool treatment. D. grandiflora, one of the glories of Table Mountain, when it has donned its fine scarlet coat, lives with its roots in the 
sides of the water courses which abound in that locality, where they are never dry, while the atmosphere, even in the hot months, is tempered by the cool mists which hang over the plateau. Here there is often snow and hail and even ice during June, July, and August, the South African winter months. On the authority of Mr. James O'Brien, a wellknown expert, D. grandiflora, in an unheated house, has passed through weeks of hard weather, stiff-frozen, in a temperature varying from $5^{\circ}$ to $14^{\circ}$ of frost, not only safely, but with better results as to flowering than others of the same species wintered in warmer quarters. This is distinct encouragement to try what can be done not only with Disas, but with other Orchids found at high altitudes. Happily, experience has already proved that one of the most charming and decorative of all, Odontoglossum crispum, wants very little coaxing to do extremely well, for it has been successfully grown in a sheltered lean-to house with a north aspect which was practically unheated. In fact, this and some other kinds, now always treated as cool-house Orchids, suffered much in the early days of their introduction from over-much coddling. Many times have I seen in the garden of a well-known anateur a low damp house of this description devoted to C. crispum and a few similar species, and admired the robust health and clean growth of the plants, to say nothing of the perfection of flower, which left nothing to be desired. 


\section{CHAPTER XVIII}

\section{SUCCULENT PLANTS}

THERE is still another class of plants, available for the unheated greenhouse, which presents especial advantages to busy people, and which must not be passed by unnoticed-those which the French call les plantes grasses, but which we term Succulents. In the days when Masson was sending home his ample stores of new discoveries from South Africa, and when Prince Salm-Dyck thought it worth while to publish his splendid monograph on the Mesembryanthemum, succulent plants in their numberless quaint forms were in high esteem, and, indeed, well deserved the attention they received. Modern methods and impatience of any but quick results have ousted most of these old favourites, but there has been a strong tendency of late years to revive the ancient love for these curious prickly things, amongst which may be found some of extraordinary brilliance and beauty of flower. The exhibits from the historic Chelsea nursery of new hybrid Phyllocacti at the Royal Horticultural Society's Shows of recent years testify to this, yet none of these can exceed the gorgeous splendour of the old Cereus speciosissimus, well-beloved of our forefathers. These "fat" plants, so singularly adapted to the dry and barren regions in which they are mostly found, are-and for an analogous reason -well suited to any one who has a taste for cultivating plants, but little time personally to devote to them, for they are not impatient, like most others, of a little neglect. 
In fact, they are much more apt to resent too much fussy attention, especially in the matter of watering, than a little wholesome negligence. Many business men have found recreation and solace in making a collection of these characteristic plants. A collection, however, hardly appeals to the majority, but a selection may well be chosen by those who have any fancy for them, for they are easily grown and easily stowed away in winter, if, indeed, they are not in flower, while they possess more fascination than might be supposed. I once gave an Echinopsis Eyriesii-one of the many-ribbed globular Cacti-to a friend, who watched, with a great deal of interest, the slow evolution of the fluffy, button-like knobs which one day were to develop into flowers. It happened just at the time that a move had to be made from the old home to a newly built house at no great distance, and, during the flitting, the greenhouse was mainly left to chance. Days passed by before the neglected plants came to mind, but in the gloaming of an early summer evening some errand occasioned a visit to the dismantled house. The key grated harshly in the unused lock, echoing through the silent, deserted rooms, yet lo ! a presence was there. A fragrance -new and unfamiliar-pervaded the still air of the empty house, filling every corner with mysterious incense. It was the Cactus, which, all unconscious of neglect or oversight, had put forth its long white trumpets after the strange, sudden manner peculiar to its kind, and was breathing out its sweetness in all the unearthly loveliness which white flowers will take on in the fading twilight-a voiceless poem, and for the moment overpowering in its simple pathos.

It is this quality of uncomplaining patience which gives to succulent plants of all kinds a value not to be estimated for busy people, and, it may be added, for invalids to whom the care of a few pot plants is often a great resource and boon. Yet it need not be supposed that there is no attraction in 


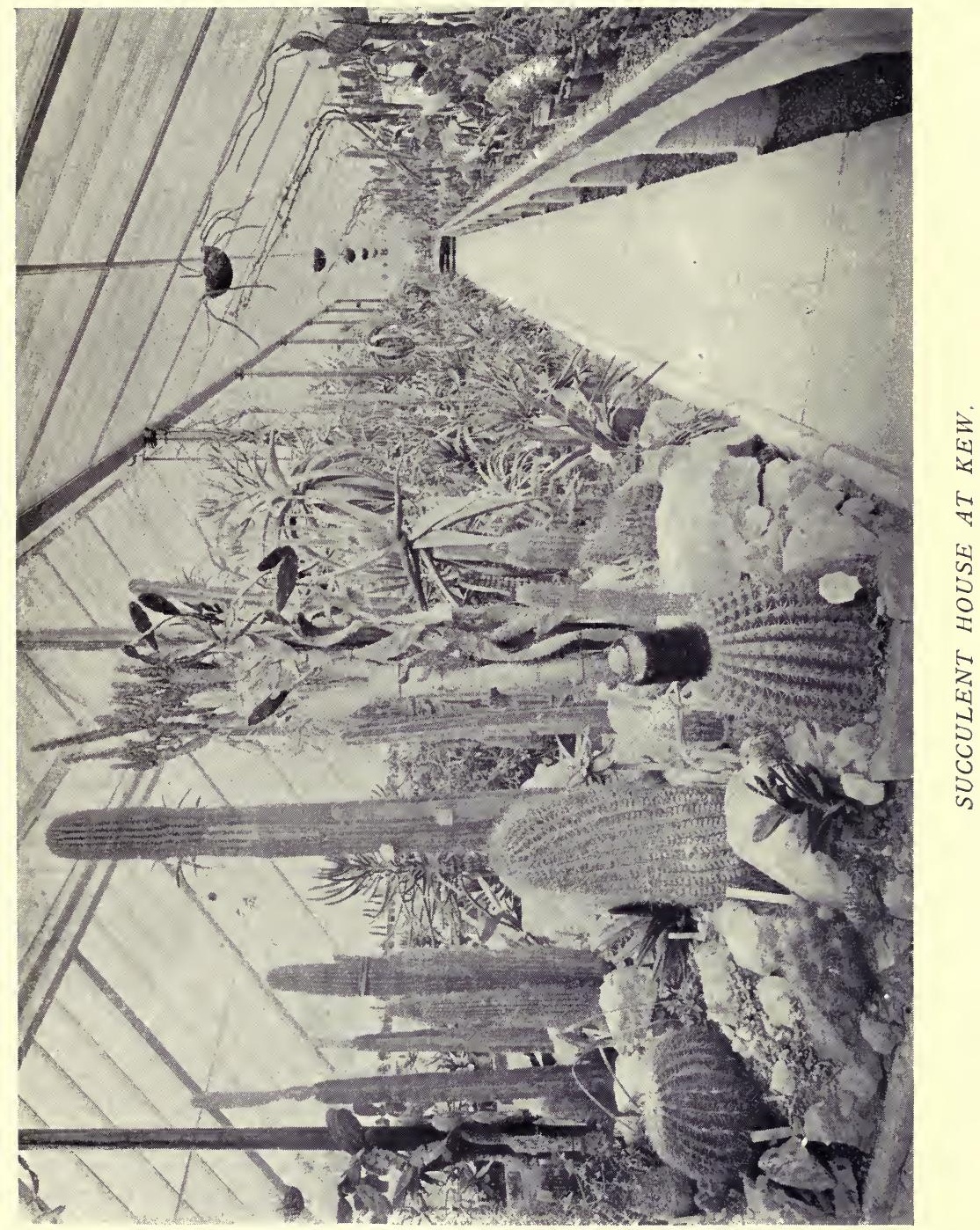




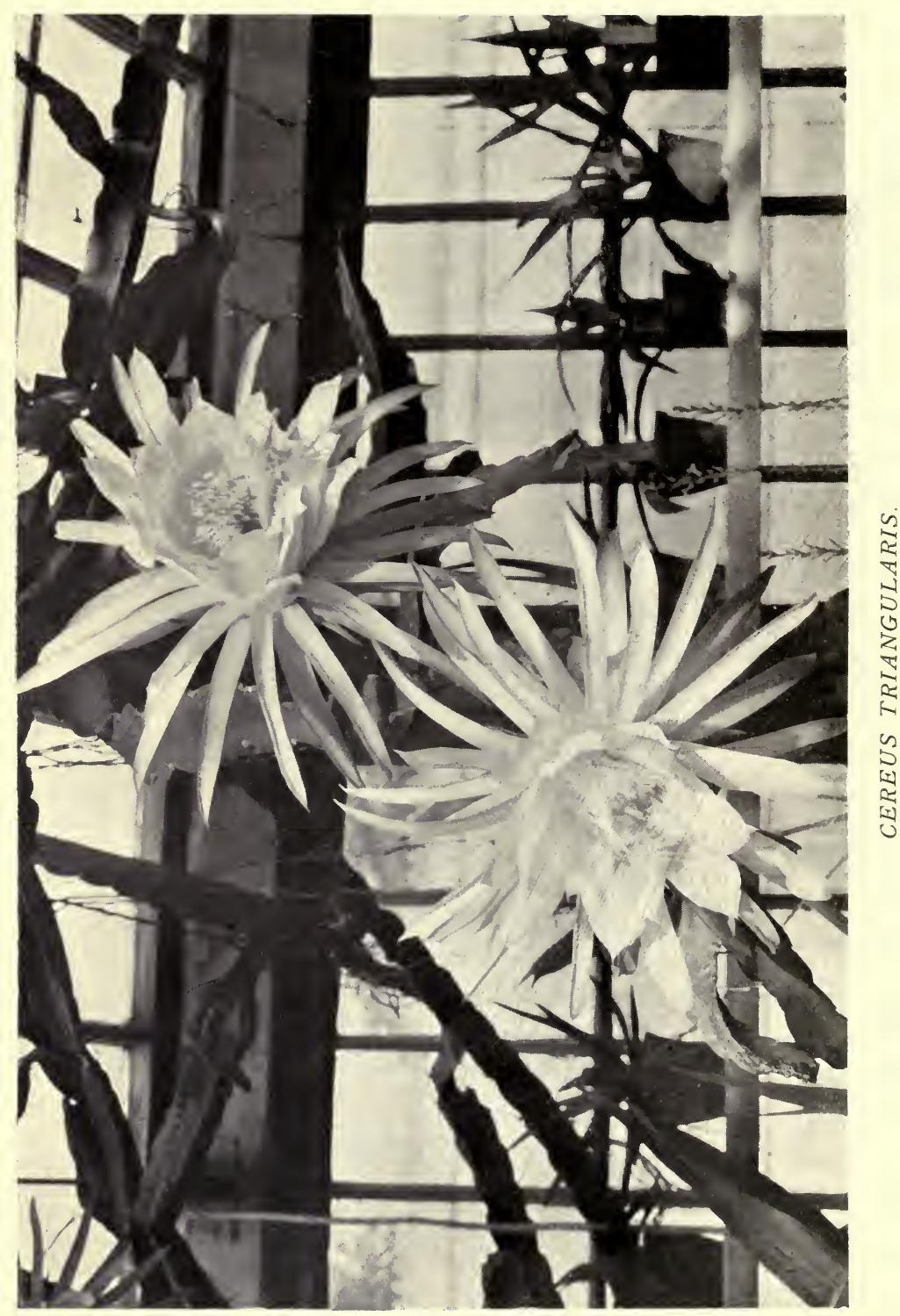


their quaint forms and brilliant colours for others besides business men and persons in feeble health. Far from it. The flat-leaved Cactuses (Phyllocacti) before-mentioned have flowers of exceeding beauty, and, besides, are not beset with the cruel spines which belong to so many of their kin. The old pink Cactus (P. phyllanthoides) is one of the most valuable of any of this section, though, strange to say, it is not very well known. The soft rose-pink tubular flowers are borne in great numbers, and are much longer-lasting than many others of the same family. The white-flowered P. crenatus and the still finer Cereus grandiflorus are still the cynosure of all eyes during their brief season of beauty, though the time has long gone by since supper parties used to be arranged in order to watch the wonderful unfolding of the shaggy grey buds of the Night-blowing Cereus into the great milk-white blossoms which were to fade so quickly before the dawn of a new-born day.

To come to another group, Agaves and Aloes also fill a very useful place, and well-grown specimens are handsome whether in or out of bloom. Echeverias and Cotyledons, though smaller, may be put into the same category. In the genial climate of the Scilly Isles and in positions sheltered from cold winds, these will all live and thrive out of doors. To show the profusion with which the somewhat shy aloes will bloom there under suitable conditions in the open air; a unique and striking decoration for a large dinner-table may be meritioned which once seen could never be forgotten, com posed entirely of the fine clear yellow flowers, tipped with green, of a species very much at home in the rock-garden, arranged with suitable greenery. One reason why succulent plants are seldom so satisfactory as they might be is because they are kept too much under glass, whereas, as gardeners express it, they cannot in most cases be grown too "hard." The hottest exposure in the garden should be allotted to them, 
where they can remain in the open air day and night during the summer months, and this attention will generally be repaid by annual flowering.

Of the different genera of succulent plants of moderate height and character Mesembryanthemums may be recommended as amongst the most interesting and profitable to grow, for two special reasons - the plentifulness of their brilliant, many-hued flowers, and the fact that a number of the finest species are quick-growing and may be treated practically as biennials or even as annuals. The usual practice is to let Mesembryanthemums grow into gnarled and woody shrubs which are ugly in themselves and never flower, until at last they are discarded as worthless. That this need not be the case is plainly shown by the fact that certain free-flowering species of the type of $\mathrm{M}$. bicolor used to be grown for market in great numbers by the nurserymen of the day when succulent plants were in vogue. It is quite true that a large proportion of Mesembryanthemums are merely of botanical interest. This must naturally be the case in a genus comprising some hundreds of species. Nothing finer, however, by way of colour can be grown for a sunny porch or greenhouse than M. bicolor, M. micans, and M. polyanthon when their masses of small daisy-shaped flowers of glittering orange and scarlet and purple are open in the sunshine. Amongst those of different character and with larger, if not more conspicuous, flowers, M. blandum, in both varieties of rose and white, is seldom entirely out of bloom, and is admirable for any position where it may be wanted to trail, or for a hangingbasket. M. aureum, an upright species with large, sparkling orange flowers, opens with the earliest spring sunshine, even in February. M. glaucum, one of the hardiest, with handsome canary-yellow blossoms from two to three inches across, flowers at all seasons, according to treatment; and M. spectabile, with pretty glaucous leaves and fine rose-coloured 


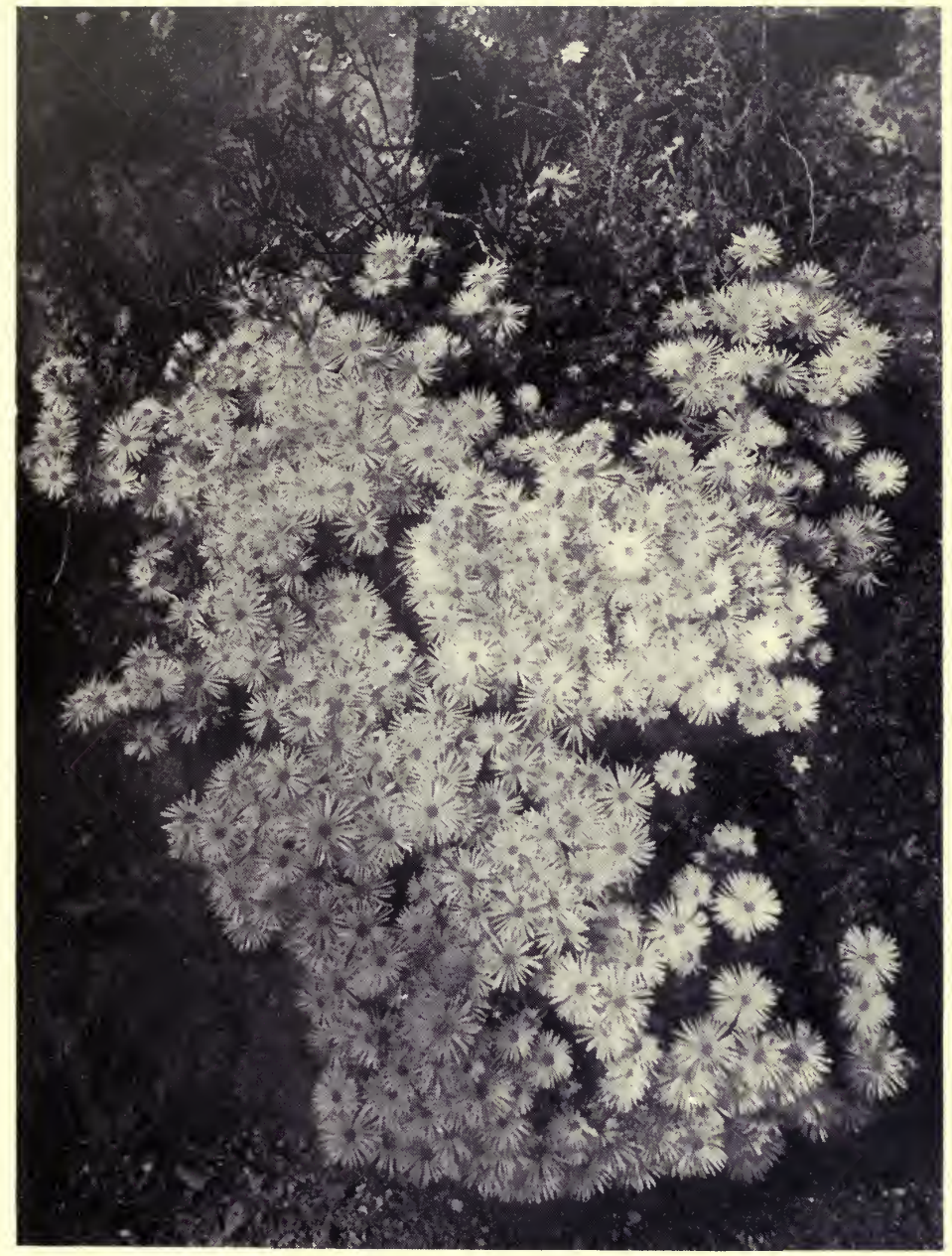

MESEMBRYANTHEMUM ROSEUM IN SOUTH DEVON. 


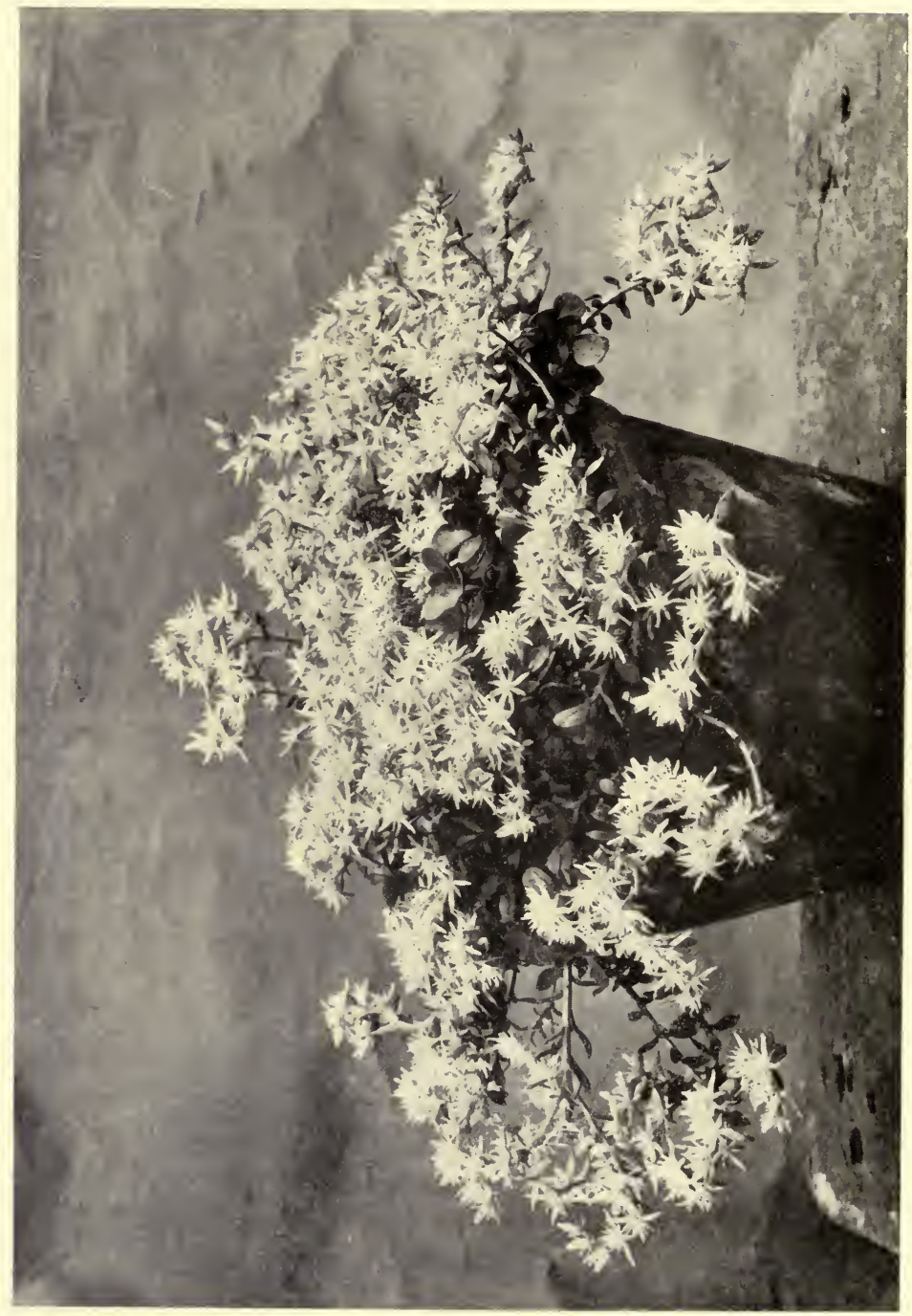

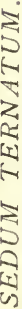


flowers is another favourite. Most of the species have the drawback of only opening in sunshine, but there are a few, like M. lacerum, which have not this failing. Indeed, the different hours at which Mesembryanthemums open is one of their most interesting peculiarities. Some expand in the morning, some at noon-day, others at four o'clock in the afternoon, and a few are night-flowering; but if for any hygrometrical reason they refuse to open at the right hour, it is seldom that any amount of coaxing from later sunshine tempts them out of their fit of sulks for the day. Besides their bright flowers, moreover, Mesembryanthemums take some of the most curious forms of leafage. Best known of these, perhaps, is M. tigrinum, with stemless boat-shaped leaves, furnished with wicked-looking interlacing claws, between which the large, solitary, golden-hued flower pushes its way. But this is only one amongst many which will repay a little study. No plants are more easily grown from cuttings. With such species as $M$. polyanthon-the copious-flowered section, as they are called by their historian, Haworth-small tops may be pricked over the surface of a pot or pan in the early spring. Every bit will root, and the young plants, without any disturbance, will give a mass of colour in two or three months' time with less trouble than any plant I know. The largerflowered sorts require rather more patience-but the main points are to let the rooted cuttings have as much open air and sunshine as possible, to harden their tissues, and to give water with moderation and good judgment, as the softer and more succulent species are easily ruined by over-watering, and should be kept quite dry during the colder months. No one who takes the trouble to understand and to grow these fine plants well will have reason to be disappointed in them if they choose the right sorts.

All kinds of Mammillarias and Echinocacti present features of interest, though it sometimes lies more particularly in their 
curious forms and in the colour and diversity of their prickly spines than in their flowers. The pretty little Texan M. lasiacantha is remarkable for the silvery, feather-like tufts which take the place of the sharp spines so characteristic of these singular Cacti.

In summering succulent plants in pots of all kinds out of doors, it is well to raise them well above the ground level, out of the way of slugs and snails, which are exceedingly fond of browsing upon their juicy stems and leaves, causing much disfigurement which cannot afterwards be remedied. A platform of some kind, however temporary, with a hard surface, as of slates, for the pots to stand on, is very much to be recommended. Mesembryanthemums more particularly fill their pots with roots very quickly, and should never be allowed to strike through the drainage-holes into the soil. Even on a hard standing-place the pots should be moved pretty often, as it tends to check over-luxuriance of growth, which not only makes them tender but hinders abundant flowering. A very sharp, gritty soil suits most succulent plants, though it is not unusual to find that, in fear of feeding this class of plant too much, growers run into the other extreme of starving them.

A large proportion of Cacti and plants of like nature are tolerably hardy. As to that, one must be guided in the choice of kinds suitable for an unheated greenhouse by a knowledge of their native habitats. Most plants from Cape Colony are subjected at times to somewhat severe frost, especially at high altitudes, and in Colorado and elsewhere in the New World where Cacti abound, they are often under snow for weeks together. What they cannot 'stand, however, is superabundance of damp in winter, either in soil or atmosphere, and drip is fatal, especially when followed by severe frost. Dry cold is not particularly injurious, but these very accommodating plants may be placed almost anywhere for safety in severe weather-in a bay-window or on a vacant 
shelf, or even, under great stress of circumstances, in a cupboard, so that they cannot be said to be very exacting in their necessities.

It is seldom that any attempt is made to group plants of this somewhat stiff character, but in a house with removable lights, such as has been elsewhere suggested, a very charming rock-garden might be made with succulent plants alone, especially if it were lofty enough to include some of the hardier Dracænas, like D. australis and D. indivisa, and such graceful subjects as Furcræas, though this would be on an ambitious scale and out of ordinary reach. Such a house would be more interesting and ornamental than the usual monotonous rows of Cacti in pots; and more than one amateur has already adopted the plan with success. Of all plants, those of a succulent nature should be grown by themselves under the conditions which suit them, because those conditions are usually detrimental to other classes of vegetation. Given complete dryness in winter when the temperature is low, and as much sun and air as possible for the rest of the year, with sufficient moisture during the growing season, their wants are few compared to the amount of interest and pleasure they will bestow upon any grower who cares to study the immense diversity in their forms and to encourage them to develop the singular beauty of their flowers. 


\section{CHAPTER XIX}

\section{THE POTTING-SHED. SUMMER QUARTERS}

Some sort of potting-shed is essential to the gardener's comfort, with a bench of suitable height at which he can work and wide enough to hold his pots, his heap of potting-soil, and his necessary tools.

For pot plants, it is usual to mix a compost according to their different requirements, for which the ordinary garden soil may be the foundation, though it is seldom satisfactory without additions. The very best preparation that can be made for potting-soil is to form a little stack by saving parings and odd pieces of turf wherever it can be procured-if from an old pasture so much the better-and turning the slabs grassdownwards to decay. In process of time this will become the basis of excellent soil for all potting purposes; and should be used in many cases chopped into small pieces or even pulled apart by the hands. A mistake which is made by most novices is to sift their potting-soil, thereby taking from it the best part of its nutriment. It is necessary, sometimes, in delicate seed-sowing to use sifted soil, but otherwise it is scarcely ever of advantage. Besides this turfy loam from the stack, we should be provided with some good sound peat, which is absolutely needful for certain classes of plants. This can be procured in large or small quantities through any local nurseryman. All leaves should be collected every autumn and carefully laid up in a heap to decay, as leaf-mould is a most important factor in lightening and enriching the soil on 
the potting-bench. Lastly there should be a supply of sharp sand, and here a few words may be needed as to its different qualities. The beginner invariably thinks that any kind of sand will answer, but this is far from being the case. Silversand is generally recommended, and answers fairly well, but for the most part it is too fine, nor is it always easy to obtain. If it be possible, therefore, to procure locally a coarser quality, more of the character of finely crushed granite or quartz, it is very much to be preferred. The coarse grit used by builders will generally do equally well for potting purposes, but builders do not always trouble themselves to get the best for their own use. Sea-sand, thoroughly washed from salt, may also be used where it can be easily obtained. But the fine sand of the green-sandstone formation, or indeed any of soft earthy texture, is positively injurious to pot plants, clogging the soil instead of making it free and open. In some districts, especially where flints abound, road-grit is the very best that can be procured for the purpose. The use of sand, be it remembered, is merely mechanical and not nutritive; nevertheless it is indispensable, as it assists drainage and keeps the soil permeable and sweet. A bag of charcoal is another addition to the potting-shed which should not be omitted. It is most useful as drainage, being much lighter than the potsheards in common use, while at the same time, it supplies a fund of nourishment to the growing roots. Pounded very small, it may be mixed with potting-soil to the great benefit of most plants, including Ferns, and especially for such as do not require re-potting every year. Where bulbs are grown in water, as they not infrequently are, a piece of charcoal dropped into it keeps the water fresh and pure. It is also a help to those cuttings-and there are many such-which it is convenient to root in water. With regard to drainage, an inch or more of broken sheards should be placed over the hole at the bottom of every pot-a single piece not being sufficient, as is too often 
supposed-and this may with advantage be supplemented by a layer of dead leaves or moss, which prevents the rubble from becoming choked. In potting, the soil should be made very firm, and a wooden rammer, which may be either round or flat, is a very useful tool to keep at hand, though the "potter's thumb" is an implement no more to be dispensed with in gardening than in the moulding of pottery. Loose potting is the mark of an inexperienced hand, and very few plants succeed under such a system-for one reason because water runs through the loose soil too quickly, draining away the nutritive particles, while insufficient moisture is left behind to sustain the roots. Besides this, however, the fibres evidently like to feel the resistance of the firm earth as they push their way into it.

Not many tools are necessary. Besides the rammer aforesaid, we must be provided with a strong, sharp knife for cuttings, a budding-knife and a pair of scissors, but one tool may be suggested which is not often used by gardeners. This is the smallest size of mason's trowel, with the sharp point rounded off, which will be found much more handy than the ordinary scoop-trowel for the work of potting. A skein of Raffia should also have its appointed hook in the potting-shed, to be ready for all tying purposes. A few bundles of wooden labels of different sizes should be at hand, as well as a pot of white paint, for a dash of this on the broad end of the label, wiped off with a bit of rag until the merest film remains, is the best preparation for legible writing.

\section{SUMMER QUARTERS}

The mention of summer quarters occurs very frequently in the preceding pages, and a properly arranged position where pot plants out of flower can be placed and cared for during their period of rest is one of the most important considera- 
tions for any possessor of a greenhouse. A bed of cocoa-nut fibre, or even ashes, under a north wall is a good situation for some plants. Others, again, require a more open, sunny position, that they may get their wood well ripened to ensure the next year's flowering. Therefore it is well to choose sites in both aspects. A cold frame with a brick or concrete floor, safe from garden vermin, and facing south, is admirable for Cacti and such like plants which enjoy summer rains as well as summer sunshine, and the lights can be entirely removed for two or three months with great benefit. Similar quarters will suit Cape bulbs at rest, such as Freesias, Nerines, and Lachenalias, but in their case the lights must be left on, as it is essential that they be kept absolutely dry and baked during the weeks which intervene between the fading of the leaf and potting-time, which comes in most cases about the end of July and during August. Cold frames are useful, besides, in a hundred different ways. In addition to these plunging-beds and wooden or brick frames, there should always be a reserve space, generally to be found in the kitchen garden, where certain plants and bulbs may be planted out to recruit after a season of flowering under glass. This is always a weakening process, though much less so in an unheated greenhouse than when stronger forcing is in practice: still, most plants are benefited by a term of free growth in the open air. Some may be lifted every autumn, and can be trusted to do their duty well, but others require to be treated on the alternate system, flowering one year and resting the next; while in the case of bulbs, if we wish to raise our own stock, a longer rotation will be necessary.

The treatment of pot plants at rest is a part of gardening sadly set aside by the average amateur. The professional gardener knows too well how much his future success depends upon the care then given to neglect it. It is true that it is not always easy to provide all the accommodation that is most 
suitable, but it behoves every grower to make the best preparation in his power for this purpose, remembering always that the greenhouse itself is far from being the fittest place in which pot plants, for the most part, can recruit their spent strength and make ready for the next season's campaign.

All the above may seem to be trifling and unimportant details, scarcely worth insising upon, for they come naturally, as it were, to old gardeners; but it is a great help to a beginner to be put on the right path from the outset, as every one will bear witness who has gone through the helpless stage of floundering in and out of initial difficulties. 


\section{CHAPTER XX}

\section{ROUTINE WORK}

THE amateur gardener who is content to supply his greenhouse with pot plants from a nursery, even though he be willing to take some care of them when flowering is over, loses a vast deal of enjoyment. The different processes of seed-raising, of propagation by cuttings by various methods, of the training and pruning of growing plants, are full of interest, and give great zest to the occupation, which then becomes a real recreation of the best type-which consists in a change of work. To have nursed a seedling one's self, through all its different stages, into a vigorous flowering plant, gives a satisfaction which the finest effort of the nurseryman will never bestow upon a mere purchaser.

A very simple form of Wardian-case and a set of bellglasses of various sizes are of the greatest assistance in raising plants either from seed or from cuttings. The case which I have long had in use was originally made with a water-tank to be heated by a lamp burning beneath it, but any artificial heating was dispensed with years ago. All that is needed is a removable zinc tray, about 2 in. deep, to hold a layer of damp sand on which the pots can stand. It is, in fact, a mere glass-box with a sloping lid, standing on legs of a convenient height, which may be made by any one who is capable of handling carpentering tools. This most useful piece of furniture can generally find a place in some unoccupied corner of a greenhouse-preferably, of 
course, in a working greenhouse, as it is not ornamental-and is then always ready to take in a pot of cuttings or of seed, and is invaluable all the year round. Seed-sowing is not merely a springtide occupation. In almost every case seeds vegetate more surely and freely when they are sown as soon as ripe, though some are benefited by a short time of waiting to harden and consolidate. The seeds of Primulas, Anemones, Gentians, and many other plants will germinate at once if sown as soon as they are gathered, but if they are held over till the spring a few may come up, but it is quite possible that there may be no crop of seedlings until the following year-not because the seed is bad, but because the vitality is in some degree lowered. For this reason, it is not wise to discard any pan containing valuable seed, without giving it the chance of germinating the following year. This may seem a formidable trial of patience, but I have done it many times and with success. Seeds should, therefore, be not only collected, but sown, as soon as they are fit. Another point to rememiber is that seeds can scarcely be sown too thinly. It is much better to have a few strong plants than dozens of spindlings elbowing themselves out of the seed-pan and driving the raiser distracted trom inability to .cope with them. Nature is prodigal in the matter of seed-sowing, but she thoroughly understands the principle of the survival of the fittest, and prepares for it in her seemingly rough and ready way. Under cultivation, lavishness of this kind is mere waste of life. Nothing is more fascinating than to watch the germination and progress of seedlings, from the unfolding of the cotyledons, through the processes of prickingout and shifting into pots of graduated size, until, after due education in the way of training and trimming into shape, they grow into fine specimen plants. The same may be said of cuttings. The little slip that one begs of a kindly neighbour and which responds to care by rooting and 
thriving gives an infinity of pleasure by association and by pride of skill. It is here that the bell-glasses come in as valuable auxiliaries. A cutting has twice the chance of striking if it be kept "close," as it is then sheltered from trying variations of temperature, for its well-doing depends largely on the leaves never losing their freshness and remaining as far as may be in workable order. It may-possiblyrecover if put in water to revive after it has become limp, and do well, but it is safer far, seeing that its leaves are its lungs, never to let a cutting flag, so that there may be no interference with the work of forming a callus. This term is applied to the granulation of the tissues at the base of the cutting, and shows that healthy action is going on, which will soon be followed by roots. As a rule, a cutting will root much more rapidly under a bell-glass, but the close treatment does not answer in every case. A pelargonium, for example, roots much more freely in full exposure to sun and light, and would suffer from the damp still air of the bell-glass. It is very necessary, in all cases, to lift the glasses at least once a day to wipe off the condensed moisture within them, otherwise the cuttings are apt to "damp off." It is difficult to give any very definite rules as to the uses of bell-glasses. Failure is probably due, when it occurs, to the cuttings being in an unfit state to strike, but they are, when properly used, indispensable additions to the amateur's garden outfit. It is well always to remember the old garden adage that "In spring you may bid your cutting to grow, but in autumn it must be asked."

The training and pruning of pot plants are arts which must be learnt by practice. The amateur seldom has courage to use the knife as much as he should, but the beauty and symmetry of most plants depend upon the treatment they receive on this point. Many kinds, both of seedlings and cuttings, have to be pinched back at an early stage to induce 
bushy growth, otherwise they may run up with a bare unsightly stem. If they are allowed to go ahead at their own sweet will, it is a difficult matter to bring them back, later on, into good shape. The time at which pruning is done is also of great importance. Too often the cutting back of a plant or shrub is neglected at the right moment-then, in a fit of energy and ignorance, we set to work and find, too late, that we have diligently cut away every hope of flowers for the coming season. Deutzias flower on the young wood, and any cutting away that is needed of the old branches should be done immediately after flowering. Clematises may be taken as another familiar example. The purple C. Jackmani flowers in the autumn on the new growth of the current year, and requires pruning back during winter before the shoots begin to break. C. montana, as well as those of the large earlier-flowering type (like C. lanuginosa), bloom, on the contrary, on the wood of the last season, and merely need thinning out, or must be cut back very sparingly when flowering is over. The same rule applies to the charming, half-hardy New Zealand species, C. indivisa. Many of the fine hybrid forms of Clematis succeed well, not as climbers, but in small pots, and are particularly well adapted for an unheated greenhouse.

Roses on their own roots of the less vigorous type, such as Catherine Mermet, are often sufficiently pruned by cutting their flowers with a tolerably long stem, whereas strongergrowers are the better for harder cutting back. A few shrubs, like Brugmansia and Desmodium, will bear cutting down to the ground level after flowering, and succeed all the better for such drastic treatment. 


\section{WATERING}

is one of the most critical operations of greenhouse work, requiring both knowledge and judgment. The plan of going round with a watering-pot and giving a driblet to every plant, whether it wants it or not, is most injurious. Many a time it happens when leaves are noticed to be flagging that more water is given, when in reality the soil is saturated and the plant is already suffering from over-doses which it has not the power to assimilate. In potting, sufficient space should be allowed below the rim of the pot to hold water. In hot, dry weather this space may have to be filled up two, or even three, times, in order that the soil may be thoroughly moistened-especially when the potting has been as firm as it should be-after which it will probably need no more for a day or two. Arums, being water-plants, are all the better for standing in a pan of water during growth, and a drop hanging from the point of the leaf is a sign of perfect health. Heaths, though they must never once be allowed to become dust-dry, will not bear sodden, water-logged soil, which will decay the fine root-fibres, and it is a matter of experience to keep the happy mean. Succulent plants, on the other hand, must be kept dry rather than moist, and in winter, as a general rule, require no water at all, unless they show signs of distress by becoming shrivelled. Almost all plants, however, during their growing season, will take ample supplies, because it must be remembered that all food reaches them in liquid form. When active growth begins to lessen and life shows signs of ebbing, it is better gradually to withhold water. Bulbs, especially those which lose their leaves, require a season of complete rest, and usually have to be kept dry. Cape bulbs, like Nerines and some others, as before, said, enjoy a few weeks of roasting on a sunny shelf or frame-the pots being turned on their sides, 
the more surely to be safe from drip-and bloom all the better for it. Scarborough Lilies (Vallota purpurea), on the contrary, being more or less evergreen, must be kept growing all the year round. The drying-off system, though admirable in many cases, does not always answer-a fact which has been proved with regard to Cyclamens, which formerly used to be so treated. I had a fine Persian Cyclamen for many years, treasured in memory of a friend, which literally gave hundreds of flowers every season. The corm was re-potted immediately after the blooming was over, and the pot sunk in a bed of hotbed refuse prepared for plants which were benefited by such treatment and kept watered. The old leaves soon disappeared, new ones taking their place almost at once, and nothing could have been more satisfactory than the result. When I see it stated, as I often do, that two-year-old corms of Cyclamen are of little value, fit only for the rubbish-heap, I call to mind my ancient comrade who fought the battle of life for many years so bravely, and sigh to think of the waste of good plants which, with a little care, might give delight to many who cannot afford the luxury of buying them.

A brass syringe is a very useful help in watering - a shower overhead being both refreshing and cleansing to most plants, and a terror to red spider. Ferns, however, and more particularly Maidenhairs, though they love a damp atmosphere about them, are not improved by having their fronds wetted. In truth, there is scarcely any part of greenhouse work which has to be learnt by experience so much as watering. Yet, oddly enough, in the absence of the rightful owner the watering-pot is generally entrusted with a light heart to any one willing to undertake the office of using it, without a thought of Nemesis.

A word may here be said on the use of Insecticides. In an unheated greenhouse there should be little occasion for such applications. Blight of all kinds, especially mealy-bug and 
scale, naturally grow apace in the warmth and close atmosphere of the hot-house, but ought never to be found where there is no artificial heat. Green fly and thrips are sometimes troublesome, but a very little watchfulness and attention will suffice to keep them under, and prevention is better than cure. In a small greenhouse, a basin with a decoction of quassia-chips, or even of plain water, and a small paint-brush always at hand in use will keep the enemy at bay. On a larger scale, fumigation occasionally will be necessary. When plants are growing vigorously, there is little to fear from insect pests, and towards this desirable end some kind of artificial manure or plant food is often a great help, such as bone meal-in certain cases to be mixed with the soil in potting-or one of the many specialities advertised for the purpose. Soot-water, made by putting a coarse canvas bag containing a peck of soot into a barrel of rain-water and letting it stand, after an occasional stir, until the liquid is of the colour of strong tea and quite clear from sediment, is one of the most valuable of fertilisers that can be used, and may be safely given to Ferns as well as to flowering plants. It should be diluted with rain-water when used, and given twice a week during the growing-and flowering-period-a much better plan than administering a strong dose haphazard. Stimulants of all kinds must naturally be discontinued when plants are at rest.

A garden-book in which entries are regularly made of plants received and from whence they come, with accurate dates of seeds sown and of their germination, with all other details of the kind which may strike the cultivator as being noteworthy, helps to lift the routine of greenhouse work out of the rut of mere commonplace, and makes it at once more systematic and scientific. Such a record faithfully kept, besides adding tenfold to our interest, increases in value year by year, and can confidently be 
appealed to for the settlement of doubtful questions which continually crop up.

It is a happy thing to have a working greenhouse of our very own where we may find occupation, not in desultory fashion, but with method and intent, and even make mistakes at our own sweet will. In doing so we learn by experiment the intricacies and the art as well as the delights of plantmanagement, which neither gardener nor printed book can teach so well as the practice of our own hands-so true is it that one grain of experience is worth a whole bushel of theory.

The unheated greenhouse has a future before it full of possibilities, while on its experimental side there is a vast amount yet for the most skilful to learn. On a large scale, it is worthy of a palace, but like all other phases of garden-work it belongs to no class and adapts itself to every home, bringing beauty and solace as much into leisured as into toiling lives as scarcely any other recreative occupation can. The trend of modern out-door gardening is towards broad effects, grand vistas, spreading lawns, and cascades of roses-in short, towards all the garden luxury which lies within the scope of ample space and riches at command-delightful beyond words for those who can indulge in them. The unheated greenhouse, while it appeals to these, for it may take on noblest proportions, appeals first and foremost to the plant votary of another calibre and to a different sense. It is within the compass, if need be, of moderate means and moderate powers of health and strength, providing a calm and restful, yet sufficiently absorbing, recreation at all times from the arduous duties, or, it may be, labours of life, whereby the simplest home and family festival may be glorified-or the hours of harass and sorrow mitigated and soothed, while the tension of anxious care is relaxed. 
The earnest wish of my heart will be fulfilled if these practical hints, slightly, but not, I hope, carelessly, strung together, may awaken greater interest in a branch of garden-work which, for some special reasons, is beyond all others suited to rest the weary brain without over-taxing a not too robust physique. 

APPENDIX 
In offering the following lists it may be well to state that the different classes of plants are arranged under distinct heads no less for the sake of clearness than with intention from a cultural point of view. In starting work in an unheated greenhouse it is desirable that the amateur gardener should choose one or, at most, two of the classes named, according to individual taste, making a specialty, for example, of roses or bulbs or alpines, as the case may be, rather than that he should attempt to grow a miscellaneous selection in which each separate plant requires a different treatment.

The subjoined lists make no claim to be descriptive, but simply supply practical hints from past experience as to the treatment of the plants named, which it is hoped may be helpful. 


\section{A SELECTION OF PLANTS SUITABLE FOR FLOWERING IN AN ALPINE HOUSE FROM JANUARY TO MAY}

Many Alpines admirable for the Rock Garden are purposely omitted from this list as unsuitable for various reasons, whilst some are named which are equally available for an ordinary unheated greenhouse. These are marked with an asterisk*.

\begin{tabular}{|c|c|c|c|c|}
\hline Name. & $\begin{array}{l}\text { Height and } \\
\text { Colour. }\end{array}$ & $\begin{array}{l}\text { Country and } \\
\text { Season under } \\
\text { Glass. }\end{array}$ & Soil. & General Remarks. \\
\hline $\begin{array}{l}\text { *Adonis amu- } \\
\text { rensis }\end{array}$ & $\begin{array}{l}\text { 6-12 ins. } \\
\text { Yellow }\end{array}$ & $\begin{array}{l}\text { N. China } \\
\text { Jan.-Feb. }\end{array}$ & $\begin{array}{l}\text { Rich } \\
\text { sandy } \\
\text { loam }\end{array}$ & $\begin{array}{l}\text { Ranunculaceæ. Much ear- } \\
\text { lier than A. vernalis, } \\
\text { which it somewhat re- } \\
\text { sembles. The Japanese } \\
\text { have taken this plant in } \\
\text { hand, and by hybridis- } \\
\text { ing have obtained many } \\
\text { finely-coloured varieties, } \\
\text { which will probably soon } \\
\text { find their way into our } \\
\text { gardens. }\end{array}$ \\
\hline $\begin{array}{l}\text { Anemone apen- } \\
\text { nina }\end{array}$ & $\begin{array}{l}6 \text { ins. } \\
\text { Lavender } \\
\text {-blue }\end{array}$ & $\begin{array}{l}\text { Italy } \\
\text { March }\end{array}$ & $\begin{array}{l}\text { Loam } \\
\text { and leaf- } \\
\text { mould }\end{array}$ & $\begin{array}{l}\text { Ranunculaceæ. Apennine } \\
\text { Wood-anemone. }\end{array}$ \\
\hline blanda & $\begin{array}{l}6 \text { ins. } \\
\text { Deep- } \\
\text { blue }\end{array}$ & $\begin{array}{l}\text { Greece } \\
\text { Jan.-Feb. }\end{array}$ & ", & $\begin{array}{l}\text { The earliest form of Wood- } \\
\text { anemone. A. bl. Scy- } \\
\text { thinica is a pure white } \\
\text { variety. }\end{array}$ \\
\hline$*_{\text {fulgens }}$ & $\begin{array}{l}9 \text { ins. } \\
\text { Scarlet }\end{array}$ & $\begin{array}{l}\text { S. Europe } \\
\text { Feb.-Mar. }\end{array}$ & $\begin{array}{c}\text { Loam } \\
\text { and a } \\
\text { little lime }\end{array}$ & $\begin{array}{l}\text { Almost all alpine anemones } \\
\text { are beautiful, and may be } \\
\text { grown with success for }\end{array}$ \\
\hline $\begin{array}{l}\text { Pulsatilla } \\
\text { (Pasque flower) }\end{array}$ & $6-9$ ins. & $\begin{array}{l}\text { N. Europe } \\
\text { Mar.-Apr. }\end{array}$ & ", & $\begin{array}{l}\text { the Alpine house, but the } \\
\text { four species mentioned } \\
\text { are the most generally } \\
\text { satisfactory for pots in } \\
\text { early Spring. }\end{array}$ \\
\hline
\end{tabular}




\begin{tabular}{|c|c|c|c|c|}
\hline Name. & $\begin{array}{l}\text { Height and } \\
\text { Colour. }\end{array}$ & $\begin{array}{c}\text { Country and } \\
\text { Season under } \\
\text { Glass. }\end{array}$ & Soil. & General Remarks. \\
\hline $\begin{array}{l}\text { Androsace Lag- } \\
\text { geri } \\
\text { sarmentosa }\end{array}$ & $\begin{array}{l}3 \text { ins. } \\
\text { Pink } \\
\text { 4-6 ins. } \\
\text { Rose }\end{array}$ & $\begin{array}{l}\text { Pyrenees } \\
\text { March } \\
\text { Himalayas } \\
\text { Apl.-May }\end{array}$ & $\begin{array}{c}\text { Sandy } \\
\text { peat and } \\
\text { loam with } \\
\text { leaf- } \\
\text { mould }\end{array}$ & $\begin{array}{l}\text { Primulacex. Many other } \\
\text { species besides the two } \\
\text { named of these delicate } \\
\text { alpine plants are grown } \\
\text { in pans and flower well in } \\
\text { the Alpine house at Kew. } \\
\text { Wedge between small } \\
\text { pieces of stone. }\end{array}$ \\
\hline $\begin{array}{l}\text { Arabis albida fl. } \\
\text { pl. (White } \\
\text { Rock-cress) }\end{array}$ & $\begin{array}{l}\text { 4-6 ins. } \\
\text { White }\end{array}$ & $\begin{array}{l}\text { Hort. var. } \\
\text { March }\end{array}$ & $\begin{array}{l}\text { Ordinary } \\
\text { loam }\end{array}$ & $\begin{array}{l}\text { Cruciferæ. A handsome } \\
\text { double form of the well- } \\
\text { known white Rock-cress. } \\
\text { New and good. }\end{array}$ \\
\hline $\begin{array}{l}\text { Aubrietia del- } \\
\text { toidea (Purple } \\
\text { Rock-cress) }\end{array}$ & $\begin{array}{l}3-6 \text { ins. } \\
\text { Lilac- } \\
\text { purple }\end{array}$ & $\begin{array}{l}\text { S. Europe } \\
\text { Mar.-May }\end{array}$ & $\begin{array}{l}\text { Sandy } \\
\text { loam }\end{array}$ & $\begin{array}{l}\text { Cruciferæ. Many fine } \\
\text { garden varieties of Au- } \\
\text { bretia have been raised } \\
\text { of late years, varying } \\
\text { much in tones of colour } \\
\text { from pale purple to al- } \\
\text { most crimson. }\end{array}$ \\
\hline $\begin{array}{l}\text { Bongardia Rau- } \\
\text { wolfii }\end{array}$ & $\begin{array}{l}6 \text { ins. } \\
\text { Golden } \\
\text { yellow }\end{array}$ & $\begin{array}{l}\text { Persia } \\
\text { April }\end{array}$ & $\begin{array}{l}\text { Sandy } \\
\text { peat and } \\
\text { leaf- } \\
\text { mould }\end{array}$ & $\begin{array}{l}\text { Berberideæ. An interest- } \\
\text { ing and pretty plant, apt } \\
\text { to perish from damp when } \\
\text { grown without protection. }\end{array}$ \\
\hline $\begin{array}{l}\text { *Cardamine } \\
\text { rhomboidea } \\
\text { purpurea fl. pl. } \\
\text { (Double Cuck- } \\
\text { oo-flower) }\end{array}$ & $\begin{array}{l}\text { 4-6 ins. } \\
\text { Lilac- } \\
\text { purple }\end{array}$ & $\begin{array}{l}\text { U.S.A. } \\
\text { March }\end{array}$ & $\begin{array}{l}\text { Moist } \\
\text { loam and } \\
\text { leaf soil }\end{array}$ & $\begin{array}{l}\text { Cruciferæ. A desirable } \\
\text { little plant, bright in } \\
\text { flower and easily man- } \\
\text { aged. Plant in reserve- } \\
\text { bed in summer. }\end{array}$ \\
\hline $\begin{array}{l}\text { * Conandron ra- } \\
\text { mondioides }\end{array}$ & $\begin{array}{l}6 \text { ins. } \\
\text { Pink to } \\
\text { purple }\end{array}$ & $\begin{array}{l}\text { Japan } \\
\text { May }\end{array}$ & $\begin{array}{l}\text { Sandy } \\
\text { peat }\end{array}$ & $\begin{array}{l}\text { Gesneraceæ. A remark- } \\
\text { ableand interesting plant, } \\
\text { allied to Ramondia and } \\
\text { Haberlea. Introduced in } \\
\text { I } 879 .\end{array}$ \\
\hline $\begin{array}{l}\text { Dodecatheon } \\
\text { Media (Ameri- } \\
\text { can Cowslip) }\end{array}$ & $\begin{array}{l}\text { 8-Io ins. } \\
\text { Purple, } \\
\text { lilac, or } \\
\text { white }\end{array}$ & $\begin{array}{l}\text { N. Ameri- } \\
\text { ca } \\
\text { April }\end{array}$ & $\begin{array}{l}\text { Moist } \\
\text { loam and } \\
\text { leaf-soil }\end{array}$ & $\begin{array}{l}\text { Primulaceæ. Slender } \\
\text { stems with umbels of } \\
\text { pointed flowers with } \\
\text { petals turned back. Dis- } \\
\text { tinct and pretty. There } \\
\text { are several good species } \\
\text { and varieties. } \\
\text { loving. }\end{array}$ \\
\hline $\begin{array}{l}\text { * Epimedium al- } \\
\text { pinum }\end{array}$ & $\begin{array}{l}6 \text { ins. } \\
\text { Crimson } \\
\text { and } \\
\text { yellow }\end{array}$ & $\begin{array}{l}\text { Cent. } \\
\text { Europe } \\
\text { March }\end{array}$ & $\begin{array}{c}\text { Peat and } \\
\text { loam }\end{array}$ & $\begin{array}{l}\text { Berberideæ. All the Epi- } \\
\text { mediums are elegant both } \\
\text { in flower and leafage, } \\
\text { and as foliage plants }\end{array}$ \\
\hline
\end{tabular}




\begin{tabular}{|c|c|c|c|c|}
\hline Name. & $\begin{array}{l}\text { Height and } \\
\text { Colour. }\end{array}$ & $\begin{array}{l}\text { Country and } \\
\text { Season under } \\
\text { Glass. }\end{array}$ & Soil. & General Remarks. \\
\hline $\begin{array}{l}\text { *alpinum ru- } \\
\text { brum }\end{array}$ & Foliage & $\underset{\text { Mar.-Apl. }}{\text { Japan }}$ & $\begin{array}{l}\text { Peat and } \\
\text { loam }\end{array}$ & $\begin{array}{l}\text { alone form a distinct } \\
\text { feature in an alpine house. }\end{array}$ \\
\hline *macranthum & $\begin{array}{l}\text { I0-1 } 2 \text { ins. } \\
\text { White }\end{array}$ & $\begin{array}{l}\text { Japan } \\
\text { April }\end{array}$ & ," & \\
\hline *pinnatum & 1 2-I 5 ins. & $\begin{array}{c}\text { Persia } \\
\text { Apl.-May }\end{array}$ & " & \\
\hline $\begin{array}{l}\text { Erysimum alpi- } \\
\text { num (Alpine } \\
\text { Wall-flower) }\end{array}$ & $\begin{array}{l}6 \text { ins. } \\
\text { Sulphur- } \\
\text { yellow }\end{array}$ & $\begin{array}{l}\text { Norway } \\
\text { April and } \\
\text { May }\end{array}$ & $\begin{array}{l}\text { Ordinary } \\
\text { loam }\end{array}$ & $\begin{array}{l}\text { Cruciferæ }=\text { Cheiranthus } \\
\text { alpinus. A well-known } \\
\text { plant. }\end{array}$ \\
\hline $\begin{array}{r}\text { Galax aphylla } \\
\text { (Wand Plant) }\end{array}$ & $\begin{array}{l}\text { 3-6 ins. } \\
\text { White }\end{array}$ & $\begin{array}{l}\text { N. Ameri- } \\
\text { ca } \\
\text { May }\end{array}$ & $\begin{array}{l}\text { Moist } \\
\text { peat and } \\
\text { leaf-soil }\end{array}$ & $\begin{array}{l}\text { Diapensiacer. Chiefly re- } \\
\text { markable for its beautiful } \\
\text { red shining leaves during } \\
\text { winter. Difficult to grow } \\
\text { well. }\end{array}$ \\
\hline $\begin{array}{l}\text { *Gentiana acau- } \\
\text { lis (Gentianella) }\end{array}$ & $\begin{array}{l}2-4 \text { ins. } \\
\text { Deep } \\
\text { blue }\end{array}$ & $\begin{array}{l}\text { European } \\
\text { Alps } \\
\text { Mar.-Apl. }\end{array}$ & $\begin{array}{l}\text { Moist } \\
\text { loam and } \\
\text { leaf-soil }\end{array}$ & $\begin{array}{l}\text { Gentianex. Like the last- } \\
\text { named, these can be } \\
\text { grown in pans kept moist } \\
\text { and cool out of doors }\end{array}$ \\
\hline verna & $\begin{array}{l}\text { I-3 ins. } \\
\text { Bright } \\
\text { blue }\end{array}$ & $\begin{array}{l}\text { April and } \\
\text { May }\end{array}$ & $\begin{array}{l}\text { Boggy } \\
\text { peat and } \\
\text { leaf-soil }\end{array}$ & $\begin{array}{l}\text { during summer. Gen- } \\
\text { tians succeed best when } \\
\text { raised from seed sown as } \\
\text { soon as ripe and disturbed } \\
\text { as little as possible after- } \\
\text { wards except for an occa- } \\
\text { top-dressing. }\end{array}$ \\
\hline $\begin{array}{ll}\text { Geranium } & \text { ro- } \\
\text { bertianum } & \text { al- } \\
\text { bum } & \end{array}$ & $\begin{array}{l}\text { 6-9 ins. } \\
\text { White }\end{array}$ & $\begin{array}{l}\text { Britain } \\
\text { Mar.-May }\end{array}$ & $\begin{array}{c}\text { Ordinary } \\
\text { loam }\end{array}$ & $\begin{array}{l}\text { Geraniaceæ. Though only } \\
\text { a form of a common Eng- } \\
\text { lish wilding, this white- } \\
\text { flowered Crane's bill may } \\
\text { be grown into an ex- } \\
\text { tremely elegant plant. }\end{array}$ \\
\hline $\begin{array}{l}\text { Haberlea rhodo- } \\
\text { pensis }\end{array}$ & $\begin{array}{l}\text { 4-6 ins. } \\
\text { Lilac }\end{array}$ & $\begin{array}{l}\text { Roumelia } \\
\text { Mar.-Apl. }\end{array}$ & $\begin{array}{l}\text { Sandy } \\
\text { peat and } \\
\text { leaf-soil }\end{array}$ & $\begin{array}{l}\text { Gesneraceæ. Somewhat } \\
\text { like a miniature gloxinia } \\
\text { with the habit of Ramon- } \\
\text { dia. Plant in a deep pot } \\
\text { with a cleft at the side, } \\
\text { wedging the roots be- } \\
\text { tween stones, so that it } \\
\text { may grow in a vertical } \\
\text { position against the side. }\end{array}$ \\
\hline $\begin{array}{l}\text { Houstonia cœ- } \\
\text { rulea (Bluets) }\end{array}$ & $\begin{array}{l}3-4 \text { ins. } \\
\text { Blue or } \\
\text { white }\end{array}$ & $\begin{array}{l}\text { Virginia } \\
\text { April and } \\
\text { May }\end{array}$ & $\begin{array}{l}\text { Sandy } \\
\text { peat }\end{array}$ & $\begin{array}{l}\text { Rubiaceæ. Forms dense } \\
\text { tufts crowded with flow- } \\
\text { ers, and may be used for } \\
\text { surfacing pots in which } \\
\text { tall bare-stemmed plants } \\
\text { are growing. }\end{array}$ \\
\hline
\end{tabular}




\begin{tabular}{|c|c|c|c|c|}
\hline Name. & $\begin{array}{l}\text { Height and } \\
\text { Colour. }\end{array}$ & $\begin{array}{l}\text { Country and } \\
\text { Season under } \\
\text { Glass. }\end{array}$ & Soil. & General Remarks. \\
\hline $\begin{array}{l}\text { Ionopsidium a- } \\
\text { caule (Violet } \\
\text { Cress) }\end{array}$ & $\begin{array}{l}2 \text { ins. } \\
\text { Lilac }\end{array}$ & $\begin{array}{l}\text { Portugal } \\
\text { Feb.-May }\end{array}$ & $\begin{array}{l}\text { Ordinary } \\
\text { loam }\end{array}$ & $\begin{array}{l}\text { Cruciferæ. A useful little } \\
\text { annual for many purposes } \\
\text { and may be had in flower } \\
\text { at any season from suc- } \\
\text { cessive sowings. Sows } \\
\text { itself freely. }\end{array}$ \\
\hline $\begin{array}{l}\text { Isopyrum tha- } \\
\text { lictroides }\end{array}$ & $\begin{array}{l}\text { 9-1 } 2 \text { ins. } \\
\text { White }\end{array}$ & $\begin{array}{c}\text { Europe } \\
\text { Mar.-Apl. }\end{array}$ & $\begin{array}{l}\text { Sandy } \\
\text { loam }\end{array}$ & $\begin{array}{l}\text { Ranunculaceæ. A grace- } \\
\text { ful little plant, with fo- } \\
\text { liage somewhat like Mai- } \\
\text { denhair fern. }\end{array}$ \\
\hline $\begin{array}{l}\text { Lithospermum } \\
\text { prostratum }\end{array}$ & $\begin{array}{l}3 \text { ins. } \\
\text { Gentian } \\
\text { blue }\end{array}$ & $\begin{array}{l}\text { S. Europe } \\
\text { April }\end{array}$ & $\begin{array}{l}\text { Sandy } \\
\text { loam }\end{array}$ & $\begin{array}{l}\text { Boragineæ. A trailing } \\
\text { evergreen, constantly in } \\
\text { flower and makes a good } \\
\text { pan. }\end{array}$ \\
\hline $\begin{array}{l}\text { Lysimachia cris- } \\
\text { pideus }\end{array}$ & $\begin{array}{l}6-9 \text { ins. } \\
\text { Pink }\end{array}$ & $\begin{array}{l}\text { China } \\
\text { Mar. }\end{array}$ & & $\begin{array}{l}\text { Primulaceæ. A dwarf } \\
\text { branching plant, flower- } \\
\text { ing profusely for a long } \\
\text { time. Of recent intro- } \\
\text { duction. }\end{array}$ \\
\hline $\begin{array}{l}\text { Mertensia al- } \\
\text { pina }\end{array}$ & $\begin{array}{l}\text { 6-1o ins. } \\
\text { Light } \\
\text { blue } \\
\text { Leaves } \\
\text { glaucous }\end{array}$ & $\begin{array}{c}\text { Rocky Mts. } \\
\text { April }\end{array}$ & $\begin{array}{l}\text { Ordinary } \\
\text { loam }\end{array}$ & $\begin{array}{l}\text { Boragineæ. A charming } \\
\text { little alpine. Another } \\
\text { sp., M. primuloides, flow- } \\
\text { ered in Alpine house, } \\
\text { Kew, April and May, } \\
\text { I902. }\end{array}$ \\
\hline $\begin{array}{l}\text { Morisia hypo- } \\
\text { gæa }\end{array}$ & $\begin{array}{l}2-3 \text { ins. } \\
\text { Yellow }\end{array}$ & $\begin{array}{l}\text { Sardinia } \\
\text { Mar. and } \\
\text { April }\end{array}$ & $\begin{array}{l}\text { Damp } \\
\text { sandy } \\
\text { loam }\end{array}$ & $\begin{array}{l}\text { Cruciferæ. A pretty little } \\
\text { plant forgrowing amongst } \\
\text { stones half-sunk in a pan. }\end{array}$ \\
\hline $\begin{array}{l}\text { Myosotis alpes- } \\
\text { tris }\end{array}$ & $\begin{array}{l}2-3 \text { ins. } \\
\text { Bright } \\
\text { blue }\end{array}$ & $\begin{array}{l}\text { Europe } \\
\text { April } \\
\text { and May }\end{array}$ & $\begin{array}{l}\text { Rich } \\
\text { moist } \\
\text { loam }\end{array}$ & $\begin{array}{l}\text { Boragineæ. The Forget- } \\
\text { me-nots make charming } \\
\text { ing pot plants. A garden }\end{array}$ \\
\hline azorica & $\begin{array}{l}4-8 \text { ins. } \\
\text { Deep } \\
\text { blue }\end{array}$ & $\begin{array}{l}\text { Azores } \\
\text { May, }\end{array}$ & $\begin{array}{l}\text { Sandy } \\
\text { loam }\end{array}$ & $\begin{array}{l}\text { form of M. azorica-Im- } \\
\text { pératrice Elizabeth-is } \\
\text { often so grown, making a }\end{array}$ \\
\hline *dissitiflora & $\begin{array}{l}6 \text { ins. } \\
\text { Sky-blue }\end{array}$ & $\begin{array}{l}\text { Switzer- } \\
\text { land } \\
\text { Jan. and } \\
\text { Feb. }\end{array}$ & $\begin{array}{l}\text { Ordinary } \\
\text { light } \\
\text { loam }\end{array}$ & $\begin{array}{l}\text { sturdy little bush of } \\
\text { about } 6 \text { ins. high and } \\
\text { flowering profusely. }\end{array}$ \\
\hline $\begin{array}{l}\text { * Nierembergia } \\
\text { rivularis }\end{array}$ & $\begin{array}{l}\text { Creeping } \\
\text { White }\end{array}$ & $\begin{array}{l}\text { La Plata } \\
\text { May }\end{array}$ & $\begin{array}{l}\text { Moist } \\
\text { sandy } \\
\text { loam and } \\
\text { leaf- } \\
\text { mould }\end{array}$ & $\begin{array}{l}\text { Solanaceæ. A fine trail- } \\
\text { ing plant when well } \\
\text { grown, rooting at the } \\
\text { joints. Large white } \\
\text { flowers. }\end{array}$ \\
\hline
\end{tabular}




\begin{tabular}{|c|c|c|c|c|}
\hline Name. & $\begin{array}{l}\text { Height and } \\
\text { Colour. }\end{array}$ & $\begin{array}{l}\text { Country and } \\
\text { Season under } \\
\text { Glass. }\end{array}$ & Soil. & Genera Remarks. \\
\hline $\begin{array}{l}\text { Omphalodes Lu- } \\
\text { ciliæ }\end{array}$ & $\begin{array}{l}\text { 4-6 ins. } \\
\text { Lilac- } \\
\text { blue } \\
\text { Leaves } \\
\text { glaucous }\end{array}$ & $\begin{array}{l}\text { Greece } \\
\text { April and } \\
\text { May }\end{array}$ & $\begin{array}{l}\text { Sandy } \\
\text { loam }\end{array}$ & $\begin{array}{l}\text { Boragineæ. A very lovely } \\
\text { mountain plant. }\end{array}$ \\
\hline $\begin{array}{l}\text { Onosma albo- } \\
\text { roseum } \\
\text { echioides (Gol- } \\
\text { den Drop) } \\
\text { stellulatum } \\
\text { tauricum }\end{array}$ & $\begin{array}{l}3-6 \text { ins. } \\
\text { White } \\
\text { and rose } \\
4-6 \text { ins. } \\
\text { Yellow } \\
6 \text {-1o ins. } \\
\text { yellow or } \\
\text { white }\end{array}$ & $\begin{array}{l}\text { Asia } \\
\text { minor } \\
\text { April } \\
\text { S. Europe } \\
\text { April } \\
\text { Caucasus } \\
\text { May }\end{array}$ & $\begin{array}{c}\text { Sandy } \\
\text { loam and } \\
\text { peat } \\
\text { " } \\
\text { ", }\end{array}$ & $\begin{array}{l}\text { Boraginex. Liable to } \\
\text { damp off in wet seasons } \\
\text { out of doors; therefore } \\
\text { suitable for cold house } \\
\text { where the climate is un- } \\
\text { genial. O. echioides is a } \\
\text { biennial. }\end{array}$ \\
\hline $\begin{array}{l}\text { Papaver alpi- } \\
\text { num }\end{array}$ & $\begin{array}{l}3-6 \text { ins. } \\
\text { Orange } \\
\text { to white }\end{array}$ & $\begin{array}{l}\text { Alps } \\
\text { N. Europe } \\
\text { Spring }\end{array}$ & $\begin{array}{l}\text { Ordinary } \\
\text { sandy } \\
\text { lcam }\end{array}$ & $\begin{array}{l}\text { Papaveraceæ. Best treated } \\
\text { as an annual. Sown in } \\
\text { August or September will } \\
\text { flower in early Spring. }\end{array}$ \\
\hline Phlox amœna & $\begin{array}{l}\text { 6-9 ins. } \\
\text { Rosy- } \\
\text { pink }\end{array}$ & $\begin{array}{l}\text { U.S.A. } \\
\text { May }\end{array}$ & $\begin{array}{l}\text { Sandy } \\
\text { loam }\end{array}$ & $\begin{array}{l}\text { Polemoniaceæ. The two } \\
\text { first make pretty pot- } \\
\text { plants. The trailing }\end{array}$ \\
\hline $\begin{array}{l}\text { divaricata ca- } \\
\text { nadensis } \\
\text { reptans }\end{array}$ & $\begin{array}{l}\text { 9-12 ins. } \\
\text { Blue } \\
\text { Crieper }\end{array}$ & $\begin{array}{l}\text { N. Am. } \\
\text { May } \\
\text { Alleghany }\end{array}$ & $"$ & $\begin{array}{l}\text { species do better for pans } \\
\text { or edging troughs. }\end{array}$ \\
\hline & & & $m$ & \\
\hline $\begin{array}{l}\text { subulata } \\
\text { (Moss-pink) }\end{array}$ & $\begin{array}{l}\text { Creeper } \\
\text { Pink- } \\
\text { lilac and } \\
\text { white }\end{array}$ & $\begin{array}{l}\text { St. of N. } \\
\text { York } \\
\text { March }\end{array}$ & 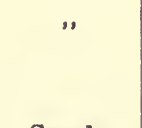 & 1 \\
\hline $\begin{array}{l}\text { Polemonium } \\
\text { Jacob's Ladder } \\
\text { (confertum) } \\
\text { v. melitum }\end{array}$ & $\begin{array}{l}6 \text { ins. } \\
\text { White }\end{array}$ & $\begin{array}{l}\text { N. West } \\
\text { America } \\
\text { April and } \\
\text { May }\end{array}$ & $\begin{array}{l}\text { Sandy } \\
\text { loam and } \\
\text { leaf-soil }\end{array}$ & $\begin{array}{l}\text { A variety more easily } \\
\text { grown than the beautiful } \\
\text { typical form with deep- } \\
\text { blue flowers. }\end{array}$ \\
\hline $\begin{array}{l}\text { Primula } \\
\text { *denticulata }\end{array}$ & $\begin{array}{l}8 \text { ins. } \\
\text { Lilac or } \\
\text { white }\end{array}$ & $\begin{array}{l}\text { Himalaya } \\
\text { Feb. on- } \\
\text { wards }\end{array}$ & $\begin{array}{l}\text { Rich } \\
\text { moist } \\
\text { loam }\end{array}$ & $\begin{array}{l}\text { Primulaceæ. The primu- } \\
\text { las are amongst the most } \\
\text { interesting of Alpine } \\
\text { plants, and there are }\end{array}$ \\
\hline marginata & $\begin{array}{l}3-4 \text { ins. } \\
\text { Lilac }\end{array}$ & $\begin{array}{l}\text { Switzer- } \\
\text { land } \\
\text { Mar.-Apl. }\end{array}$ & ", & $\begin{array}{l}\text { many more species than } \\
\text { can be enumerated here. } \\
\text { P. marginata has leaves } \\
\text { silver-edged with farina. }\end{array}$ \\
\hline megaseæfolia & $\begin{array}{l}\text { 4-6 ins. } \\
\text { Purple }\end{array}$ & $\begin{array}{c}\text { Feb. } \\
\text { onwards }\end{array}$ & & $\begin{array}{l}\text { P. megaseæfolia is a valu- } \\
\text { able new species. }\end{array}$ \\
\hline
\end{tabular}




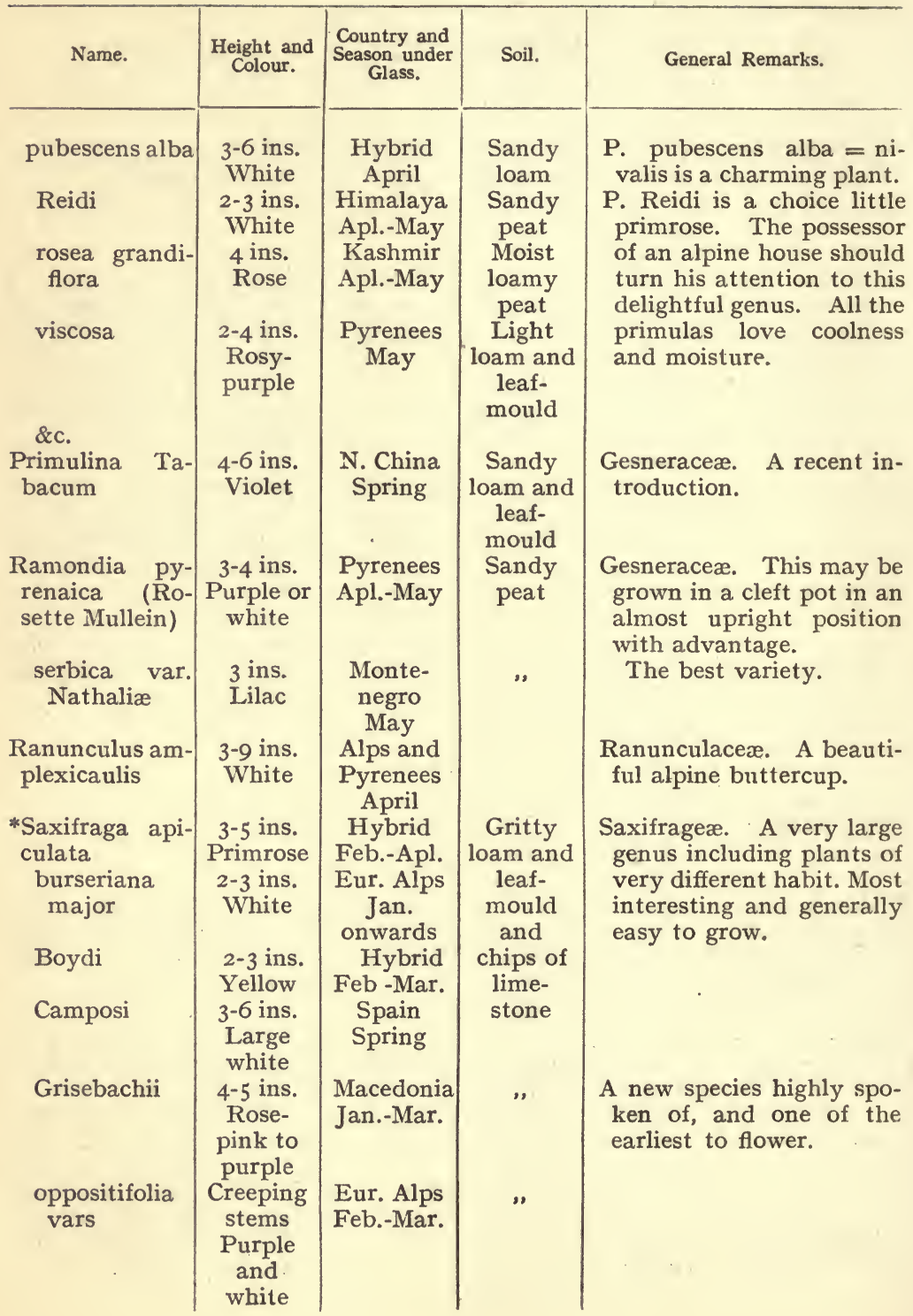




\begin{tabular}{|c|c|c|c|c|}
\hline Name. & $\begin{array}{l}\text { Height and } \\
\text { Colour. }\end{array}$ & $\begin{array}{l}\text { Country and } \\
\text { Season under } \\
\text { Glass. }\end{array}$ & Soil. & General Remarks. \\
\hline Rhei & $\begin{array}{l}2-4 \text { ins. } \\
\text { Pink }\end{array}$ & & $\begin{array}{l}\text { Gritty } \\
\text { loam and }\end{array}$ & \\
\hline $\begin{array}{l}\text { *Stracheyi (Me- } \\
\text { gasæa section) } \\
\text { \&c. \&c. }\end{array}$ & $\begin{array}{l}4-8 \text { ins. } \\
\text { Pink or } \\
\text { white }\end{array}$ & $\begin{array}{l}\text { W. Hims. } \\
\text { March } \\
\text {-April }\end{array}$ & $\begin{array}{l}\text { leaf- } \\
\text { mould } \\
\text { and } \\
\text { chips of } \\
\text { lime- } \\
\text { stone }\end{array}$ & \\
\hline $\begin{array}{l}\text { Schizocodon sol- } \\
\text { danellioides }\end{array}$ & $\begin{array}{l}2-3 \text { ins. } \\
\text { Rose }\end{array}$ & $\begin{array}{l}\text { Japan } \\
\text { March }\end{array}$ & $\begin{array}{l}\text { Sandy } \\
\text { peat }\end{array}$ & $\begin{array}{l}\text { Diapensiaceæ. A most } \\
\text { beautiful plant of recent } \\
\text { introduction (1893), and } \\
\text { still scarce. }\end{array}$ \\
\hline $\begin{array}{l}\text { Sempervivum } \\
\text { arachnoideum } \\
\text { (Cobweb House } \\
\text {-leek) }\end{array}$ & $\begin{array}{l}3-4 \text { ins. } \\
\text { (flower } \\
\text { stems) } \\
\text { Red }\end{array}$ & $\begin{array}{l}\text { Central } \\
\text { Europe } \\
\text { May }\end{array}$ & $\begin{array}{l}\text { Gritty } \\
\text { loam and } \\
\text { leaf- } \\
\text { mould }\end{array}$ & Crassulaceæ. \\
\hline $\begin{array}{l}\text { *Shortia galaci- } \\
\text { folia }\end{array}$ & $\begin{array}{l}2-3 \text { ins. } \\
\text { White }\end{array}$ & $\begin{array}{l}\text { N. Caro- } \\
\text { lina } \\
\text { March }\end{array}$ & $\begin{array}{l}\text { Fibrous } \\
\text { loam and } \\
\text { leaf- } \\
\text { mould }\end{array}$ & $\begin{array}{l}\text { Diapensiacex. One of the } \\
\text { gems cf the alpine house. } \\
\text { This and the above schi- } \\
\text { zocodon belong to the } \\
\text { same natural order, and } \\
\text { are worth any trouble to } \\
\text { establish. Both have a } \\
\text { tendency to deep-coloured } \\
\text { foliage, like Galax aphylla } \\
\text { - a near ally. }\end{array}$ \\
\hline $\begin{array}{l}\text { Soldanella alp- } \\
\text { in a var. Wheel- } \\
\text { eri }\end{array}$ & $\begin{array}{l}3 \text { ins. } \\
\text { Violet }\end{array}$ & $\begin{array}{l}\text { Tyrol and } \\
\text { Swiss Alps } \\
\text { Mar.-Apl. }\end{array}$ & $\begin{array}{c}\text { Moist } \\
\text { sandy } \\
\text { loam and } \\
\text { peat }\end{array}$ & $\begin{array}{l}\text { Primulaceæ. Difficult to } \\
\text { flower. For culture in } \\
\text { sphagnum moss see Chap, } \\
\text { VI. }\end{array}$ \\
\hline $\begin{array}{l}\text { *Symphyandra } \\
\text { Wanneri }\end{array}$ & $\begin{array}{l}\text { 6-8 ins. } \\
\text { Purple- } \\
\text { blue }\end{array}$ & $\begin{array}{l}\text { Transyl- } \\
\text { vania } \\
\text { May }\end{array}$ & $\begin{array}{l}\text { Sandy } \\
\text { loam }\end{array}$ & $\begin{array}{l}\text { Campanulaceæ. Biennial. } \\
\text { A very desirable plant } \\
\text { nearly allied to Campa- } \\
\text { nula. Likes shade. }\end{array}$ \\
\hline $\begin{array}{l}\text { Thalictrum ane- } \\
\text { monoides }\end{array}$ & $\begin{array}{l}6 \text { ins. } \\
\text { White }\end{array}$ & $\begin{array}{l}\text { N. Ameri- } \\
\text { ca } \\
\text { March }\end{array}$ & $\begin{array}{l}\text { Moist } \\
\text { sandy } \\
\text { peat }\end{array}$ & $\begin{array}{l}\text { Ranunculaceæ. An ele- } \\
\text { gant little plant, best } \\
\text { raised from seed. }\end{array}$ \\
\hline $\begin{array}{ll}\text { *Tiarella } & \text { cordi- } \\
\text { folia } & \text { (Foam } \\
\text { flower) } & \end{array}$ & $\begin{array}{l}6-9 \text { ins. } \\
\text { White }\end{array}$ & $\begin{array}{l}\text { N. Ameri- } \\
\text { ca } \\
\text { April }\end{array}$ & $\begin{array}{l}\text { Ordinary } \\
\text { light } \\
\text { loam }\end{array}$ & $\begin{array}{l}\text { Saxifragex. Rather larger } \\
\text { than most of the alpines } \\
\text { given in this list, but } \\
\text { very useful. Feathery } \\
\text { white spikes. }\end{array}$ \\
\hline $\begin{array}{l}\text { Trientalis ame- } \\
\text { ricana (Star- } \\
\text { flower) }\end{array}$ & $\begin{array}{l}\text { 6-9 ins. } \\
\text { White }\end{array}$ & $\begin{array}{l}\text { N. W. Am. } \\
\text { April }\end{array}$ & $\begin{array}{l}\text { Sandy } \\
\text { peat }\end{array}$ & $\begin{array}{l}\text { Primulaceæ. Very similar } \\
\text { to the European species } \\
\text { but a finer plant. }\end{array}$ \\
\hline
\end{tabular}




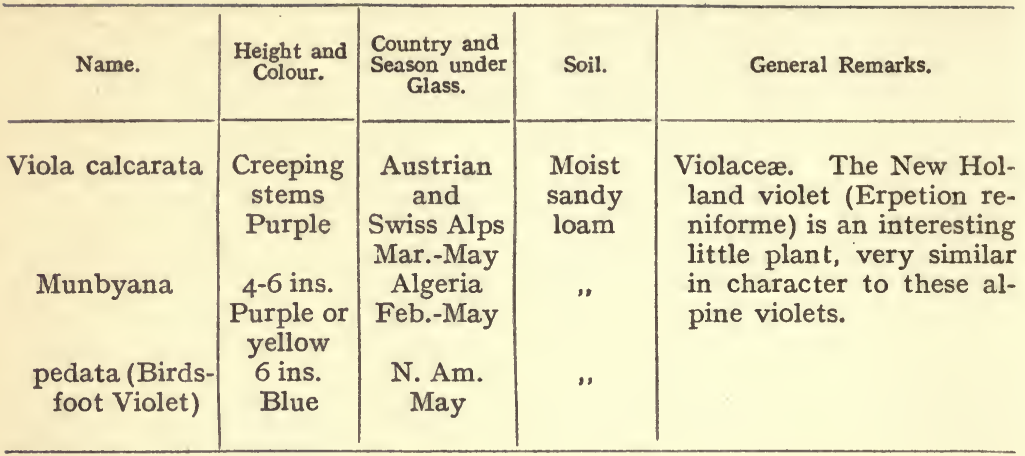




\section{BULBS AND TUBERS SUITABLE FOR ASSOCIATING WITH ALPINE PLANTS IN FLOWER FROM JANUARY TO MAY}

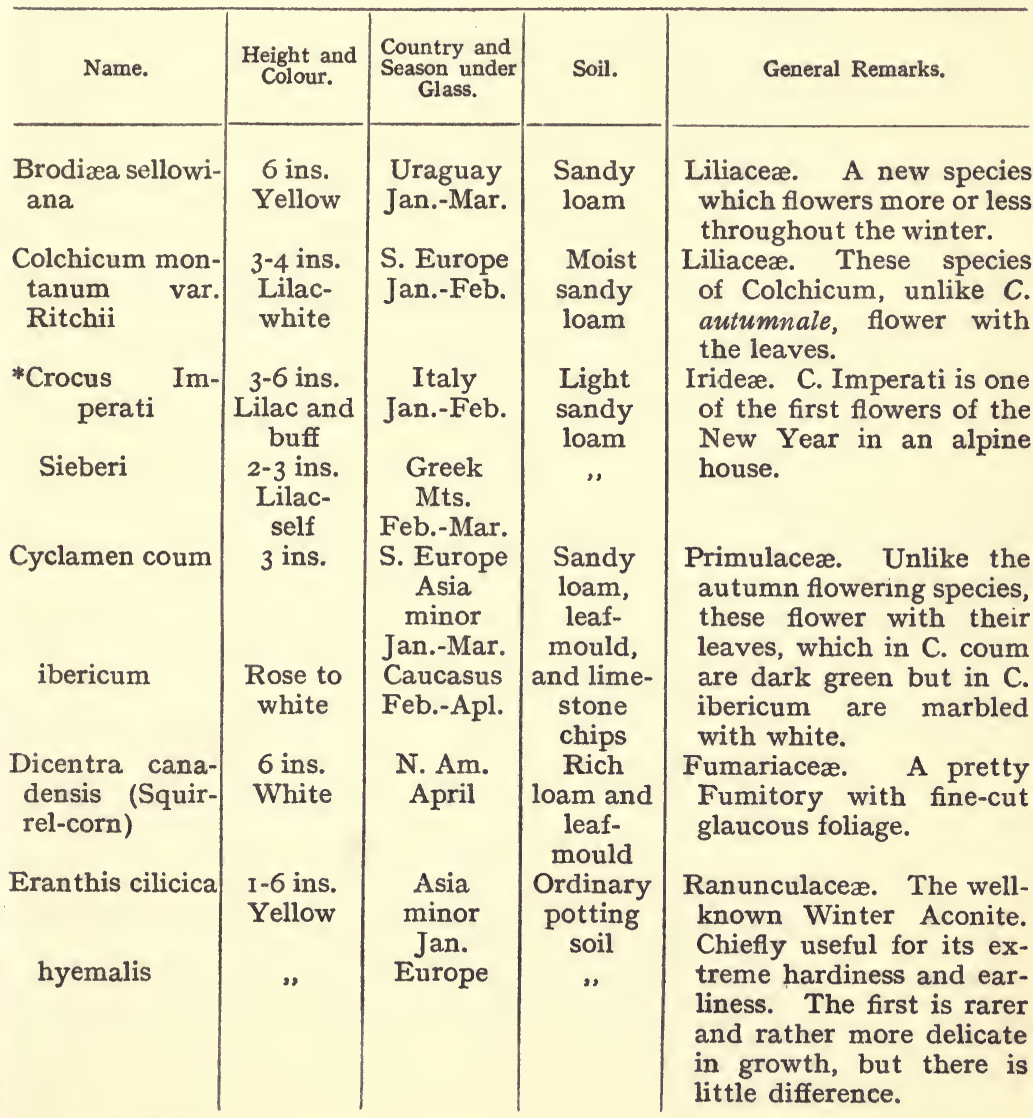




\begin{tabular}{|c|c|c|c|c|}
\hline Name. & $\begin{array}{l}\text { Height and } \\
\text { Colour. }\end{array}$ & $\begin{array}{l}\text { Country and } \\
\text { Season under } \\
\text { Glass. }\end{array}$ & Soil. & General Remarks. \\
\hline $\begin{array}{l}\text { *Erythronium } \\
\text { grandiflorum } \\
\text { robustum }\end{array}$ & $\begin{array}{l}3-6 \text { ins. } \\
\text { Yellow }\end{array}$ & $\begin{array}{l}\text { Mts. of } \\
\text { Washing- } \\
\text { ton } \\
\text { March }\end{array}$ & & $\begin{array}{l}\text { Liliaceæ. These rare Dog's } \\
\text { Tooth Violets mostly have } \\
\text { mottled leaves and make }\end{array}$ \\
\hline Hartwegi & $\begin{array}{l}4-8 \text { ins. } \\
\text { Cream- } \\
\text { white }\end{array}$ & $\begin{array}{l}\text { California } \\
\text { Mar.-Apl. }\end{array}$ & Loam & $\begin{array}{l}\text { pot-plants, being taller } \\
\text { and more lasting in flower } \\
\text { than the well-known E. }\end{array}$ \\
\hline Hendersoni & $\begin{array}{l}4-6 \text { ins. } \\
\text { Pale- } \\
\text { rose }\end{array}$ & $\begin{array}{c}\text { Oregon } \\
\text { Mar.-Apl. }\end{array}$ & and & Dens canis. \\
\hline Howelli & $\begin{array}{l}4-6 \text { ins. } \\
\text { Pale } \\
\text { mauve }\end{array}$ & $"$ & peat & \\
\hline Johnstoni & $\begin{array}{l}4-6 \text { ins. } \\
\text { Rose- } \\
\text { pink }\end{array}$ & " & & \\
\hline $\begin{array}{l}\text { *Fritillaria au- } \\
\text { rea } \\
\text { pudica }\end{array}$ & $\begin{array}{l}6 \text { ins. } \\
\text { Yellow } \\
4-6 \text { ins. } \\
\text { Yellow }\end{array}$ & $\begin{array}{l}\text { A. minor } \\
\text { March } \\
\text { Rocky } \\
\text { Mts. } \\
\text { April }\end{array}$ & $\begin{array}{l}\text { Sandy } \\
\text { loam and } \\
\text { leaf- } \\
\text { mould }\end{array}$ & $\begin{array}{l}\text { Liliaceæ. F. aurea has a } \\
\text { large drooping bell yel- } \\
\text { low flecked with brown. } \\
\text { A lovely plant. Several } \\
\text { bulbs should be grown } \\
\text { in a pan. F. pudica is } \\
\text { quite distinct. }\end{array}$ \\
\hline $\begin{array}{l}\text { Hyacinthusazu- } \\
\text { reus }\end{array}$ & $\begin{array}{l}\text { 4-6 ins. } \\
\text { Sky blue }\end{array}$ & $\begin{array}{l}\text { A. minor } \\
\text { Jan.-Feb. }\end{array}$ & $\begin{array}{l}\text { Loam } \\
\text { and leaf- } \\
\text { mould }\end{array}$ & $\begin{array}{l}\text { Liliaceæ. Several bulbs } \\
\text { should be grown in a pot. }\end{array}$ \\
\hline Iris bakeriana & $\begin{array}{l}4-6 \text { ins. } \\
\text { Blue and } \\
\text { violet }\end{array}$ & $\begin{array}{l}\text { Armenia } \\
\text { Jan.- } \\
\text { March }\end{array}$ & & $\begin{array}{l}\text { Irideæ. All here named } \\
\text { are bulbous species. I. } \\
\text { Heldreichi is very dis- }\end{array}$ \\
\hline Danfordiæ & $\begin{array}{l}3 \text { ins. } \\
\text { Yellow }\end{array}$ & $\begin{array}{l}\text { A. minor } \\
\text { Jan.-Feb. }\end{array}$ & $\begin{array}{l}\text { Rich } \\
\text { gritty }\end{array}$ & \\
\hline *Heldreichi & $\begin{array}{l}2-5 \text { ins. } \\
\text { Grey-blue } \\
\text { and } \\
\text { purple }\end{array}$ & $\begin{array}{l}\text { A. minor } \\
\text { Jan.-Feb. }\end{array}$ & $\begin{array}{l}\text { loam } \\
\text { and }\end{array}$ & $\begin{array}{l}\text { most beautiful of the re- } \\
\text { cent introductions from } \\
\text { Asia minor, only a few of } \\
\text { which are given here. }\end{array}$ \\
\hline${ }^{*}$ Histrio & $\begin{array}{l}4-6 \text { ins. } \\
\text { Blue with } \\
\text { spotted } \\
\text { falls }\end{array}$ & $\begin{array}{l}\text { Palestine } \\
\text { Jan.-Feb. }\end{array}$ & $\begin{array}{l}\text { leaf- } \\
\text { mould }\end{array}$ & \\
\hline persica & $\begin{array}{c}\text { 3-4 ins. } \\
\text { Pale } \\
\text { bluish, } \\
\text { green and } \\
\text { violet }\end{array}$ & $\begin{array}{l}\text { Persia } \\
\text { Feb.- } \\
\text { March }\end{array}$ & & \\
\hline
\end{tabular}




\begin{tabular}{|c|c|c|c|c|}
\hline Name. & $\begin{array}{l}\text { Height and } \\
\text { Colour. }\end{array}$ & $\begin{array}{l}\text { Country and } \\
\text { Season under } \\
\text { Glass. }\end{array}$ & Soil. & General Remarks. \\
\hline $\begin{array}{l}\text { Leucojum ver- } \\
\text { num (Spring } \\
\text { Snowflake) }\end{array}$ & $\begin{array}{l}\text { 6-8 ins. } \\
\text { White }\end{array}$ & $\begin{array}{l}\text { Cent. } \\
\text { Europe } \\
\text { Feb.-Mar. }\end{array}$ & $\begin{array}{l}\text { Ordinary } \\
\text { potting } \\
\text { soil }\end{array}$ & $\begin{array}{l}\text { Amaryllideæ. A well- } \\
\text { known Spring bulb. }\end{array}$ \\
\hline $\begin{array}{l}\text { Merendera cau- } \\
\text { casica }\end{array}$ & $\begin{array}{l}3-4 \text { ins. } \\
\text { Pale } \\
\text { purple }\end{array}$ & $\begin{array}{l}\text { Caucasus } \\
\text { Feb.-Mar. }\end{array}$ & $\begin{array}{l}\text { Moist } \\
\text { sandy } \\
\text { loam }\end{array}$ & $\begin{array}{l}\text { Liliaceæ. Very like a } \\
\text { small colchicum, to which } \\
\text { it is nearly related. }\end{array}$ \\
\hline $\begin{array}{l}\text { Narcissus Bul- } \\
\text { bocodium }= \\
\text { Corbularia } \\
\text { (Hooped Petti- } \\
\text { coat) } \\
\text { *vars. citri- } \\
\text { nus } \\
\text { *conspicuus }\end{array}$ & $\begin{array}{l}\text { 4-6 ins. } \\
\text { Sulphur }\end{array}$ & Feb. and & $\begin{array}{l}\text { Sandy } \\
\text { loam } \\
\text { and } \\
\text { leaf- } \\
\text { mould }\end{array}$ & $\begin{array}{l}\text { Amaryllideæ. These small } \\
\text { Narcissi are all charming, } \\
\text { and with care do well and } \\
\text { increase in pots. The } \\
\text { bulbs are so small that } \\
\text { they are only suitable for } \\
\text { a rock garden otherwise. }\end{array}$ \\
\hline
\end{tabular}

\section{*monophylla}

Narcissus clamineus

minor

minimus triandrus

Puschkinia scillioides

Scilla bifolia var. taurica

sibirica

Scoliopus Bigelovii
4-8 ins.

Yellow

3-4 ins.

White

6-8 ins.

Pale

yellow

4-6 ins.

Bright

yellow

3-4 ins.

6-10 ins.

White to

sulphur

Algeria

Jan.-Feb.

Portugal

March

Europe

Feb.-

March

Spain and

Portugal

Mar.-Apl.

4-8 ins.

White

striped

blue

6-8 ins.

Bright

blue

or white

A. minor

March

3-6 ins.

A. minor

Feb.

Siberia

Feb.

Chocolate Jan.-Feb.

brown

\section{Moist soil \\ N. cyclamineus has re flexed petals, as denoted by its name.}

Ordinary potting soil

\section{Sandy} loam and

leaf-

mould

Rich

sandy

loam

Sandy

loam

1

Sandy

loam
These are the smallest Trumpet daffodils.

A charming little species with many varieties. Well adapted for pot culture. Petals reflexed.

Jiliaceæ. Allied to Scilla.

Liliaceæ. The best var. of S. bifolia.

A curious and attractive little bulb, in habit and leaf like Erythronium, with a small three-petalled flower of remarkable colouring. Introduced about ten years ago. 


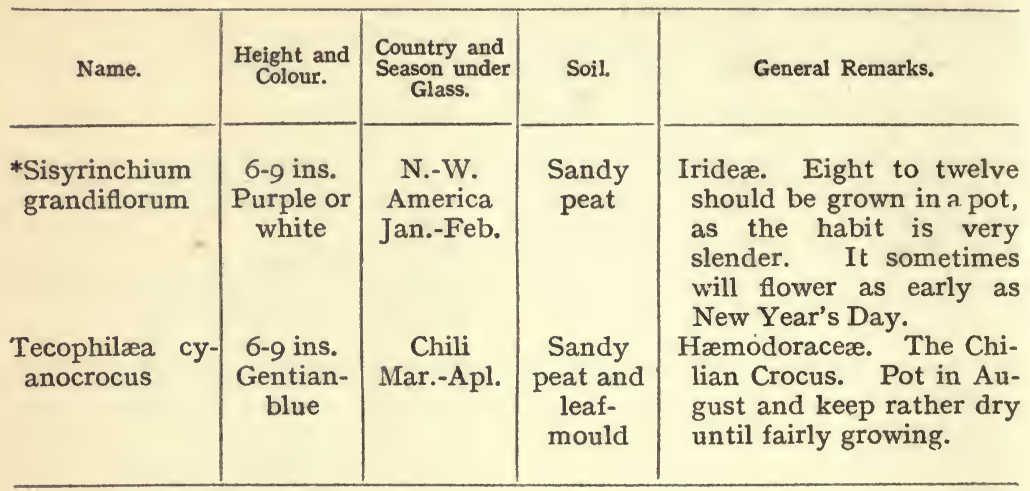




\section{HARDY BULBS AND TUBERS NOT MENTIONED UNDER ALPINE HOUSE LIST}

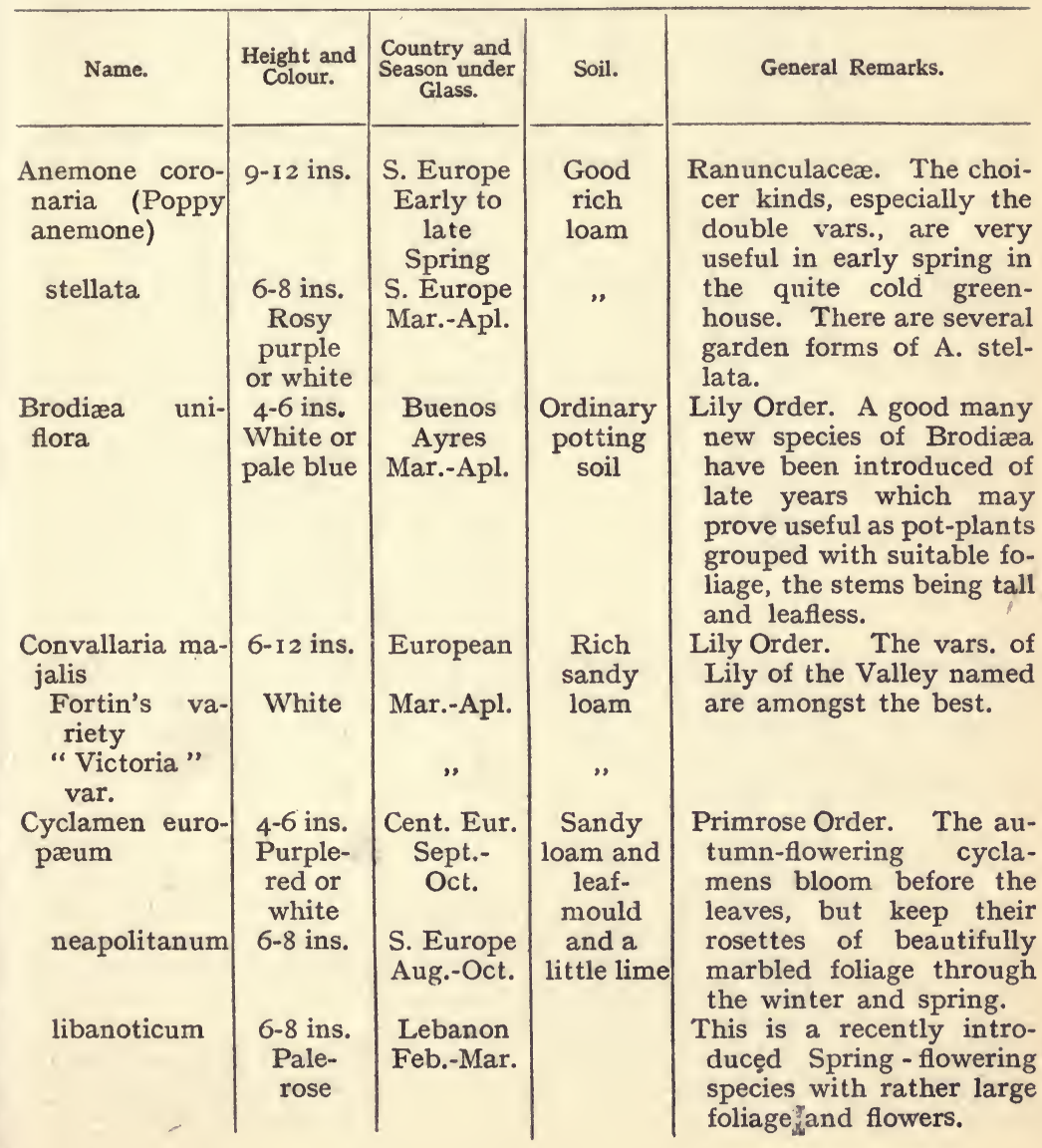




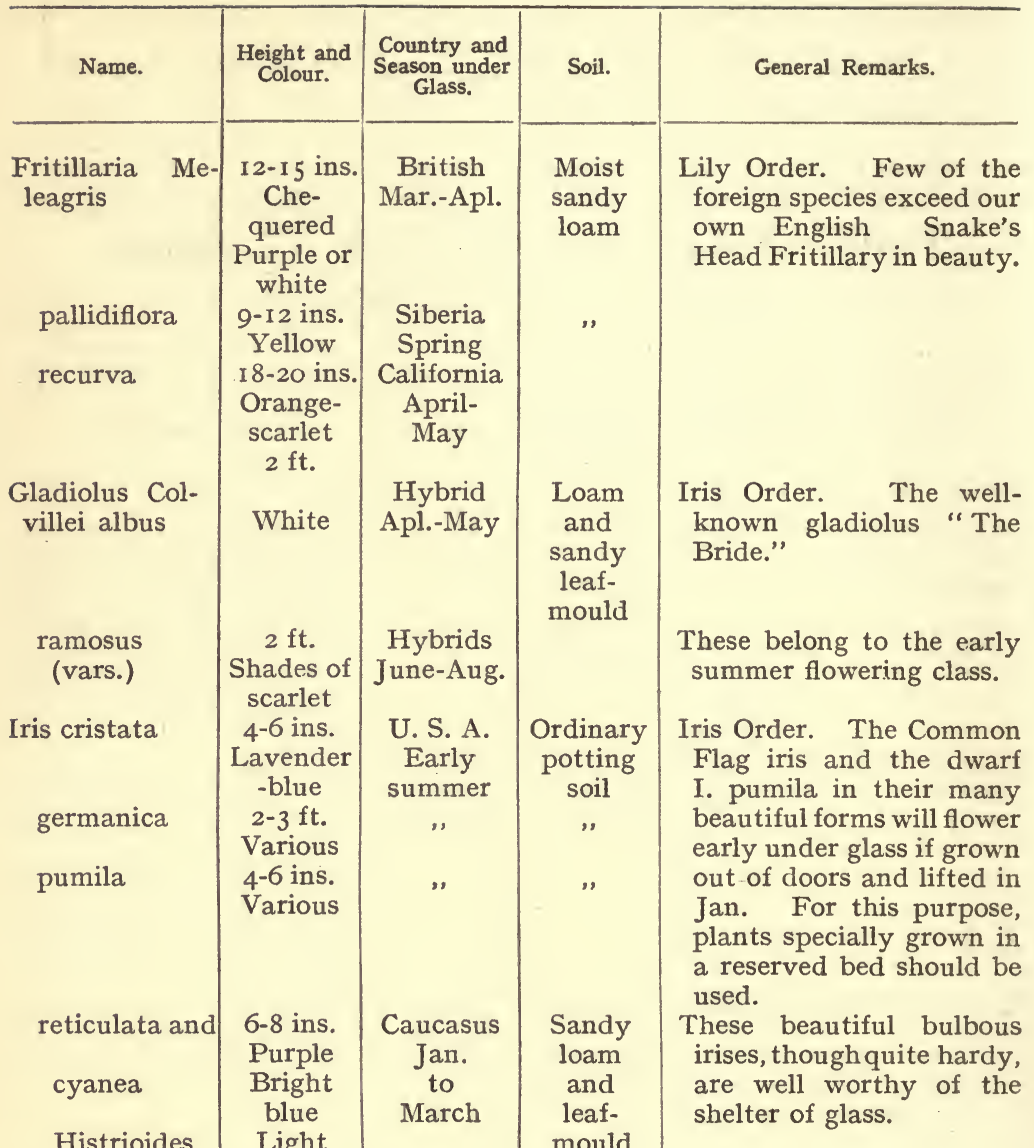

\begin{tabular}{|c|c|c|c|}
\hline Histrioides & Light & & mould \\
\hline Krelagei & $\begin{array}{l}\text { Red- } \\
\text { purple }\end{array}$ & & \\
\hline Sophenensis & Varies & & \\
\hline sindjarensis & $\begin{array}{l}\text { 9-1 } 2 \text { ins. } \\
\text { Slaty }\end{array}$ & $\begin{array}{l}\text { Mesopota- } \\
\text { mia }\end{array}$ & $\begin{array}{l}\text { Sandy } \\
\text { loam }\end{array}$ \\
\hline & $\begin{array}{l}\text { blue and } \\
\text { cream }\end{array}$ & March & \\
\hline $\begin{array}{l}\text { Xiphioides } \\
\text { (English I.) }\end{array}$ & $\begin{array}{l}2-3 \mathrm{ft} . \\
\text { Various }\end{array}$ & $\begin{array}{l}\text { Pyrenees } \\
\text { July }\end{array}$ & " \\
\hline
\end{tabular}

A pretty new bulbous species.

English Iris is stronger growing with larger flowers than the Spanish I. 


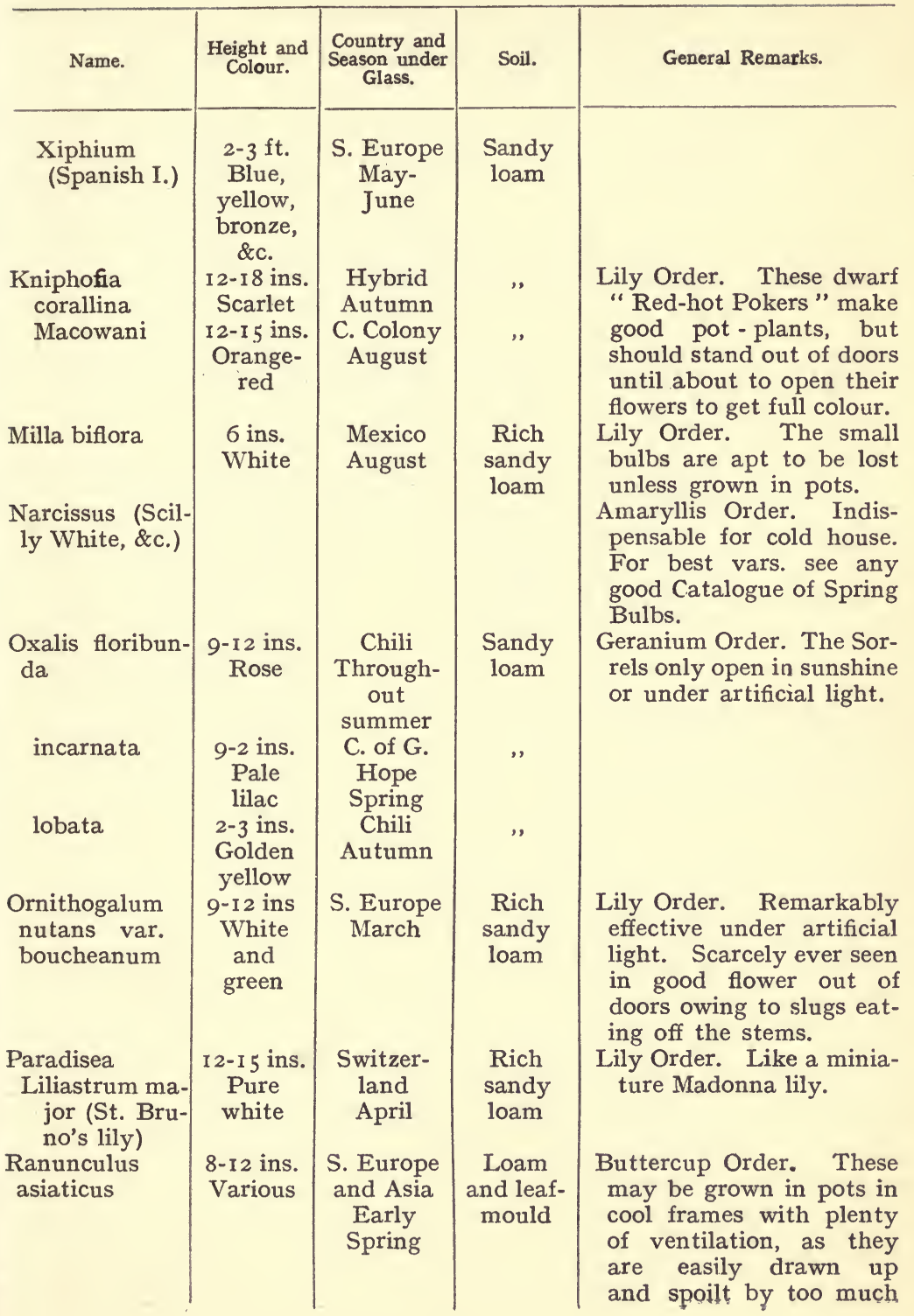




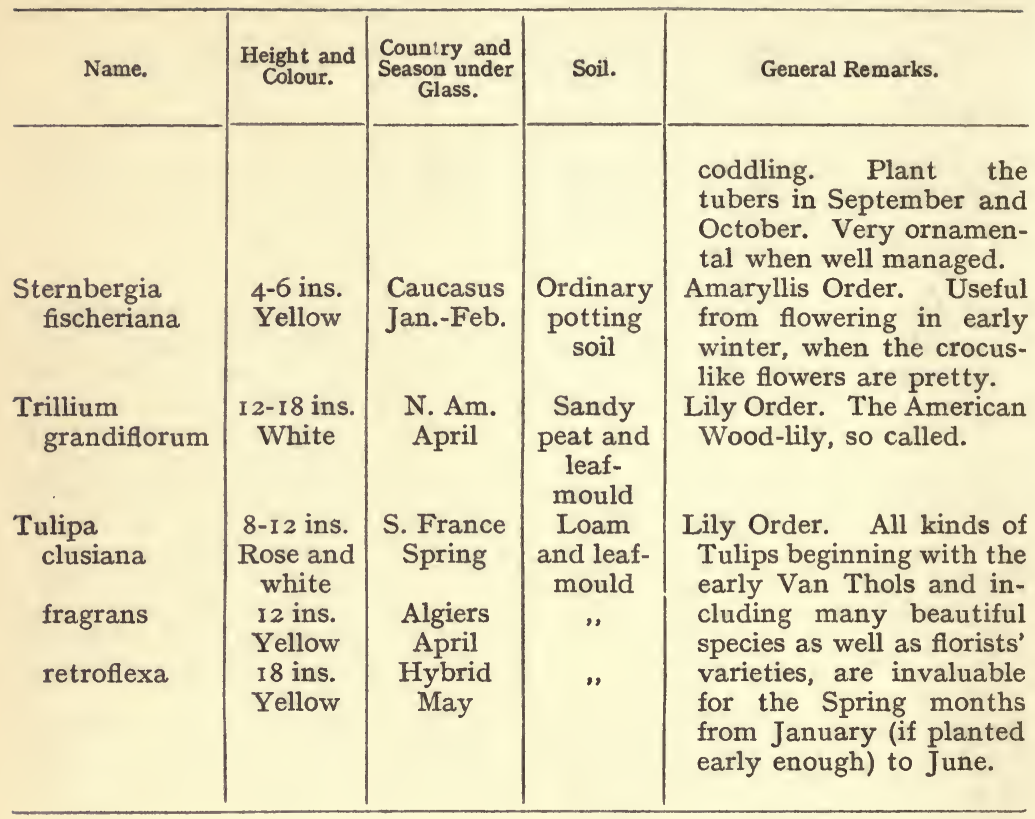




\section{HALF-HARDY BULBS AND TUBERS.}

\begin{tabular}{|c|c|c|c|c|}
\hline Name. & $\begin{array}{l}\text { Height and } \\
\text { Colour. }\end{array}$ & $\begin{array}{l}\text { Country and } \\
\text { Season under } \\
\text { Glass. }\end{array}$ & Soil. & General Remarks. \\
\hline $\begin{array}{l}\text { Agapanthus } \\
\text { umbellatus }\end{array}$ & $\begin{array}{l}2-3 \mathrm{ft} . \\
\text { Blue and } \\
\text { white } \\
\text { var. }\end{array}$ & $\begin{array}{l}\text { S. Africa } \\
\text { Summer } \\
\text { and } \\
\text { Autumn }\end{array}$ & $\begin{array}{l}\text { Good } \\
\text { rich } \\
\text { loam }\end{array}$ & $\begin{array}{l}\text { Lily Order. Admirable in } \\
\text { pots and tubs for many } \\
\text { purposes, and can be } \\
\text { stowed in an out-house } \\
\text { during winter. }\end{array}$ \\
\hline $\begin{array}{l}\text { Alstrœmeria pe- } \\
\text { legrina alba }\end{array}$ & $\begin{array}{l}\text { I } 2-15 \text { ins. } \\
\text { White }\end{array}$ & $\begin{array}{c}\text { Chili } \\
\text { May-June }\end{array}$ & $\begin{array}{l}\text { Sandy } \\
\text { loam and } \\
\text { leaf- } \\
\text { mould } \\
\text { and a } \\
\text { little peat }\end{array}$ & $\begin{array}{l}\text { Amaryllis Order. A lovely } \\
\text { plant. Best grown in a } \\
\text { long lily pot. }\end{array}$ \\
\hline $\begin{array}{l}\text { Anoiganthus } \\
\text { breviflorus }\end{array}$ & & & & \\
\hline $\begin{array}{l}\text { Arthropodium } \\
\text { cirrhatum } \\
\text { paniculatum }\end{array}$ & $\begin{array}{l}2 \mathrm{ft} \text {. and } \\
\text { upwards } \\
\text { White } \\
\text { I } 8 \text { ins. } \\
\text { White }\end{array}$ & $\begin{array}{l}\text { N. Zealand } \\
\text { May } \\
\text { N. S. } \\
\text { Wales } \\
\text { May }\end{array}$ & $\begin{array}{l}\text { Sandy } \\
\text { loam } \\
\text { and peat }\end{array}$ & $\begin{array}{l}\text { Lily Order. Beautiful } \\
\text { plants both in foliage and } \\
\text { branching heads of small } \\
\text { but numerous flowers. }\end{array}$ \\
\hline $\begin{array}{l}\text { Begonias } \\
\text { Tuberous } \\
\text { vars. }\end{array}$ & $\begin{array}{l}\text { Scarlet } \\
\text { to white } \\
\text { and } \\
\text { yellow }\end{array}$ & Hybrids & $\begin{array}{l}\text { Sandy } \\
\text { loam and } \\
\text { leaf- } \\
\text { mould }\end{array}$ & $\begin{array}{l}\text { Begonia Order. A great } \\
\text { summer show can be } \\
\text { made with these popular } \\
\text { plants, and the tubers can } \\
\text { be kept in sand or cocoa- } \\
\text { fibre in any safe place } \\
\text { away from winter frost. }\end{array}$ \\
\hline Canna indica & $\begin{array}{l}\text { Dwarf } \\
\text { and tall } \\
\text { vars. } \\
\text { Shades of } \\
\text { scarlet } \\
\text { and } \\
\text { yellow }\end{array}$ & $\begin{array}{l}\text { Hybrids } \\
\text { Summer } \\
\text { and } \\
\text { Autumn }\end{array}$ & $\begin{array}{l}\text { Rich } \\
\text { loam and } \\
\text { sandy } \\
\text { peat }\end{array}$ & $\begin{array}{l}\text { Ginger Order. These are } \\
\text { most accommodating } \\
\text { plants, and are admirable } \\
\text { both in foliage and flower. } \\
\text { It is better to start the } \\
\text { root-stocks early in a cu- } \\
\text { cumber frame. These } \\
\text { can be stored during win- } \\
\text { ter in any dry frost-proof } \\
\text { place. }\end{array}$ \\
\hline
\end{tabular}




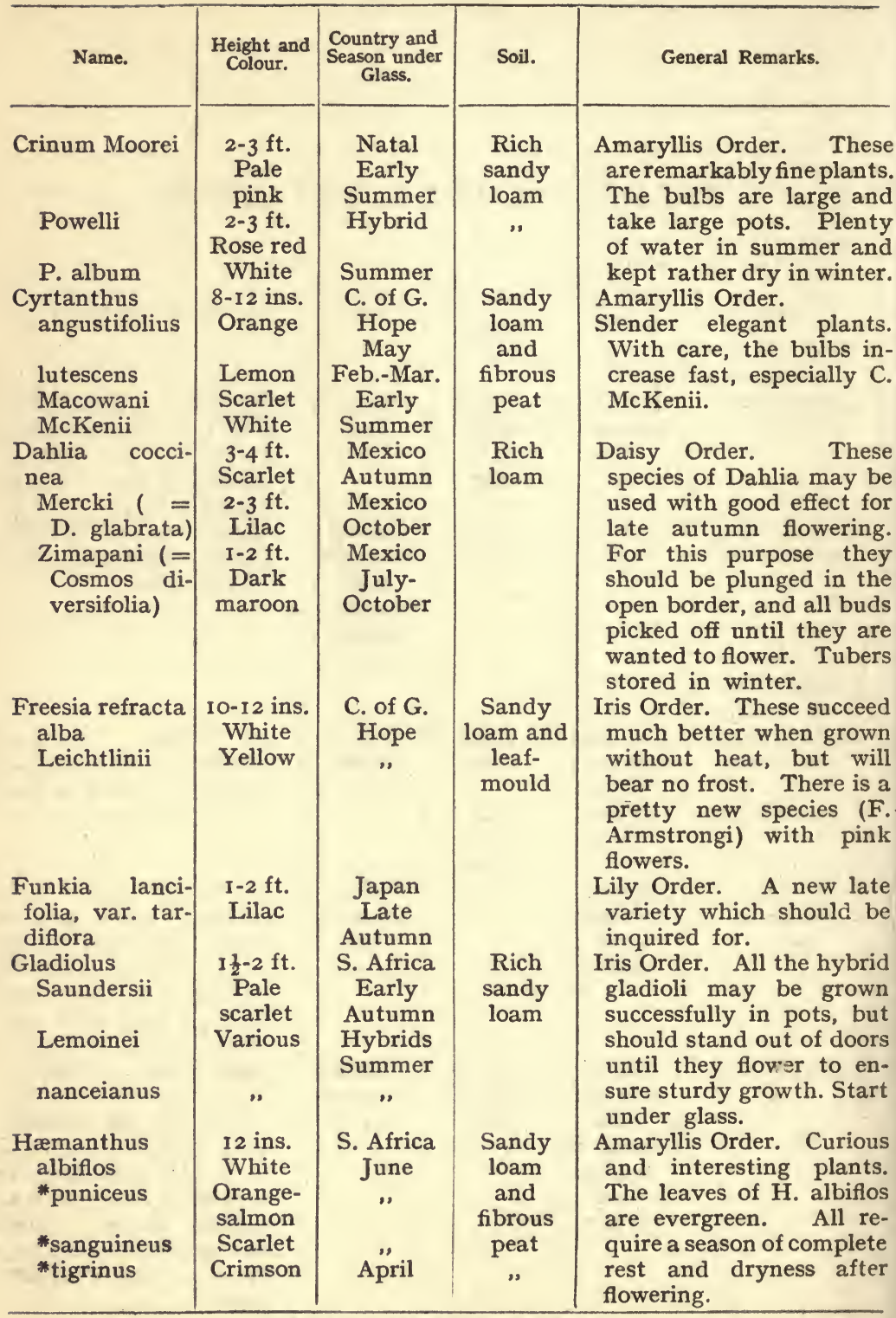




\begin{tabular}{|c|c|c|c|c|}
\hline Name. & $\begin{array}{l}\text { Height and } \\
\text { Colour. }\end{array}$ & $\begin{array}{l}\text { Country and } \\
\text { Season under } \\
\text { Glass. }\end{array}$ & Soil. & General Remarks. \\
\hline $\begin{array}{l}\text { Iris fimbriata } \\
(=\mathrm{I} \text {. chinen- } \\
\text { sis })\end{array}$ & $\begin{array}{l}\mathrm{I}-\mathrm{I} \frac{1}{2} \mathrm{ft} . \\
\text { Lilac- } \\
\text { blue }\end{array}$ & $\begin{array}{l}\text { China } \\
\text { Apl.-May }\end{array}$ & $\begin{array}{l}\text { Sandy } \\
\text { loam and } \\
\text { leaf- } \\
\text { mould }\end{array}$ & $\begin{array}{l}\text { Iris Order. A charming } \\
\text { but rather tender species, } \\
\text { which is impatient of } \\
\text { root disturbance. Stand } \\
\text { out of doors after flower- } \\
\text { ing. }\end{array}$ \\
\hline Ixias & $\begin{array}{l}\text { I } 2-18 \text { ins. } \\
\text { Various }\end{array}$ & $\begin{array}{l}\text { S. Africa } \\
\text { May-June }\end{array}$ & $\begin{array}{l}\text { Sandy } \\
\text { light } \\
\text { loam }\end{array}$ & $\begin{array}{l}\text { Iris Order. Ixias do best } \\
\text { potted in October and } \\
\text { sheltered in a cold frame. } \\
\text { Six or eight corms to a } \\
5 \text {-in. pot. I. viridiflora is } \\
\text { one of the most beautiful. }\end{array}$ \\
\hline $\begin{array}{l}\text { Lachenalia } \\
\text { luteola }\end{array}$ & $\begin{array}{l}6-8 \text { ins. } \\
\text { Yellow } \\
\text { and red }\end{array}$ & $\begin{array}{l}\text { S. Africa } \\
\text { May }\end{array}$ & $\begin{array}{c}\text { Loam } \\
\text { with a } \\
\text { large pro- }\end{array}$ & Lily Order. Beautiful and \\
\hline $\begin{array}{l}\text { Nelsoni } \\
\text { pendula }\end{array}$ & $\begin{array}{l}\text { Golden } \\
\text { Rosy } \\
\text { purple }\end{array}$ & November & $\begin{array}{l}\text { portion of } \\
\text { sharp } \\
\text { coarse }\end{array}$ & $\begin{array}{l}\text { easily-managed bulbs (see } \\
\text { p. } 5^{8} \text { ) }\end{array}$ \\
\hline $\begin{array}{l}\text { tricolor } \\
\text { and vars. }\end{array}$ & $\begin{array}{l}\text { Y̌ellow, } \\
\text { scarlet, } \\
\text { and } \\
\text { purple } \\
\text { edged }\end{array}$ & Early & & \\
\hline $\begin{array}{l}\text { Laipeyrousia } \\
\text { cruenta } \\
\text { (= Anoma- } \\
\text { theca) }\end{array}$ & $\begin{array}{l}\text { 6-1o ins. } \\
\text { Pale } \\
\text { carmine } \\
\text { Spotted } \\
\text { crimson }\end{array}$ & $\begin{array}{l}\text { S. Africa } \\
\text { June }\end{array}$ & $\begin{array}{l}\text { Light } \\
\text { sandy } \\
\text { loam }\end{array}$ & $\begin{array}{l}\text { Iris Order. Charming } \\
\text { little bulbs, which flower } \\
\text { for a long time. Repot } \\
\text { every season in Feb. or } \\
\text { March. Easily raised } \\
\text { from seed and flower the } \\
\text { following year. }\end{array}$ \\
\hline $\begin{array}{l}\text { Libertia formo- } \\
\text { sa }\end{array}$ & $\begin{array}{l}\text { I2-I } 8 \text { ins. } \\
\text { White }\end{array}$ & $\begin{array}{l}\text { Chili } \\
\text { May }\end{array}$ & $\begin{array}{l}\text { Rich } \\
\text { sandy } \\
\text { peat }\end{array}$ & $\begin{array}{l}\text { Iris Order. A pretty and } \\
\text { uncommon plant. }\end{array}$ \\
\hline $\begin{array}{l}\text { Nerine corusca } \\
\text { Fothergilli } \\
\text { Sarniensis } \\
\text { (Guernsey } \\
\text { lily) } \\
\text { rosea } \\
\text { pudica } \\
\text { undulata }\end{array}$ & $\begin{array}{l}\text { IO-12 ins. } \\
\text { Scarlet } \\
\text { Crimson }\end{array}$ & $\begin{array}{l}\text { S. Africa } \\
\text { All } \\
\text { Autumn } \\
\text { flowering }\end{array}$ & $\begin{array}{l}\text { Loam } \\
\text { and leaf- } \\
\text { mould } \\
\text { with } \\
\text { crushed } \\
\text { charcoal } \\
\text { is an } \\
\text { excellent } \\
\text { compost } \\
\text { for these }\end{array}$ & $\begin{array}{l}\text { Amaryllis Order. Most } \\
\text { beautiful bulbs with large } \\
\text { heads of flowers which } \\
\text { appear before the leaves. } \\
\text { (See pp. 62,63.) }\end{array}$ \\
\hline
\end{tabular}




\begin{tabular}{|c|c|c|c|c|}
\hline Name. & $\begin{array}{l}\text { Height and } \\
\text { Colour. }\end{array}$ & $\begin{array}{l}\text { Country and } \\
\text { Season under } \\
\text { Glass. }\end{array}$ & Soil. & General Remarks. \\
\hline $\begin{array}{l}\text { Ornithogalum } \\
\text { arabicum } \\
\text { aureum }\end{array}$ & $\begin{array}{l}\text { I2-I } 5 \text { ins. } \\
\text { White } \\
\text { 6-I } 2 \text { ins. } \\
\text { Golden } \\
\text { yellow }\end{array}$ & $\begin{array}{l}\text { Spain } \\
\text { Summer } \\
\text { Cape } \\
\text { June }\end{array}$ & $\begin{array}{l}\text { Sandy } \\
\text { loam } \\
\text { and leaf- } \\
\text { mould }\end{array}$ & $\begin{array}{l}\text { Lily Order. Handsome } \\
\text { cool greenhouse bulbs. }\end{array}$ \\
\hline Oxalis Bowei & $\begin{array}{l}\text { 6-1o ins. } \\
\text { Deep- } \\
\text { rose } \\
6 \text { ins. }\end{array}$ & $\begin{array}{l}\text { Cape } \\
\text { August }\end{array}$ & $\begin{array}{l}\text { Sandy } \\
\text { light } \\
\text { loam }\end{array}$ & $\begin{array}{l}\text { Geranium Order. O. cer- } \\
\text { nua is an excellent basket } \\
\text { plant for sunny positions. }\end{array}$ \\
\hline $\begin{array}{l}\text { cernua } \\
\text { enneaphylla }\end{array}$ & $\begin{array}{l}6 \text { ins. } \\
\text { Lemon } \\
4 \text { ins. } \\
\text { White or } \\
\text { pale pink }\end{array}$ & $\begin{array}{l}\text { Madeira } \\
\text { April } \\
\text { Fuegia } \\
\text { June }\end{array}$ & " & \\
\hline $\begin{array}{l}\text { Pancratium } \\
\text { illyricum } \\
\text { maritimum }\end{array}$ & $\begin{array}{c}\text { I-I } \frac{1}{2} \mathrm{ft} . \\
\text { White } \\
\quad "\end{array}$ & $\begin{array}{c}\text { S. Europe } \\
\text { Summer } \\
n\end{array}$ & $\begin{array}{l}\text { Very } \\
\text { sandy } \\
\text { loam }\end{array}$ & $\begin{array}{l}\text { Amaryllis Order. Fine } \\
\text { sweet-scented flowers. } \\
\text { Grow three in a large pot } \\
\mathrm{P} \text {. illyricum is the har- } \\
\text { diest. }\end{array}$ \\
\hline $\begin{array}{l}\text { Richardia æthio- } \\
\text { pica }\end{array}$ & $\begin{array}{l}\text { I-2 ft. } \\
\text { White }\end{array}$ & $\begin{array}{l}\text { S. Africa } \\
\text { May-June }\end{array}$ & $\begin{array}{l}\text { Rich } \\
\text { loam and } \\
\text { leaf- } \\
\text { mould }\end{array}$ & $\begin{array}{l}\text { Arum Order. When } \\
\text { brought on for early } \\
\text { flowering, arums must be } \\
\text { carefully protected from } \\
\text { frost in cold greenhouse } \\
\text { as the leaves are easily } \\
\text { injured. This plant is the } \\
\text { Pig-lily of Cape Colony, } \\
\text { where it will probably be } \\
\text { a lost plant in a few } \\
\text { years! }\end{array}$ \\
\hline $\begin{array}{c}\text { Roscoea pur- } \\
\text { purea }\end{array}$ & $\begin{array}{l}6 \text { ins. } \\
\text { Purple } \\
\text { (Orchis- } \\
\text { like) }\end{array}$ & $\begin{array}{l}\text { Himalaya } \\
\text { July-Aug. }\end{array}$ & $\begin{array}{l}\text { Sandy } \\
\text { loam } \\
\text { and peat }\end{array}$ & $\begin{array}{l}\text { Ginger Order. This plant } \\
\text { used to be grown in stove- } \\
\text { heat, but has proved to be } \\
\text { hardy in the southern } \\
\text { counties. }\end{array}$ \\
\hline $\begin{array}{l}\text { Sparaxis } \\
\text { Dierama }) \\
\text { pulcherrima }\end{array}$ & $\begin{array}{l}\text { 3-4 } \mathrm{ft} \text {. } \\
\text { and } \\
\text { upwards } \\
\text { Purple- } \\
\text { red } \\
\text { Lilac }\end{array}$ & $\begin{array}{l}\text { Autumn } \\
\text { June }\end{array}$ & $\begin{array}{l}\text { Light } \\
\text { sandy } \\
\text { loam }\end{array}$ & $\begin{array}{l}\text { Iris Order. Better known } \\
\text { as Sparaxis, but now } \\
\text { Dierama. Treatment as } \\
\text { for Ixias. Very fine } \\
\text { plants. }\end{array}$ \\
\hline $\begin{array}{l}\text { Sprekelia } \\
\text { formosissima }\end{array}$ & $\begin{array}{l}\text { 6- } 12 \text { ins. } \\
\text { Blood red }\end{array}$ & $\begin{array}{l}\text { Mexico } \\
\text { Mid- } \\
\text { summer }\end{array}$ & $\begin{array}{l}\text { Sandy } \\
\text { fibrous } \\
\text { loam and } \\
\text { leaf- } \\
\text { mould }\end{array}$ & $\begin{array}{l}\text { Amaryllis Order. Jaco- } \\
\text { bæa Lily. Remarkable } \\
\text { in form and colour. } \\
\text { Bulbs can be stored } \\
\text { through the winter. }\end{array}$ \\
\hline
\end{tabular}




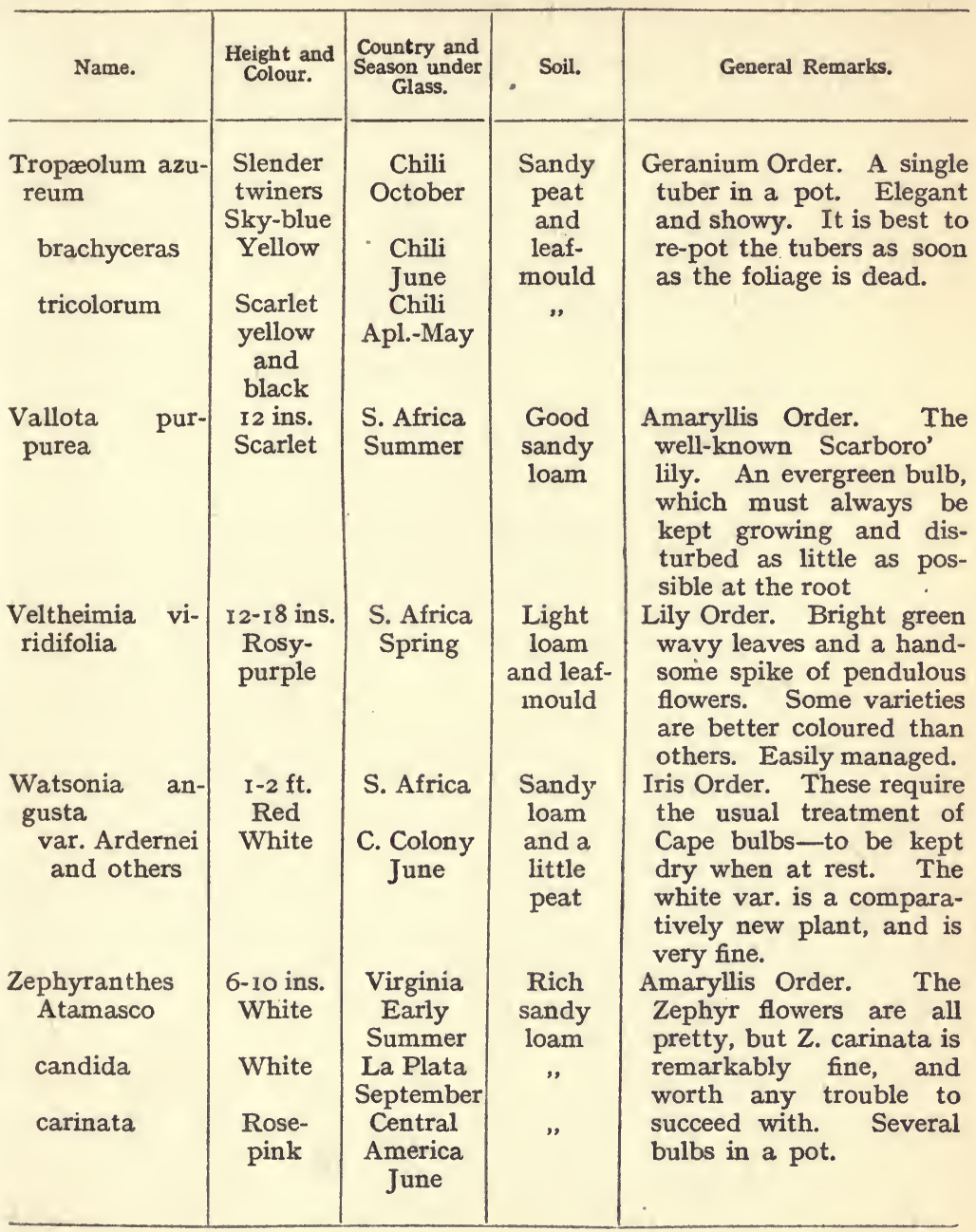




\section{LILIES FOR POTS}

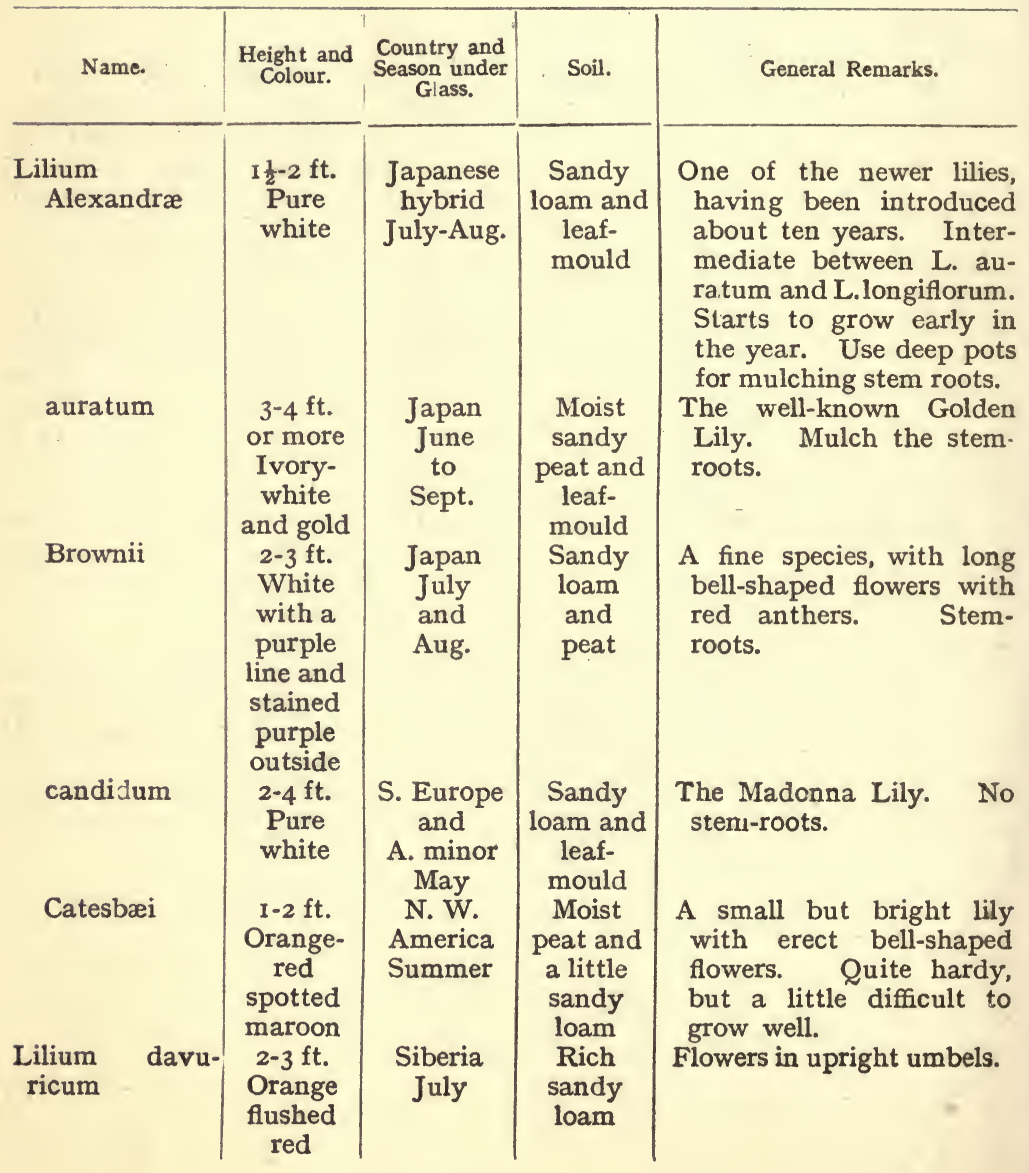




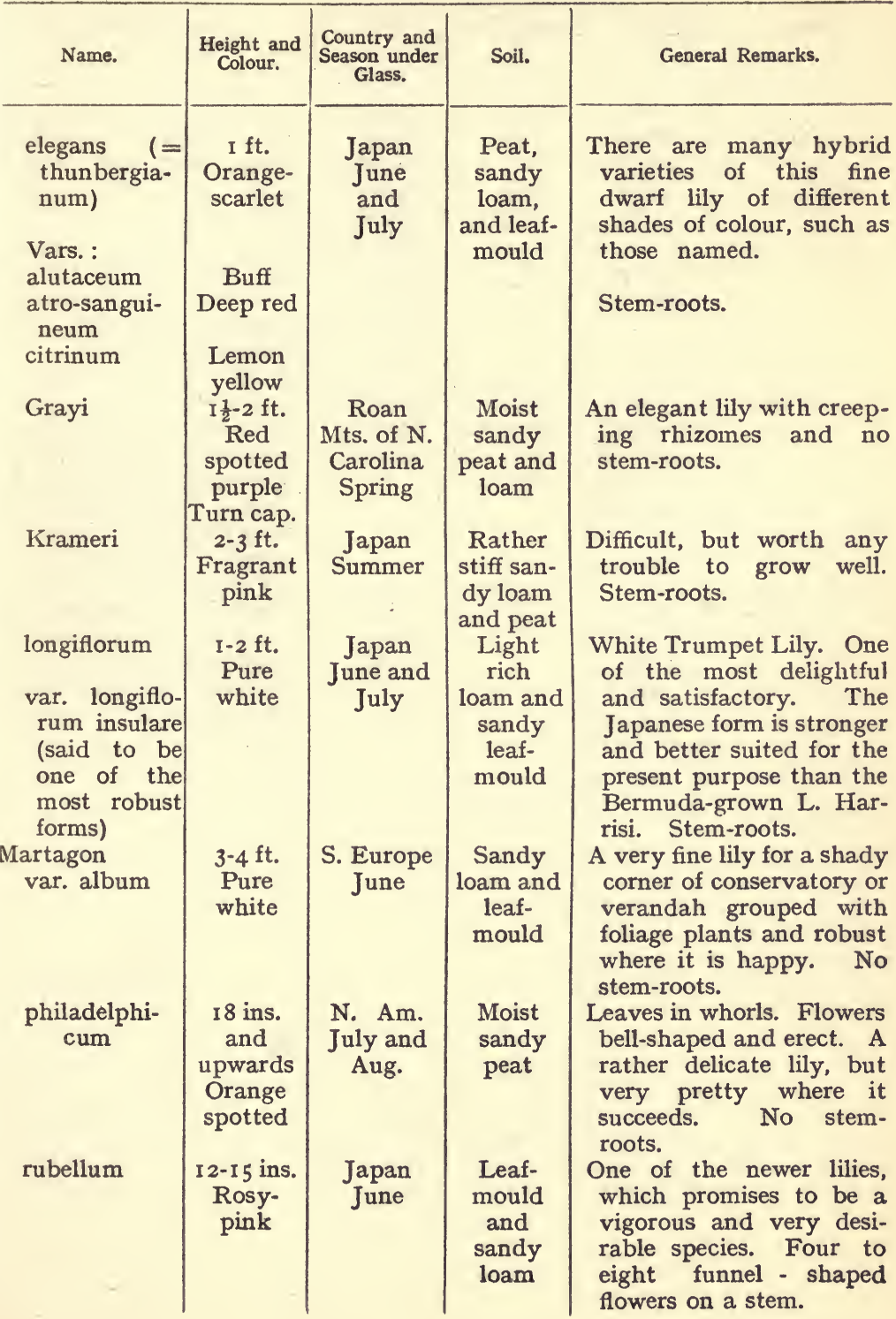




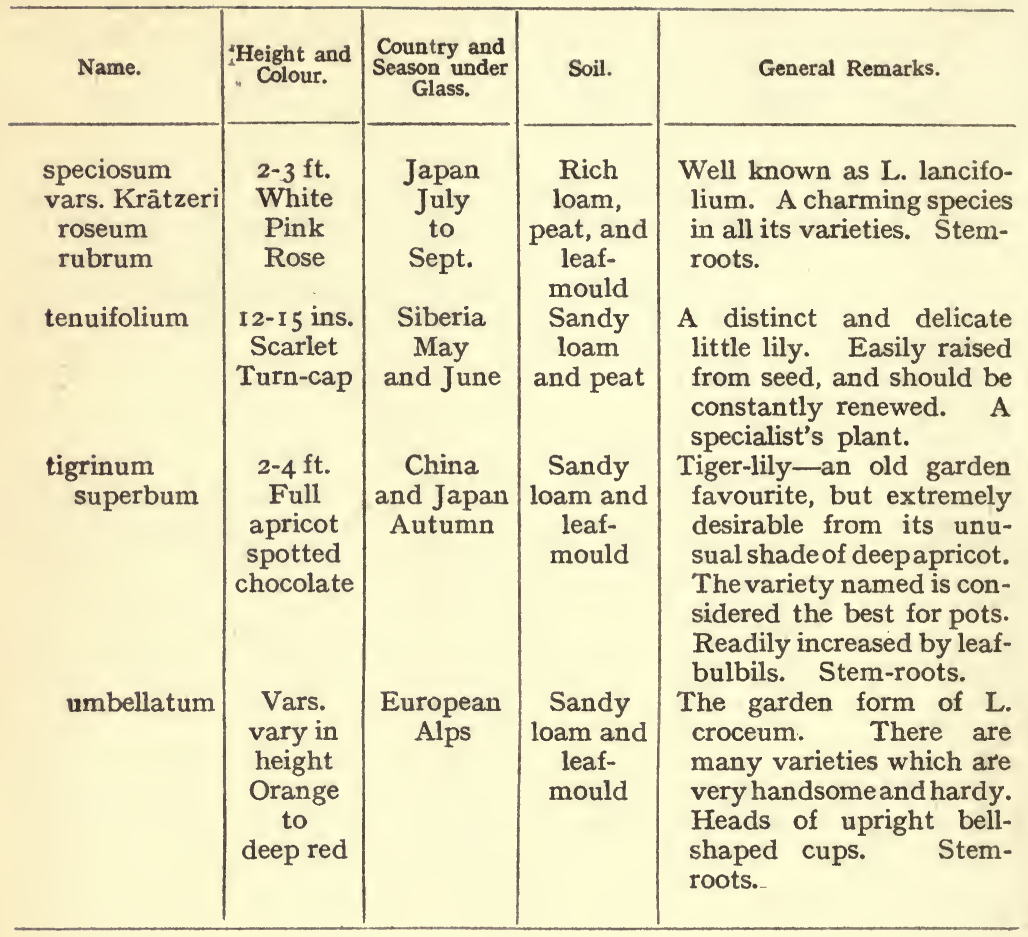




\section{HARDY FOLIAGE PLANTS FOR GROUPING}

\begin{tabular}{|c|c|c|c|c|}
\hline Name. & $\begin{array}{l}\text { Height and } \\
\text { Colour. }\end{array}$ & $\begin{array}{l}\text { Country and } \\
\text { Season under } \\
\text { Glass. }\end{array}$ & Soil. & General Remarks. \\
\hline $\begin{array}{l}\text { Acanthus } \\
\text { latifolius } \\
\text { spinosus }\end{array}$ & $\begin{array}{l}\text { Ever- } \\
\text { green } \\
2-3 \mathrm{ft} .\end{array}$ & $\begin{array}{l}\text { Cent. and } \\
\text { S. Europe } \\
\text { ", }\end{array}$ & $\begin{array}{l}\text { Ordinary } \\
\text { potting } \\
\text { soil }\end{array}$ & $\begin{array}{l}\text { Acanthus Order. These } \\
\text { make fine pot plants, and } \\
\text { may be planted out to } \\
\text { recruit during the sum- } \\
\text { mer and lifted for winter } \\
\text { foliage. }\end{array}$ \\
\hline $\begin{array}{l}\text { Aralia Sieboldi } \\
=\text { Fatsia ja- } \\
\text { ponica }\end{array}$ & $\begin{array}{l}\mathrm{I}-3 \mathrm{ft} . \\
\text { Ever- } \\
\text { green }\end{array}$ & Japan & $\begin{array}{l}\text { Rich } \\
\text { potting } \\
\text { soil }\end{array}$ & $\begin{array}{l}\text { Ivy Order. A useful and } \\
\text { fine shrub either in a } \\
\text { small or large state. }\end{array}$ \\
\hline $\begin{array}{l}\text { Araucaria } \\
\text { Bidwillii } \\
\text { excelsa }\end{array}$ & $\begin{array}{l}\text { Ever- } \\
\text { green } \\
\text { ", }\end{array}$ & $\begin{array}{l}\text { Moreton } \\
\text { Bay } \\
\text { Norfolk I. }\end{array}$ & $\begin{array}{l}\text { Sandy } \\
\text { loam and } \\
\text { leaf- } \\
\text { mould }\end{array}$ & $\begin{array}{l}\text { Conifers. These two pines } \\
\text { are very useful in a small } \\
\text { state, and may be grown } \\
\text { in pots for years. They } \\
\text { can be raised from seed. }\end{array}$ \\
\hline $\begin{array}{l}\text { Bambusa } \\
\text { tessellata }\end{array}$ & $\begin{array}{l}2-2 \frac{1}{2} \mathrm{ft} . \\
\text { Large } \\
\text { leaved }\end{array}$ & $\begin{array}{c}\text { China } \\
\text { and Japan }\end{array}$ & $\begin{array}{l}\text { Good } \\
\text { rich } \\
\text { loam }\end{array}$ & $\begin{array}{l}\text { Grass Order. This is a } \\
\text { dwarfspecies, whichmight } \\
\text { be employed in various } \\
\text { ways, but some of the } \\
\text { taller bamboos should be } \\
\text { tried. They are largely } \\
\text { grown in Italy in pottery. }\end{array}$ \\
\hline $\begin{array}{l}\text { Centaurea } \\
\text { ragusina }\end{array}$ & $\begin{array}{l}\text { I-2 ft. } \\
\text { Silvery } \\
\text { foliage }\end{array}$ & S. Europe & $\begin{array}{l}\text { Sandy } \\
\text { loam }\end{array}$ & $\begin{array}{l}\text { Daisy Order. Handsome } \\
\text { where grey-toned leafage } \\
\text { is wanted. }\end{array}$ \\
\hline $\begin{array}{l}\text { Chamæcyparis } \\
\text { obtusa } \\
\text { pisifera }\end{array}$ & $\begin{array}{l}\text { Dwarf } \\
\text { Ever- } \\
\text { green }\end{array}$ & Japan & $\begin{array}{l}\text { Rich } \\
\text { and } \\
\text { rather } \\
\text { moist } \\
\text { loam, but } \\
\text { well } \\
\text { drained }\end{array}$ & $\begin{array}{l}\text { Conifers. Popularly } \\
\text { known as Retinosporas, } \\
\text { and valuable for winter } \\
\text { greenery. }\end{array}$ \\
\hline
\end{tabular}




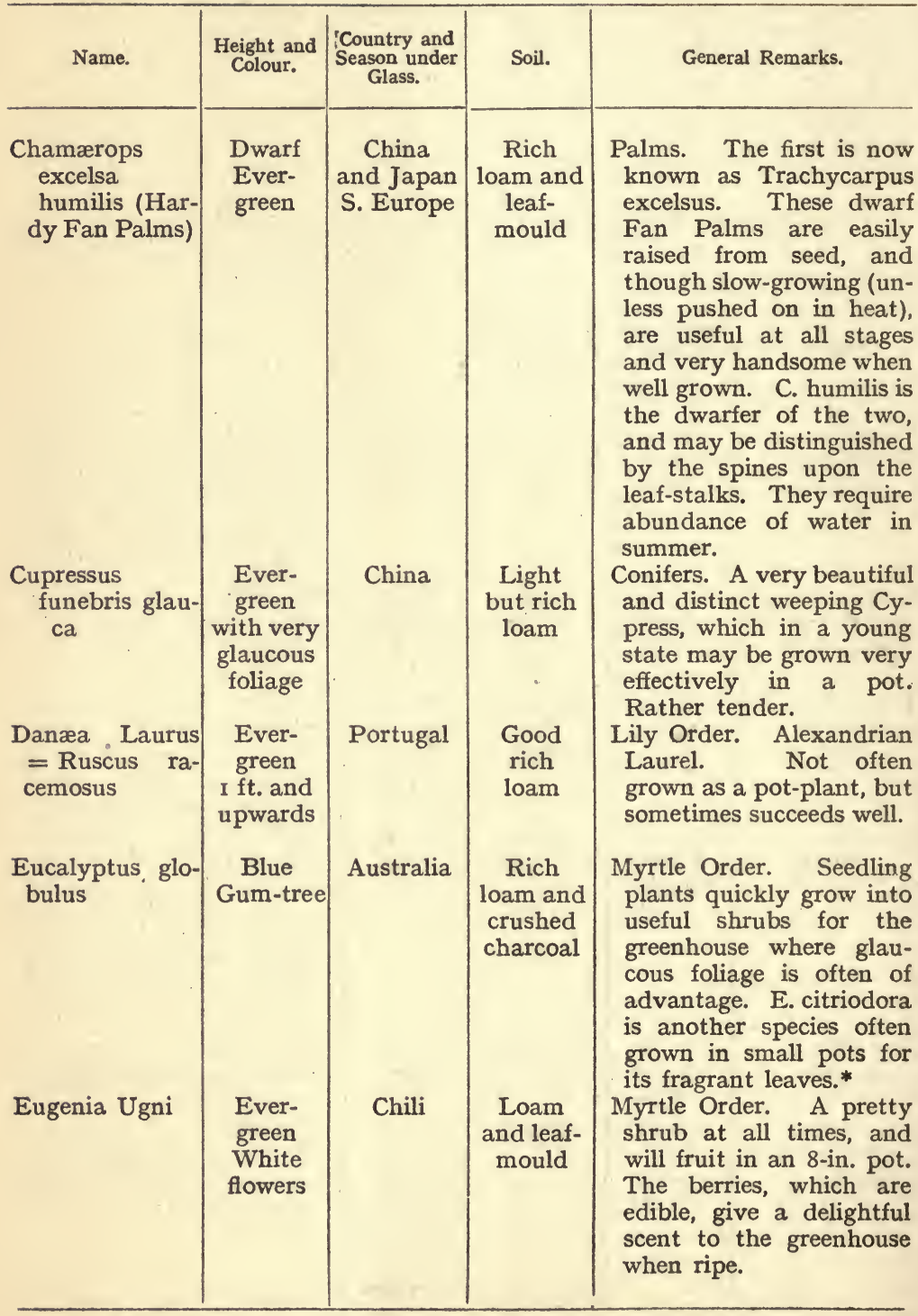

* E. globulus will stand a cortain amount of frost, where there is no draught. 


\begin{tabular}{|c|c|c|c|c|}
\hline Name. & $\begin{array}{l}\text { Height and } \\
\text { Colour. }\end{array}$ & $\begin{array}{l}\text { Country and } \\
\text { Season under } \\
\text { Glass. }\end{array}$ & Soil. & General Remarks. \\
\hline $\begin{array}{l}\text { Euonymus ra- } \\
\text { dicans varie- } \\
\text { gatus }\end{array}$ & $\begin{array}{l}\text { Dwarf } \\
\text { Ever- } \\
\text { green }\end{array}$ & Japan & $\begin{array}{l}\text { Ordinary } \\
\text { potting } \\
\text { soil }\end{array}$ & $\begin{array}{l}\text { Spindle-tree Order. The } \\
\text { var. named roseo-argen- } \\
\text { teis with a tinge of red in } \\
\text { the variegation is the } \\
\text { best form. }\end{array}$ \\
\hline $\begin{array}{l}\text { Funkia (Plan- } \\
\text { tain Lily) } \\
\text { grandiflora }\end{array}$ & $\begin{array}{l}\text { Herba- } \\
\text { ceous } \\
\text { I } 2-18 \text { ins. } \\
\text { White } \\
\text { flowers }\end{array}$ & $\begin{array}{l}\text { Japan } \\
\text { Autumn }\end{array}$ & $\begin{array}{l}\text { Rich } \\
\text { sandy } \\
\text { loam }\end{array}$ & $\begin{array}{l}\text { Lily Order. A flowering } \\
\text { plant, but invaluable as } \\
\text { greenery for associating } \\
\text { with other tall growing } \\
\text { lilies. Rather tender. }\end{array}$ \\
\hline sieboldiana & $\begin{array}{l}\text { Pale lilac } \\
\text { flowers }\end{array}$ & $"$ & ", & $\begin{array}{l}\text { Beautiful glaucous foliage } \\
\text { of a peculiar shade. Quite } \\
\text { hardy. }\end{array}$ \\
\hline Hedera Helix & $\begin{array}{l}\text { Climbers } \\
\text { or } \\
\text { trailers }\end{array}$ & $\begin{array}{l}\text { British } \\
\text { mostly }\end{array}$ & & $\begin{array}{l}\text { Ivy Order. All kinds of } \\
\text { Ivy are invaluable for the } \\
\text { cold greenhouse, and may }\end{array}$ \\
\hline $\begin{array}{cc}\begin{array}{cc}\text { Many } & \text { varie- } \\
\text { ties, } & \text { both } \\
\text { green } & \text { and } \\
\text { variegated }\end{array}\end{array}$ & & & & $\begin{array}{l}\text { be used in various ways- } \\
\text { for screens, hanging-pots, } \\
\& \text { c. The smaller varieties } \\
\text { are best for pots. All can } \\
\text { be struck easily from cut- } \\
\text { tings, but some of the } \\
\text { variegated kinds are } \\
\text { rather tender and root } \\
\text { best under a bell-glass in } \\
\text { shade and moisture. }\end{array}$ \\
\hline $\begin{array}{l}\text { Mühlenbeckia } \\
\text { complexa }\end{array}$ & $\begin{array}{l}\text { Ever- } \\
\text { green } \\
\text { climber } \\
\text { or } \\
\text { trailer } \\
\text { with long } \\
\text { wiry } \\
\text { stems }\end{array}$ & $\begin{array}{c}\text { New } \\
\text { Zealand }\end{array}$ & $\begin{array}{l}\text { Moist } \\
\text { gritty } \\
\text { loam }\end{array}$ & $\begin{array}{l}\text { Buckwheat Order. In a } \\
\text { small state this makes a } \\
\text { pretty basket-plant. May } \\
\text { be freely cut, and the } \\
\text { dark stems with small } \\
\text { Spleen-wort-like leaves } \\
\text { are very useful in floral } \\
\text { decorations. }\end{array}$ \\
\hline $\begin{array}{l}\text { Myrtus commu- } \\
\text { nis } \\
\text { Many vars. }\end{array}$ & $\begin{array}{l}\text { Ever- } \\
\text { green } \\
\text { bush }\end{array}$ & $\begin{array}{l}\text { S. Europe } \\
\text { Fls. July }\end{array}$ & $\begin{array}{l}\text { Sandy } \\
\text { loam and } \\
\text { leaf- } \\
\text { mould }\end{array}$ & $\begin{array}{l}\text { Myrtle Order. Both the } \\
\text { Common and the Box- } \\
\text { leaved Myrtles (fls. Sept.) } \\
\text { are good stand-by plants } \\
\text { for cold greenhouse. Sy- } \\
\text { ringe often in summer. }\end{array}$ \\
\hline $\begin{array}{l}\text { Nandina domes- } \\
\text { tica }\end{array}$ & $\begin{array}{l}\text { Erect } \\
\text { ever- } \\
\text { green } \\
3-5 \mathrm{ft} \text {. }\end{array}$ & $\begin{array}{l}\text { China } \\
\text { Red } \\
\text { fruit }\end{array}$ & $\begin{array}{l}\text { Loam } \\
\text { and } \\
\text { sandy } \\
\text { peat }\end{array}$ & $\begin{array}{l}\text { Barberry Order. A hand- } \\
\text { some Bamboo-like plant. } \\
\text { Young foliage tinged with } \\
\text { red. }\end{array}$ \\
\hline
\end{tabular}




\begin{tabular}{|c|c|c|c|c|}
\hline Name. & $\begin{array}{l}\text { Height and } \\
\text { Colour. }\end{array}$ & $\begin{array}{l}\text { Country and } \\
\text { Season under } \\
\text { Glass. }\end{array}$ & Soil. & General Remarks: \\
\hline $\begin{array}{c}\text { Origanum Dic- } \\
\text { tamnus }\end{array}$ & $\begin{array}{l}\text { 6-9 ins. } \\
\text { Grey- } \\
\text { green } \\
\text { herb }\end{array}$ & $\begin{array}{l}\text { Crete } \\
\text { Summer }\end{array}$ & $\begin{array}{l}\text { Sandy } \\
\text { loam }\end{array}$ & $\begin{array}{l}\text { Lavender Order. A pretty } \\
\text { little plant with grey } \\
\text { woolly leaves and hop- } \\
\text { like heads of flower with } \\
\text { pinky-green bracts. }\end{array}$ \\
\hline $\begin{array}{l}\text { Othonna cheiri- } \\
\text { folia }\end{array}$ & $\begin{array}{l}9 \text { ins. } \\
\text { Prostrate } \\
\text { stems } \\
\text { Yellow } \\
\text { fls. }\end{array}$ & N. Africa & " & $\begin{array}{l}\text { Daisy Order. A semi-suc- } \\
\text { culent perennial with } \\
\text { glaucous foliage. }\end{array}$ \\
\hline $\begin{array}{l}\text { Phalaris arun- } \\
\text { dinacea varie- } \\
\text { gata (Ribbon } \\
\text { Grass) }\end{array}$ & $2-3 \mathrm{ft}$ & British & $\begin{array}{l}\text { Moist } \\
\text { sandy } \\
\text { loam }\end{array}$ & $\begin{array}{l}\text { Grass Order. Useful for } \\
\text { foliage with early bulbs. } \\
\text { Several of the annual } \\
\text { grasses may be grown in } \\
\text { pots for the same purpose } \\
\text {-e.g., Hordeum iubatum } \\
\text { (Squirrel tail grass), La- } \\
\text { gurus ovatus (Hare's tail } \\
\text { grass), and Briza maxima } \\
\text { (Quaking grass). }\end{array}$ \\
\hline $\begin{array}{l}\text { Polygonatum } \\
\text { multiflorum } \\
\text { (Solomon's } \\
\text { Seal) }\end{array}$ & $\mathrm{I} \frac{1}{2}-2 \mathrm{ft}$. & European & $\begin{array}{l}\text { Rich } \\
\text { sandy } \\
\text { loam }\end{array}$ & $\begin{array}{l}\text { Lily Order. Invaluable } \\
\text { for arching foliage with } \\
\text { Spring bulbs. }\end{array}$ \\
\hline $\begin{array}{c}\text { Reineckia car- } \\
\text { nea variegata }\end{array}$ & $\begin{array}{l}\text { Creeping } \\
\text { rhizomes }\end{array}$ & Japan & $\begin{array}{l}\text { Loam } \\
\text { and leaf- } \\
\text { mould }\end{array}$ & $\begin{array}{l}\text { Lily Order. Tufts of } \\
\text { lance-shaped leaves with } \\
\text { cream-white stripes. }\end{array}$ \\
\hline $\begin{array}{c}\text { Senecio mari- } \\
\text { tima }\end{array}$ & $\begin{array}{l}\mathrm{I}-\mathrm{I} \frac{1}{2} \mathrm{ft} \text {. } \\
\text { Silver- } \\
\text { white } \\
\text { foliage }\end{array}$ & S. France & $\begin{array}{l}\text { Sandy } \\
\text { loam }\end{array}$ & $\begin{array}{l}\text { Daisy Order. Better } \\
\text { known as Cineraria marn- } \\
\text { tima. Easily raised from } \\
\text { seed, but a good variety } \\
\text { should be selected and } \\
\text { increased by cuttings. }\end{array}$ \\
\hline $\begin{array}{l}\text { mikanoides } \\
\text { (German Ivy }\end{array}$ & Climber & S. Africa & $\begin{array}{l}\text { Ordinary } \\
\text { potting } \\
\text { soil }\end{array}$ & $\begin{array}{l}\text { Useful where a quici } \\
\text { growth is wanted for } \\
\text { trellis or otherwise. Na- } \\
\text { turalised in Cornwall, but } \\
\text { must not be mistaken for } \\
\text { Cape Ivy (S. macrog- } \\
\text { lossus), which is more } \\
\text { tender. }\end{array}$ \\
\hline
\end{tabular}




\begin{tabular}{|c|c|c|c|c|}
\hline Name. & $\begin{array}{l}\text { Height and } \\
\text { Colour. }\end{array}$ & $\begin{array}{c}\text { Country and } \\
\text { Season under } \\
\text { Glass. }\end{array}$ & Soil. & General Remarks. \\
\hline $\begin{array}{l}\text { Sibthorpia euro- } \\
\text { pæa variegata }\end{array}$ & $\begin{array}{l}\text { Minute } \\
\text { trailer }\end{array}$ & British & $\begin{array}{c}\text { Moist } \\
\text { peat and } \\
\text { loam }\end{array}$ & $\begin{array}{l}\text { Foxglove Order. The } \\
\text { green-leaved type is a } \\
\text { rare British plant, car- } \\
\text { petting boggy spots in } \\
\text { Cornwall. The variegated } \\
\text { form is a charming little } \\
\text { trailer, each little leaf } \\
\text { being bordered with white } \\
\text { and succeeds well with } \\
\text { living sphagnum in a } \\
\text { basket. }\end{array}$ \\
\hline $\begin{array}{l}\text { Veronica } \\
\text { pressoides }\end{array}$ & $\begin{array}{l}\text { Dwarf } \\
\text { shrub } \\
\text { I } 2 \text { ins. } \\
\text { I-2 ft. }\end{array}$ & N. Zealand & $\begin{array}{c}\text { Moist } \\
\text { sandy } \\
\text { loam and } \\
\text { leaf- } \\
\text { mould }\end{array}$ & $\begin{array}{l}\text { Foxglove Order. These } \\
\text { interesting shrubby Ve- } \\
\text { ronicas somewhat resem- } \\
\text { ble certain forms of Coni- } \\
\text { fers. They are often } \\
\text { allowed to starve for want } \\
\text { of water. }\end{array}$ \\
\hline
\end{tabular}




\section{FERNS (BRITISH AND FOREIGN)}

The soil in which most ferns will flourish is sandy peat and leaf-mould.

\begin{tabular}{|c|c|c|c|}
\hline Name. & $\begin{array}{l}\text { Height and } \\
\text { Colour. }\end{array}$ & $\begin{array}{l}\text { Country and } \\
\text { Season under } \\
\text { Glass. }\end{array}$ & Genera Remarks. \\
\hline $\begin{array}{l}\text { Adiantum Ca- } \\
\text { pillus-veneris } \\
\text { var. grande }\end{array}$ & 6-12 ins. & $\begin{array}{l}\text { Temp. } \\
\text { Zone }\end{array}$ & $\begin{array}{l}\text { Evergreen. There are many va- } \\
\text { rieties of the Common Maidenhair. } \\
\text { This is a fine sort with very large } \\
\text { leaflets. }\end{array}$ \\
\hline pedatum & 9-1 2 ins. & N. Am. & $\begin{array}{l}\text { Deciduous. Other Adiantums, } \\
\text { such as A. cuneatum and A. for- } \\
\text { mosum; will succeed perfectly } \\
\text { where frost is excluded, but are } \\
\text { only half-hardy. }\end{array}$ \\
\hline $\begin{array}{l}\text { Aspidium acule- } \\
\text { atum, var. pro- } \\
\text { liferum }\end{array}$ & $\mathrm{I}-2 \mathrm{ft}$ & British & $\begin{array}{l}\text { Prickly-shield Fern. Many beau- } \\
\text { tiful varieties. }\end{array}$ \\
\hline falcatum & I $2-15$ ins. & Japan & \\
\hline Lonchitis & 10- 18 ins. & zome & Holly Fern. \\
\hline Asplenium & & & Black Maidenhair Spleenwort. \\
\hline $\begin{array}{l}\text { Adiantum-ni- } \\
\text { grum }\end{array}$ & 4-12 ins. & British & "French Fern" of the florist. \\
\hline bulbiferum & $\begin{array}{l}\text { I } 2-18 \text { ins. } \\
\text { or more }\end{array}$ & Australia & A vigorous and useful fern. \\
\hline Ceterach & $\begin{array}{l}3 \text { ins. in } \\
\text { dense tuft }\end{array}$ & British & Scaly Spleen-wort. \\
\hline $\begin{array}{c}\text { Felix-fœmina } \\
\text { var. plumosum }\end{array}$ & $2-3 \mathrm{ft}$ & $"$ & $\begin{array}{l}\text { Lady Fern. Many very beautiful } \\
\text { forms. }\end{array}$ \\
\hline flaccidum & $\begin{array}{l}\text { Long } \\
\text { weeping } \\
\text { fronds }\end{array}$ & Australia & A form of A. bulbiferum. \\
\hline marinum & $4^{-12} \mathrm{ins}$. & British & $\begin{array}{l}\text { Sea Spleen-wort. Grows best in } \\
\text { moist shade, sheltered from } \\
\text { draught. }\end{array}$ \\
\hline
\end{tabular}




\begin{tabular}{|c|c|c|c|}
\hline Name. & $\begin{array}{l}\text { Height and } \\
\text { Colour. }\end{array}$ & $\begin{array}{l}\text { Country and } \\
\text { Season under } \\
\text { Glass. }\end{array}$ & General Remarks. \\
\hline Trichomanes & $\begin{array}{l}\text { Tufts of } \\
\text { narrow } \\
\text { fronds }\end{array}$ & British & $\begin{array}{l}\text { Maidenhair Spleenwort. This and } \\
\text { A. Ceterach are good for moist } \\
\text { rock work at the edge of a green- } \\
\text { house pool or fountain. }\end{array}$ \\
\hline $\begin{array}{l}\text { Blechnum Spi- } \\
\text { cant (= Lo- } \\
\text { maria) }\end{array}$ & $\begin{array}{l}\text { 9-12 ins. } \\
\text { and upw. }\end{array}$ & British & $\begin{array}{l}\text { Hard fern. Bog soil kept moist. } \\
\text { Many good forms. Evergreen. }\end{array}$ \\
\hline $\begin{array}{l}\text { Cheilanthes fra- } \\
\text { grans }\end{array}$ & $2-4$ ins. & S. Europe & $\begin{array}{l}\text { Half-hardy. A small but beautiful } \\
\text { fern and sweet-scented. }\end{array}$ \\
\hline $\begin{array}{l}\text { Cryptogramma } \\
\text { crispa }\end{array}$ & 6-10 ins. & $\begin{array}{l}\text { N. Temp. } \\
\text { zone }\end{array}$ & $\begin{array}{l}\text { Parsley Fern. Deciduous. Plant } \\
\text { between stones in pot or pan. }\end{array}$ \\
\hline $\begin{array}{l}\text { Cystopteris } \\
\text { bulbifera } \\
\text { fragilis }\end{array}$ & & $\begin{array}{l}\text { N. Am. } \\
\text { British }\end{array}$ & $\begin{array}{l}\text { Bladder Fern. A deciduous species. } \\
\text { Multiplied by numerous small } \\
\text { dark-green bulblets, which fall and } \\
\text { become new plants. C. fragilis is } \\
\text { also deciduous but very hardy and } \\
\text { elegant. Suitable for small rock- } \\
\text { work. }\end{array}$ \\
\hline $\begin{array}{c}\text { Davallia cana- } \\
\text { riensis }\end{array}$ & I $2-18$ ins. & Canaries & $\begin{array}{l}\text { Hare's-foot Fern. Deciduous and } \\
\text { half-hardy. }\end{array}$ \\
\hline Doodia aspera & $6-12$ ins. & $\begin{array}{l}\text { Temp. } \\
\text { Australia }\end{array}$ & Evergreen, but half-hardy. \\
\hline $\begin{array}{l}\text { Nephrodium di- } \\
\text { latatum }\end{array}$ & $2-3 \mathrm{ft}$. & British & Broad Buckler Fern. \\
\hline Filix-mas & $\mathrm{I}-3 \mathrm{ft}$ & N 7 eolad & Male Buckler Fern. \\
\hline $\begin{array}{l}\text { hispldum } \\
\text { Nephrolepis ex- } \\
\text { altata }\end{array}$ & $\begin{array}{l}\text { I } 2-18 \text { ins. } \\
\text { 1-2 ft. }\end{array}$ & $\begin{array}{l}\text { N. Zealand } \\
\text { Tropics }\end{array}$ & $\begin{array}{l}\text { Half-hardy. } \\
\text { This fine fern, though tender, will } \\
\text { succeed with care in a room in } \\
\text { winter. Greenhouse where it can } \\
\text { be kept rather moist in summer. }\end{array}$ \\
\hline $\begin{array}{l}\text { Onoclea ger- } \\
\text { manica } \quad(= \\
\text { Struthiopteris } \\
\text { germanica) } \\
\text { sensibilis }\end{array}$ & & $\begin{array}{l}\text { N. Temp. } \\
\text { zone } \\
\text { but not } \\
\text { British } \\
\text { N. Am. }\end{array}$ & $\begin{array}{l}\text { Ostrich Fern. These are large- } \\
\text { growing, handsome ferns, belonging } \\
\text { to the so-called Flowering Ferns } \\
\text { like Osmunda. Better for planting } \\
\text { out than for pots. }\end{array}$ \\
\hline $\begin{array}{l}\text { Onychium } \\
\text { ponicum }\end{array}$ & I 2 - I 5 ins. & $\begin{array}{l}\text { China and } \\
\text { Japan }\end{array}$ & $\begin{array}{l}\text { A light graceful fern suitable for } \\
\text { pots. }\end{array}$ \\
\hline $\begin{array}{l}\text { Osmunda cinna- } \\
\text { momea }\end{array}$ & $2-3 \mathrm{ft}$. & Canada & Flowering Ferns. \\
\hline claytoniana & $\mathrm{I}-2 \mathrm{ft}$. & $\begin{array}{c}\text { Himalayas } \\
\text { and N. } \\
\text { America }\end{array}$ & \\
\hline $\begin{array}{l}\text { regalis } \\
\text { Pellæa hastata }\end{array}$ & $\begin{array}{l}2-4 \mathrm{ft} . \\
6-12 \text { ins. }\end{array}$ & $\begin{array}{l}\text { British } \\
\text { S. Africa }\end{array}$ & $\begin{array}{l}\text { Royal Fern. } \\
\text { A pretty half-hardy species. }\end{array}$ \\
\hline
\end{tabular}




\begin{tabular}{|c|c|c|c|}
\hline Name. & $\begin{array}{l}\text { Height and } \\
\text { Colour. }\end{array}$ & $\begin{array}{l}\text { Country and } \\
\text { Season under } \\
\text { Glass. }\end{array}$ & General Remarks. \\
\hline $\begin{array}{l}\text { Polypodium au- } \\
\text { reum }\end{array}$ & I-2 ft. & & $\begin{array}{l}\text { Tender, but does well in a room in } \\
\text { winter. }\end{array}$ \\
\hline Dryopteris & 6-10 ins. & British & Oak Fern. Deciduous. \\
\hline $\begin{array}{l}\text { Phegopteris } \\
\text { var. crista- } \\
\text { tum }\end{array}$ & 6-9 ins. & " & $\begin{array}{l}\text { Beech Fern. Deciduous. } \\
\text { A fine crested form. }\end{array}$ \\
\hline $\begin{array}{l}\text { P. vulgare } \\
\text { var. cambri- } \\
\text { cum } \\
\text { var. elegantis- }\end{array}$ & 9-1 2 ins. & British & $\begin{array}{l}\text { Common Polypody and fine varie- } \\
\text { ties. This fern likes plenty of } \\
\text { moisture both at the root and on } \\
\text { the fronds. }\end{array}$ \\
\hline $\begin{array}{l}\text { var. elegantis- } \\
\text { simum }\end{array}$ & 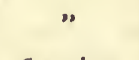 & & the fronds. \\
\hline $\begin{array}{cc}\text { Pteris } & \text { cretica, } \\
\text { var. } & \text { albo-li- } \\
\text { neata } & \end{array}$ & $6-12$ ins. & Crete & $\begin{array}{l}\text { Brake Ferns-the group to which } \\
\text { our common Bracken belongs. } \\
\text { P. cretica and P. serrulata are }\end{array}$ \\
\hline scaberula & I $2-15$ ins. & N. Zealand & $\begin{array}{l}\text { amongst the best known of our } \\
\text { ordinary greenhouse ferns. }\end{array}$ \\
\hline serrulata & 9-1 8 ins. & China & The common Ribbon Fern. \\
\hline tremula & $\begin{array}{l}2 \mathrm{ft} \text {. and } \\
\text { upwards }\end{array}$ & Australia & A handsome pale green species. \\
\hline $\begin{array}{l}\text { Scolopendrium } \\
\text { vulgare }\end{array}$ & $6-18$ ins. & British & $\begin{array}{l}\text { Hart's tongue, of which there are } \\
\text { many beautiful frilled and crested } \\
\text { varieties. }\end{array}$ \\
\hline $\begin{array}{l}\text { Trichomanes ra- } \\
\text { dicans }\end{array}$ & $4^{-12}$ ins. & Ireland & $\begin{array}{l}\text { The Killarney Fern. A very fine } \\
\text { fern, but, like all the Filmy ferns, } \\
\text { succeeds best under a bell-glass or } \\
\text { in a Wardian Case. }\end{array}$ \\
\hline $\begin{array}{l}\text { Woodsia hyper- } \\
\text { borea }\end{array}$ & & $\begin{array}{l}\text { Arc. } \\
\text { Europe }\end{array}$ & $\begin{array}{l}\text { Small tufted ferns, liking coolness } \\
\text { and moisture. }\end{array}$ \\
\hline $\begin{array}{l}\text { ilvensis } \\
\text { obtusa }\end{array}$ & $\begin{array}{l}3-6 \text { ins. } \\
6-9 \text { ins. }\end{array}$ & $\begin{array}{l}\text { I. of Elba } \\
\text { U. S. Am. }\end{array}$ & \\
\hline $\begin{array}{l}\text { Woodwardia ra- } \\
\text { dicans }\end{array}$ & $2-3 \mathrm{ft}$. & & $\begin{array}{l}\text { A very large handsome fern of } \\
\text { drooping habit, proliferous at the } \\
\text { tips of the fronds. }\end{array}$ \\
\hline
\end{tabular}




\section{FERN ALLIES}

\begin{tabular}{|c|c|c|c|}
\hline Name. & $\begin{array}{l}\text { Height and } \\
\text { Colour. }\end{array}$ & $\begin{array}{l}\text { Country and } \\
\text { Season under } \\
\text { Glass. }\end{array}$ & General Remarks. \\
\hline $\begin{array}{l}\text { Equisetum syl- } \\
\text { vaticum }\end{array}$ & $\mathrm{I}-2 \mathrm{ft}$ & British & $\begin{array}{l}\text { Wood Horse-tail. A very elegant } \\
\text { plant, too spreading to plant out; } \\
\text { but may be grown in a pot or pan } \\
\text { to sink amongst stones at the edge } \\
\text { of greenhouse pool. }\end{array}$ \\
\hline $\begin{array}{l}\text { Selaginella den- } \\
\text { ticulata }\end{array}$ & $\begin{array}{l}\text { Trailing } \\
\text { and }\end{array}$ & S. Europe & The ordinary " Lycopodium." \\
\hline helvetica & moss-like & $\begin{array}{l}\text { Switzer- } \\
\text { land }\end{array}$ & $\begin{array}{l}\text { A very hardy species, but does not } \\
\text { mat so much. Excellent for } \\
\text { feathering up damp stones. }\end{array}$ \\
\hline uncinata & ", & China & $\begin{array}{l}\text { The blue-tinted Selaginella }=\mathrm{S} \text {. } \\
\text { cæsia. Half-hardy. Cuttings put } \\
\text { in early in autumn will winter well } \\
\text { under a bell-glass, and will make } \\
\text { good plants for the following } \\
\text { season. }\end{array}$ \\
\hline
\end{tabular}




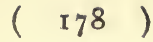

\section{FLOWERING SHRUBS WHICH MAY BE GROWN IN POTS (MISCELLANEOUS)}

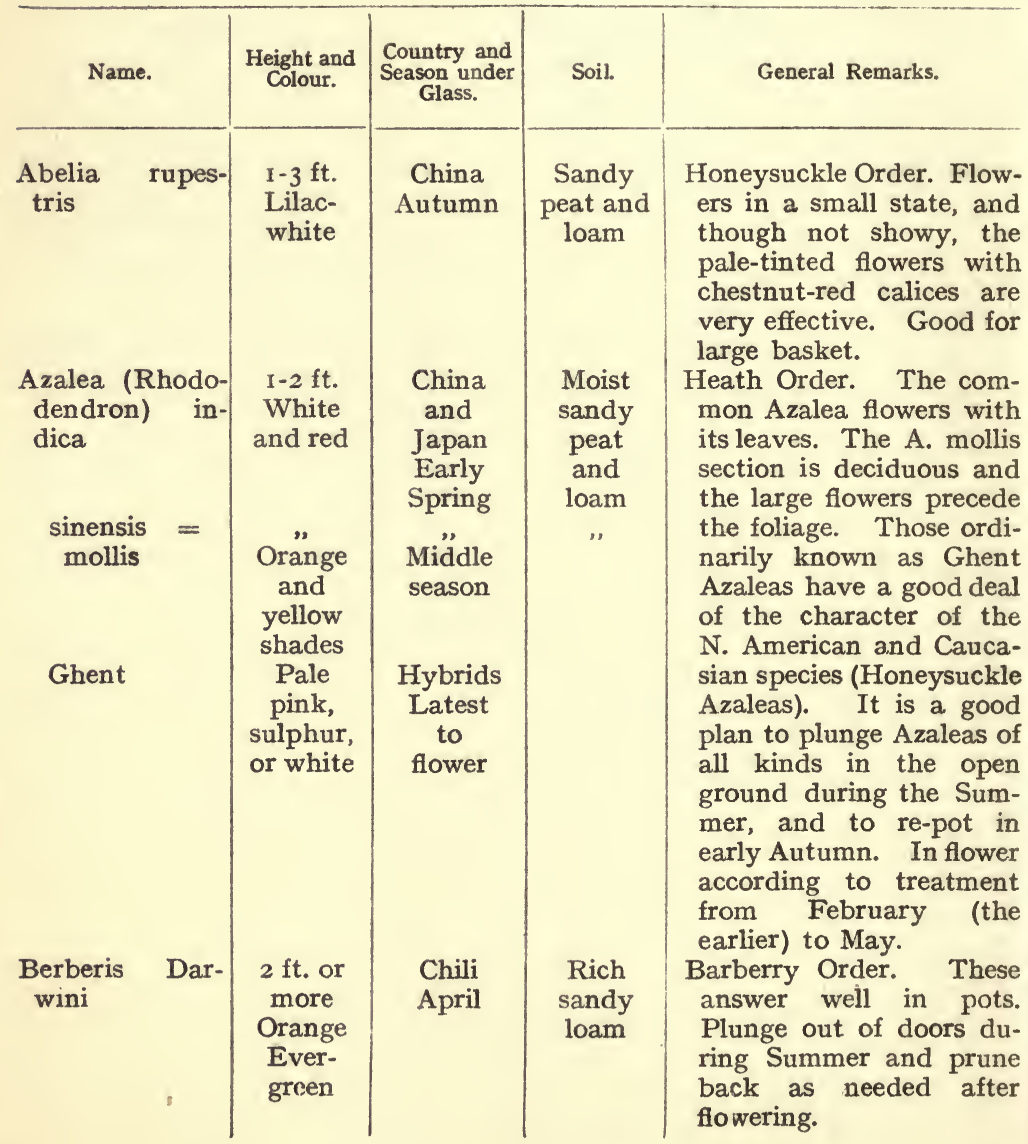




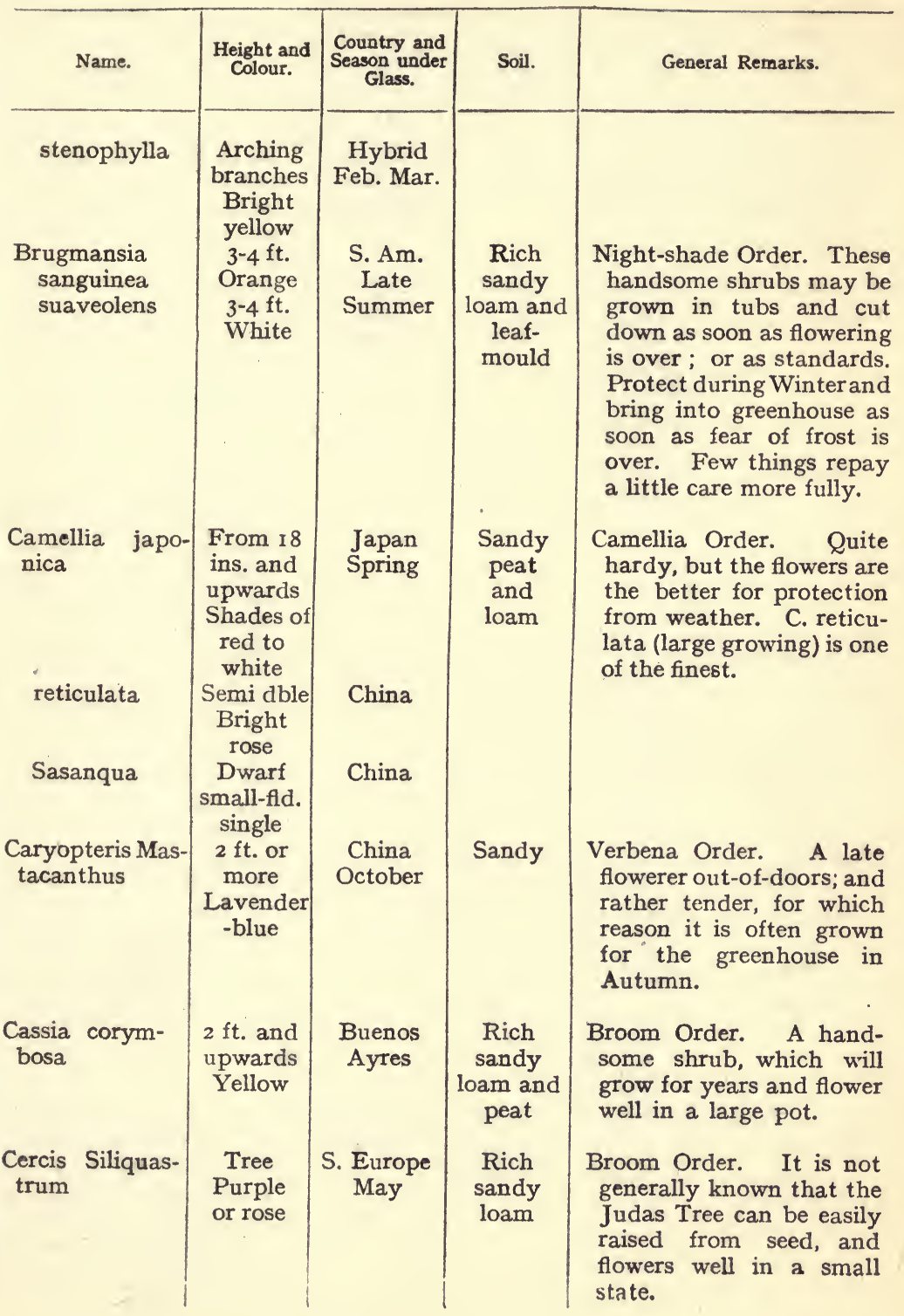




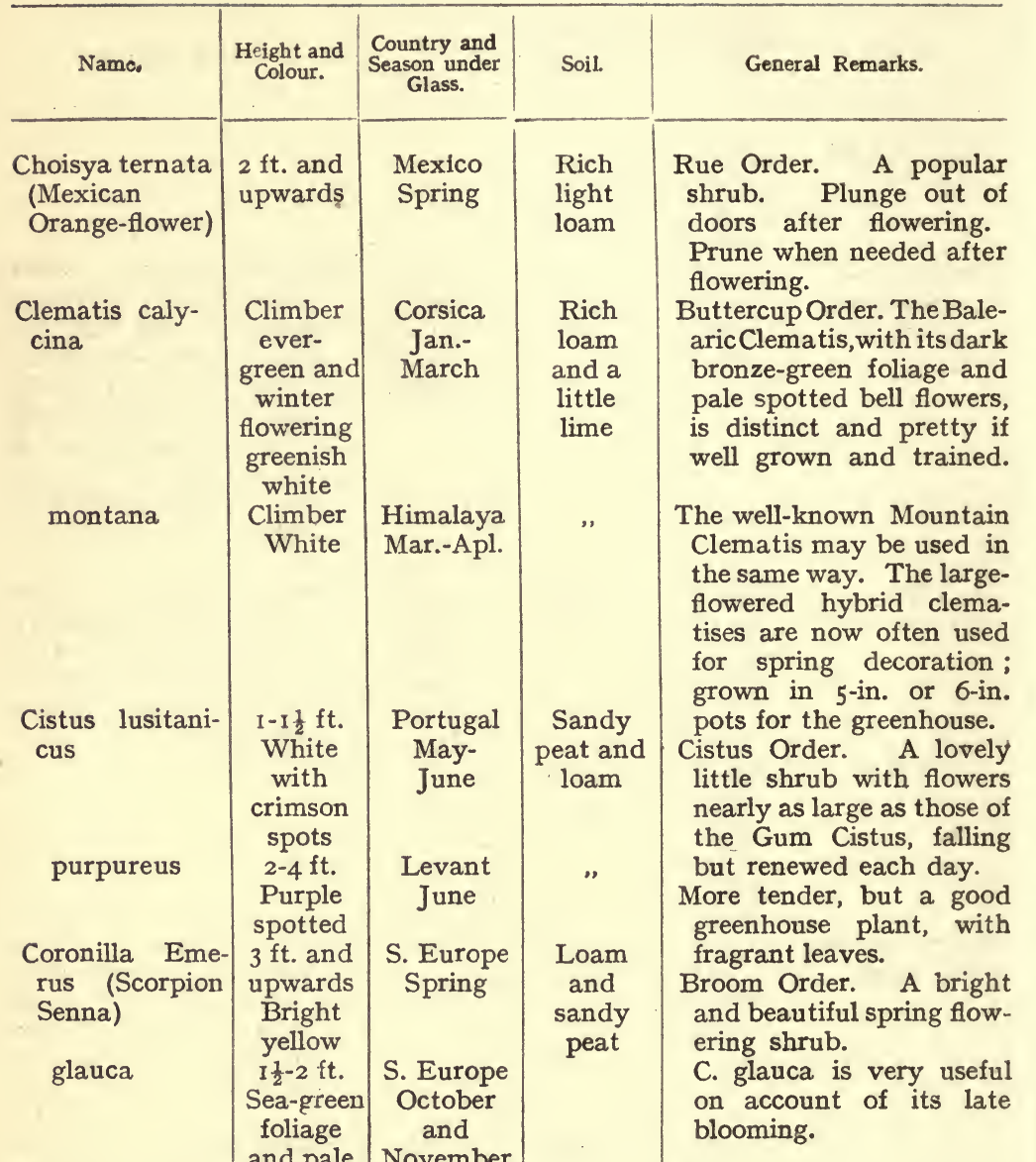

Cytisus fragrans filipes racemosus and pale yellow flowers Yellow

White
November

Canary Islands Teneriffe
Sandy loam
Broom Order. Hardy in the southern counties, and may be grown in greenhouse protected from actual frost. C. filipes is very graceful as a weeping plant grafted on laburnum. 


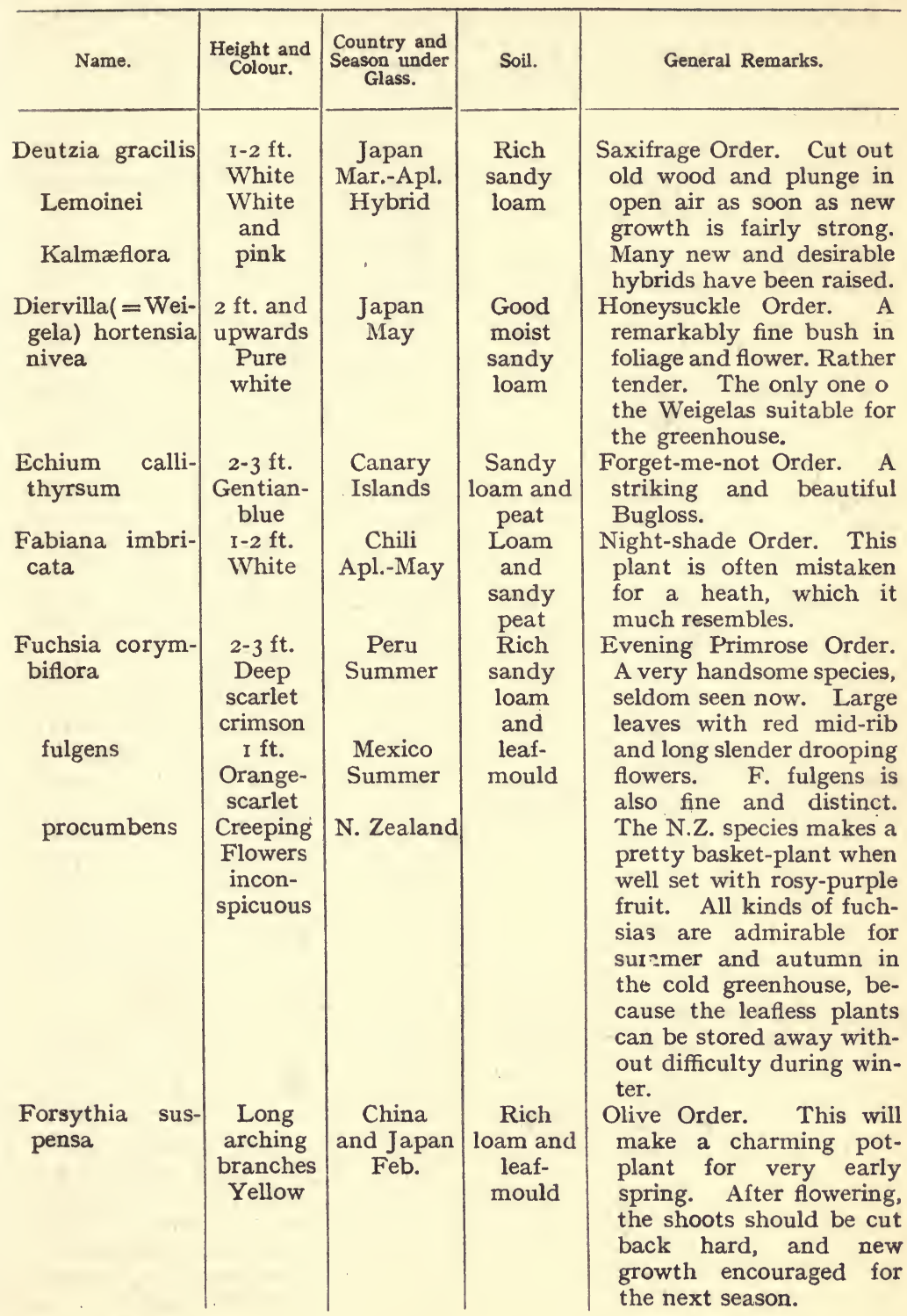




\begin{tabular}{|c|c|c|c|c|}
\hline Name. & $\begin{array}{l}\text { Height and } \\
\text { Colour. }\end{array}$ & $\begin{array}{l}\text { Country and } \\
\text { Season under } \\
\text { Glass. }\end{array}$ & Soil. & General Remarks. \\
\hline $\begin{array}{l}\text { Gillenia trifo- } \\
\text { liata }\end{array}$ & $\begin{array}{c}\mathrm{I}-2 \mathrm{ft} . \\
\text { Pink and } \\
\text { white }\end{array}$ & $\begin{array}{l}\text { N. Am. } \\
\text { June and } \\
\text { July }\end{array}$ & $\begin{array}{l}\text { Moist } \\
\text { sandy } \\
\text { peat and } \\
\text { loam }\end{array}$ & $\begin{array}{l}\text { Rose Order. An elegant } \\
\text { little shrub somewhat like } \\
\text { Spiræa. }\end{array}$ \\
\hline $\begin{array}{l}\text { var. Thomas } \\
\text { Hogg }\end{array}$ & $\begin{array}{l}\text { I-2 ft. } \\
\text { Pink or } \\
\text { blue }\end{array}$ & $\begin{array}{l}\text { China } \\
\text { Early } \\
\text { summer } \\
\text { to } \\
\text { autumn }\end{array}$ & $\begin{array}{l}\text { Rich } \\
\text { gritty } \\
\text { loam }\end{array}$ & $\begin{array}{l}\text { Saxifrage Order. No spe- } \\
\text { cific compost has yet been } \\
\text { discovered to give blue } \\
\text { flowers without fail. } \\
\text { Crushed Cornish granite } \\
\text { in the soil and sea-air } \\
\text { seem to favour their pro- } \\
\text { duction. The white var. } \\
\text { is very good. }\end{array}$ \\
\hline $\begin{array}{l}\text { Hypericum chi- } \\
\text { nensis }\end{array}$ & $\begin{array}{l}8-12 \text { ins. } \\
\text { Yellow }\end{array}$ & $\begin{array}{l}\text { China } \\
\text { Spring }\end{array}$ & $\begin{array}{l}\text { Sandy } \\
\text { loam }\end{array}$ & $\begin{array}{l}\text { St. John's Worts. A pretty } \\
\text { low-growing, spreading } \\
\text { shrub for a basket. Flow } \\
\text { ers } 2 \text { ins. across. }\end{array}$ \\
\hline Kerria japonica & $\begin{array}{l}2 \mathrm{ft} \text {. and } \\
\text { upwards } \\
\text { Yellow }\end{array}$ & $\begin{array}{l}\text { Japan } \\
\text { Early } \\
\text { spring }\end{array}$ & $\begin{array}{l}\text { Good } \\
\text { sandy } \\
\text { loam }\end{array}$ & $\begin{array}{l}\text { Rose Order. The single } \\
\text { form is very pretty and } \\
\text { not very common. }\end{array}$ \\
\hline $\begin{array}{l}\text { Lonicera frag- } \\
\text { rantissima }\end{array}$ & $\begin{array}{l}\text { Low } \\
\text { Ever- } \\
\text { green } \\
\text { climber }\end{array}$ & $\begin{array}{l}\text { China } \\
\text { Jan.- } \\
\text { Feb. }\end{array}$ & $\begin{array}{l}\text { Light } \\
\text { rich } \\
\text { loam }\end{array}$ & $\begin{array}{l}\text { Honeysuckle Order. This } \\
\text { is not showy, but is wel- } \\
\text { come from its very early } \\
\text { sweet-scented flowers. }\end{array}$ \\
\hline $\begin{array}{l}\text { Magnolia stel- } \\
\text { lata }\end{array}$ & $\begin{array}{l}\text { I-3 ft. } \\
\text { White }\end{array}$ & $\begin{array}{l}\text { Japan } \\
\text { Feb.-Mar. }\end{array}$ & $\begin{array}{c}\text { Rich } \\
\text { sandy } \\
\text { loam and } \\
\text { leaf- } \\
\text { mould }\end{array}$ & $\begin{array}{l}\text { Magnolia Order. A lovely } \\
\text { speciés, and the one most } \\
\text { suitable for pots. Should } \\
\text { be plunged in a warm } \\
\text { sheltered position during } \\
\text { summer. M. conspicua is } \\
\text { sometimes used in the } \\
\text { same way for a large con- } \\
\text { servatory. }\end{array}$ \\
\hline $\begin{array}{l}\text { NeriumOleander } \\
\text { and varieties }\end{array}$ & $\begin{array}{c}\text { Ever- } \\
\text { green } \\
3-4 \mathrm{ft} . \\
\text { Pink, } \\
\text { white, or } \\
\text { buff }\end{array}$ & $\begin{array}{l}\text { Palestine } \\
\text { and } \\
\text { S. Europe } \\
\text { Late } \\
\text { summer }\end{array}$ & $\begin{array}{l}\text { Moist } \\
\text { rich } \\
\text { loam and } \\
\text { leaf- } \\
\text { mould }\end{array}$ & $\begin{array}{l}\text { Periwinkle Order. The } \\
\text { best varieties of Oleander } \\
\text { both single and double, } \\
\text { are of continental origin. } \\
\text { They should be grown in } \\
\text { a sunny open air posi- } \\
\text { tion during early summer } \\
\text { and may stand in a deep } \\
\text { saucer of water. This } \\
\text { should be discontinued } \\
\text { after flowering is over, } \\
\text { when the plants go to }\end{array}$ \\
\hline
\end{tabular}




\begin{tabular}{|c|c|c|c|c|}
\hline Name. & $\begin{array}{l}\text { Height and } \\
\text { Colour. }\end{array}$ & $\begin{array}{l}\text { Country and } \\
\text { Season under } \\
\text { Glass. }\end{array}$ & Soil. & General Remarks. \\
\hline $\begin{array}{l}\text { Pernettya mu- } \\
\text { cronata }\end{array}$ & $\begin{array}{l}\text { Ever- } \\
\text { green } \\
\text { I } \frac{1}{2}-2 \mathrm{ft} . \\
\text { Fls. white } \\
\text { with } \\
\text { coloured } \\
\text { berries }\end{array}$ & $\begin{array}{l}\text { Straits } \\
\text { of } \\
\text { Magellan }\end{array}$ & $\begin{array}{c}\text { Moist } \\
\text { sandy } \\
\text { peat and } \\
\text { leaf- } \\
\text { mould }\end{array}$ & $\begin{array}{l}\text { rest and may then be cut } \\
\text { back. Much grown all } \\
\text { over the continent even } \\
\text { by the peasants, who } \\
\text { winter their plants in- } \\
\text { doors in cowsheds or } \\
\text { cellars. } \\
\text { Heath Order. Very effec- } \\
\text { tive when in fruit during } \\
\text { late autumn and winter. } \\
\text { Many varieties with large } \\
\text { berries of various shades } \\
\text { of pink, red, purple, to } \\
\text { white. }\end{array}$ \\
\hline $\begin{array}{l}\text { Pieris }(=\text { An- } \\
\text { dromeda) flori- } \\
\text { bunda } \\
\text { japonica }\end{array}$ & $\begin{array}{l}2-4 \mathrm{ft} . \\
\text { White } \\
3 \mathrm{ft} . \\
\text { White }\end{array}$ & $\begin{array}{c}\text { U. S. A. } \\
\text { Mar.-Apl. } \\
\text { Japan } \\
\text { May }\end{array}$ & $\begin{array}{l}\text { Moist } \\
\text { peat } \\
\text { and } \\
\text { leaf- } \\
\text { mould }\end{array}$ & $\begin{array}{l}\text { Heath Order. Evergreens } \\
\text { with waxy Arbutus-like } \\
\text { flowers. These do best } \\
\text { planted out during sum- } \\
\text { mer and lifted and potted } \\
\text { about October. }\end{array}$ \\
\hline $\begin{array}{l}\text { Prunus sinensis } \\
\text { alba plena }\end{array}$ & $\begin{array}{l}\text { Dwarf } \\
\text { and } \\
\text { slender } \\
\text { White } \\
\text { Pink } \\
\text { Pink and } \\
\text { white }\end{array}$ & $\begin{array}{c}\text { China } \\
\text { Mar. Apl. }\end{array}$ & $\begin{array}{l}\text { Rich } \\
\text { potting } \\
\text { soil }\end{array}$ & $\begin{array}{l}\text { Rose Order. A charming } \\
\text { Plum for early forwarding } \\
\text { under glass. P. triloba } \\
\text { does best planted out } \\
\text { against a wall, but, where } \\
\text { it cannot be otherwise } \\
\text { grown, will succeed with } \\
\text { car: in a pot. }\end{array}$ \\
\hline $\begin{array}{l}\text { Punica granata } \\
\text { (Pomegranate) }\end{array}$ & $\begin{array}{l}\text { Tall and } \\
\text { dwarf } \\
\text { vars. } \\
\text { Scarlet }\end{array}$ & $\begin{array}{l}\text { Persia } \\
\text { Summer } \\
\text { and } \\
\text { autumn }\end{array}$ & $\begin{array}{l}\text { Rich } \\
\text { sandy } \\
\text { loam }\end{array}$ & $\begin{array}{l}\text { Loosestrife Order. This, } \\
\text { though a wall-tree, is } \\
\text { much grown in Germany } \\
\text { in pots or tubs, and } \\
\text { should be so employed } \\
\text { more frequently in Eng- } \\
\text { land for corridors or } \\
\text { verandahs. }\end{array}$ \\
\hline $\begin{array}{l}\text { Rhaphiolepis } \\
\text { japonica }\end{array}$ & $\begin{array}{c}3 \mathrm{ft} . \\
\text { Pure } \\
\text { white and } \\
\text { sweet- } \\
\text { scented }\end{array}$ & $\begin{array}{l}\text { Japan } \\
\text { May }\end{array}$ & $\begin{array}{l}\text { Sandy } \\
\text { loam and } \\
\text { peat }\end{array}$ & $\begin{array}{l}\text { Rose Order. Japanese } \\
\text { Hawthorn. A distinct } \\
\text { and desirable shrub. }\end{array}$ \\
\hline
\end{tabular}




\begin{tabular}{|c|c|c|c|}
\hline Name. & $\begin{array}{l}\text { Height and } \\
\text { Colour. }\end{array}$ & $\begin{array}{c}\text { Country and } \\
\text { Season under } \\
\text { Glass. }\end{array}$ & Soil. \\
\hline $\begin{array}{l}\text { Rhododendron } \\
\text { dauricum } \\
\text { præcox } \\
\text { racemosum }\end{array}$ & $\begin{array}{c}3 \mathrm{ft} . \\
\text { Purple } \\
\text { Rosy } \\
\text { purple } \\
\text { I ft. and } \\
\text { upwards } \\
\text { Pink and } \\
\text { white }\end{array}$ & $\begin{array}{l}\text { Siberia } \\
\text { Jan.-Mar. } \\
\text { Hybrid } \\
\text { Feb.-Mar. } \\
\text { China } \\
\text { April }\end{array}$ & $\begin{array}{l}\text { Peat, } \\
\text { loam, } \\
\text { and } \\
\text { leaf- } \\
\text { mould }\end{array}$ \\
\hline $\begin{array}{l}\text { Spiræa, var. } \\
\text { Houttei }\end{array}$ & $\begin{array}{l}\text { I } \frac{1}{2}-2 \mathrm{ft} . \\
\text { White }\end{array}$ & $\begin{array}{l}\text { Hybrid } \\
\text { April }\end{array}$ & $\begin{array}{l}\text { Rich } \\
\text { light } \\
\text { loam }\end{array}$ \\
\hline $\begin{array}{l}\text { Veronica hul- } \\
\text { keana }\end{array}$ & $\begin{array}{l}\text { Ever- } \\
\text { green } \\
\text { I-2 ft. } \\
\text { Lilac }\end{array}$ & $\begin{array}{l}\text { N. Zealand } \\
\text { May }\end{array}$ & $\begin{array}{l}\text { Good } \\
\text { moist } \\
\text { sandy } \\
\text { loam }\end{array}$ \\
\hline $\begin{array}{l}\text { speciosa (many } \\
\text { varieties) }\end{array}$ & $\begin{array}{l}\text { Shades } \\
\text { of purple } \\
\text { and } \\
\text { crimson }\end{array}$ & $\begin{array}{l}\text { N. Zealand } \\
\text { Summer }\end{array}$ & \\
\hline $\begin{array}{l}\text { Viburnum pli- } \\
\text { catum } \\
\text { Tinus(Laurus- } \\
\text { tinus) }\end{array}$ & $\begin{array}{l}2-3 \mathrm{ft} \text {. } \\
\text { White } \\
\mathrm{I} \frac{1}{2}-2 \mathrm{ft} \text {. } \\
\text { White }\end{array}$ & $\begin{array}{c}\text { Japan } \\
\text { April } \\
\text { S. Europe } \\
\text { Dec.-Mar. }\end{array}$ & $\begin{array}{l}\text { Rich } \\
\text { free } \\
\text { moist } \\
\text { loam }\end{array}$ \\
\hline $\begin{array}{l}\text { Wistaria sinen- } \\
\text { sis } \\
\text { Zenobia speci- } \\
\text { osa } \\
\text { pulverulenta }\end{array}$ & $\begin{array}{l}\text { Climber } \\
\text { Lilac or } \\
\text { white } \\
2 \mathrm{ft} \text {. and } \\
\text { upwards } \\
\text { White }\end{array}$ & $\begin{array}{l}\text { China } \\
\text { April- } \\
\text { June } \\
\text { Southern } \\
\text { U. S. A. } \\
\text { May }\end{array}$ & $\begin{array}{l}\text { Ordinary } \\
\text { potting } \\
\text { soil } \\
\text { Moist } \\
\text { sandy } \\
\text { peat }\end{array}$ \\
\hline
\end{tabular}

General Remarks.

Heath Order. These small flowered early Rhods. are extremely useful for winter and spring, where there is only a glass shelter. B. racemosum is new, with terminal racemes of pink and white flowers, and is very distinct.

Rose Order. Much grown for pots. A desirable variety for early spring.

Foxglove Order. Many of the smaller growing $N$. Zealand Veronicas make good pot-plants. They like sun and abundance of water.

Guelder Rose Order. A fine shrub, and does well in pots. Most desirable for cold house where it will not flower outside.

Broom Order. Very good grown in standard form for early spring flowering. Heath Order. A very beautiful dwarf shrub, with glaucous foliage and white bell-flowers. 
FLOWERING SHRUBS BETTER SUITED FOR PLANTING OUT IN LARGE GLASS STRUCTURES, WITH TEMPERATURE NEVER LOWER THAN $35^{\circ}$ FAHR.

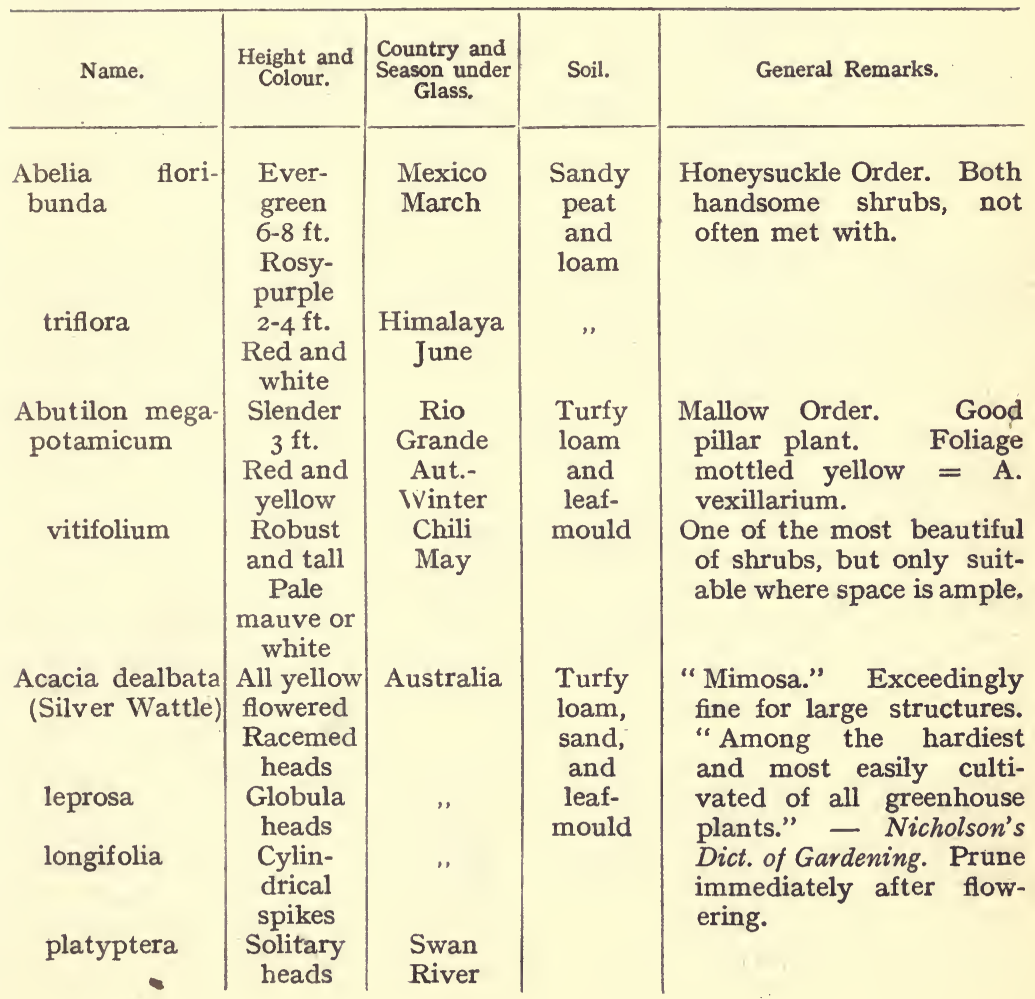




\begin{tabular}{|c|c|c|c|c|}
\hline Name. & $\begin{array}{l}\text { Height and } \\
\text { Colour. }\end{array}$ & $\begin{array}{l}\text { Country and } \\
\text { Season under } \\
\text { Glass. }\end{array}$ & Soil. & General Remarks. \\
\hline $\begin{array}{l}\text { riceana } \\
\text { and others }\end{array}$ & $\begin{array}{l}\text { Long } \\
\text { weeping } \\
\text { spikes }\end{array}$ & Tasmania & & \\
\hline $\begin{array}{l}\text { Anopterus glan- } \\
\text { dulosus }\end{array}$ & $\begin{array}{l}\text { Ever } \\
\text { green } \\
3 \mathrm{ft} \text {. } \\
\text { White }\end{array}$ & $\begin{array}{l}\text { Tasmania } \\
\text { April- } \\
\text { May }\end{array}$ & $\begin{array}{l}\text { Sandy } \\
\text { loam and } \\
\text { peat } \\
\text { Rich }\end{array}$ & $\begin{array}{l}\text { Saxifrage Order. A very } \\
\text { handsome shrub with po- } \\
\text { lished leaves and long } \\
\text { panicles of white flowers. }\end{array}$ \\
\hline $\begin{array}{c}\text { Buddleia } \\
\text { villei }\end{array}$ & $\begin{array}{l}\text { 4-6 ft. } \\
\text { Pendu- } \\
\text { lous } \\
\text { crimson } \\
\text { flowers }\end{array}$ & $\begin{array}{l}\text { Himalaya } \\
\text { May- } \\
\text { June }\end{array}$ & $\begin{array}{l}\text { light } \\
\text { loam }\end{array}$ & $\begin{array}{l}\text { Strychnine Order. Fine } \\
\text { and very distinct from } \\
\text { the well-known } B \text {. glo- } \\
\text { bosa with orange balls. }\end{array}$ \\
\hline $\begin{array}{l}\text { Cantua buxi- } \\
\text { folia }\end{array}$ & $\begin{array}{l}\text { Ever- } \\
\text { green } \\
3-4 \mathrm{ft} . \\
\text { Rosy-red } \\
\text { tubular } \\
\text { flowers }\end{array}$ & $\begin{array}{l}\text { Peruvian } \\
\text { Andes } \\
\text { April }\end{array}$ & $\begin{array}{l}\text { Turfy } \\
\text { loam } \\
\text { and } \\
\text { leaf- } \\
\text { mould }\end{array}$ & $\begin{array}{l}\text { Phlox Order. A very } \\
\text { beautiful shrub when in } \\
\text { flower. Rarely seen. }\end{array}$ \\
\hline $\begin{array}{r}\text { Carpenteria } \\
\text { california }\end{array}$ & $\begin{array}{l}4-8 \mathrm{ft} . \\
\text { White } \\
\text { flowers } \\
2-3 \text { ins. } \\
\text { across }\end{array}$ & $\begin{array}{l}\text { Sierra } \\
\text { Nevada } \\
\text { May- } \\
\text { June }\end{array}$ & $\begin{array}{l}\text { Light } \\
\text { rich } \\
\text { loam }\end{array}$ & $\begin{array}{l}\text { Saxifrage Order. One of } \\
\text { the finest of white-flow- } \\
\text { ered shrubs. May bs } \\
\text { grown in a pot or tub, } \\
\text { but shows its character } \\
\text { much better when planted } \\
\text { out. }\end{array}$ \\
\hline $\begin{array}{l}\text { Cassia corym- } \\
\text { bosa }\end{array}$ & $\begin{array}{l}4-8 \mathrm{ft} . \\
\text { Yellow }\end{array}$ & $\begin{array}{l}\text { Buenos } \\
\text { Ayres } \\
\text { Summer }\end{array}$ & $\begin{array}{c}\text { Rich } \\
\text { sandy } \\
\text { loam and } \\
\text { peat }\end{array}$ & $\begin{array}{l}\text { Broom Order. Flowere } \\
\text { profusely with fine heads } \\
\text { of bloom. }\end{array}$ \\
\hline $\begin{array}{l}\text { Ceanothus azu- } \\
\text { reus }\end{array}$ & $\begin{array}{c}2-4 \mathrm{ft} . \\
\text { Pale blue }\end{array}$ & $\begin{array}{l}\text { Mexico } \\
\text { Apl.-May }\end{array}$ & $\begin{array}{l}\text { Light } \\
\text { rich } \\
\text { loam }\end{array}$ & $\begin{array}{l}\text { Buckthorn Order. "Gloire } \\
\text { de Versailles" is one of } \\
\text { the best, but there are } \\
\text { other fine varieties which } \\
\text { vary from blue to rose- } \\
\text { colour. }\end{array}$ \\
\hline $\begin{array}{l}\text { Chimonanthus } \\
\text { fragrans gran- } \\
\text { diflorus (Win- } \\
\text { ter Sweet) }\end{array}$ & $\begin{array}{l}3 \mathrm{ft} \text {. and } \\
\text { upwards } \\
\text { Yellow } \\
\text { and } \\
\text { brown } \\
\text { Very } \\
\text { sweet- } \\
\text { scented }\end{array}$ & $\begin{array}{l}\text { Japan } \\
\text { Jan. } \\
\text { to } \\
\text { March }\end{array}$ & $\begin{array}{l}\text { Turfy } \\
\text { loam } \\
\text { and } \\
\text { leaf- } \\
\text { mould }\end{array}$ & $\begin{array}{l}\text { Allspice Order. Flowers } \\
\text { on leafless branches at } \\
\text { Midwinter. Generally } \\
\text { trained against a wall, } \\
\text { but that is quite un- } \\
\text { necessary. Prune after } \\
\text { flowering. }\end{array}$ \\
\hline
\end{tabular}




\begin{tabular}{|c|c|c|c|c|}
\hline Name. & $\begin{array}{l}\text { Height and } \\
\text { Colour. }\end{array}$ & $\begin{array}{l}\text { Country and } \\
\text { Season under } \\
\text { Glass. }\end{array}$ & Soil. & General Remarks. \\
\hline Clethra arborea & $\begin{array}{l}6 \mathrm{ft} . \text { and } \\
\text { upwards } \\
\text { White }\end{array}$ & $\begin{array}{l}\text { Madeira } \\
\text { July-Aug. }\end{array}$ & $\begin{array}{l}\text { Loam } \\
\text { and } \\
\text { sandy } \\
\text { peat }\end{array}$ & $\begin{array}{l}\text { Heath Order. Few green- } \\
\text { house shrubs are more } \\
\text { beautiful. }\end{array}$ \\
\hline $\begin{array}{l}\text { Clianthus puni- } \\
\text { ceus (Glory } \\
\text { Pea) }\end{array}$ & $\begin{array}{l}3 \mathrm{ft} . \\
\text { Scarlet }\end{array}$ & $\begin{array}{l}\text { N. Zealand } \\
\text { May }\end{array}$ & $\begin{array}{l}\text { Loam } \\
\text { and } \\
\text { sandy } \\
\text { leaf- } \\
\text { mould } \\
\text { with } \\
\text { broken } \\
\text { charcoal }\end{array}$ & $\begin{array}{l}\text { Broom Order. A good } \\
\text { pillar or wall plant. Sub- } \\
\text { ject to red spider, and } \\
\text { requires free syringing. } \\
\text { C. Dampieri grafted on } \\
\text { this or on Colutea arbo- } \\
\text { rescens makes a fine } \\
\text { basket, as grown at } \\
\text { Kew. }\end{array}$ \\
\hline $\begin{array}{l}\text { Daphne } \\
\text { phini }\end{array}$ & $\begin{array}{l}\text { Ever- } \\
\text { green } \\
3 \mathrm{ft} \text {. and } \\
\text { upwards } \\
\text { Purple }\end{array}$ & $\begin{array}{l}\text { Hybrid } \\
\text { Spring }\end{array}$ & $\begin{array}{l}\text { Sandy } \\
\text { loam } \\
\text { and } \\
\text { leaf- } \\
\text { mould }\end{array}$ & $\begin{array}{l}\text { Mezereon Order. A good } \\
\text { hybrid form, and in flower } \\
\text { for a long time. }\end{array}$ \\
\hline Genkwa & $\left|\begin{array}{c}\text { Deciduous } \\
2-3 \mathrm{ft} . \\
\text { Lilac }\end{array}\right|$ & $\underset{\text { Mar.-Apl. }}{\text { Japan }}$ & " & $\begin{array}{l}\text { This species flowers before } \\
\text { the leaves appear. Both } \\
\text { are fragrant. }\end{array}$ \\
\hline $\begin{array}{l}\text { Desfontainea } \\
\text { spinosa }\end{array}$ & $\begin{array}{l}\text { Ever- } \\
\text { green } \\
3 \mathrm{ft} \text {. } \\
\text { Scarlet } \\
\text { and } \\
\text { yellow } \\
\text { tubular } \\
\text { flowers }\end{array}$ & $\begin{array}{l}\text { Chili } \\
\text { August }\end{array}$ & $\begin{array}{l}\text { Light } \\
\text { loam } \\
\text { and } \\
\text { peat }\end{array}$ & $\begin{array}{l}\text { Strychnine Order. Very } \\
\text { like a holly in leafage. } \\
\text { Flowers } \frac{1}{4} \text {-in. in length. } \\
\text { This also succeeds in a } \\
\text { pot, and is good and dis- } \\
\text { tinct. }\end{array}$ \\
\hline $\begin{array}{l}\text { Desmodium } \\
\text { penduliflorum }\end{array}$ & $\begin{array}{c}5 \mathrm{ft} \text {. and } \\
\text { upwards } \\
\text { Deep red, } \\
\text { purple, } \\
\text { or white }\end{array}$ & $\begin{array}{l}\text { N. China } \\
\text { Autumn }\end{array}$ & $\begin{array}{l}\text { Good } \\
\text { rich } \\
\text { loam }\end{array}$ & $\begin{array}{l}\text { Broom Order. Prune to } \\
\text { ground level after flower- } \\
\text { ering. }\end{array}$ \\
\hline $\begin{array}{l}\text { Fremontia cali- } \\
\text { fornica }\end{array}$ & $\begin{array}{l}4 \mathrm{ft} \text {. and } \\
\text { upwards } \\
\text { Bright } \\
\text { yellow }\end{array}$ & $\begin{array}{l}\text { Sierra } \\
\text { Nevada } \\
\text { Apl.-May }\end{array}$ & $\begin{array}{l}\text { Sandy } \\
\text { loam }\end{array}$ & $\begin{array}{l}\text { Mallow Order. A fine de- } \\
\text { ciduous shrub with leaves } \\
\text { somewhat resembling the } \\
\text { Fig. The flowers owe } \\
\text { their colour to the calyx } \\
\text { and not to their petals. }\end{array}$ \\
\hline
\end{tabular}




\begin{tabular}{|c|c|c|c|c|}
\hline Name. & $\begin{array}{l}\text { Height and } \\
\text { Colour. }\end{array}$ & $\begin{array}{c}\text { Country and } \\
\text { Season under } \\
\text { Glass. }\end{array}$ & Soil. & General Remarks. \\
\hline Crating & & & & \\
\hline $\begin{array}{l}\text { Grevillea ros- } \\
\text { marinifolia } \\
\text { theleman- } \\
\text { niana }\end{array}$ & $\begin{array}{l}3 \mathrm{ft} \text {. and } \\
\text { upwards } \\
\text { Red } \\
\text { I ft. and } \\
\text { upwards } \\
\text { Bright } \\
\text { red and } \\
\text { red and } \\
\text { yellow }\end{array}$ & $\begin{array}{l}\text { Australia } \\
\text { June } \\
\text { Australia } \\
\text { Spring }\end{array}$ & $\begin{array}{l}\text { Sandy } \\
\text { peat and } \\
\text { loam }\end{array}$ & $\begin{array}{l}\text { Protea Order. The first } \\
\text { is hardy in the S. of Eng- } \\
\text { land. G. thelemanniana } \\
\text { is a remarkably pretty } \\
\text { shrub with foliage like } \\
\text { southernwood, and gem- } \\
\text { like flowers. Half-hardy. }\end{array}$ \\
\hline $\begin{array}{l}\text { Hoheria popul- } \\
\text { nea }\end{array}$ & $\begin{array}{l}\text { 6-1o ft. } \\
\text { White }\end{array}$ & $\begin{array}{l}\text { N. Zealand } \\
\text { Autumn }\end{array}$ & $\begin{array}{l}\text { Turfy } \\
\text { loam and } \\
\text { leaf- } \\
\text { mould }\end{array}$ & $\begin{array}{l}\text { Mallow Order. As yet but } \\
\text { little known, but likely to } \\
\text { prove valuable as an au- } \\
\text { tumn flowering shrub in } \\
\text { the cold greenhouse. }\end{array}$ \\
\hline Kalmia latifolia & $\begin{array}{l}3 \mathrm{ft} \text {. and } \\
\text { upwards } \\
\text { Pink and } \\
\text { white } \\
\text { Climber }\end{array}$ & $\begin{array}{l}\text { N. Am. } \\
\text { April and } \\
\text { May }\end{array}$ & $\begin{array}{l}\text { Moist } \\
\text { sandy } \\
\text { peat }\end{array}$ & $\begin{array}{l}\text { Heath Order. A rhodo- } \\
\text { dendron house would also } \\
\text { suit these beautiful } \\
\text { shrubs. }\end{array}$ \\
\hline $\begin{array}{l}\text { Lapageria alba } \\
\text { rosea }\end{array}$ & & $\begin{array}{l}\text { Chili } \\
\text { Late } \\
\text { summer } \\
\text { and } \\
\text { autumn }\end{array}$ & $\begin{array}{l}\text { Fibrous } \\
\text { peat, } \\
\text { loam, } \\
\text { and } \\
\text { charcoal }\end{array}$ & $\begin{array}{l}\text { Lily Order. Lapagerias of } \\
\text { either variety will suc- } \\
\text { ceed sometimes in shady } \\
\text { positions which are un- } \\
\text { suitable for other plants. } \\
\text { A narrow restricted root- } \\
\text { run suits them best, and } \\
\text { they answer well trained } \\
\text { over a corridor. They re- } \\
\text { quire plenty of water } \\
\text { when growing and fre- } \\
\text { quent syringing, as well } \\
\text { as protection from slugs } \\
\text { for the young shoots. } \\
\text { Difficult to establish, but } \\
\text { admirably well suited to } \\
\text { the cold greenhouse. }\end{array}$ \\
\hline $\begin{array}{l}\text { Lonicera sem } \\
\text { pervirens }\end{array}$ & $\begin{array}{l}\text { Ever- } \\
\text { green } \\
\text { climber } \\
\text { Scarlet } \\
\text { and } \\
\text { yellow }\end{array}$ & $\begin{array}{l}\text { N. Am. } \\
\text { May- } \\
\text { June }\end{array}$ & $\begin{array}{l}\text { Rich } \\
\text { light } \\
\text { loam }\end{array}$ & $\begin{array}{l}\text { Honeysuckle Order. The } \\
\text { Trumpet Honeysuckle. A } \\
\text { very fine climber. Half- } \\
\text { hardy. }\end{array}$ \\
\hline
\end{tabular}




\begin{tabular}{|c|c|c|c|c|}
\hline Name. & $\begin{array}{c}\text { Height and } \\
\text { Colour. }\end{array}$ & $\begin{array}{l}\text { Country and } \\
\text { Season under } \\
\text { Glass. }\end{array}$ & Soil. & General Remarks. \\
\hline Standishii & $\begin{array}{c}\text { Deciduous } \\
\text { shrub } \\
4-6 \mathrm{ft} . \\
\text { White } \\
\text { Fragrant }\end{array}$ & $\begin{array}{l}\text { China } \\
\text { Feb.- } \\
\text { March }\end{array}$ & $\begin{array}{l}\text { Rich } \\
\text { light } \\
\text { loam }\end{array}$ & $\begin{array}{l}\text { L. Standishii is nearly } \\
\text { allied to L. fragrantissima, } \\
\text { but flowers before the fo- } \\
\text { liage appears. Good for } \\
\text { winter flowering. }\end{array}$ \\
\hline $\begin{array}{l}\text { Mitraria cocci- } \\
\text { nea }\end{array}$ & $\begin{array}{l}\text { Dwarf } \\
\text { Ever- } \\
\text { green } \\
\text { with } \\
\text { climbing } \\
\text { habit } \\
\text { Scarlet }\end{array}$ & $\begin{array}{l}\text { Chili } \\
\text { July- } \\
\text { October }\end{array}$ & $\begin{array}{l}\text { Sandy } \\
\text { peat } \\
\text { and } \\
\text { loam }\end{array}$ & $\begin{array}{l}\text { Gloxina Order. A pretty } \\
\text { and uncommon shrub, } \\
\text { with somewhat the habit } \\
\text { of a fuchsia. The shoots } \\
\text { should be pinched now } \\
\text { and then to induce bushy } \\
\text { growth, and cut back } \\
\text { after flowering. }\end{array}$ \\
\hline $\begin{array}{c}\text { Olearia macro- } \\
\text { donta }\end{array}$ & $\begin{array}{l}2 \mathrm{ft} \text {. and } \\
\text { upwards } \\
\text { White } \\
\text { daisy-like } \\
\text { fls. in } \\
\text { heads }\end{array}$ & $\begin{array}{c}\text { N. Zealand } \\
\text { June- } \\
\text { July } \\
\end{array}$ & $\begin{array}{l}\text { Rich } \\
\text { loam and } \\
\text { leaf- } \\
\text { mould }\end{array}$ & $\begin{array}{l}\text { Daisy Order. One of the } \\
\text { "Daisy-trees" of N. Zea- } \\
\text { land, and a fine species. }\end{array}$ \\
\hline $\begin{array}{l}\text { Plumbago ca- } \\
\text { pensis }\end{array}$ & $\begin{array}{l}2 \mathrm{ft} \text {. or } \\
\text { more, of } \\
\text { climbing } \\
\text { habit } \\
\text { Pale blue }\end{array}$ & $\begin{array}{l}\text { C. of } \\
\text { G. Hope } \\
\text { Summer }\end{array}$ & $\begin{array}{l}\text { Fibrous } \\
\text { loam and } \\
\text { sand }\end{array}$ & $\begin{array}{l}\text { Thrift Order. Rather ten- } \\
\text { der, but succeeds in a } \\
\text { cold greenhouse when cut } \\
\text { back hard after flowering } \\
\text { and kept rather dry in } \\
\text { temperature not lower } \\
\text { than } 35^{\circ} \text { Fahr. }\end{array}$ \\
\hline $\begin{array}{l}\text { Poinciana } \\
\text { liesii ( }=\text { Cærsal- } \\
\text { pinia) }\end{array}$ & $\begin{array}{l}\text { Ever- } \\
\text { green } \\
\text { 6-12 ft. } \\
\text { Yellow } \\
\text { with red } \\
\text { stamens }\end{array}$ & $\begin{array}{l}\text { S. Am. } \\
\text { Early } \\
\text { summer }\end{array}$ & $\begin{array}{l}\text { Sandy } \\
\text { peat and } \\
\text { loam }\end{array}$ & $\begin{array}{l}\text { Broom Order. A tropical } \\
\text { looking shrub, and very } \\
\text { fine where there is ample } \\
\text { space. Hardy in I. of } \\
\text { Wight. }\end{array}$ \\
\hline $\begin{array}{l}\text { Rhododendron } \\
\text { ciliatum and } \\
\text { many Hima- } \\
\text { layan species } \\
\text { and hybrids }\end{array}$ & & & $\begin{array}{l}\text { Light } \\
\text { sandy } \\
\text { peat or } \\
\text { sandy } \\
\text { loam and } \\
\text { leaf- } \\
\text { mould } \\
\text { No lime }\end{array}$ & $\begin{array}{l}\text { Heath Order. For large } \\
\text { unheated glass structures } \\
\text { of the Winter Garden } \\
\text { order, Himalayan Rho- } \\
\text { dodendrons and their nu- } \\
\text { merous hybrids are mag- } \\
\text { nificent, flowering earlier } \\
\text { than the same out of } \\
\text { doors. }\end{array}$ \\
\hline $\begin{array}{l}\text { Sophora tetrap- } \\
\text { tera (= Ed- } \\
\text { wardsia gran- } \\
\text { diflora) }\end{array}$ & $\begin{array}{l}6-8 \mathrm{ft} . \\
\text { Yellow } \\
\text { flowers } \\
\text { I-2 ins. } \\
\text { long }\end{array}$ & $\begin{array}{l}\text { N. Zealand } \\
\text { Spring }\end{array}$ & $\begin{array}{l}\text { Good } \\
\text { sandy } \\
\text { loam }\end{array}$ & $\begin{array}{l}\text { Broom Order. The N.Z. } \\
\text { Laburnum. A very fine } \\
\text { shrub for the winter } \\
\text { garden. }\end{array}$ \\
\hline
\end{tabular}




\begin{tabular}{|c|c|c|c|c|}
\hline Name. & $\begin{array}{l}\text { Height and } \\
\text { Colour. }\end{array}$ & $\begin{array}{l}\text { Country and } \\
\text { Season under } \\
\text { Glass. }\end{array}$ & Soil. & General Remarks. \\
\hline $\begin{array}{l}\text { Vaccinium ser- } \\
\text { pens }\end{array}$ & $\begin{array}{l}\text { Dwarf } \\
\text { evergreen } \\
\text { with } \\
\text { arching } \\
\text { branches } \\
\text { Scarlet }\end{array}$ & $\begin{array}{c}\text { Himalaya } \\
\text { April- } \\
\text { May }\end{array}$ & $\begin{array}{l}\text { Sandy } \\
\text { peat or } \\
\text { loam } \\
\text { No lime }\end{array}$ & $\begin{array}{l}\text { Cranberry Order. A very } \\
\text { distinct and beautiful } \\
\text { shrub with a tuberous } \\
\text { root-stock and graceful } \\
\text { habit. }\end{array}$ \\
\hline $\begin{array}{l}\text { Vitis hetero- } \\
\text { phylla humuli- } \\
\text { folia } \\
\text { *var. tricolor }\end{array}$ & $\begin{array}{l}\text { Deciduous } \\
\text { climber } \\
\text { with } \\
\text { turquoise } \\
\text {-blue } \\
\text { fruit }\end{array}$ & $\begin{array}{l}\text { China } \\
\text { and } \\
\text { Japan }\end{array}$ & $\begin{array}{l}\text { Rich } \\
\text { sandy } \\
\text { loam }\end{array}$ & $\begin{array}{l}\text { Vine Order. The Hop- } \\
\text { leaved Vine is sometimes } \\
\text { called the Blue-berried } \\
\text { Vine. Thereisa good varie- } \\
\text { gated form.* Though } \\
\text { fairly hardy, it often fails } \\
\text { to fruit out of doors, and } \\
\text { so misses a main feature } \\
\text { of its beauty. }\end{array}$ \\
\hline
\end{tabular}




\section{HARD-WOODED PLANTS}

General Cultural Hints.-Pot very firmly in clean pots. Winter in a dry temperature, never falling below $35^{\circ} \mathrm{Fahr}$. Give plenty of air at all times by day (but without draughts), except in severe weather. After flowering cut back freely, and when growth is fairly re-established repot the plant if required into one size larger. Two or three weeks later, most kinds will be benefited by being plunged in the open air for a couple of months. Water carefully at all times. Return to the greenhouse before there is any fear of frost to perfect growth and set flower buds.

\begin{tabular}{|c|c|c|c|c|}
\hline Name. & $\begin{array}{l}\text { Height and } \\
\text { Colour. }\end{array}$ & $\begin{array}{l}\text { Country and } \\
\text { Season under } \\
\text { Glass. }\end{array}$ & Soil. & General Remarks. \\
\hline Acacia armata & $\begin{array}{l}\text { Ever- } \\
\text { green } \\
\text { I } 8 \text { ins. } \\
\text { and upw. } \\
\text { Globular } \\
\text { yellow } \\
\text { heads }\end{array}$ & $\begin{array}{l}\text { Australia } \\
\text { March } \\
\text { and } \\
\text { April }\end{array}$ & $\begin{array}{l}\text { Peat } \\
\text { or } \\
\text { loam } \\
\text { with } \\
\text { sharp } \\
\text { sand }\end{array}$ & $\begin{array}{l}\text { Broom Order. Amongst } \\
\text { the most easy to grow of } \\
\text { hard-wooded plants, and } \\
\text { will flower in either small } \\
\text { or large pots. }\end{array}$ \\
\hline juniperina & $\begin{array}{c}\text { Pale } \\
\text { lemon } \\
\text { cylindrical } \\
\text { heads } \\
\text { Yellow }\end{array}$ & $\begin{array}{c}\text { Swan } \\
\text { River } \\
\text { April } \\
\text { Tasmania } \\
\text { May }\end{array}$ & & \\
\hline $\begin{array}{c}\text { Bauera } \\
\text { oides }\end{array}$ & $\begin{array}{c}\text { Ever- } \\
\text { green } \\
\mathrm{I}-2 \mathrm{ft} . \\
\text { Pink }\end{array}$ & $\begin{array}{c}\text { N. S. } \\
\text { Wales } \\
\text { Mar.-Apl. }\end{array}$ & $\begin{array}{l}\text { Sandy } \\
\text { peat and } \\
\text { loam }\end{array}$ & $\begin{array}{l}\text { Saxifrage Order. A pretty } \\
\text { little shrub with saucer- } \\
\text { shaped flowers continu- } \\
\text { ing for some weeks. } \\
\text { Young shoots root easily } \\
\text { under bell-glass. }\end{array}$ \\
\hline
\end{tabular}




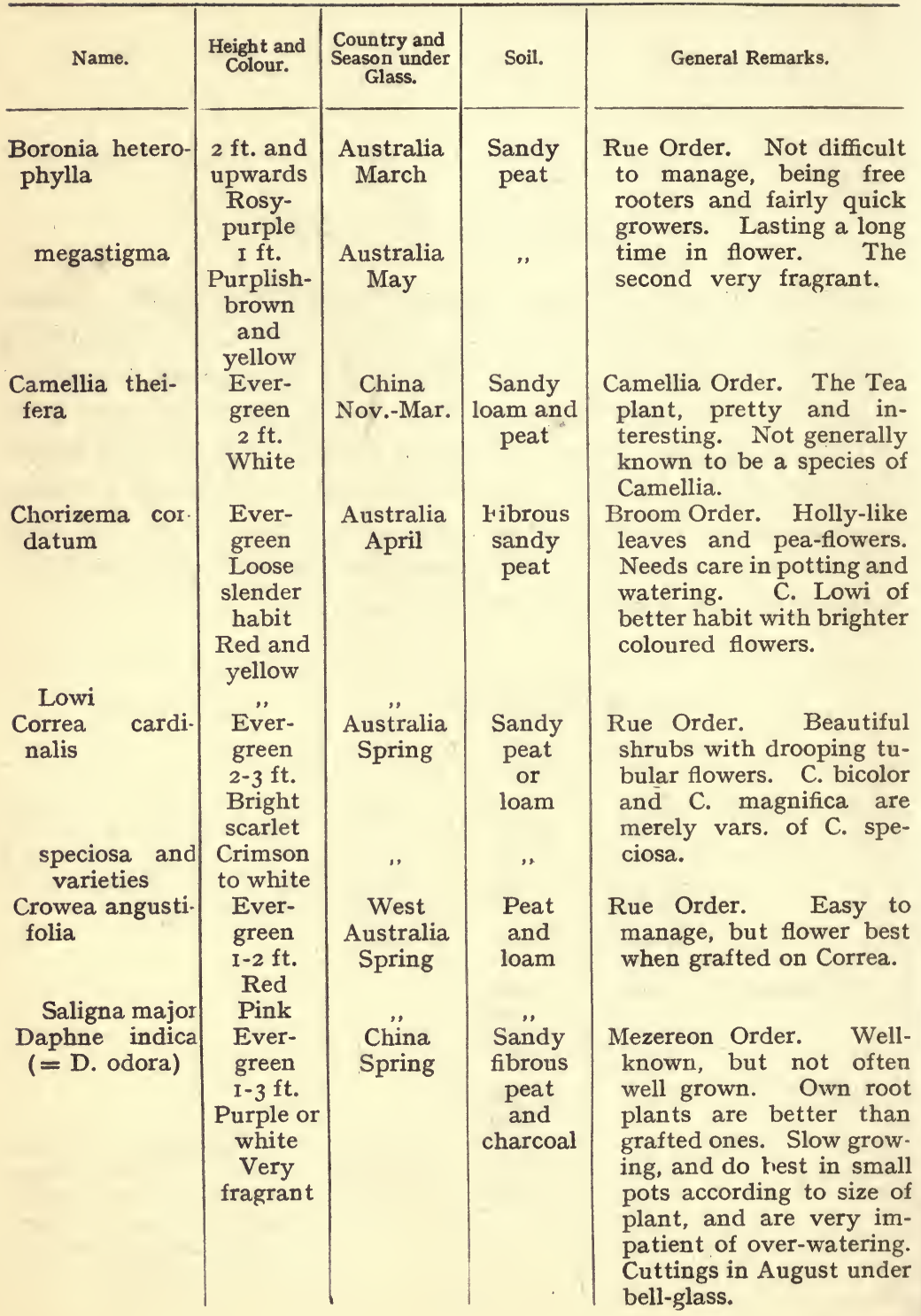




\begin{tabular}{|c|c|c|c|c|}
\hline Name. & $\begin{array}{l}\text { Height and } \\
\text { Colour. }\end{array}$ & $\begin{array}{l}\text { Country and } \\
\text { Season under } \\
\text { Glass. }\end{array}$ & Soil. & General Remarks. \\
\hline $\begin{array}{c}\text { Darwinia mac- } \\
\text { rostegia }\end{array}$ & $\begin{array}{l}\text { Ever- } \\
\text { green } \\
\text { I-2 ft. } \\
\text { Bell- } \\
\text { shaped } \\
\text { fls. } \\
\text { Cream- } \\
\text { white } \\
\text { streaked } \\
\text { red }\end{array}$ & $\begin{array}{l}\text { Australia } \\
\text { May- } \\
\text { June }\end{array}$ & $\begin{array}{l}\text { Good } \\
\text { fibrous } \\
\text { peat } \\
\text { and } \\
\text { sand }\end{array}$ & $\begin{array}{l}\text { Myrtle Order. The "Tu- } \\
\text { lip-Myrtle" is so fine that } \\
\text { it is included in this list } \\
\text { though somewhat more } \\
\text { difficult to grow than } \\
\text { some others of its class. } \\
\text { A healthy plant will begin } \\
\text { to flower from } 6 \text { ins. high. } \\
\text { The buds for the next } \\
\text { season are formed whilst } \\
\text { it is still in bloom and } \\
\text { open-air summer treat- } \\
\text { ment does not suit it. A } \\
\text { good plant for cold green- } \\
\text { house, as it resents heat. }\end{array}$ \\
\hline $\begin{array}{l}\text { Desfontainea } \\
\text { spinosa }\end{array}$ & $\begin{array}{l}\text { Ever- } \\
\text { green } \\
2-3 \mathrm{ft} \text {. } \\
\text { Tubular } \\
\text { fls. } \\
\text { Scarlet } \\
\text { and } \\
\text { yellow }\end{array}$ & $\begin{array}{l}\text { Peru } \\
\text { August }\end{array}$ & $\begin{array}{c}\text { Sandy } \\
\text { loam } \\
\text { Especially } \\
\text { averse } \\
\text { to lime }\end{array}$ & $\begin{array}{l}\text { Strychnine Order. This } \\
\text { fine shrub should be } \\
\text { grown as much as possible } \\
\text { in the open air. It sel- } \\
\text { dom flowers well two fol- } \\
\text { lowing seasons, therefore } \\
\text { the alternate system suits } \\
\text { it best. }\end{array}$ \\
\hline $\begin{array}{l}\text { Epacris hyacin- } \\
\text { thina }\end{array}$ & $\begin{array}{l}\text { Ever- } \\
\text { green } \\
\text { I-2 ft. } \\
\text { White } \\
\text { Red, } \\
\text { tipped } \\
\text { white }\end{array}$ & $\begin{array}{l}\text { Australia } \\
\text { Early } \\
\text { Spring }\end{array}$ & $\begin{array}{l}\text { Good } \\
\text { fibrous } \\
\text { sandy } \\
\text { peat } \\
\text {,, }\end{array}$ & $\begin{array}{l}\text { Epacris Order. These } \\
\text { lovely plants are not } \\
\text { hard to grow, but are } \\
\text { generaily over-watered. } \\
\text { A large number of garden } \\
\text { varieties to choose from. } \\
\text { Pure white to deep rose. }\end{array}$ \\
\hline $\begin{array}{l}\text { Erica caven- } \\
\text { dishiana } \\
\text { hyemalis }\end{array}$ & $\begin{array}{c}\text { Ever- } \\
\text { green } \\
\text { Yellow } \\
\text { Pale pink }\end{array}$ & $\begin{array}{l}\text { Cape } \\
\text { (hybrid) } \\
\text { May-July } \\
\text { Winter } \\
\text { and } \\
\text { spring }\end{array}$ & $\begin{array}{l}\text { Sandy } \\
\text { peat }\end{array}$ & $\begin{array}{l}\text { Heath Order. Air-loving } \\
\text { plants, but will not en- } \\
\text { dure draught or over- } \\
\text { much damp. Both these } \\
\text { and Epacris require } \\
\text { special conditions to grow }\end{array}$ \\
\hline $\begin{array}{l}\text { propendens } \\
\text { and many } \\
\text { others }\end{array}$ & Lilac & May-June & & $\begin{array}{l}\text { them well. A cold frame } \\
\text { during summer suits } \\
\text { them well. }\end{array}$ \\
\hline $\begin{array}{l}\text { Eriostemon } \\
\text { buxifolius }\end{array}$ & $\begin{array}{l}\text { Ever- } \\
\text { green } \\
\text { I-3 ft. } \\
\text { White } \\
\text { and pink }\end{array}$ & $\begin{array}{l}\text { Australia } \\
\text { Mar.-June }\end{array}$ & $\begin{array}{l}\text { Sandy } \\
\text { fibrous } \\
\text { peat }\end{array}$ & $\begin{array}{l}\text { Rue Order. A very pretty } \\
\text { shrub which will flower } \\
\text { profusely in a small pot. } \\
\text { It should stand out of } \\
\text { doors from July to the } \\
\text { end of September. }\end{array}$ \\
\hline
\end{tabular}




\begin{tabular}{|c|c|c|c|c|}
\hline Name. & $\begin{array}{l}\text { Height and } \\
\text { Colour. }\end{array}$ & $\begin{array}{l}\text { Country and } \\
\text { Season under } \\
\text { Glass. }\end{array}$ & Soil. & General Remarks. \\
\hline Hovea celsia & $\begin{array}{l}\text { Ever- } \\
\text { green } \\
\text { Blue- } \\
\text { purple }\end{array}$ & $\begin{array}{c}\text { Australia } \\
\text { April- } \\
\text { June }\end{array}$ & $\begin{array}{l}\text { Sandy } \\
\text { fibrous } \\
\text { peat }\end{array}$ & $\begin{array}{l}\text { Broom Order. The habit } \\
\text { of this pretty plant } \\
\text { is somewhat straggling, } \\
\text { therefore it must be kept } \\
\text { pinched in and trained } \\
\text { from the first. It may } \\
\text { also be grown as a stan- } \\
\text { dard. }\end{array}$ \\
\hline $\begin{array}{r}\text { Leschenaultia } \\
\text { biloba major }\end{array}$ & $\begin{array}{l}\text { Ever- } \\
\text { green } \\
\text { I ft. } \\
\text { Bright } \\
\text { blue } \\
\text { I ft. } \\
\text { Scarlet }\end{array}$ & $\begin{array}{l}\text { Australia } \\
\text { June-Aug. }\end{array}$ & $\begin{array}{l}\text { Sandy } \\
\text { fibrous } \\
\text { peat }\end{array}$ & $\begin{array}{l}\text { Goodenovia Order. Very } \\
\text { careful potting is neces- } \\
\text { sary as the roots are par- } \\
\text { ticularly susceptible of } \\
\text { injury. They do not take } \\
\text { kindly to open-air treat- } \\
\text { ment, and also like rather } \\
\text { more warmth }\left(45^{\circ}\right) \text { than } \\
\text { any other hard-wooded } \\
\text { subjects named. Remark- } \\
\text { ably fine plants. }\end{array}$ \\
\hline $\begin{array}{l}\text { Pimelia ferru- } \\
\text { ginea }(=\mathrm{P} \text {. } \\
\text { decussata) }\end{array}$ & $\begin{array}{l}\text { Ever- } \\
\text { green } \\
\mathrm{I}-2 \mathrm{ft} . \\
\text { Pink }\end{array}$ & $\begin{array}{c}\text { Australia } \\
\text { May }\end{array}$ & $\begin{array}{l}\text { Sandy } \\
\text { loam }\end{array}$ & $\begin{array}{l}\text { Mezereon Order. Ihis } \\
\text { likes more water both at } \\
\text { the roots and overhead } \\
\text { than many Australian } \\
\text { plants. }\end{array}$ \\
\hline$\underset{\text { maisiana }}{\text { Polygala dal- }}$ & $\begin{array}{l}\text { Ever- } \\
\text { green } \\
\mathrm{I}-3 \mathrm{ft} . \\
\text { Purple }\end{array}$ & $\begin{array}{l}\text { S. Africa } \\
\text { April- } \\
\text { May }\end{array}$ & $\begin{array}{l}\text { Sandy } \\
\text { fibrous } \\
\text { peat or } \\
\text { loam }\end{array}$ & $\begin{array}{l}\text { Milk-wort Order. Easy to } \\
\text { manage and a good plant } \\
\text { to begin on in this class. } \\
\text { Cut well back after flow- } \\
\text { ering. }\end{array}$ \\
\hline $\begin{array}{l}\text { Sparmannia af- } \\
\text { ricana }\end{array}$ & $\begin{array}{l}\text { Ever. } \\
\text { gre n } \\
\text { I ft. and } \\
\text { upwards } \\
\text { White } \\
\text { with } \\
\text { crimson } \\
\text { stamens }\end{array}$ & $\begin{array}{l}\text { S. Africa } \\
\text { May }\end{array}$ & $\begin{array}{l}\text { Turfy } \\
\text { loam } \\
\text { and } \\
\text { sand }\end{array}$ & $\begin{array}{l}\text { Lime-tree Order. African } \\
\text { Hemp. An easily grown } \\
\text { and rather popular soft- } \\
\text { leaved shrub which flow- } \\
\text { ers at a small stage, but } \\
\text { will grow into a tree. }\end{array}$ \\
\hline $\begin{array}{l}\text { Trachelosper- } \\
\text { mum jasmin- } \\
\text { oides (= Rhyn- } \\
\text { chospermum) }\end{array}$ & $\begin{array}{l}\text { Ever- } \\
\text { green } \\
\text { semi- } \\
\text { twining } \\
\text { Clusters } \\
\text { of white } \\
\text { fls. }\end{array}$ & $\begin{array}{l}\text { China } \\
\text { Summer }\end{array}$ & $\begin{array}{l}\text { Rich } \\
\text { sandy } \\
\text { loam } \\
\text { and } \\
\text { peat }\end{array}$ & $\begin{array}{l}\text { Periwinkle Order. This } \\
\text { does well as a trained pot } \\
\text { specimen and is easily } \\
\text { managed, lasting some } \\
\text { time in bloom and very } \\
\text { sweet-scented. }\end{array}$ \\
\hline
\end{tabular}




\section{MISCELLANEOUS PLANTS FOR POT CULTURE}

\begin{tabular}{|c|c|c|c|c|}
\hline Name. & $\begin{array}{l}\text { Height and } \\
\text { Colour. }\end{array}$ & $\begin{array}{l}\text { Country and } \\
\text { Season under } \\
\text { Glass. }\end{array}$ & Soll. & General Remarks. \\
\hline $\begin{array}{l}\text { Calceolaria vio- } \\
\text { lacea }\end{array}$ & $\begin{array}{l}2 \mathrm{ft} . \\
\text { Pale } \\
\text { mauve } \\
\text { Hardy }\end{array}$ & $\begin{array}{l}\text { Chili } \\
\text { June- } \\
\text { July }\end{array}$ & $\begin{array}{l}\text { Rich } \\
\text { sandy } \\
\text { loam and } \\
\text { leaf- } \\
\text { mould }\end{array}$ & $\begin{array}{l}\text { Foxglove Order. A very } \\
\text { distinct species with hel- } \\
\text { met-shaped flowers. }\end{array}$ \\
\hline Celsia Arcturus & $\begin{array}{l}\text { I-2 ft. } \\
\text { Yellow } \\
\text { H.-hardy }\end{array}$ & $\begin{array}{l}\text { Crete } \\
\text { May- } \\
\text { Sept. }\end{array}$ & $\begin{array}{l}\text { Sandy } \\
\text { loam }\end{array}$ & $\begin{array}{l}\text { Foxglove Order. The large } \\
\text { Mullein-like flowers with } \\
\text { purple stamens set on } \\
\text { wiry stems are always } \\
\text { admired. }\end{array}$ \\
\hline $\begin{array}{l}\text { Cytisus frag- } \\
\text { raus (= race- } \\
\text { mosus) }\end{array}$ & $\begin{array}{l}\mathrm{I} \frac{1}{2}-2 \mathrm{ft} . \\
\text { Yellow } \\
\text { H.-hardy }\end{array}$ & $\begin{array}{l}\text { Canary Is. } \\
\text { Spring }\end{array}$ & $\begin{array}{l}\text { Sandy } \\
\text { fibrous } \\
\text { loam }\end{array}$ & $\begin{array}{l}\text { Broom Order. Does per- } \\
\text { fectly well in a cold green- } \\
\text { house. }\end{array}$ \\
\hline $\begin{array}{l}\text { Diplacus gluti- } \\
\text { nosus } \\
\text { coccineus }\end{array}$ & $\begin{array}{l}\text { I } \frac{1}{2}-2 \mathrm{ft} . \\
\text { Orange- } \\
\text { buff } \\
\text { Crimson } \\
\text { H.-hardy }\end{array}$ & $\begin{array}{l}\text { Cali- } \\
\text { fornia } \\
\text { May- } \\
\text { July }\end{array}$ & $\begin{array}{l}\text { Sandy } \\
\text { loam } \\
\text { and } \\
\text { peat }\end{array}$ & $\begin{array}{l}\text { Foxglove Order. Shrubby } \\
\text { Mimulus. Showy ever- } \\
\text { green slender shrubs, } \\
\text { very free-flowering and } \\
\text { liking partial shade. }\end{array}$ \\
\hline $\begin{array}{l}\text { Erythrina Cris- } \\
\text { ta-galli }\end{array}$ & $\begin{array}{l}\text { Herba- } \\
\text { crous } \\
\text { stems } \\
\text { Fls. deep } \\
\text { scarlet }\end{array}$ & $\begin{array}{l}\text { Brazil } \\
\text { July }\end{array}$ & $\begin{array}{l}\text { Sandy } \\
\text { loam } \\
\text { and } \\
\text { peat }\end{array}$ & $\begin{array}{l}\text { Broom Order. Coral Tree. } \\
\text { Almost hardy in the S. } \\
\text { counties. The annual } \\
\text { stems have to be cut } \\
\text { down in autumn and the } \\
\text { roots stored for winter. } \\
\text { Repot when the stems are } \\
\text { 3-4 ins. high, taking great } \\
\text { care not to injure the } \\
\text { growing shoots. }\end{array}$ \\
\hline $\begin{array}{l}\text { Fabiana imbri- } \\
\text { cata }\end{array}$ & $\begin{array}{l}\text { Ever- } \\
\text { green } \\
\text { I } \frac{1}{2} \mathrm{ft} . \text { and } \\
\text { upwards } \\
\text { White } \\
\text { tubular } \\
\text { flowers }\end{array}$ & $\begin{array}{l}\text { Chili } \\
\text { May }\end{array}$ & $\begin{array}{l}\text { Ordinary } \\
\text { potting } \\
\text { soil }\end{array}$ & $\begin{array}{l}\text { Nightshade Order. An old } \\
\text { favourite, not so often } \\
\text { grown now as formerly } \\
\text { for the greenhouse, but } \\
\text { free flowering and useful. } \\
\text { Hardy in south counties. }\end{array}$ \\
\hline
\end{tabular}




\begin{tabular}{|c|c|c|c|c|}
\hline Name. & $\begin{array}{l}\text { Height and } \\
\text { Colour. }\end{array}$ & $\begin{array}{l}\text { Country and } \\
\text { Season under } \\
\text { Glass. }\end{array}$ & Soil. & General Remarks. \\
\hline $\begin{array}{l}\text { Fuchsias } \\
\text { (Named vars.) }\end{array}$ & $\begin{array}{c}\text { Deciduous } \\
\text { I-4 ft. } \\
\text { Hardy }\end{array}$ & $\begin{array}{l}\text { Garden } \\
\text { hybrids } \\
\text { Summer } \\
\text { and } \\
\text { autumn }\end{array}$ & $\begin{array}{l}\text { Rich } \\
\text { sandy } \\
\text { loam and } \\
\text { leaf- } \\
\text { mould }\end{array}$ & $\begin{array}{l}\text { Evening Primrose Order. } \\
\text { Fuchsias are particularly } \\
\text { well suited for the un- } \\
\text { heated greenhouse in } \\
\text { summer from the ease } \\
\text { with which they can be } \\
\text { kept through the winter. } \\
\text { They may be cut down } \\
\text { almost to the pot level } \\
\text { or only trimmed and al- } \\
\text { lowed to retain their } \\
\text { woody growth to make } \\
\text { large specimens year } \\
\text { after year. In either case } \\
\text { they can be stored safely } \\
\text { in a cellar or even in an } \\
\text { outhouse. }\end{array}$ \\
\hline $\begin{array}{l}\text { Hydrangea hor- } \\
\text { tensia } \\
\text { var. Thomas } \\
\text { Hogg } \\
\text { paniculata } \\
\text { grandiflora }\end{array}$ & $\begin{array}{l}\text { I-3 ft. } \\
\text { Pink or } \\
\text { blue } \\
\text { Pure } \\
\text { white } \\
\text { Cream- } \\
\text { white } \\
\text { Hardy }\end{array}$ & $\begin{array}{l}\text { China } \\
\text { April- } \\
\text { Sept. } \\
\text { Garden } \\
\text { var. good }\end{array}$ & $\begin{array}{l}\text { Loam } \\
\text { and } \\
\text { decayed } \\
\text { manure } \\
\text { in } \\
\text { equal } \\
\text { parts }\end{array}$ & $\begin{array}{l}\text { Saxifrage Order. Decora- } \\
\text { tive and easily managed. } \\
\text { They are particularly use- } \\
\text { ful as tub plants for ve- } \\
\text { randah, terrace, or cor- } \\
\text { ridor, and succeed in } \\
\text { shade. }\end{array}$ \\
\hline $\begin{array}{l}\text { Hypericum chi- } \\
\text { nense }\end{array}$ & $\begin{array}{l}\text { 9-I } 2 \text { ins. } \\
\text { Bright } \\
\text { yellow } \\
\text { H.-hardy }\end{array}$ & $\begin{array}{l}\text { China } \\
\text { Summer }\end{array}$ & $\begin{array}{l}\text { Rich } \\
\text { sandy } \\
\text { loam }\end{array}$ & $\begin{array}{l}\text { St. John's Wort Order. A } \\
\text { handsome evergreen bas- } \\
\text { ket-plant, with flowers } \\
\text { nearly as large as the } \\
\text { dwarf species known pop- } \\
\text { ularly as the " Rose of } \\
\text { Sharon." }\end{array}$ \\
\hline $\begin{array}{l}\text { Maurandya bar- } \\
\text { clayana }\end{array}$ & $\begin{array}{c}\text { Slender } \\
\text { twiner } \\
\text { Purple or } \\
\text { white } \\
\text { H.-hardy }\end{array}$ & $\begin{array}{l}\text { Mexico } \\
\text { Summer }\end{array}$ & $\begin{array}{l}\text { Good } \\
\text { sandy } \\
\text { loam }\end{array}$ & $\begin{array}{l}\text { Foxglove Order. Easily } \\
\text { grown from seed on cut- } \\
\text { tings, and useful for a } \\
\text { greenhouse trellis. Free- } \\
\text { flowering and showy. }\end{array}$ \\
\hline $\begin{array}{l}\text { Rubus rosæfo- } \\
\text { lius fl. pl. }\end{array}$ & $\begin{array}{l}\text { I-I } \frac{1}{2} \text { ft. } \\
\text { White } \\
\text { H.-hardy }\end{array}$ & $\begin{array}{c}\text { Himalayas } \\
\text { August }\end{array}$ & $\begin{array}{l}\text { Sandy } \\
\text { loam and } \\
\text { leaf- } \\
\text { mould }\end{array}$ & $\begin{array}{l}\text { Rose Order. A pretty and } \\
\text { distinct Bramble like a } \\
\text { miniature rose. }\end{array}$ \\
\hline $\begin{array}{l}\text { Swainsonia ga- } \\
\text { legifolia alba }\end{array}$ & $\begin{array}{l}\text { I ft. and } \\
\text { upwards } \\
\text { White } \\
\text { H.-hardy }\end{array}$ & $\begin{array}{l}\text { Australia } \\
\text { July }\end{array}$ & $\begin{array}{l}\text { Sandy } \\
\text { loam and } \\
\text { peat }\end{array}$ & $\begin{array}{l}\text { Broom Order. A charm- } \\
\text { ing Pea-flower, now very } \\
\text { generally grown. }\end{array}$ \\
\hline
\end{tabular}




\begin{tabular}{ll|c|c|c|c}
\hline Name. & $\begin{array}{c}\text { Height and } \\
\text { Colour. }\end{array}$ & $\begin{array}{c}\text { Country and } \\
\text { Season under } \\
\text { Glass. }\end{array}$ & Soil. & General Remarks. \\
\hline dersoni & An- & $\begin{array}{c}\mathrm{I}-\mathrm{I} \frac{1}{2} \mathrm{ft} . \\
\text { Bluish- } \\
\text { violet } \\
\text { or white } \\
\text { H.-hardy }\end{array}$ & $\begin{array}{c}\text { Garden } \\
\text { hybrid } \\
\text { Summer } \\
\text { and } \\
\text { Autumn }\end{array}$ & $\begin{array}{c}\text { Good } \\
\text { sandy } \\
\text { loam }\end{array}$ & $\begin{array}{c}\text { Foxglove Order. The } \\
\text { variegated form of V. } \\
\text { Andersoni is very good. } \\
\text { Several of the N. Zealand } \\
\text { shrubby veronicas make } \\
\text { good pot-plants. }\end{array}$ \\
\hline
\end{tabular}




\section{SOME HARDY PERENNIALS FOR SPRING FLOWERING UNDER GLASS}

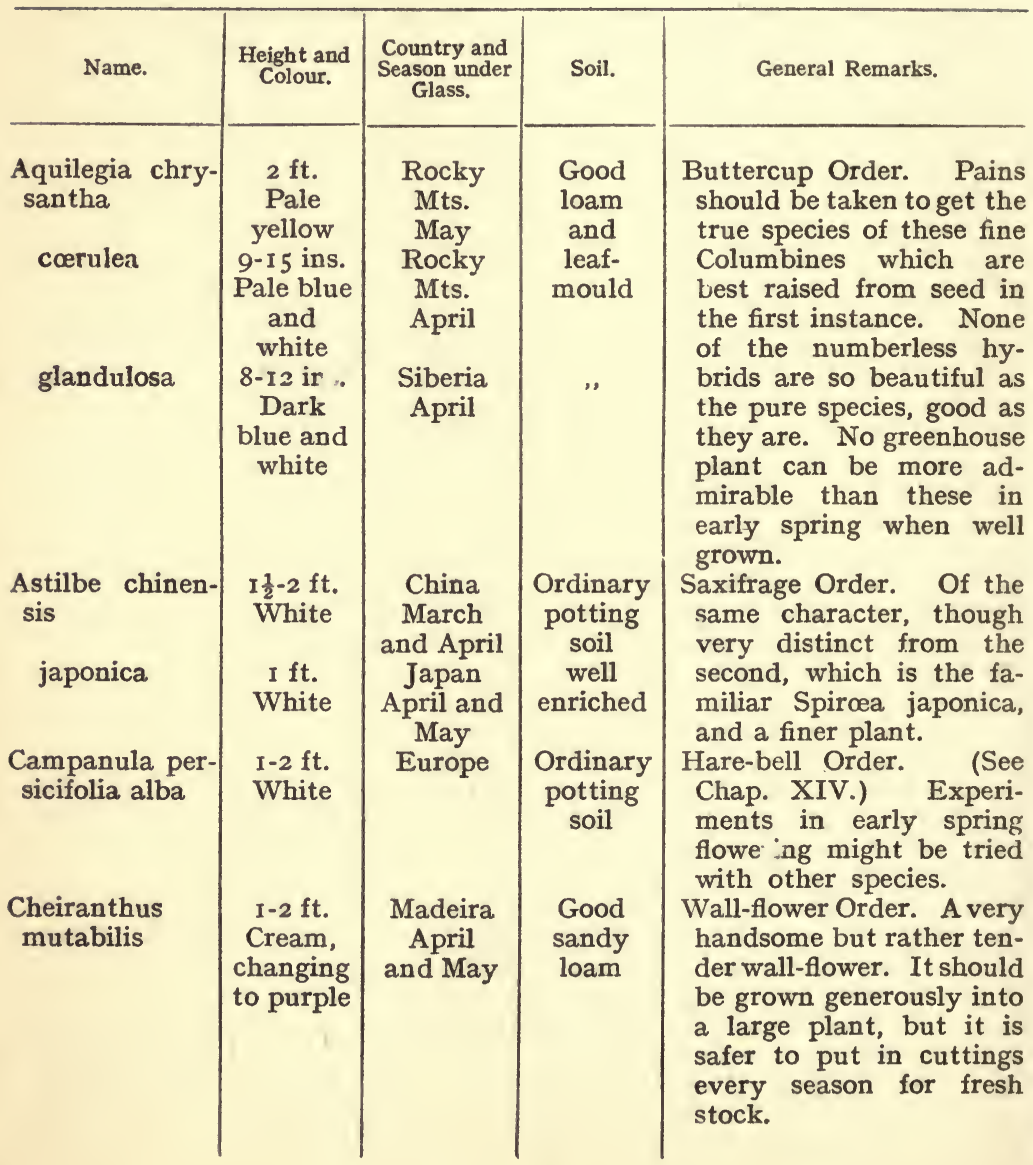




\begin{tabular}{|c|c|c|c|c|}
\hline Name. & $\begin{array}{l}\text { Height and } \\
\text { Colour. }\end{array}$ & $\begin{array}{l}\text { Country and } \\
\text { Season under } \\
\text { Glass. }\end{array}$ & Soil. & General Remarks. \\
\hline $\begin{array}{l}\text { Convolvulus al- } \\
\text { thæoides }\end{array}$ & $\begin{array}{l}\text { Slender } \\
\text { twiner } \\
\text { Pink }\end{array}$ & $\begin{array}{l}\text { S. Europe } \\
\text { Spring }\end{array}$ & $\begin{array}{l}\text { Rich } \\
\text { sandy } \\
\text { loam and } \\
\text { leaf- } \\
\text { mould }\end{array}$ & $\begin{array}{l}\text { Bindweed Order. The sil- } \\
\text { very foliage alone is very } \\
\text { beautiful for a trellis or } \\
\text { screen, and it flowers } \\
\text { freely. Hardy herba- } \\
\text { ceous. }\end{array}$ \\
\hline $\begin{array}{l}\text { Dicentra spec- } \\
\text { tabilis (= Die- } \\
\text { lytra) }\end{array}$ & $\begin{array}{c}\mathrm{I}-2 \mathrm{ft} . \\
\text { Rose-red }\end{array}$ & $\begin{array}{l}\text { Japan } \\
\text { Spring }\end{array}$ & $\begin{array}{l}\text { Rich } \\
\text { loam }\end{array}$ & $\begin{array}{l}\text { Fumitory Order. An old } \\
\text { favourite and good pot- } \\
\text { plant. Put out in reserve } \\
\text { border during summer. }\end{array}$ \\
\hline $\begin{array}{l}\text { Doronicum cau- } \\
\text { casicum }\end{array}$ & $\begin{array}{l}\text { 6-12 ins. } \\
\text { Yellow }\end{array}$ & $\begin{array}{l}\text { Caucasus } \\
\text { Feb.-Mar. }\end{array}$ & $\begin{array}{l}\text { Ordinary } \\
\text { potting } \\
\text { soil }\end{array}$ & $\begin{array}{l}\text { Daisy Order. This little } \\
\text { Doronicum is welcome } \\
\text { under glass in Feb. It } \\
\text { should be grown in the } \\
\text { reserve border and potted } \\
\text { in late autumn. The tall } \\
\text { D. excelsum is neithe1 } \\
\text { so early nor so satisfac- } \\
\text { tory. }\end{array}$ \\
\hline Fragaria indica & $\begin{array}{l}\text { Trailer } \\
\text { Golden- } \\
\text { yellow } \\
\text { H.-hardy }\end{array}$ & $\begin{array}{l}\text { India } \\
\text { May }\end{array}$ & $\begin{array}{l}\text { Ordinary } \\
\text { potting } \\
\text { soil }\end{array}$ & $\begin{array}{l}\text { Rose Order. A pretty } \\
\text { little basket-plant. The } \\
\text { red berries are ornamen- } \\
\text { tal, not edible. }\end{array}$ \\
\hline Francoa ramosa & $\begin{array}{l}2 \mathrm{ft} \text {. and } \\
\text { upwards } \\
\text { White } \\
\text { H.-hardy }\end{array}$ & $\begin{array}{l}\text { Chili } \\
\text { May }\end{array}$ & $\begin{array}{l}\text { Light } \\
\text { loam and } \\
\text { leaf- } \\
\text { mould }\end{array}$ & $\begin{array}{l}\text { Saxifrage Order. Popu- } \\
\text { larly known as the "Mai- } \\
\text { dens' Wreath" from its } \\
\text { long arching stems of } \\
\text { pure white flowers. }\end{array}$ \\
\hline $\begin{array}{l}\text { Helleborus ni- } \\
\text { ger }\end{array}$ & $\begin{array}{l}\text { 6-1 } 2 \text { ins. } \\
\text { Pure } \\
\text { white }\end{array}$ & $\begin{array}{l}\text { Cent. } \\
\text { Europe } \\
\text { and } \\
\text { A. Minor } \\
\text { Jan.-Feb. }\end{array}$ & $\begin{array}{l}\text { Good } \\
\text { rich } \\
\text { loam }\end{array}$ & $\begin{array}{l}\text { Buttercup Order. Christ- } \\
\text { mas Rose. (See Chap. } \\
\text { XIV.) }\end{array}$ \\
\hline var. maximus & $\begin{array}{l}\text { Pink } \\
\text { outside, } \\
\text { white } \\
\text { within }\end{array}$ & $\begin{array}{l}\text { Nov.- } \\
\text { Jan. }\end{array}$ & & $\begin{array}{l}\text { This var. is much earlier } \\
\text { than the type. }\end{array}$ \\
\hline $\begin{array}{l}\text { Heuchera san- } \\
\text { guinea }\end{array}$ & $\begin{array}{l}\text { 9-1 } 8 \text { ins. } \\
\text { Carmine- } \\
\text { scarlet } \\
\text { H.-hardy }\end{array}$ & $\begin{array}{l}\text { Mexico } \\
\text { May- } \\
\text { June }\end{array}$ & $\begin{array}{l}\text { Rich } \\
\text { loam and } \\
\text { leaf- } \\
\text { mould }\end{array}$ & $\begin{array}{l}\text { Saxifrage Order. A very } \\
\text { effective pot-plant which } \\
\text { responds to generous } \\
\text { treatment. It has lately } \\
\text { been taken in hand by } \\
\text { experts, and fine hybrids } \\
\text { are resulting from the } \\
\text { crosses. }\end{array}$ \\
\hline
\end{tabular}




\begin{tabular}{|c|c|c|c|c|}
\hline Name. & $\begin{array}{l}\text { Height and } \\
\text { Colour. }\end{array}$ & $\begin{array}{l}\text { Country and } \\
\text { Season under } \\
\text { Glass. }\end{array}$ & Soil. & General Remarks. \\
\hline $\begin{array}{l}\text { Iberis correæ- } \\
\text { folia }\end{array}$ & $\begin{array}{l}\text { Hardy } \\
\text { Ever- } \\
\text { green } \\
\text { I2 ins. } \\
\text { Long } \\
\text { heads of } \\
\text { white fls. } \\
\text { I2 ins. } \\
\text { Pale lilac }\end{array}$ & $\begin{array}{l}\text { Garden } \\
\text { hybrid } \\
\text { April } \\
\text { and May }\end{array}$ & $\begin{array}{l}\text { Ordinary } \\
\text { potting } \\
\text { soil }\end{array}$ & $\begin{array}{l}\text { Wall-flower Order. The } \\
\text { typical form of I. gibral- } \\
\text { taria which is usually } \\
\text { grown is not so compact } \\
\text { in habit as I. g. hybrids, } \\
\text { an improved variety. }\end{array}$ \\
\hline $\begin{array}{l}\text { Lathyrus } \text { ver- } \\
\text { nus }(=\text { Orobus } \\
\text { vernus) }\end{array}$ & $\begin{array}{l}\text { 12 ins. } \\
\text { Purple } \\
\text { or white } \\
\text { Hardy }\end{array}$ & $\begin{array}{l}\text { Europe } \\
\text { March }\end{array}$ & $\begin{array}{l}\text { Ordinary } \\
\text { potting } \\
\text { soil }\end{array}$ & $\begin{array}{l}\text { Broom Order. Flowers } \\
\text { very early under glass. } \\
\text { Should be planted in re- } \\
\text { serve border after flower- } \\
\text { ing and re-potted in } \\
\text { September or October. }\end{array}$ \\
\hline $\begin{array}{l}\text { Linum } \\
\text { reum }\end{array}$ & $\begin{array}{l}\mathrm{I}-\mathrm{I} \frac{1}{2} \mathrm{ft} . \\
\text { Yellow }\end{array}$ & $\begin{array}{l}\text { Crete } \\
\text { Feb. and } \\
\text { March }\end{array}$ & $\begin{array}{l}\text { Sandy } \\
\text { loam } \\
\text { and }\end{array}$ & $\begin{array}{l}\text { Flax Order. A pretty } \\
\text { shrubby perennial which } \\
\text { will flower early under }\end{array}$ \\
\hline narbonense & $\begin{array}{l}\text { I- I } \frac{1}{2} \mathrm{ft} . \\
\text { Bright } \\
\text { blue }\end{array}$ & $\begin{array}{l}\text { S. Europe } \\
\text { April }\end{array}$ & $\begin{array}{l}\text { leaf- } \\
\text { mould }\end{array}$ & $\begin{array}{l}\text { glass. L. narbonense is } \\
\text { of very different habit, } \\
\text { and a lovely plant if the } \\
\text { right species is obtained, } \\
\text { but } \mathrm{L} \text {. perenne is often } \\
\text { substituted for it. }\end{array}$ \\
\hline $\begin{array}{l}\text { Mimulus macu- } \\
\text { losus }\end{array}$ & $\begin{array}{l}\text { 8-12 ins. } \\
\text { Yellow } \\
\text { and } \\
\text { brown }\end{array}$ & $\begin{array}{l}\text { Garden } \\
\text { forms } \\
\text { Spring }\end{array}$ & $\begin{array}{l}\text { Rich } \\
\text { loam and } \\
\text { leaf- } \\
\text { mould }\end{array}$ & $\begin{array}{l}\text { Foxglove Order. Hybrids } \\
\text { of M. cupreus (Chili). } \\
\text { Flower quickly from seed } \\
\text { but the creeping under- } \\
\text { ground stems are peren- } \\
\text { nial. }\end{array}$ \\
\hline $\begin{array}{r}\text { moschatus } \\
\text { (Musk) }\end{array}$ & $\begin{array}{l}2-3 \text { ins. } \\
\text { Yellow }\end{array}$ & $\begin{array}{l}\text { N. W. } \\
\text { America } \\
\text { Summer }\end{array}$ & & $\begin{array}{l}\text { Harrison's is the largest } \\
\text { flowered variety of the } \\
\text { Common Musk. }\end{array}$ \\
\hline $\begin{array}{l}\text { Myosotidium } \\
\text { nobile (New } \\
\text { Zealand For- } \\
\text { get-me-not) }\end{array}$ & $\begin{array}{l}\text { I-I } \frac{1}{2} \mathrm{ft} . \\
\text { Rich blue } \\
\text { H.-hardy }\end{array}$ & $\begin{array}{l}\text { Chatham } \\
\text { Island } \\
\text { Apl.-May }\end{array}$ & $\begin{array}{l}\text { Sandy } \\
\text { peat and } \\
\text { leaf- } \\
\text { mould }\end{array}$ & $\begin{array}{l}\text { Forget-me-not Order. This } \\
\text { fine plant is unfortunately } \\
\text { a little difficult to grow. } \\
\text { It dislikes root disturb- } \\
\text { ance, and does best in a } \\
\text { deep pan in a cool corner } \\
\text { of a sheltered frame, } \\
\text { carefully watered through } \\
\text { the summer and brought } \\
\text { into the greenhouse in the }\end{array}$ \\
\hline
\end{tabular}




\begin{tabular}{|c|c|c|c|c|}
\hline Name. & $\begin{array}{l}\text { Height and } \\
\text { Colour. }\end{array}$ & $\begin{array}{l}\text { Country and } \\
\text { Season under } \\
\text { Glass. }\end{array}$ & Soil. & General Remarks. \\
\hline & & & & $\begin{array}{l}\text { autumn. Seedlings will } \\
\text { not flower before eigh- } \\
\text { teen months. To flower } \\
\text { it well is an achievement } \\
\text { worth trying for. }\end{array}$ \\
\hline $\begin{array}{l}\text { Megasea ( } \\
\text { Saxifraga) } \\
\text { cordifolia }\end{array}$ & $\begin{array}{l}\text { Ever- } \\
\text { green } \\
\text { I ft. } \\
\text { Rose- } \\
\text { pink }\end{array}$ & $\begin{array}{c}\text { Siberia } \\
\text { Mar.-Apl. }\end{array}$ & $\begin{array}{l}\text { Ordinary } \\
\text { potting } \\
\text { soil }\end{array}$ & $\begin{array}{l}\text { Saxifrage Order. Large } \\
\text { thick - leaved section, } \\
\text { making pretty pot-plants } \\
\text { for early spring. The two } \\
\text { last are half-hardy. }\end{array}$ \\
\hline $\begin{array}{l}\text { ligulata var. } \\
\text { ciliata }\end{array}$ & $\begin{array}{c}\text { Deciduous } \\
\text { I ft. } \\
\text { Bluish- } \\
\text { white }\end{array}$ & $\begin{array}{l}\text { Nepaul } \\
\text { Feb.-Mar. }\end{array}$ & ", & \\
\hline Stracheyi & $\begin{array}{l}4-8 \text { ins. } \\
\text { Pink or } \\
\text { white }\end{array}$ & $\begin{array}{c}\text { Himalayas } \\
\text { April }\end{array}$ & ", & \\
\hline $\begin{array}{l}\text { Papaver nudi- } \\
\text { caule }\end{array}$ & $\begin{array}{l}9-18 \text { ins. } \\
\text { Orange, } \\
\text { yellow, } \\
\text { or white }\end{array}$ & Iceland & $\begin{array}{l}\text { Sandy } \\
\text { loam }\end{array}$ & $\begin{array}{l}\text { Poppy Order. Seed sown } \\
\text { in August or September } \\
\text { and potted off singly will } \\
\text { flower early under glass. } \\
\text { Iceland poppies are pe- } \\
\text { rennial though often } \\
\text { treated as annuals. }\end{array}$ \\
\hline Primula acaulis & $\begin{array}{l}3-4 \text { ins. } \\
\text { Crimson } \\
\text { to } \\
\text { white } \\
3-6 \text { ins. } \\
\text { Yellow, } \\
\text { purple, } \\
\text { or claret }\end{array}$ & $\begin{array}{l}\text { British } \\
\text { (garden } \\
\text { forms) } \\
\text { Feb.-Mar. } \\
\text { European } \\
\text { Alps } \\
\text { Mar.- } \\
\text { April }\end{array}$ & $\begin{array}{l}\text { Loam } \\
\text { and } \\
\text { leaf- } \\
\text { mould } \\
\text { moist } \\
\text { and } \\
\text { cool }\end{array}$ & $\begin{array}{l}\text { Primrose Order. Hybrid } \\
\text { forms raised early in } \\
\text { spring will be amongst } \\
\text { the earliest flowers of the } \\
\text { following winter under } \\
\text { glass, and look very well } \\
\text { grown in baskets or pans } \\
\text { surfaced with moss. The }\end{array}$ \\
\hline Sieboldii & $\begin{array}{l}\text { 8-1 } 2 \text { ins. } \\
\text { Rose and } \\
\text { lavender } \\
\text { to pure } \\
\text { white }\end{array}$ & $\begin{array}{l}\text { Japan } \\
\text { April- } \\
\text { May }\end{array}$ & $\begin{array}{l}\text { Sandy } \\
\text { loam and } \\
\text { leaf- } \\
\text { mould }\end{array}$ & $\begin{array}{l}\text { large-flowered Polyan- } \\
\text { thus-primroses should not } \\
\text { be overlooked for this } \\
\text { purpose. The Alpine } \\
\text { section of Auricula will } \\
\text { also make good display, } \\
\text { giving rich colours set off } \\
\text { by the mealy foliage. It } \\
\text { is important to get good } \\
\text { strains of seed in all } \\
\text { classes. The garden } \\
\text { forms of P. sieboldii are } \\
\text { an improvement on the } \\
\text { type. }\end{array}$ \\
\hline
\end{tabular}




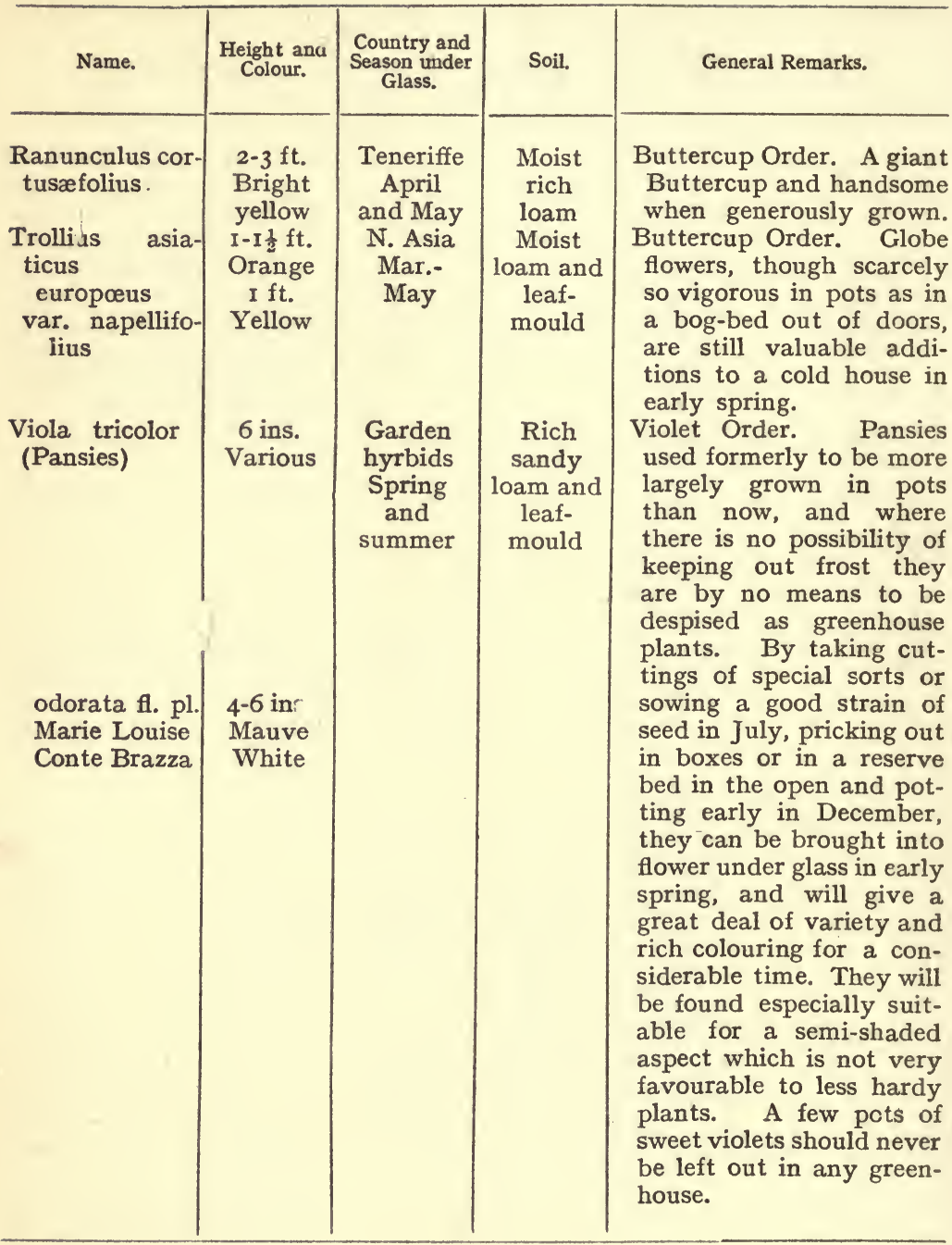




\section{AUTUMN-FLOWERING PERENNIALS}

\begin{tabular}{|c|c|c|c|c|}
\hline Name. & $\begin{array}{l}\text { Height and } \\
\text { Colour. }\end{array}$ & $\begin{array}{l}\text { Country and } \\
\text { Season under } \\
\text { Glass. }\end{array}$ & Soil. & General Remarks. \\
\hline $\begin{array}{l}\text { Amphicome } \\
\text { Emodi }\end{array}$ & $\begin{array}{c}\text { Herba- } \\
\text { ceous } \\
\text { I-I } \frac{1}{2} \mathrm{ft} . \\
\text { Fls. } \\
\text { tubular } \\
\text { Rose } \\
\text { H.-hardy }\end{array}$ & $\begin{array}{c}\text { Himalayas } \\
\text { Aug.- } \\
\text { October }\end{array}$ & $\begin{array}{l}\text { Sandy } \\
\text { loam and } \\
\text { leaf- } \\
\text { mould }\end{array}$ & $\begin{array}{l}\text { Bignonia Order. A very } \\
\text { beautiful perennial but } \\
\text { little known, and a valu- } \\
\text { ableaddition to cold green- } \\
\text { house plants. It may be } \\
\text { seen in the Cape House at } \\
\text { Kew in its season, which } \\
\text { seems to vary under cul- } \\
\text { tivation as it was in } \\
\text { flower there in April } \\
\text { I902. }\end{array}$ \\
\hline $\begin{array}{l}\text { Anemone japo- } \\
\text { nica Honorine } \\
\text { Jobert }\end{array}$ & $\begin{array}{l}2-3 \mathrm{ft} \\
\text { White }\end{array}$ & $\begin{array}{l}\text { Japan } \\
\text { Aug. and } \\
\text { Sept. }\end{array}$ & $\begin{array}{l}\text { Loam } \\
\text { and leaf- } \\
\text { mould }\end{array}$ & $\begin{array}{l}\text { Buttercup Order. These } \\
\text { are very good for small } \\
\text { tubs. They require a } \\
\text { good deal of root room, } \\
\text { but if treated liberally } \\
\text { with a good top dressing } \\
\text { of fresh soil in spring and } \\
\text { copious supplies of water } \\
\text { in hot weather, the plants } \\
\text { may be left undisturbed } \\
\text { for two or even three } \\
\text { years and are capital } \\
\text { additions to groups for } \\
\text { porch, verandah, or cor- } \\
\text { ridor. They may be } \\
\text { retarded by dis-budding } \\
\text { as soon as the jarliest } \\
\text { flowers begin to show. }\end{array}$ \\
\hline
\end{tabular}




\begin{tabular}{|c|c|c|c|c|}
\hline Name. & $\begin{array}{l}\text { Height and } \\
\text { Colour. }\end{array}$ & $\begin{array}{l}\text { Country and } \\
\text { Season under } \\
\text { Glass. }\end{array}$ & I Soil. & General Remarks. \\
\hline $\begin{array}{l}\text { Arctotis aspera } \\
\text { var. arbores- } \\
\text { cens }\end{array}$ & $\begin{array}{l}\text { Shrubby } \\
\mathrm{I}-\mathrm{I} \frac{1}{2} \mathrm{ft} . \\
\text { Stems } \\
\text { spreading } \\
\text { and } \\
\text { procum- } \\
\text { bent } \\
\text { Fls. } \\
\text { cream- } \\
\text { white } \\
\text { with pink } \\
\text { reverse } \\
\mathrm{I}-\mathrm{I} \frac{1}{2} \mathrm{ft} . \\
\text { Bright }\end{array}$ & $\begin{array}{l}\text { Cape } \\
\text { July } \\
\text { October }\end{array}$ & $\begin{array}{l}\text { Sandy } \\
\text { loam } \\
\text { and } \\
\text { leaf- } \\
\text { mould }\end{array}$ & $\begin{array}{l}\text { Daisy Order. Both va- } \\
\text { rieties are remarkably } \\
\text { fine half-hardy plants- } \\
\text { the colour of the flowers } \\
\text { being the main difference. } \\
\text { They require to be kept } \\
\text { safe from frost and rather } \\
\text { dry at the roots, but can } \\
\text { be managed successfully } \\
\text { in a temperature of } 35^{\circ} \\
\text { minimum. Large grow- } \\
\text { ing, and not suitable } \\
\text { where space is limited. }\end{array}$ \\
\hline $\begin{array}{l}\text { Aster grandi- } \\
\text { florus } \\
\text { and others }\end{array}$ & $\begin{array}{l}2-3 \mathrm{ft} . \\
\text { Purple } \\
\text { various }\end{array}$ & $\begin{array}{l}\text { N. Am. } \\
\text { Nov.- } \\
\text { Dec. }\end{array}$ & $\begin{array}{l}\text { Ordinary } \\
\text { potting } \\
\text { soil }\end{array}$ & $\begin{array}{l}\text { Daisy Order. Good forms } \\
\text { of Michaelmas Daisies } \\
\text { make very effective pot- } \\
\text { plants-a fact not gene- } \\
\text { rally realised. }\end{array}$ \\
\hline Calceolaria alba & $\begin{array}{l}\text { I } \frac{1}{2}-2 \mathrm{ft} . \\
\text { White } \\
\text { H.-hardy }\end{array}$ & $\begin{array}{l}\text { Chili } \\
\text { Aug.- } \\
\text { Sept. }\end{array}$ & $\begin{array}{l}\text { Sandy } \\
\text { peat } \\
\text { and } \\
\text { loam }\end{array}$ & $\begin{array}{l}\text { Foxglove Order. This } \\
\text { charming species is most } \\
\text { desirable for early and } \\
\text { late autumn. It can be } \\
\text { raised from seed or cut- } \\
\text { tings. Old plants may be } \\
\text { cut down and stored } \\
\text { safely from frost and will } \\
\text { break again from the } \\
\text { base in spring. The same } \\
\text { may be said of } C \text {. am- }\end{array}$ \\
\hline amplexicaulis & $\begin{array}{l}\text { Herba- } \\
\text { ceous } \\
\text { Lax } \\
\text { growth } \\
\text { Fls. } \\
\text { lemon- } \\
\text { yellow } \\
\text { H.-hardy }\end{array}$ & $\begin{array}{l}\text { Peru } \\
\text { Late } \\
\text { summer } \\
\text { and } \\
\text { autumn }\end{array}$ & & $\begin{array}{l}\text { plexicaulis, an old species } \\
\text { with soft pale-green stem- } \\
\text { clasping leaves, not so } \\
\text { much in fashion now as } \\
\text { it might be. The last } \\
\text { might easily be mistaken } \\
\text { for a fuchsia when not in } \\
\text { flower. }\end{array}$ \\
\hline fuchsiæfolia & $\begin{array}{l}2-3 \mathrm{ft} . \\
\text { Fls. } \\
\text { bright } \\
\text { yellow } \\
\text { H.-hardy }\end{array}$ & $\begin{array}{c}\text { Peru } \\
\text { Autumn }\end{array}$ & & \\
\hline
\end{tabular}




\begin{tabular}{|c|c|c|c|c|}
\hline Name. & $\begin{array}{l}\text { Height and } \\
\text { Colour. }\end{array}$ & $\begin{array}{l}\text { Country and } \\
\text { Season under } \\
\text { Glass. }\end{array}$ & Soil. & General Remarks. \\
\hline $\begin{array}{l}\text { Campanula } \\
\text { dali }\end{array}$ & $\begin{array}{c}\text { I-2 ft. } \\
\text { Foliage } \\
\text { semi- } \\
\text { succulent } \\
\text { Fls. waxy } \\
\text { white } \\
\text { H.-hardy }\end{array}$ & $\begin{array}{l}\text { Azores } \\
\text { August }\end{array}$ & $\begin{array}{l}\text { Sandy } \\
\text { loam } \\
\text { and } \\
\text { leaf- } \\
\text { mould }\end{array}$ & $\begin{array}{l}\text { Hare-bell Order. A dis- } \\
\text { tinct and pretty plant if } \\
\text { well grown. Of shrubby } \\
\text { character. }\end{array}$ \\
\hline $\begin{array}{l}\text { Chrysanthe- } \\
\text { mum frutesceus } \\
\text { var. Etoile d'Or }\end{array}$ & $\begin{array}{l}\text { I } \frac{1}{2}-2 \mathrm{ft} . \\
\text { White } \\
\text { sulphur } \\
\text { H.-hardy }\end{array}$ & $\begin{array}{l}\text { Canary } \\
\text { Islands } \\
\text { Summer } \\
\text { and } \\
\text { Autumn }\end{array}$ & $\begin{array}{l}\text { Rich } \\
\text { sandy } \\
\text { loam }\end{array}$ & $\begin{array}{l}\text { Daisy Order. Paris Daisy } \\
\text { or Yellow and White } \\
\text { Marguerites. }\end{array}$ \\
\hline $\begin{array}{l}\text { Coleus thyrsoi- } \\
\text { deus }\end{array}$ & $\begin{array}{l}2-3 \mathrm{ft} . \\
\text { Spikes of } \\
\text { deep-blue } \\
\text { flowers } \\
\text { H.-hardy }\end{array}$ & $\begin{array}{l}\text { E. Africa } \\
\text { at high } \\
\text { elevations } \\
\text { Nov.- } \\
\text { Dec. }\end{array}$ & $\begin{array}{l}\text { Sandy } \\
\text { loam }\end{array}$ & $\begin{array}{l}\text { Lavender Order. This new } \\
\text { Coleus, which has much } \\
\text { the habit of a Salvia, is as } \\
\text { yet untried for the un- } \\
\text { heated greenhouse, but is } \\
\text { so handsome that it is } \\
\text { mentioned here, as it } \\
\text { grows at an altitude of } \\
6000-7000 \mathrm{ft} \text {. and may } \\
\text { probably become accli- } \\
\text { mated. }\end{array}$ \\
\hline $\begin{array}{c}\text { Jacobinia mag- } \\
\text { nifica carnea }\end{array}$ & $\begin{array}{c}2 \mathrm{ft} . \\
\text { Pink } \\
\text { H.-hardy }\end{array}$ & $\begin{array}{l}\text { Brazil } \\
\text { Aug.- } \\
\text { Sept. }\end{array}$ & $\begin{array}{l}\text { Sandy } \\
\text { loam and } \\
\text { leaf- } \\
\text { mould }\end{array}$ & $\begin{array}{l}\text { Acanthus Order. This } \\
\text { species has been grown } \\
\text { successfully in a green- } \\
\text { house just protected from } \\
\text { frost, and when well } \\
\text { pinched back to promote } \\
\text { bushy growth is a most } \\
\text { decorative plant. The } \\
\text { splendid J. chrysoste- } \\
\text { phana (Golden Crowned), } \\
\text { which is far finer, would } \\
\text { be well worth trying. }\end{array}$ \\
\hline $\begin{array}{l}\text { Moschosma } \\
\text { parium }\end{array}$ & $\begin{array}{l}2-3 \mathrm{ft} . \\
\text { Branch- } \\
\text { ing heads } \\
\text { of small } \\
\text { white fls. } \\
\text { H.-hardy }\end{array}$ & $\begin{array}{l}\text { S. Africa } \\
\text { Late } \\
\text { autumn }\end{array}$ & $\begin{array}{l}\text { Sandy } \\
\text { loam }\end{array}$ & $\begin{array}{l}\text { Lavender Order. A new } \\
\text { and useful plant from its } \\
\text { late blooming, though not } \\
\text { particularly showy. }\end{array}$ \\
\hline
\end{tabular}




\begin{tabular}{|c|c|c|c|c|}
\hline Name. & $\begin{array}{l}\text { Height and } \\
\text { Colour. }\end{array}$ & $\begin{array}{l}\text { Country and } \\
\text { Season under } \\
\text { Glass. }\end{array}$ & Soil. & General Remarks. \\
\hline Nicotiana affinis & $\begin{array}{l}2 \mathrm{ft} \text {. } \\
\text { White }\end{array}$ & $\begin{array}{l}\text { Brazil } \\
\text { Summer } \\
\text { and } \\
\text { autumn }\end{array}$ & $\begin{array}{l}\text { Moist } \\
\text { rich } \\
\text { loam and } \\
\text { leaf- } \\
\text { mould }\end{array}$ & $\begin{array}{l}\text { Nightshade Order. Well } \\
\text { known and a true peren- } \\
\text { nial, but more often } \\
\text { treated as an annual. } \\
\text { Flowers well in a } 6 \text {-in. pot } \\
\text { and is very useful for the } \\
\text { greenhouse in autumn. } \\
N \text {. sylvestris, a newer but } \\
\text { very similar plant of } \\
\text { more vigorous growth, } \\
\text { has the advantage of } \\
\text { keeping its flowers open } \\
\text { by day. }\end{array}$ \\
\hline $\begin{array}{l}\text { Nierembergia } \\
\text { frutescens }\end{array}$ & $\begin{array}{l}\text { Shrubby } \\
\mathrm{I}-\mathrm{I} \frac{1}{2} \mathrm{ft} \text {. } \\
\text { Fls. blue } \\
\text { shaded } \\
\text { to white }\end{array}$ & $\begin{array}{l}\text { Chili } \\
\text { Early } \\
\text { autumn }\end{array}$ & $\begin{array}{l}\text { Rich } \\
\text { sandy } \\
\text { loam }\end{array}$ & $\begin{array}{l}\text { Nightshade Order. Pretty } \\
\text { and free-flowering. N. } \\
\text { gracilis is less hardy than } \\
\text { the first, but is a good } \\
\text { greenhouse plant. }\end{array}$ \\
\hline gracilis & $\begin{array}{l}\text { 6-I } 2 \text { ins. } \\
\text { Fls. white } \\
\text { and } \\
\text { purple } \\
\text { H.-hardy }\end{array}$ & $\begin{array}{c}\text { Buenos } \\
\text { Ayres }\end{array}$ & " & \\
\hline Petunia & $\begin{array}{l}\mathrm{I}-\mathrm{I} \frac{1}{2} \mathrm{ft} . \\
\text { Fls. from } \\
\text { purple } \\
\text { to white }\end{array}$ & $\begin{array}{l}\text { Garden } \\
\text { hybrids } \\
\text { Summer } \\
\text { and } \\
\text { autumn }\end{array}$ & $\begin{array}{l}\text { Rich } \\
\text { sandy } \\
\text { loam }\end{array}$ & $\begin{array}{l}\text { Nightshade Order. The } \\
\text { double forms make very } \\
\text { showy pot-plants, and } \\
\text { should be grown always } \\
\text { under glass, as they do } \\
\text { not succeed with open- } \\
\text { air treatment. }\end{array}$ \\
\hline $\begin{array}{l}\text { Physalis Fran- } \\
\text { cheti }\end{array}$ & $\begin{array}{l}\text { I-2 ft. } \\
\text { Calyces } \\
\text { Orange- } \\
\text { scarlet }\end{array}$ & $\begin{array}{l}\text { Japan } \\
\text { Nov.- } \\
\text { Dec. }\end{array}$ & $\begin{array}{l}\text { Sandy } \\
\text { loam and } \\
\text { leaf- } \\
\text { mould }\end{array}$ & $\begin{array}{l}\text { Nightshade Order. A finer } \\
\text { and more vigorous species } \\
\text { than the old Winter } \\
\text { Cherry (P. Alkekengi), } \\
\text { and very ornamental as } \\
\text { a pot-plant in autumn, } \\
\text { grown in bushy form. }\end{array}$ \\
\hline $\begin{array}{c}\text { Statice Holfordi } \\
\text { profusa }\end{array}$ & 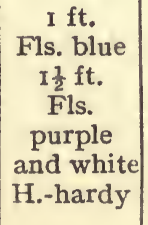 & $\begin{array}{l}\text { Garden } \\
\text { hybrids } \\
\text { Autumn }\end{array}$ & $\begin{array}{l}\text { Turfy } \\
\text { loam } \\
\text { and } \\
\text { sand }\end{array}$ & $\begin{array}{l}\text { Thrift Order. Well-known } \\
\text { species. Th: earliest } \\
\text { flower-stems may be } \\
\text { pinched if the plants are } \\
\text { inclined to flower too } \\
\text { soon. }\end{array}$ \\
\hline
\end{tabular}




\begin{tabular}{|c|c|c|c|c|}
\hline Name. & $\begin{array}{l}\text { Height and } \\
\text { Colour. }\end{array}$ & $\begin{array}{l}\text { Country and } \\
\text { Season under } \\
\text { Glass. }\end{array}$ & Soil. & General Remarks. \\
\hline Senecio pulcher & $\begin{array}{c}\text { Herba- } \\
\text { ceous } \\
2-2 \frac{1}{2} \mathrm{ft} . \\
\text { Red- } \\
\text { purple }\end{array}$ & $\begin{array}{l}\text { Uruguay } \\
\text { Sept.-- }\end{array}$ & $\begin{array}{l}\text { Moist } \\
\text { sandy } \\
\text { loam }\end{array}$ & $\begin{array}{l}\text { Daisy Order. Several } \\
\text { plants should be arranged } \\
\text { in a good group with a } \\
\text { background of foliage to } \\
\text { give the best effect. Root } \\
\text { cuttings strike freely after } \\
\text { the manner of Sea-kale. }\end{array}$ \\
\hline Kæmpferi & $\begin{array}{c}\text { I-I } \frac{1}{2} \text { ft. } \\
\text { Yellow } \\
\text { H.-hardy }\end{array}$ & $\begin{array}{l}\text { Japan } \\
\text { Autumn }\end{array}$ & $\begin{array}{c}\text { Moist } \\
\text { loam and } \\
\text { peat }\end{array}$ & $\begin{array}{l}\text { S. Kæmpferi is a Colts- } \\
\text { foot-like plant with broad } \\
\text { pale-green leaves splashed } \\
\text { with creamy-white heads } \\
\text { of large golden-yellow } \\
\text { rayed flowers. Fine. }\end{array}$ \\
\hline Stokesia cyanea & $\begin{array}{c}\text { I } \frac{1}{2} \mathrm{ft} . \\
\text { Blue } \\
\text { aster-like } \\
\mathrm{fl} \text {. heads }\end{array}$ & $\begin{array}{l}\text { N. Am. } \\
\text { Aug.- } \\
\text { Sept. }\end{array}$ & $\begin{array}{c}\text { Sandy } \\
\text { loam and } \\
\text { leaf- } \\
\text { mould }\end{array}$ & $\begin{array}{l}\text { Daisy Order. This hardy } \\
\text { perennial succeeds best } \\
\text { grown out of doors and } \\
\text { potted in summer for } \\
\text { autumn flowering under } \\
\text { glass. }\end{array}$ \\
\hline Tricyrtis hirta & $\begin{array}{l}\text { I-I } \mathrm{d} \text { ft. } \\
\text { White } \\
\text { flecked } \\
\text { with } \\
\text { mauve }\end{array}$ & $\begin{array}{l}\text { Japan } \\
\text { Aug.- } \\
\text { Oct. }\end{array}$ & $\begin{array}{l}\text { Sandy } \\
\text { loam } \\
\text { and } \\
\text { peat }\end{array}$ & $\begin{array}{l}\text { Liy Order. Though a lili- } \\
\text { aceous plant botanically, } \\
\text { Tricyrtis has more the } \\
\text { appearance of an Orchid, } \\
\text { and is both pretty and } \\
\text { uncommon looking. Very } \\
\text { easily managed. }\end{array}$ \\
\hline
\end{tabular}




\section{TRAILING PLANTS FOR BASKETS}

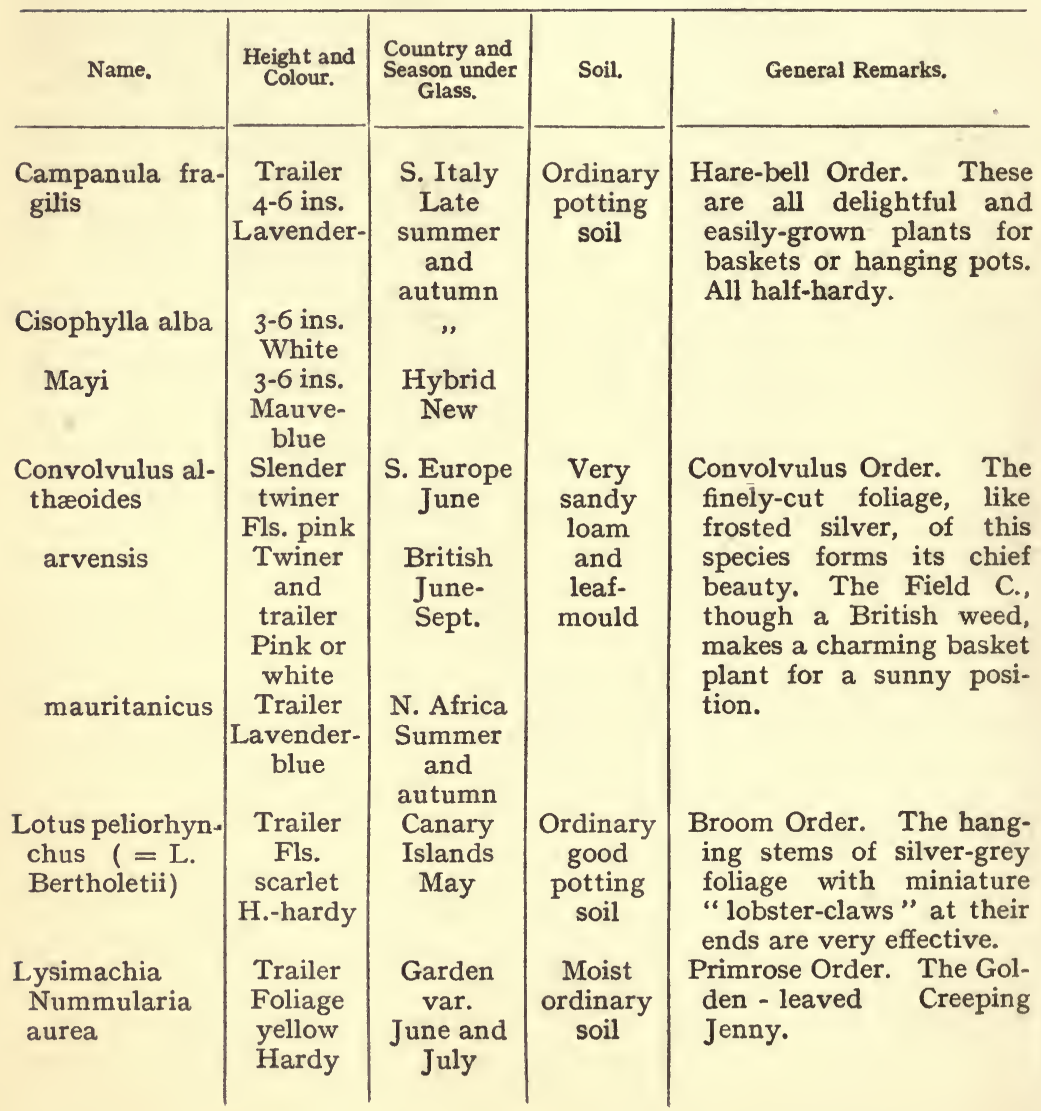




\begin{tabular}{|c|c|c|c|c|}
\hline Name. & $\begin{array}{l}\text { Height and } \\
\text { Colour. }\end{array}$ & $\begin{array}{l}\text { Country and } \\
\text { Season under } \\
\text { Glass. }\end{array}$ & Soil. & General Remarks. \\
\hline Mitchella repens & $\begin{array}{l}\text { Trailing } \\
\text { ever- } \\
\text { green } \\
\text { White } \\
\text { Hardy }\end{array}$ & $\begin{array}{l}\text { N. Am. } \\
\text { Spring }\end{array}$ & $\begin{array}{l}\text { Moist } \\
\text { sandy } \\
\text { loam and } \\
\text { leaf- } \\
\text { mould }\end{array}$ & $\begin{array}{l}\text { Woodruff Order. A charm- } \\
\text { ing little plant with lea- } \\
\text { thery dark-green leaves } \\
\text { and white jasmine-like } \\
\text { flowers in May followed } \\
\text { by scarlet berries which } \\
\text { remain through the win- } \\
\text { ter. It likes shade and } \\
\text { moisture. }\end{array}$ \\
\hline $\begin{array}{c}\text { Nertera de- } \\
\text { pressa }\end{array}$ & $\begin{array}{c}\text { Creeping } \\
\text { in dense } \\
\text { tufts of } \\
\text { minute } \\
\text { leaves } \\
\text { Fls. in- } \\
\text { conspicu- } \\
\text { ous } \\
\text { Orange- } \\
\text { scarlet } \\
\text { berries } \\
\text { H.-hardy }\end{array}$ & $\begin{array}{l}\text { N. Zealand } \\
\text { Summer } \\
\text { and } \\
\text { autumn }\end{array}$ & $\begin{array}{l}\text { Moist } \\
\text { light } \\
\text { sandy } \\
\text { loam } \\
\text { and } \\
\text { leaf- } \\
\text { mould }\end{array}$ & $\begin{array}{l}\text { Woodruff Order. Bead } \\
\text { Plant. Generally grown } \\
\text { in a pan. Erroneously } \\
\text { known as New Zealand } \\
\text { Duckweed. }\end{array}$ \\
\hline $\begin{array}{l}\text { Nierembergia } \\
\text { rivularis }\end{array}$ & $\begin{array}{l}\text { Trailer } \\
\text { White } \\
\text { cup- } \\
\text { shaped fls. } \\
\text { Hardy }\end{array}$ & $\begin{array}{l}\text { La Plata } \\
\text { Autumn }\end{array}$ & $\begin{array}{l}\text { Moist } \\
\text { sandy } \\
\text { loam }\end{array}$ & $\begin{array}{l}\text { Nightshade Order. This } \\
\text { plant may be used in } \\
\text { various ways, e.g., to sur- } \\
\text { face large pots, as well as } \\
\text { for baskets. }\end{array}$ \\
\hline $\begin{array}{r}\text { Parochetus } \\
\text { communis }\end{array}$ & $\begin{array}{l}\text { Creeping } \\
\text { stems } \\
\text { rooting } \\
\text { at joints } \\
\text { Cobalt- } \\
\text { blue }\end{array}$ & $\begin{array}{c}\text { Himalayas } \\
\text { Oct.- } \\
\text { Nov. }\end{array}$ & $\begin{array}{l}\text { Well- } \\
\text { drained } \\
\text { sandy } \\
\text { loam and } \\
\text { leaf- } \\
\text { mould }\end{array}$ & $\begin{array}{l}\text { Broom Order. "Sham- } \\
\text { rock Pea." Clover-like } \\
\text { leaves and rather large } \\
\text { pea-flowers of an unusual } \\
\text { shade of blue. A pretty } \\
\text { plant. }\end{array}$ \\
\hline
\end{tabular}




\section{ANNUALS SUITABLE FOR POT CULTURE}

HARDY Annuals may be sown in August and September, to flower under glass in early Spring. Half-hardy and Tender Annuals do best sown in a Wardian frame in March and April to flower in summer and autumn.

Most Annuals require a fairly rich compost consisting of three parts of good loam and one of thoroughly decayed manure with some sharp sand.

\begin{tabular}{|c|c|c|c|c|}
\hline Name. & Height. & Colour. & $\begin{array}{l}\text { Country and } \\
\text { Season under } \\
\text { Glass. }\end{array}$ & General Remarks. \\
\hline $\begin{array}{l}\text { Arctotis brevis- } \\
\text { capa } \\
\text { grandis }\end{array}$ & $\begin{array}{l}6-12 \text { ins. } \\
1-1 \frac{1}{2} \mathrm{ft} .\end{array}$ & $\begin{array}{l}\text { Orange } \\
\text { White }\end{array}$ & $\begin{array}{l}\text { Cape } \\
\text { Summer } \\
\text { and }\end{array}$ & $\begin{array}{l}\text { Daisy Order. Handsome } \\
\text { and choice but requiring } \\
\text { full sun. Half-hardy. }\end{array}$ \\
\hline $\begin{array}{l}\text { Browallia gran- } \\
\text { diflora } \\
\text { speciosa ma- } \\
\text { jor }\end{array}$ & $\begin{array}{l}\text { I } \frac{1}{2} \mathrm{ft} \\
\text { I } 2 \text { ins. }\end{array}$ & $\begin{array}{l}\text { Pale blue } \\
\text { or white } \\
\text { Deep blue }\end{array}$ & $\begin{array}{c}\text { Peru } \\
\text { Autumn }\end{array}$ & $\begin{array}{l}\text { Nightshade Order. For } \\
\text { large specimens put three } \\
\text { in a pot. Sown early } \\
\text { these flower in autumn } \\
\text { and will continue until } \\
\text { cold weather disables } \\
\text { them. Good greenhouse } \\
\text { plants. Rather tender. }\end{array}$ \\
\hline $\begin{array}{l}\text { Campanula } \\
\text { macrostyla }\end{array}$ & 12 ins. & $\begin{array}{l}\text { Purple } \\
\text { veined }\end{array}$ & $\begin{array}{l}\text { Taurus } \\
\text { Mts. } \\
\text { July }\end{array}$ & $\begin{array}{l}\text { Harebell Order. A re- } \\
\text { markable and interesting } \\
\text { species. Hardy. }\end{array}$ \\
\hline $\begin{array}{l}\text { Clintonia pul- } \\
\text { chella (= Dow- } \\
\text { ningia) }\end{array}$ & 6 ins. & $\begin{array}{l}\text { Rich blue } \\
\text { or blue } \\
\text { and white }\end{array}$ & $\begin{array}{l}\text { Cali- } \\
\text { fornia } \\
\text { Summer }\end{array}$ & $\begin{array}{l}\text { Harebell Order. Ex- } \\
\text { tremely pretty for a } \\
\text { hanging pot or basket. } \\
\text { Half-hardy. }\end{array}$ \\
\hline $\begin{array}{l}\text { Collinsia bicolor } \\
\text { verna } \\
\text { violacea }\end{array}$ & $\begin{array}{l}12-15 \text { ins. } \\
12 \text { ins. } \\
6-12 \text { ins. }\end{array}$ & $\begin{array}{l}\text { Lilac and } \\
\text { white } \\
\text { Blue and } \\
\text { white } \\
\text { Purple } \\
\text { and white }\end{array}$ & $\begin{array}{c}\text { Cali- } \\
\text { fornia } \\
\text { Mar.-May } \\
\text { Arkansas } \\
\text { Early } \\
\text { summer }\end{array}$ & $\begin{array}{l}\text { Foxglove Order. Autumn } \\
\text { sowing is best, and the } \\
\text { plants will be very at- } \\
\text { tractive in early spring. } \\
\text { Hardy. }\end{array}$ \\
\hline
\end{tabular}




\begin{tabular}{|c|c|c|c|c|}
\hline Name. & Height. & Colour. & $\begin{array}{l}\text { Country and } \\
\text { Season under } \\
\text { Glass. }\end{array}$ & General Remarks. \\
\hline $\begin{array}{l}\text { Cosmos bipin- } \\
\text { natus }\end{array}$ & $\begin{array}{l}2 \mathrm{ft} \text {. or } \\
\text { more }\end{array}$ & $\begin{array}{l}\text { Mauve, } \\
\text { rose, or } \\
\text { white }\end{array}$ & $\begin{array}{l}\text { Mexico } \\
\text { Late } \\
\text { autumn }\end{array}$ & $\begin{array}{l}\text { Daisy Order. Very late } \\
\text { flowering. They may be } \\
\text { planted in outside border } \\
\text { and carefully lifted in } \\
\text { September to flower in } \\
\text { the greenhouse. Half- } \\
\text { hardy. }\end{array}$ \\
\hline $\begin{array}{l}\text { Dianthus Hed- } \\
\text { dewigii }\end{array}$ & 9 ins. & $\begin{array}{l}\text { Crimson } \\
\text { or white }\end{array}$ & $\begin{array}{l}\text { Japan } \\
\text { Summer }\end{array}$ & $\begin{array}{l}\text { Carnation Order. Sow in } \\
\text { autumn for early spring } \\
\text { flowering. The large } \\
\text { single vars., such as Crim- } \\
\text { son Belle and Eastern } \\
\text { Queen, are the most ef- } \\
\text { fective and do well in } \\
\text { pots. Hardy. }\end{array}$ \\
\hline $\begin{array}{l}\text { Gaillardia am- } \\
\text { blyodon } \\
\text { picta }\end{array}$ & $\begin{array}{l}\mathrm{I}-\mathrm{I} \frac{1}{2} \mathrm{ft} . \\
\mathrm{I} 2 \text { ins. }\end{array}$ & $\begin{array}{l}\text { Deep red } \\
\text { Orange- } \\
\text { red and } \\
\text { yellow }\end{array}$ & $\begin{array}{l}\text { Texas } \\
\text { Sept.- } \\
\text { October }\end{array}$ & $\begin{array}{l}\text { Daisy Order. Well-known } \\
\text { and showy for autumn } \\
\text { blooming. Half-hardy. }\end{array}$ \\
\hline $\begin{array}{l}\text { Godetia Whit- } \\
\text { neyi and vars. }\end{array}$ & $\mathrm{I} \frac{1}{2} \mathrm{ft}$. & $\begin{array}{l}\text { Crimson } \\
\text { to white }\end{array}$ & $\begin{array}{l}\text { Cali- } \\
\text { fornia } \\
\text { July- } \\
\text { October }\end{array}$ & $\begin{array}{l}\text { Evening Primrose Order. } \\
\text { All the named varieties } \\
\text { make fine pot-plants for } \\
\text { summer and autumn. } \\
\text { Hardy. }\end{array}$ \\
\hline $\begin{array}{c}\text { Helichrysum } \\
\text { bracteatum }\end{array}$ & $\mathrm{I} \frac{1}{2}-2 \mathrm{ft}$. & $\begin{array}{l}\text { Shades of } \\
\text { crimson } \\
\text { and } \\
\text { yellow }\end{array}$ & $\begin{array}{l}\text { Australia } \\
\text { August- } \\
\text { Sept. }\end{array}$ & $\begin{array}{l}\text { Daisy Order. Strong } \\
\text { growing everlastings } \\
\text { which are often grown in } \\
\text { pots. Half-hardy. }\end{array}$ \\
\hline $\begin{array}{l}\text { Impatiens Bal- } \\
\text { samina }\end{array}$ & $\mathrm{I}-2 \mathrm{ft}$. & $\begin{array}{l}\text { Purple, } \\
\text { rose, or } \\
\text { white }\end{array}$ & $\begin{array}{l}\text { Trop. } \\
\text { Asia } \\
\text { Early } \\
\text { autumn }\end{array}$ & $\begin{array}{l}\text { Geranium Order. Balsam. } \\
\text { These are decorative } \\
\text { plants if well grown. } \\
\text { Sow singly in thumb-pots } \\
\text { in March. Give the } \\
\text { young plants successive } \\
\text { shifts into a larger size } \\
\text { until they are in } 8 \text {-in. or } \\
\text { ro-in. pots. Feed gene- } \\
\text { rously. Stand out of } \\
\text { doors in good weather, } \\
\text { and disbud for a time, if } \\
\text { very large specimens are } \\
\text { required. Tender. }\end{array}$ \\
\hline
\end{tabular}




\begin{tabular}{|c|c|c|c|c|}
\hline Name & Height. & Colour. & $\begin{array}{c}\text { Country and } \\
\text { Season under } \\
\text { Glass. }\end{array}$ & General Remarks. \\
\hline $\begin{array}{l}\text { Ionopsidium } \\
\text { acaule }\end{array}$ & $2-3$ ins. & Lilac & Portugal & $\begin{array}{l}\text { Wallflower Order. A mi- } \\
\text { nute but useful little car- } \\
\text { peting plant. In flower } \\
\text { at all seasons as it gene- } \\
\text { rally sows itself. Hardy. }\end{array}$ \\
\hline $\begin{array}{l}\text { Ipomœa hede- } \\
\text { racea }\end{array}$ & $\begin{array}{l}\text { Twiners } \\
6 \text { - Io ft. }\end{array}$ & $\begin{array}{l}\text { Light blue } \\
\text { and white }\end{array}$ & $\begin{array}{l}\text { S. Am. } \\
\text { July- } \\
\text { Sept. }\end{array}$ & $\begin{array}{l}\text { Convolvulus Order. Both } \\
\text { pretty species of green- } \\
\text { house convolvulus not }\end{array}$ \\
\hline Quamoclit & $6 \mathrm{ft}$. & $\begin{array}{l}\text { Scarlet or } \\
\text { dark red }\end{array}$ & ", & $\begin{array}{l}\text { often seen, and very dis- } \\
\text { tinct from each other. } \\
\text { The foliage of I. Quamo- } \\
\text { clit is finely cut. Tender. }\end{array}$ \\
\hline $\begin{array}{l}\text { Lathyrus odora- } \\
\text { tus (Sweet } \\
\text { Peas) }\end{array}$ & 4-6 ft. & $\begin{array}{l}\text { Garden } \\
\text { vars. } \\
\text { many hued }\end{array}$ & Sicily & $\begin{array}{l}\text { Broom Order. Sow in } \\
\text { July and August for win- } \\
\text { ter flowering under glass. } \\
\text { It has recently been } \\
\text { stated that cuttings can } \\
\text { be easily struck from } \\
\text { side shoots-which is } \\
\text { worth doing of an extra } \\
\text { good variety. Hardy. }\end{array}$ \\
\hline $\begin{array}{l}\text { Lavatera tri- } \\
\text { mestris, var. } \\
\text { splendens } \\
\text { var. alba }\end{array}$ & $2-3 \mathrm{ft}$. & $\begin{array}{l}\text { Rose- } \\
\text { pink } \\
\text { White }\end{array}$ & $\begin{array}{l}\text { S. Europe } \\
\text { Summer }\end{array}$ & $\begin{array}{l}\text { Mallow Order. An im- } \\
\text { proved form of a well- } \\
\text { known showy annual. }\end{array}$ \\
\hline $\begin{array}{l}\text { Leptosiphon al- } \\
\text { bus } \\
\text { aureus } \\
\text { roseus }\end{array}$ & 6 ins. & $\begin{array}{l}\text { White } \\
\text { Orange } \\
\text { Pink }\end{array}$ & $\begin{array}{l}\text { Cali- } \\
\text { fornia } \\
\text { Early } \\
\text { spring }\end{array}$ & $\begin{array}{l}\text { Phlox Order. Low-grow- } \\
\text { ing plants with brilliant } \\
\text { but small flowers. Hardy. }\end{array}$ \\
\hline $\begin{array}{l}\text { Limnanthes } \\
\text { Douglassii }\end{array}$ & $6-8$ ins. & $\begin{array}{l}\text { Yellow } \\
\text { and white }\end{array}$ & $\begin{array}{l}\text { Cali- } \\
\text { fornia } \\
\text { Very } \\
\text { early } \\
\text { spring }\end{array}$ & $\begin{array}{l}\text { Geranium Order. Good } \\
\text { for baskets in spring. } \\
\text { Very hardy. Sow in } \\
\text { autumn. }\end{array}$ \\
\hline Lobelia tenuior & 12 ins. & $\begin{array}{l}\text { Deep blue } \\
\text { and white }\end{array}$ & $\begin{array}{c}\text { Australia } \\
\text { Sept. }\end{array}$ & $\begin{array}{l}\text { Harebell Order. A pretty } \\
\text { species lately re-intro- } \\
\text { duced. Half-hardy. }\end{array}$ \\
\hline $\begin{array}{l}\text { Martynia frag- } \\
\text { rans }\end{array}$ & $\mathrm{I} \frac{1}{2} \mathrm{ft}$ & $\begin{array}{l}\text { Crimson- } \\
\text { purple, } \\
\text { yellow } \\
\text { throat }\end{array}$ & $\begin{array}{l}\text { Mexico } \\
\text { July- } \\
\text { Sept. }\end{array}$ & $\begin{array}{l}\text { Pedalineæ Order. A hand- } \\
\text { some large-growing plant } \\
\text { not often seen, and sweet- } \\
\text { scented. Half-hardy. }\end{array}$ \\
\hline $\begin{array}{l}\text { Mesembryan- } \\
\text { themum pome- } \\
\text { ridianum }\end{array}$ & $6-8$ ins. & Yellow & $\begin{array}{l}\text { Cape } \\
\text { July }\end{array}$ & $\begin{array}{l}\text { Fig-marigold Order. The } \\
\text { first expands after mid- } \\
\text { day as its name implies. }\end{array}$ \\
\hline
\end{tabular}




\begin{tabular}{|c|c|c|c|c|}
\hline Name. & Height. & Colour. & $\begin{array}{l}\text { Country and } \\
\text { Season under } \\
\text { Glass. }\end{array}$ & General Remarks. \\
\hline $\begin{array}{l}\text { tricolor and } \\
\text { var. album }\end{array}$ & 4-6 ins. & $\begin{array}{l}\text { Rose and } \\
\text { white } \\
\text { Pure white }\end{array}$ & $\begin{array}{l}\text { April } \\
\text { and } \\
\text { May }\end{array}$ & $\begin{array}{l}\text { All are good for sunny } \\
\text { greenhouses, and do best } \\
\text { in very sandy soil. }\end{array}$ \\
\hline Mina lobata & Climber & $\begin{array}{l}\text { Red and } \\
\text { cream- } \\
\text { white }\end{array}$ & $\begin{array}{l}\text { S. Mexico } \\
\text { Summer }\end{array}$ & $\begin{array}{l}\text { Convolvulus Order. A } \\
\text { beautiful annual climber } \\
\text { when treated generously. } \\
\text { The spikes of flowers } \\
\text { which change colour as } \\
\text { they mature are remark- } \\
\text { able. Seldom seen in per- } \\
\text { fection. Half-hardy. }\end{array}$ \\
\hline $\begin{array}{l}\text { Nemesia stru- } \\
\text { mosa }\end{array}$ & I 2 ins. & $\begin{array}{l}\text { White, } \\
\text { orange to } \\
\text { carmine }\end{array}$ & $\begin{array}{c}\text { Cape } \\
\text { Summer }\end{array}$ & $\begin{array}{l}\text { Foxglove Order. A most } \\
\text { distinct and lovely an- } \\
\text { nual. }\end{array}$ \\
\hline $\begin{array}{l}\text { Nemophila in- } \\
\text { signis and vars. }\end{array}$ & $\begin{array}{l}\text { Trailer } \\
4-6 \text { ins. }\end{array}$ & $\begin{array}{l}\text { Sky-blue } \\
\text { or white }\end{array}$ & $\begin{array}{l}\text { Cali- } \\
\text { fornia } \\
\text { Spring } \\
\text { or } \\
\text { summer }\end{array}$ & $\begin{array}{l}\text { Nemophila Order. Sown } \\
\text { in August or September, } \\
\text { this is capital for baskets } \\
\text { or pans for early spring } \\
\text { flowering. A single plant } \\
\text { makes a good specimen. } \\
\text { Hardy. }\end{array}$ \\
\hline $\begin{array}{l}\text { Papaver glau- } \\
\text { cum } \\
\text { Rheas (Shir- } \\
\text { ley vars.) }\end{array}$ & $\begin{array}{l}\mathrm{I} \frac{1}{2} \mathrm{ft} . \\
2 \frac{1}{2} \mathrm{ft} .\end{array}$ & $\begin{array}{l}\text { Crimson- } \\
\text { scarlet } \\
\text { Many } \\
\text { coloured }\end{array}$ & $\begin{array}{c}\text { Syria } \\
\text { Spring } \\
\quad,\end{array}$ & $\begin{array}{l}\text { Poppy Order. The various } \\
\text { kinds of Poppy are es- } \\
\text { pecially valuable sown in } \\
\text { autumn for spring flower- } \\
\text { ing. Very hardy. }\end{array}$ \\
\hline P. umbrosum & $I_{\frac{1}{2}} \mathrm{ft}$. & $\begin{array}{c}\text { Deep } \\
\text { scarlet }\end{array}$ & Caucasus. & \\
\hline $\begin{array}{l}\text { Rodanthe Man- } \\
\text { glesi (= Helip- } \\
\text { terum) }\end{array}$ & 12 ins. & $\begin{array}{l}\text { Pink or } \\
\text { white }\end{array}$ & $\begin{array}{l}\text { Australia } \\
\text { Summer } \\
\text { and } \\
\text { autumn }\end{array}$ & $\begin{array}{l}\text { Daisy Order. Delicate } \\
\text { little everlastings which } \\
\text { are much grown from 6-8 } \\
\text { in a 5-in. pot. (For } \\
\text { another plan see Chapter } \\
\text { XVI.) Half-hardy. }\end{array}$ \\
\hline $\begin{array}{l}\text { Sabbatia cam- } \\
\text { pestris }\end{array}$ & 9 ins. & Rose-pink & $\begin{array}{l}\text { N. Am. } \\
\text { Summer }\end{array}$ & $\begin{array}{l}\text { Gentian Order. A pretty } \\
\text { and uncommon plant. A } \\
\text { good plan is to place the } \\
\text { pot in a saucer, filling it } \\
\text { frequently but not letting } \\
\text { the plant stand altogether } \\
\text { in water. Half-hardy. }\end{array}$ \\
\hline $\begin{array}{l}\text { Salpiglossis si- } \\
\text { nuata nana }\end{array}$ & $\mathrm{I}-\mathrm{I} \frac{1}{2} \mathrm{ft}$. & $\begin{array}{l}\text { Crimson, } \\
\text { purple or } \\
\text { yellow } \\
\text { reticulated }\end{array}$ & $\begin{array}{l}\text { Chili } \\
\text { Late } \\
\text { summer } \\
\text { and } \\
\text { autumn }\end{array}$ & $\begin{array}{l}\text { Nightshade Order. Best } \\
\text { sown in early spring for } \\
\text { summer and autumn } \\
\text { flowering. Rich soil. } \\
\text { Half-hardy. }\end{array}$ \\
\hline
\end{tabular}




\begin{tabular}{|c|c|c|c|c|}
\hline Name. & Height. & Colour. & $\begin{array}{l}\text { Country and } \\
\text { Season under } \\
\text { Glass. }\end{array}$ & General Remarks. \\
\hline $\begin{array}{l}\text { Schizanthus } \\
\text { Wisetonensis }\end{array}$ & 12 ins. & Various & $\begin{array}{c}\text { Chili } \\
\text { (Garden } \\
\text { forms) } \\
\text { Autumn }\end{array}$ & $\begin{array}{l}\text { Foxglove Order. These } \\
\text { new hybrids, lately in- } \\
\text { troduced of an old and } \\
\text { favourite plant are very } \\
\text { fine. Sown early and } \\
\text { shifted into larger pots } \\
\text { as required, single plants } \\
\text { will be very ornamental } \\
\text { for autumn in the un- } \\
\text { heated house, but will } \\
\text { not answer for winter } \\
\text { flowering. Half-hardy. }\end{array}$ \\
\hline $\begin{array}{l}\text { Statice Bon- } \\
\text { duellii } \\
\text { Suworowii }\end{array}$ & $\begin{array}{l}\mathrm{I} 2 \mathrm{ins} . \\
\mathrm{I} \frac{1}{2} \mathrm{ft} .\end{array}$ & $\begin{array}{l}\text { Yellow } \\
\text { Lilac }\end{array}$ & $\begin{array}{c}\text { Algeria } \\
\text { Turkes- } \\
\text { tan } \\
\text { Summer } \\
\text { or } \\
\text { autumn }\end{array}$ & $\begin{array}{l}\text { Thrift Order. Flowers } \\
\text { everlasting. Seed of } \\
\text { these annual species of } \\
\text { Statices may be sown } \\
\text { either in spring or au- } \\
\text { tumn as desired for sea- } \\
\text { son of blooming. Au- } \\
\text { tumn seedlings will re- } \\
\text { quire a little extra care } \\
\text { during winter. Half- } \\
\text { hardy. }\end{array}$ \\
\hline $\begin{array}{l}\text { Thunbergia } \\
\text { alata }\end{array}$ & $\begin{array}{l}\text { Dwarf } \\
\text { twiner } \\
2 \frac{1}{2} \mathrm{ft} .\end{array}$ & $\begin{array}{l}\text { Buff or } \\
\text { white } \\
\text { with dark } \\
\text { eye }\end{array}$ & $\begin{array}{l}\text { S. Africa } \\
\text { Summer }\end{array}$ & $\begin{array}{l}\text { Acanthus Order. These } \\
\text { must be started in a close } \\
\text { frame or Wardian case } \\
\text { and, when the seedlings } \\
\text { are strong enough and } \\
\text { have been gradually har- } \\
\text { dened off, make charming } \\
\text { basket or trellis plants. } \\
\text { Tender. }\end{array}$ \\
\hline $\begin{array}{l}\text { Tropœolum } \\
\text { lobbianum } \\
\text { vars. }\end{array}$ & Climber & $\begin{array}{l}\text { Scarlet- } \\
\text { orange or } \\
\text { yellow }\end{array}$ & $\begin{array}{l}\text { Columbia } \\
\text { Summer }\end{array}$ & $\begin{array}{l}\text { Geranium Order. These } \\
\text { fine "Nasturtiums" are } \\
\text { really perennial, but are } \\
\text { generally treated as an- } \\
\text { nuals. They make fine } \\
\text { pillar plants or baskets. } \\
\text { The soil should not be too } \\
\text { rich for the latter pur- } \\
\text { pose, otherwise they are } \\
\text { apt to become too vigo- } \\
\text { rous. The Tom Thumb } \\
\text { section of T. majus are } \\
\text { very handsome, and, in }\end{array}$ \\
\hline
\end{tabular}




\begin{tabular}{|c|c|c|c|c|}
\hline Name. & Height. & Colour. & $\begin{array}{c}\text { Country and } \\
\text { Season under } \\
\text { Glass. }\end{array}$ & General Remarks. \\
\hline $\begin{array}{l}\text { Verbena hy- } \\
\text { brida }\end{array}$ & I 2 ins. & $\begin{array}{l}\text { Scarlet, } \\
\text { purple to } \\
\text { white }\end{array}$ & $\begin{array}{l}\text { Mexico } \\
\text { Summer }\end{array}$ & $\begin{array}{l}\text { default of anything more } \\
\text { choice, would make a } \\
\text { small greenhouse gay in } \\
\text { a few weeks during sum- } \\
\text { mer and autumn. } \\
\text { Verbena Order. These are } \\
\text { now very generally trea- } \\
\text { ted as annuals, and raised } \\
\text { from seed year by year. } \\
\text { With a little training } \\
\text { they succeed very well as } \\
\text { pot plants. }\end{array}$ \\
\hline
\end{tabular}




\section{BIENNIALS}

\begin{tabular}{|c|c|c|c|c|}
\hline Name. & Height. & Colour. & $\begin{array}{l}\text { Country and } \\
\text { Season under } \\
\text { Glass. }\end{array}$ & General Remarks. \\
\hline $\begin{array}{l}\text { Campanula } \\
\text { Medium }\end{array}$ & $2-2 \frac{1}{2} \mathrm{ft}$ & $\begin{array}{l}\text { White to } \\
\text { deep } \\
\text { purple } \\
\text { and pink }\end{array}$ & $\begin{array}{l}\text { S. Europe } \\
\text { Spring }\end{array}$ & $\begin{array}{l}\text { Harebell Order. The well- } \\
\text { known "Canterbury } \\
\text { Bells." These make very } \\
\text { fine pot-plants. }\end{array}$ \\
\hline pyramidalis & $2 \frac{1}{2}-4 \mathrm{ft}$. & $\begin{array}{l}\text { Lavender- } \\
\text { blue or } \\
\text { white }\end{array}$ & $\begin{array}{l}\text { Europe } \\
\text { Autumn }\end{array}$ & $\begin{array}{l}\text { The "Chimney" C. is } \\
\text { really perennial, but does } \\
\text { best treated as a biennial. } \\
\text { Side shoots can be rooted } \\
\text { if desired, but seedlings } \\
\text { generally make the best } \\
\text { plants. }\end{array}$ \\
\hline $\begin{array}{l}\text { Chamœpeuce } \\
\text { Casabonæ } \\
\text { (Fishbone } \\
\text { Thistle) }\end{array}$ & $\begin{array}{l}\text { Rosettes } \\
\text { of deep } \\
\text { green } \\
\text { leaves } \\
\text { veined } \\
\text { white }\end{array}$ & $\begin{array}{l}\text { Pale } \\
\text { purple }\end{array}$ & S. Europe & $\begin{array}{l}\text { Daisy Order. Chiefly val- } \\
\text { uable as foliage plants } \\
\text { when young for green- } \\
\text { house or plant groups. } \\
\text { They do not flower till the } \\
\text { second year. Sow in au- }\end{array}$ \\
\hline Diacantha & $\begin{array}{l}\text { Leaves } \\
\text { spiny } \\
\text { with } \\
\text { silvery } \\
\text { veins and } \\
\text { spines }\end{array}$ & Purple & Syria & tumn. Hardy. \\
\hline $\begin{array}{l}\text { Cheiranthus } \\
\text { Cheiri (Wall- } \\
\text { flower) }\end{array}$ & $\mathrm{I}-2 \mathrm{ft}$ & Various & $\begin{array}{c}\text { North } \\
\text { and } \\
\text { Central } \\
\text { Europe } \\
\text { Late } \\
\text { autumn, } \\
\text { winter, } \\
\text { and } \\
\text { spring }\end{array}$ & $\begin{array}{l}\text { Wall-flower Order. Ger- } \\
\text { man, French, and English } \\
\text { hybrids are distinct from } \\
\text { each other, and all are } \\
\text { fine. The German are } \\
\text { mostly double forms of } \\
\text { the Rocket Wall-flower. } \\
\text { The old English double } \\
\text { Wall-flowers must be pro- }\end{array}$ \\
\hline
\end{tabular}




\begin{tabular}{|c|c|c|c|c|}
\hline Name. & Height. & Colour. & $\begin{array}{l}\text { Country and } \\
\text { Season under } \\
\text { Glass. }\end{array}$ & General Remarks. \\
\hline Exacum affine & 6 ins. & Lilac-blue & $\begin{array}{l}\text { Socotra } \\
\text { Summer } \\
\text { and } \\
\text { autumn }\end{array}$ & $\begin{array}{l}\text { pagated by cuttings. The } \\
\text { single forms by seed. } \\
\text { Harbinger, a rich crimson } \\
\text { brown, begins to flower } \\
\text { before Christmas, and is } \\
\text { invaluable where there is } \\
\text { only the shelter of glass. } \\
\text { Very hardy. } \\
\text { Gentian Order. A rather } \\
\text { uncommon plant and } \\
\text { generally grown in heat, } \\
\text { but it has been managed } \\
\text { successfully by raising } \\
\text { seedlings in autumn in a } \\
\text { Wardian case, in which } \\
\text { they remained until all } \\
\text { danger of frost was over } \\
\text { in spring. Tender. }\end{array}$ \\
\hline Humea elegans & $3-4 \mathrm{ft}$. & $\begin{array}{l}\text { Minute } \\
\text { brown } \\
\text { flowers } \\
\text { in large } \\
\text { branching } \\
\text { panicle }\end{array}$ & $\begin{array}{c}\text { Australia } \\
\text { July- } \\
\text { October }\end{array}$ & $\begin{array}{l}\text { Daisy Order. Sow the } \\
\text { seed in July and pot } \\
\text { singly when large enough, } \\
\text { letting them grow slowly } \\
\text { or in a light airy position } \\
\text { in frame or greenhouse. } \\
\text { In spring, they must } \\
\text { be encouraged to grow, } \\
\text { giving successive shifts } \\
\text { until they reach a 9-in. } \\
\text { pot. Rather difficult to } \\
\text { grow well, but have a } \\
\text { very good sub-tropical } \\
\text { effect. Tender. }\end{array}$ \\
\hline $\begin{array}{l}\text { Matthiola (In- } \\
\text { termediate } \\
\text { Stocks) }\end{array}$ & 12-1 5 ins. & $\begin{array}{c}\text { Red and } \\
\text { white }\end{array}$ & $\begin{array}{l}\text { Garden } \\
\text { forms } \\
\text { Spring }\end{array}$ & $\begin{array}{l}\text { Wall-flower Order. East } \\
\text { Lothian Intermediate } \\
\text { Stocks are more for pots } \\
\text { than the Brompton Sec- } \\
\text { tion, and are quite worth } \\
\text { growing for the green- } \\
\text { house. They like extra } \\
\text { rich soil. Hardy. }\end{array}$ \\
\hline $\begin{array}{l}\text { Pentstemon Co- } \\
\text { bæa } \\
\text { murrayanus }\end{array}$ & $\begin{array}{l}\mathrm{I}-1 \frac{1}{2} \mathrm{ft} . \\
2-3 \mathrm{ft} .\end{array}$ & $\begin{array}{l}\text { Purple] } \\
\text { and white } \\
\text { Scarlet }\end{array}$ & $\begin{array}{l}\text { Texas } \\
\text { Autumn } \\
\text { Western } \\
\text { U.S. A. }\end{array}$ & $\begin{array}{l}\text { Foxglove Order. Hand- } \\
\text { some plants not often met } \\
\text { with, and better under } \\
\text { glass than in the open. }\end{array}$ \\
\hline
\end{tabular}




\begin{tabular}{|c|c|c|c|c|}
\hline Name. & Height. & Colour. & $\begin{array}{c}\text { Country and } \\
\text { Season under } \\
\text { Glass. }\end{array}$ & General Remarks. \\
\hline Wrightii & $2 \mathrm{ft}$. & Rosy-red & $\begin{array}{c}\text { Hybrid } \\
\text { June }\end{array}$ & $\begin{array}{l}P . \text { murrayanus is rather } \\
\text { tender. The others are } \\
\text { hardy. }\end{array}$ \\
\hline $\begin{array}{l}\text { Scabiosa atro- } \\
\text { purpurea } \\
\text { and vars. }\end{array}$ & $2-2 \frac{1}{2} \mathrm{ft}$. & $\begin{array}{l}\text { Maroon } \\
\text { to white }\end{array}$ & $\begin{array}{c}\text { S. Europe } \\
\text { July- } \\
\text { August }\end{array}$ & $\begin{array}{l}\text { Teasel Order. Seeds sown } \\
\text { in June and July and al- } \\
\text { lowed to make their } \\
\text { growth in an open frame } \\
\text { will make useful bloom- } \\
\text { ing plants in early spring. }\end{array}$ \\
\hline
\end{tabular}




\section{HARDY TERRESTRIAL ORCHIDS}

THE compost usually recommended for Terrestrial Orchids is a mixture of sandy loam, peat, and chopped sphagnum moss with a little charcoal in small lumps. Leaf-mould is now largely used by Orchid growers as a substitute for peat. The bog-species like plenty of moisture. Most of the plants here named will do well with cold-frame culture and brought into a greenhouse to flower.

\begin{tabular}{|c|c|c|c|}
\hline Name. & $\begin{array}{l}\text { Height and } \\
\text { Colour. }\end{array}$ & $\begin{array}{l}\text { Country and } \\
\text { Season under } \\
\text { Glass. }\end{array}$ & General Remarks. \\
\hline $\begin{array}{l}\text { Bletia hyacin- } \\
\text { thina }\end{array}$ & $\begin{array}{l}\text { I } 2 \text { ins. } \\
\text { Purple }\end{array}$ & $\begin{array}{c}\text { China } \\
\text { Mar.-June }\end{array}$ & $\begin{array}{l}\text { This used to be treated as a stove- } \\
\text { plant, but has proved to be } \\
\text { quite hardy in the open garden. } \\
\text { Quite worthy of a greenhouse, } \\
\text { and lasts long in flower. }\end{array}$ \\
\hline $\begin{array}{l}\text { Calopogon pul- } \\
\text { chellus }\end{array}$ & $\begin{array}{l}\text { I5-18 ins. } \\
\text { Purple } \\
\text { with pale } \\
\text { yellow } \\
\text { fringed } \\
\text { lin }\end{array}$ & $\begin{array}{l}\text { N. Am. } \\
\text { July-Aug. }\end{array}$ & $\begin{array}{l}\text { Tuberous rooted, with grass- } \\
\text { like leaves. Grows naturally } \\
\text { in swamps where Cranberries } \\
\text { thrive. }\end{array}$ \\
\hline Calypso borealis & $\begin{array}{l}4 \text { ins. } \\
\text { Rose with } \\
\text { brown pen- } \\
\text { cillings } \\
\text { and yellow } \\
\text { crested } \\
\text { lip }\end{array}$ & $\begin{array}{l}\text { Northern } \\
\text { Hemi- } \\
\text { sphere } \\
\text { May }\end{array}$ & $\begin{array}{l}\text { A miniature plant, but very beau- } \\
\text { tiful in its delicate colouring and } \\
\text { markings. Shade from scorch- } \\
\text { ing spring sun. }\end{array}$ \\
\hline $\begin{array}{l}\text { Cephalanthera } \\
\text { grandiflora } \\
\text { (White Hellebo- } \\
\text { rine) }\end{array}$ & $\begin{array}{l}\text { I-2 ft. } \\
\text { Cream- } \\
\text { white }\end{array}$ & $\begin{array}{c}\text { Britain } \\
\text { May-June }\end{array}$ & $\begin{array}{l}\text { A shade and chalk-loving British } \\
\text { Orchid but rare. Probably } \\
\text { would not succeed without some } \\
\text { addition of lime in the soil. }\end{array}$ \\
\hline
\end{tabular}




\begin{tabular}{|c|c|c|c|}
\hline Name. & $\begin{array}{l}\text { Height and } \\
\text { Colour. }\end{array}$ & $\begin{array}{l}\text { Country and } \\
\text { Season under } \\
\text { Glass. }\end{array}$ & General Remarks. \\
\hline $\begin{array}{l}\text { Cypripedium } \\
\text { acaule } \\
\text { var. alba }\end{array}$ & $\begin{array}{l}\text { 8-1o ins. } \\
\text { Broad } \\
\text { twin } \\
\text { leaves } \\
\text { Sepals and } \\
\text { petals } \\
\text { greenish } \\
\text { Lip, rose- } \\
\text { purple }\end{array}$ & $\begin{array}{l}\text { Northern } \\
\text { U.S.A. } \\
\text { May- } \\
\text { June }\end{array}$ & $\begin{array}{l}\text { It is stated that this species is } \\
\text { only found in swamps in N. } \\
\text { America growing amongst the } \\
\text { sphagnum without a particle of } \\
\text { soil near its roots. In such situa- } \\
\text { tions it is common but not else- } \\
\text { where. It thrives in the full sun } \\
\text { in the wet moss. The white var. } \\
\text { is rarer than the type. }\end{array}$ \\
\hline candidum & $\begin{array}{l}12-18 \text { ins. } \\
\text { Leafy } \\
\text { stem } \\
\text { Sepals and } \\
\text { petals } \\
\text { brown } \\
\text { Lip, } \\
\text { yellow } \\
\text { I } 2 \text { ins. } \\
\text { Sepals and } \\
\text { petals } \\
\text { greenish- } \\
\text { brown }\end{array}$ & $\begin{array}{l}\text { European } \\
\text { and } \\
\text { British }\end{array}$ & $\begin{array}{l}\text { One of our rarest English wild- } \\
\text { flowers in limestone districts in } \\
\text { Northern counties. Difficult to } \\
\text { cultivate, and must not be kept } \\
\text { wet like the above, though it } \\
\text { likes shade and moisture in } \\
\text { summer and comparative dry- } \\
\text { ness when at rest. } \\
\text { An expert writes : "C. candidum } \\
\text { is found in peat bogs, where the } \\
\text { roots are always wet, while the } \\
\text { tops (in summer) are fully ex- } \\
\text { posed to sunlight." }\end{array}$ \\
\hline
\end{tabular}

guttatum

macranthum

Lip, white 6-9 ins. Twin leaves White, marbled rosypurple 9-I 2 ins. Large Rosypurple or red self

parviflorum

I $\frac{1}{2}-2 \mathrm{ft}$. Leafy stem Sepals and petals brown, spirally twisted

Lip,yellow
N. Russia June

Siberia MayJune

A small but rare and charming species. Sandy leaf-mould and sphagnum recommended. Likes shade and should be kept rather dry when at rest.

A very beautiful species, if true to name, and hardy but difficult to flower. It requires a stronger compost than others, and thrives best in good fibrous loam mixed with broken charcoal, which helps to keep the soil sweet, as root disturbance is to be avoided.

N. Am. A good species, the long-twisted Early summer petals being a distinct feature. Compost of peat and leaf-soil with partial shade and moisture. 


\begin{tabular}{|c|c|c|c|}
\hline Name. & $\begin{array}{l}\text { Height and } \\
\text { Colour. }\end{array}$ & $\begin{array}{l}\text { Country and } \\
\text { Season under } \\
\text { Glass. }\end{array}$ & General Remarks. \\
\hline pubescens & $\begin{array}{l}\mathrm{I}-2 \mathrm{ft} \\
\text { Leafy } \\
\text { stems } \\
\text { Fls. brown } \\
\text { and } \\
\text { yellow }\end{array}$ & $\begin{array}{l}\text { N. Am. } \\
\text { May- } \\
\text { June }\end{array}$ & $\begin{array}{l}\text { The most vigorous and easily } \\
\text { grown of the yellow-flowered } \\
\text { species. It is not so particular as } \\
\text { to soil, but will thrive and flower } \\
\text { well under the ordinary condi- } \\
\text { tions which suit Cypripediums. } \\
\text { A very desirable species. }\end{array}$ \\
\hline spectabile & $\begin{array}{l}\text { I } \frac{1}{2}-2 \frac{1}{2} \mathrm{ft} . \\
\text { Leafy } \\
\text { stems } \\
\text { Sepals and } \\
\text { petals } \\
\text { white } \\
\text { Large } \\
\text { rounded }\end{array}$ & $\begin{array}{l}\text { N. Am. } \\
\text { May- } \\
\text { June }\end{array}$ & $\begin{array}{l}\text { The Red Indian's "Moccasin } \\
\text { Flower." This species is essen- } \\
\text { tially a shade lover and is said to } \\
\text { dwindle and die if the trees } \\
\text { which give it coolness and } \\
\text { shelter in its native swamp are } \\
\text { cut down. }\end{array}$ \\
\hline
\end{tabular}

Disa grandiflora

Diuris alba

aurea

lilacina graminifolia

(Blue Disa) lip,

rose or

pink

$\mathrm{I} \frac{1}{2}-2 \mathrm{ft}$.

Scarlet

and light

pink

I $\frac{1}{2}-2 \mathrm{ft}$.

Fls. not

large

but

brilliant

blue

12-1 8 ins.

Bluish-

white

Yellow

Purple-

lilac
Australia

C. Colony JuneJuly

Table Mountain Summer
There are some other hardy $\mathrm{Cy}$ pripediums, such as $C$. arietinum and $C$. montanum, but the above comprise the best known.

A cold-house Orchid of brilliant colouring and not hard to grow. There are several varieties, e.g., D. grandiflora Barrellii and D. g. superba. Disas grow naturally on the banks of streams, and in times of flood are often submerged. They should never be allowed to become very dry even in winter, and too much water can scarcely be given when they are making their growth. Pans with perforated side-holes suit them best. The Blue Disa requires rather stiff soil.

A great number of terrestrial orchids are indigenous to Australia and Tasmania. The three species of Diuris here given are distinct and pretty with grass-like foliage. The long-tailed flowers of D. lilacina are borne in succession on a spike for some time. All will do well in a mixture of loam and peat. 


\begin{tabular}{|c|c|c|c|}
\hline [Name. & $\begin{array}{l}\text { Height and } \\
\text { Colour. }\end{array}$ & $\begin{array}{l}\text { Country and } \\
\text { Season under } \\
\text { Glass. }\end{array}$ & General Remarks. \\
\hline $\begin{array}{l}\text { Goodyera pubes- } \\
\text { cens }\end{array}$ & $\begin{array}{l}3 \text { ins. } \\
\text { Foliage } \\
\text { green } \\
\text { veined } \\
\text { white } \\
\text { Ever- } \\
\text { green }\end{array}$ & $\begin{array}{l}\text { N. Am. } \\
\text { July }\end{array}$ & $\begin{array}{l}\text { A pretty low-growing surfacing } \\
\text { plant with silver tracery of } \\
\text { veins. The dark-green leaves of } \\
\text { the British species are not white- } \\
\text { veined. Both like shade and } \\
\text { leaf-mould. }\end{array}$ \\
\hline Habenaria ciliaris & $\begin{array}{l}\mathrm{I} \frac{1}{2}-2 \mathrm{ft} . \\
\text { Orange- } \\
\text { yellow } \\
\text { with } \\
\text { fringed } \\
\text { lip } \\
\mathrm{I}-\mathrm{I} \frac{1}{2} \mathrm{ft} .\end{array}$ & $\begin{array}{l}\text { N. Am. } \\
\text { Early }\end{array}$ & $\begin{array}{l}\text { Habenarias are of the type of our } \\
\text { British Butterfly orchis }(H \text {. bi- } \\
\text { folia); but many of the exotic } \\
\text { species are far finer. For the } \\
\text { most part they seem to grow } \\
\text { naturally in wet swampy ground } \\
\text { amongst the sphagnum. }\end{array}$ \\
\hline 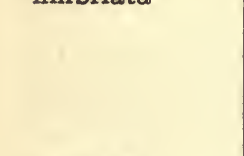 & $\begin{array}{l}\text { Lilac- } \\
\text { purple } \\
\text { fringed } \\
\text { fl. spikes } \\
4 \text { - Io ins. }\end{array}$ & $\begin{array}{l}\text { (In full } \\
\text { sun) }\end{array}$ & \\
\hline psycodes & $\begin{array}{l}\text { Rose to } \\
\text { crimson } \\
\text { fringed } \\
\text { Fragrant }\end{array}$ & $\begin{array}{l}\text { N. Am. } \\
\text { (In deep } \\
\text { shade) }\end{array}$ & \\
\hline $\begin{array}{l}\text { Ophrys apifera } \\
\text { (Bee-orchis) }\end{array}$ & $\begin{array}{l}6-8 \text { ins. } \\
\text { Lilac with } \\
\text { brown lip }\end{array}$ & $\begin{array}{l}\text { Britain } \\
\text { June- } \\
\text { July }\end{array}$ & $\begin{array}{l}\text { This species grows freely on dry } \\
\text { chalk banks, often by roadsides } \\
\text { in full sun-conditions rather } \\
\text { difficult to imitate under culti- } \\
\text { vation to their satisfaction. }\end{array}$ \\
\hline insectifera & $\begin{array}{l}\text { Of the } \\
\text { same type } \\
\text { as above } \\
\text { but } \\
\text { larger }\end{array}$ & $\begin{array}{l}\text { S. Europe } \\
\text { April- } \\
\text { May }\end{array}$ & $\begin{array}{l}\text { These include Spider and Bumble- } \\
\text { bee orchises. }\end{array}$ \\
\hline $\begin{array}{l}\text { muscifera (Fly } \\
\text { orchis) }\end{array}$ & $\begin{array}{l}\text { Slender } \\
\text { spike } \\
6 \text { ins. } \\
\text { Fls. } \\
\text { maroon } \\
\text { with blue } \\
\text { spot }\end{array}$ & $\begin{array}{l}\text { Britain } \\
\text { In shady } \\
\text { woods on } \\
\text { chalk } \\
\text { May- } \\
\text { July }\end{array}$ & $\begin{array}{l}\text { In shape and colour of flower } \\
\text { this is quite distinct from all the } \\
\text { above species of Ophrys. }\end{array}$ \\
\hline speculum & 4-12 ins. & S. Europe & $\begin{array}{l}\text { The Looking-glass Orchis, so- } \\
\text { called from its central shining } \\
\text { steel-coloured disk. Well known } \\
\text { on the Italian and French Ri- } \\
\text { vieras. }\end{array}$ \\
\hline
\end{tabular}




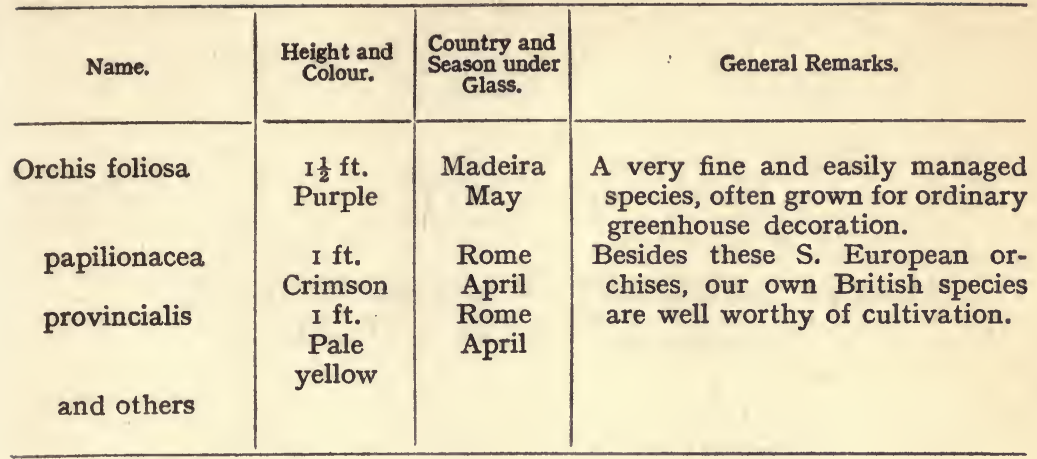

COOL-HOUSE ORCHIDS WHICH MAY BE TRIED IN

A GREENHOUSE-MINIMUM TEMPERATURE THIRTY-FIVE TO FORTY DEGREES

Dendrobium nobile . . . . N. China and India. Lycaste Skinneri . . . . Guatemala. Masdevallias . . . . . Mexico and Peru. Odontoglossum Crispum . . . Alexandræ Mexico.

I have had so much success in growing various tender plants in greenhouses where the minimum winter temperature was never lower, but very frequently as low as $35^{\circ} \mathrm{Fahr}$. that it seems more than likely that under other suitable conditions some of the hardier of the Cool-House Orchids would do well. The experiment would be an extremely interesting and valuable one. 


\section{PLANTS SUITABLE FOR ASSOCIATING WITH ORCHIDS IN A COLD-HOUSE}

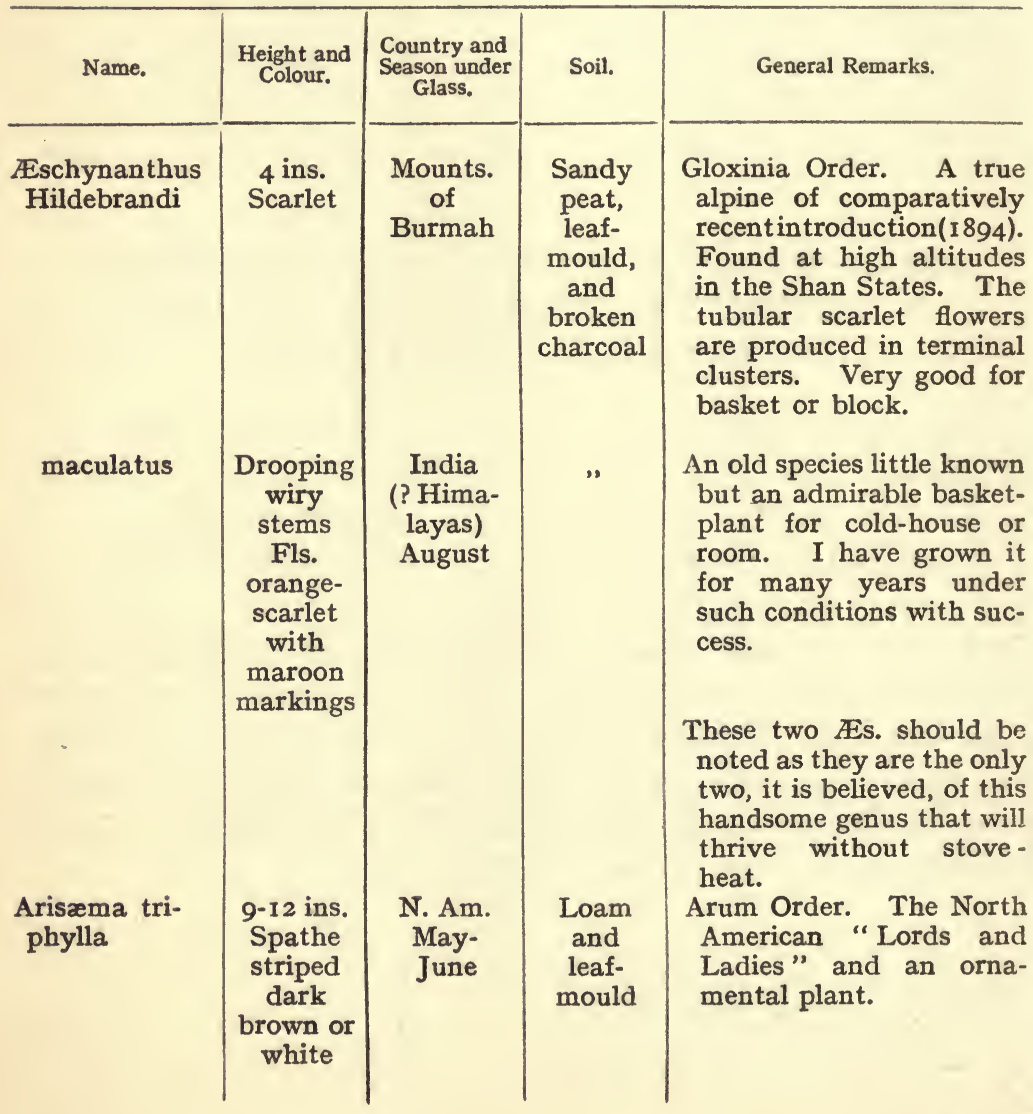




\begin{tabular}{|c|c|c|c|c|}
\hline Name. & $\begin{array}{l}\text { Height and } \\
\text { Colour. }\end{array}$ & $\begin{array}{l}\text { Country and } \\
\text { Season under } \\
\text { Glass. }\end{array}$ & Soil. & General Remarks. \\
\hline $\begin{array}{l}\text { Cephalotus folli- } \\
\text { cularis }\end{array}$ & $\begin{array}{l}2-3 \text { ins. } \\
\text { Spike of } \\
\text { rather } \\
\text { incon- } \\
\text { spicuous } \\
\text { white } \\
\text { flowers. }\end{array}$ & $\begin{array}{l}\text { Western } \\
\text { Australia }\end{array}$ & $\begin{array}{l}\text { Sandy } \\
\text { rough } \\
\text { peat and } \\
\text { sphag- } \\
\text { num }\end{array}$ & $\begin{array}{l}\text { Saxifrage Order. New Hol- } \\
\text { land Pitcher-plant. A } \\
\text { pretty and singular spe- } \\
\text { cies which must be grown } \\
\text { under a bell-glass. The } \\
\text { pitcher-like leaves with } \\
\text { lids form its chief in- } \\
\text { terest. Well worthy of } \\
\text { cultivation. }\end{array}$ \\
\hline $\begin{array}{l}\text { Darlingtonia } \\
\text { californica }\end{array}$ & $\begin{array}{c}\text { I-I } \frac{1}{2} \mathrm{ft} . \\
\text { Pitcher- } \\
\text { like erect } \\
\text { leaves } \\
\text { veined } \\
\text { white } \\
\text { and rose } \\
\text { Fls. pale } \\
\text { green and } \\
\text { yellow }\end{array}$ & $\begin{array}{l}\text { Cali- } \\
\text { fornia } \\
\text { April }\end{array}$ & $\begin{array}{c}\text { Well- } \\
\text { drained } \\
\text { sandy } \\
\text { peat and } \\
\text { chopped } \\
\text { sphagnum } \\
\text { with } \\
\text { nodules of } \\
\text { limestone } \\
\text { or charcoal }\end{array}$ & $\begin{array}{l}\text { Sarracenia Order. An in- } \\
\text { teresting and curious spe- } \\
\text { cies of hardy Pitcher- } \\
\text { plant allied to Sarra- } \\
\text { cenias. }\end{array}$ \\
\hline Drosera binata & $\begin{array}{l}\text { with dark } \\
\text { veins } \\
6 \text { ins. } \\
\text { White } \\
\text { I ft. } \\
\text { Purple }\end{array}$ & $\begin{array}{l}\text { Australia } \\
\text { June- } \\
\text { Sept. } \\
\text { N. Am. } \\
\text { June- } \\
\text { July }\end{array}$ & $\begin{array}{c}\text { As } \\
\text { above }\end{array}$ & $\begin{array}{l}\text { Sundew Order. Insecti- } \\
\text { verous plants easily } \\
\text { grown and very interest- } \\
\text { ing, though not showy. } \\
\text { Drain well but let the pot } \\
\text { stand in pan of water. } \\
\text { Our British Sundews also } \\
\text { make interesting green- } \\
\text { house plants. }\end{array}$ \\
\hline $\begin{array}{l}\text { Sarmienta re- } \\
\text { pens }\end{array}$ & $\begin{array}{l}\text { Trailer } \\
\text { Scarlet }\end{array}$ & $\begin{array}{c}\text { Chili } \\
\text { Summer }\end{array}$ & $\begin{array}{l}\text { Moist } \\
\text { sandy } \\
\text { peat } \\
\text { sphag- } \\
\text { num and } \\
\text { charcoal }\end{array}$ & $\begin{array}{l}\text { Gloxinia Order. A pretty } \\
\text { little creeping shrub suit- } \\
\text { able for an orchid basket } \\
\text { or to root over a tree-fern } \\
\text { stem. Shade and plenty } \\
\text { of water. }\end{array}$ \\
\hline $\begin{array}{l}\text { Sarracenia flava } \\
\text { (Side-saddle } \\
\text { Flower) } \\
\text { rubra }\end{array}$ & $\begin{array}{l}2 \mathrm{ft} \text {. } \\
\text { Yellow } \\
4 \text { ins. } \\
\text { across } \\
\text { I-I } \frac{1}{2} \mathrm{ft} . \\
\text { Reddish- } \\
\text { purple }\end{array}$ & $\begin{array}{l}\text { N. Am. } \\
\text { April } \\
\text { May } \\
\text { N. Am. } \\
\text { Apl.-May }\end{array}$ & $\begin{array}{c}\text { Fibrous } \\
\text { peat and } \\
\text { sphag- } \\
\text { num } \\
\text { ", }\end{array}$ & $\begin{array}{l}\text { Sarracenia Order. Many } \\
\text { beautiful hybrid forms } \\
\text { have been raised of these } \\
\text { singular hardy Pitcher- } \\
\text { plants. They require } \\
\text { still damp atmosphere, } \\
\text { and are extremely hand- } \\
\text { some when well grown. } \\
\text { Bog plants which grow in } \\
\text { company with Cypripe- } \\
\text { diums. }\end{array}$ \\
\hline
\end{tabular}




\begin{tabular}{|c|c|c|c|c|}
\hline Vame. & $\begin{array}{l}\text { Height and } \\
\text { Colour. }\end{array}$ & $\begin{array}{l}\text { Country and } \\
\text { Season under } \\
\text { Glass. }\end{array}$ & Soil. & General Remarks. \\
\hline $\begin{array}{l}\text { Saxifraga cus- } \\
\text { cutæformis } \\
\text { (The Dodder } \\
\text { Saxifrage) }\end{array}$ & $\begin{array}{c}\text { Trailer } \\
4-6 \text { ins. } \\
\text { Fls. white }\end{array}$ & $\begin{array}{l}\text { China } \\
\text { June and } \\
\text { July }\end{array}$ & $\begin{array}{l}\text { Sandy } \\
\text { loam and } \\
\text { grit }\end{array}$ & $\begin{array}{l}\text { Saxifrage Order. A charm- } \\
\text { ing little half-hardy plant, } \\
\text { with soft variegated mar- } \\
\text { bled and veined leaves. }\end{array}$ \\
\hline $\begin{array}{l}\text { Sarmentosa var. } \\
\text { tricolor }\end{array}$ & $\begin{array}{l}\text { Leaves } \\
\text { cream- } \\
\text { white, } \\
\text { green, } \\
\text { and red }\end{array}$ & $\begin{array}{c}\text { Garden } \\
\text { origin }\end{array}$ & ", & $\begin{array}{l}\text { The variegated form of } \\
\text { the well-known "Mother } \\
\text { of Thousands." A some- } \\
\text { what delicate but ex- } \\
\text { tremely pretty plant. } \\
\text { Half-hardy. }\end{array}$ \\
\hline $\begin{array}{l}\text { Sibthorpia euro- } \\
\text { pæa variegata }\end{array}$ & $\begin{array}{l}\text { Trailer } \\
\text { with } \\
\text { minute } \\
\text { flowers of } \\
\text { no } \\
\text { account }\end{array}$ & $\begin{array}{l}\text { Garden } \\
\text { origin }\end{array}$ & $\begin{array}{l}\text { Sandy } \\
\text { loam and } \\
\text { leaf- } \\
\text { mould }\end{array}$ & $\begin{array}{l}\text { Foxglove Order. The small } \\
\text { round leaves are edged } \\
\text { with a silver margin. } \\
\text { Grown in semi-shade is } \\
\text { very charming for the } \\
\text { surface of pans or hang- } \\
\text { ing baskets. }\end{array}$ \\
\hline
\end{tabular}




\section{SUCCULENT PLANTS}

Any in the subjoined list may be grown in a dry winter temperature never lower than $35^{\circ} \mathrm{Fahr}$. The soil that suits most succulent plants is composed of rather rich loam mixed with coarse grit and a little lime rubble. It is a mistake to starve them for want of water in summer, but they must be kept dry in winter.

\begin{tabular}{|c|c|c|c|}
\hline Name. & $\begin{array}{l}\text { Height and } \\
\text { Colour. }\end{array}$ & $\begin{array}{l}\text { Country and } \\
\text { Season under } \\
\text { Glass. }\end{array}$ & General Remarks. \\
\hline $\begin{array}{c}\text { Agave americana } \\
\text { var. variegata }\end{array}$ & $\begin{array}{l}\text { Tall } \\
\text { spreading } \\
\text { rosette } \\
\text { with } \\
\text { recurved } \\
\text { leaves }\end{array}$ & $\begin{array}{l}\text { South } \\
\text { America }\end{array}$ & $\begin{array}{l}\text { Amaryllis Order. A fine plant } \\
\text { for pots either in a small or large } \\
\text { state. Increased freely by } \\
\text { suckers. }\end{array}$ \\
\hline Victoriæ Reginæ & $\begin{array}{l}\text { Stiff } \\
\text { stemless } \\
\text { rosette } \\
\text { with } \\
\text { curiously } \\
\text { margined } \\
\text { leaves }\end{array}$ & Mexico & $\begin{array}{l}\text { A distinct and very handsome } \\
\text { Agave introduced in } 1875 \text {. No } \\
\text { mode of propagation except by } \\
\text { seed. }\end{array}$ \\
\hline $\begin{array}{l}\text { Aloe arborescens } \\
\text { var. frutescens }\end{array}$ & $\begin{array}{c}\text { Tall stems } \\
\text { with } \\
\text { rosettes of } \\
\text { very glau- } \\
\text { cous spring } \\
\text { leaves } \\
\text { Fls. red } \\
\text { Rather }\end{array}$ & S. Africa & $\begin{array}{l}\text { Lily Order. } \\
\text { The species here given are dis- } \\
\text { tinct, and are all worth growing } \\
\text { in a small collection of succulent } \\
\text { plants. The heads of brilliant } \\
\text { coloured flowers are not unlike } \\
\text { those of a dwarf Kniphofia. }\end{array}$ \\
\hline ciliata & $\begin{array}{l}\text { Rather } \\
\text { climbing } \\
\text { dark-green } \\
\text { leaves } \\
\text { Fls. scarlet } \\
\text { Very good }\end{array}$ & $"$ & te \\
\hline
\end{tabular}




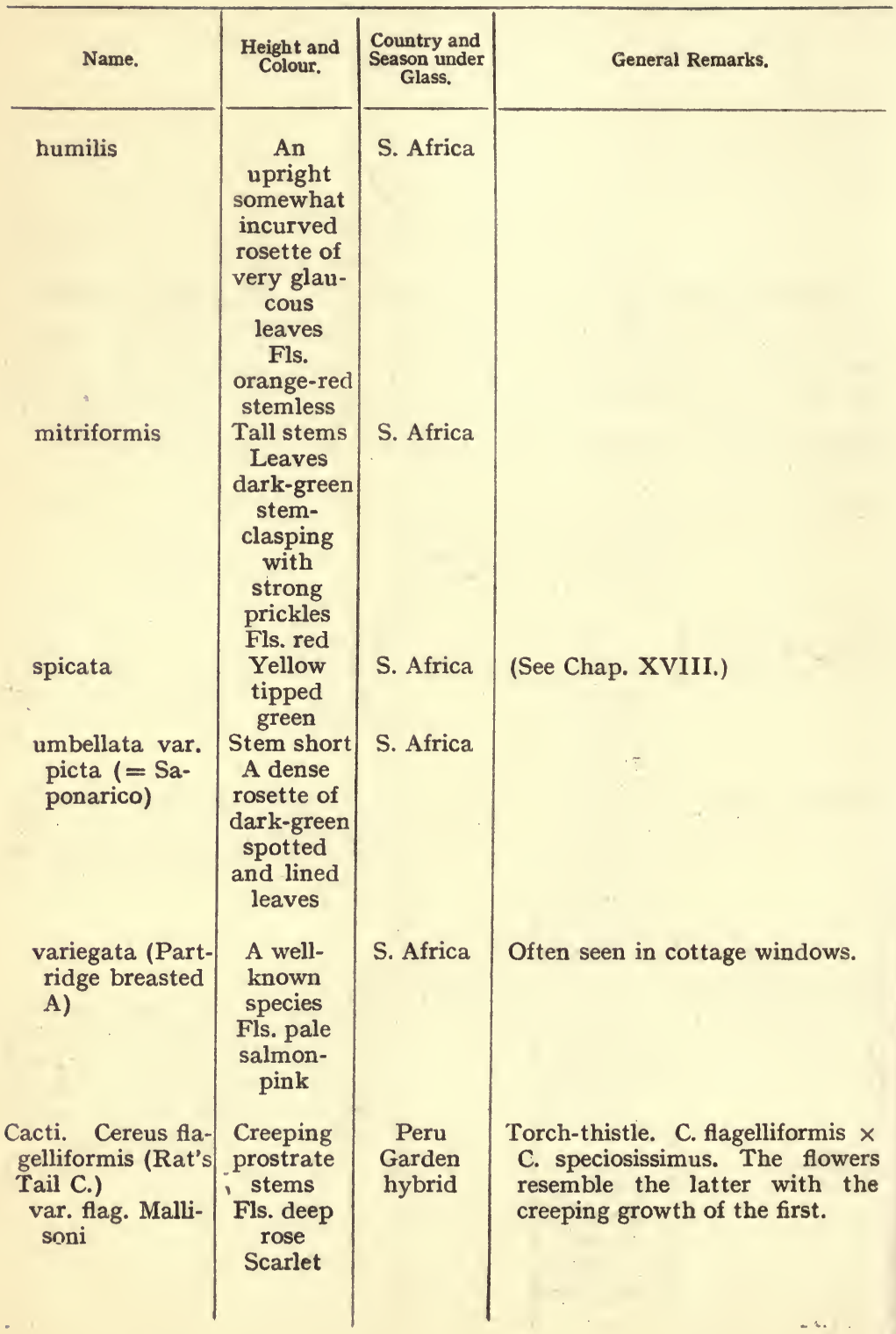




\begin{tabular}{|c|c|c|c|}
\hline Name. & $\begin{array}{l}\text { Height and } \\
\text { Colour. }\end{array}$ & $\begin{array}{l}\text { Country and } \\
\text { Season under } \\
\text { Glass. }\end{array}$ & General Remarks. \\
\hline $\begin{array}{l}\text { grandiflorus } \\
\text { nycticalus }\end{array}$ & $\begin{array}{l}\text { White } \\
\text { Night } \\
\text { flowering } \\
\text { White }\end{array}$ & $\begin{array}{l}\text { W. Indies } \\
\text { Mexico }\end{array}$ & $\begin{array}{l}\text { The Night-flowering Cactus. This } \\
\text { is generally treated as a stove } \\
\text { plant, but if kept safe from frost } \\
\text { may be grown with the rest. It } \\
\text { will flower well in a 6-in. pot if } \\
\text { well managed and trained to a } \\
\text { light trellis. }\end{array}$ \\
\hline speciosissimus & $\begin{array}{l}\text { Four- } \\
\text { angled } \\
\text { stems } \\
\text { Fls. } \\
\text { scarlet } \\
\text { shaded } \\
\text { violet }\end{array}$ & Mexico & 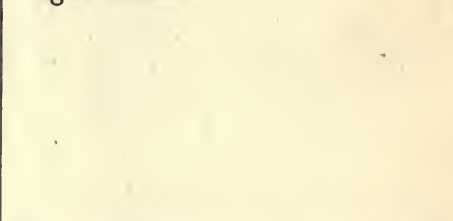 \\
\hline $\begin{array}{l}\text { Echinocactus cap- } \\
\text { ricornis }\end{array}$ & $\begin{array}{l}\text { Globular } \\
\text { ribbed } \\
\text { spotted } \\
\text { with } \\
\text { white dots } \\
\text { Yellow } \\
\text { flowers }\end{array}$ & Mexico & $\begin{array}{l}\text { Hedge-hog Cactus. A fine species } \\
\text { with spines mostly at the apex. }\end{array}$ \\
\hline cornigerus & $\begin{array}{l}\text { Globular } \\
\text { with } \\
\text { strong flat } \\
\text { spines } \\
\text { coloured } \\
\text { red or } \\
\text { yellow } \\
\text { Fls. purple }\end{array}$ & Mexico & $\begin{array}{l}\text { A very formidable-looking spe- } \\
\text { cies as most of them are, but the } \\
\text { interest of these curious plants } \\
\text { consists largely in their many- } \\
\text { coloured and diversely shaped } \\
\text { prickles. Splendid specimens } \\
\text { may be grown planted out on } \\
\text { rock-work under glass as at Kew. }\end{array}$ \\
\hline Grusoni & $\begin{array}{l}\text { Globular } \\
\text { golden } \\
\text { spined }\end{array}$ & Mexico & \\
\hline Lecontei : & $\begin{array}{l}\text { Spines } \\
\text { from pale } \\
\text { yellow } \\
\text { to pure } \\
\text { white }\end{array}$ & Mexico & \\
\hline 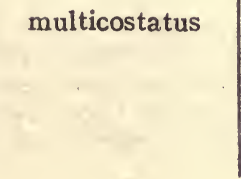 & $\begin{array}{c}\text { Many } \\
\text { ribbed and } \\
\text { varies } \\
\text { greatly } \\
\text { Fls.'white }\end{array}$ & Mexico & 站 \\
\hline
\end{tabular}




\begin{tabular}{|c|c|c|c|}
\hline Name. & $\begin{array}{l}\text { Height and } \\
\text { Colour. }\end{array}$ & $\begin{array}{l}\text { Country and } \\
\text { Season under } \\
\text { Glass. }\end{array}$ & General Remarks. \\
\hline Simpsoni & $\begin{array}{c}\text { Globular } \\
\text { clustered } \\
\text { Pink fls. } \\
\text { Small- } \\
\text { growing } \\
\text { sp. } \\
\text { Very } \\
\text { hardy }\end{array}$ & Colorado & \\
\hline $\begin{array}{l}\text { Wislizeni (Fish- } \\
\text { hook Cactus) }\end{array}$ & $\begin{array}{c}\text { A large } \\
\text { growing } \\
\text { sp. with } \\
\text { very } \\
\text { strong } \\
\text { hooked } \\
\text { ribs }\end{array}$ & $\begin{array}{l}\text { Southern } \\
\text { U.S.A. }\end{array}$ & 30 \\
\hline $\begin{array}{l}\text { Echinocereus } \\
\text { Berlandieri }\end{array}$ & $\begin{array}{c}\text { Procum- } \\
\text { bent stems } \\
\text { Fls. purple }\end{array}$ & $\begin{array}{l}\text { Texas } \\
\text { and } \\
\text { Mexico }\end{array}$ & $\begin{array}{l}\text { Mostly low-growing or procum. } \\
\text { bent with pretty flowers. }\end{array}$ \\
\hline candicans & $\begin{array}{l}\text { Spines } \\
\text { deep red } \\
\text { to cream- } \\
\text { white }\end{array}$ & Chili & Rainbow Cactus. \\
\hline enneacanthus & $\begin{array}{l}\text { Branching } \\
\text { stems } \\
3-6 \text { ins. } \\
\text { in clusters } \\
\text { Fls. } \\
\text { reddish- } \\
\text { purple }\end{array}$ & Texas & $\begin{array}{l}\text { A free-flowering sp. Spines yel- } \\
\text { low and short. }\end{array}$ \\
\hline pectinatus & $\begin{array}{c}\text { Clustered } \\
\text { stems } \\
\text { Spines } \\
\text { white } \\
\text { Fls. } \\
\text { mauve- } \\
\text { pink }\end{array}$ & Mexico & $\begin{array}{l}\text { The flowers of this species are } \\
\text { large and fragrant. }\end{array}$ \\
\hline procumbens & $\begin{array}{l}\text { Prostrate } \\
\text { stems } \\
3-4 \text { ins. } \\
\text { Fls. rosy- } \\
\text { purple }\end{array}$ & Mexico & $\begin{array}{l}\text { This species requires more warm th } \\
\text { in winter than most, and to be } \\
\text { kept very dry. }\end{array}$ \\
\hline $\begin{array}{l}\text { Echinopsis Ey- } \\
\text { riesii }\end{array}$ & $\begin{array}{l}\text { Very short } \\
\text { spines } \\
\text { Fls. pure } \\
\text { white }\end{array}$ & Argentina & $\begin{array}{l}\text { The flowers of Echinopsis are } \\
\text { funnel-shaped, sometimes 8-10 } \\
\text { ins. long, and produced from the } \\
\text { side of the globular-ribbed stem. }\end{array}$ \\
\hline
\end{tabular}




\begin{tabular}{|c|c|c|c|}
\hline Name. & $\begin{array}{l}\text { Height and } \\
\text { Colour. }\end{array}$ & $\begin{array}{l}\text { Country and } \\
\text { Season under } \\
\text { Glass. }\end{array}$ & General Remarks. \\
\hline and others & $\begin{array}{l}\text { Fls. rose- } \\
\text { colour } \\
\text { and } \\
\text { double }\end{array}$ & Hybrid & $\begin{array}{l}\text { They must never be over-watered } \\
\text { as the very succulent stems be- } \\
\text { come overcharged with moisture } \\
\text { which results in a disease akin } \\
\text { to dropsy. Otherwise they are } \\
\text { very hardy. }\end{array}$ \\
\hline $\begin{array}{l}\text { Epiphyllum rus- } \\
\text { sellianum } \\
\text { var. Gaertneri }\end{array}$ & $\begin{array}{l}\text { Dwarf on } \\
\text { their own } \\
\text { roots, } \\
\text { but } \\
\text { usually } \\
\text { grafted } \\
\text { Fls. } \\
\text { scarlet }\end{array}$ & $\begin{array}{l}\text { Brazil } \\
\text { (Type) }\end{array}$ & $\begin{array}{l}\text { This variety is of garden origin, } \\
\text { and, as it does not flower till } \\
\text { May and June can be kept safe } \\
\text { from frost more easily than the } \\
\text { well-known } E \text {. truncatum. It } \\
\text { is, moreover, a very fine plant. }\end{array}$ \\
\hline $\begin{array}{l}\text { Mamillaria appla- } \\
\text { nata }\end{array}$ & $\begin{array}{l}\text { Long tu- } \\
\text { bercles } \\
\text { with tufts } \\
\text { of white } \\
\text { spines } \\
\text { Fls. white } \\
\text { tinged red } \\
\text { Small }\end{array}$ & Mexico & $\begin{array}{l}\text { This Mamillaria has long scarlet } \\
\text { fruit which gives it a special } \\
\text { character. }\end{array}$ \\
\hline bocasana & $\begin{array}{l}\text { Hooked } \\
\text { spines set } \\
\text { in silky } \\
\text { tufts }\end{array}$ & Mexico & Small, but very distinct. \\
\hline glacilis pulchella & $\begin{array}{l}\text { Spines in } \\
\text { silvery } \\
\text { stars }\end{array}$ & Mexico & A clustered species. \\
\hline lasiacantha & $\begin{array}{l}\text { Spines in } \\
\text { feathery } \\
\text { rosettes }\end{array}$ & Texas & $\begin{array}{l}\text { A very choice little Mamillaria. } \\
\text { The Kew Hand-list gives more } \\
\text { than a hundred species and va- } \\
\text { rieties. The four here given are } \\
\text { sufficiently typical. }\end{array}$ \\
\hline $\begin{array}{l}\text { Opuntia micro- } \\
\text { dasys }\end{array}$ & $\begin{array}{l}\text { Flat } \\
\text { jointed } \\
\text { stems } \\
\text { closely } \\
\text { spotted } \\
\text { with tufts } \\
\text { of spiny } \\
\text { gold- } \\
\text { coloured } \\
\text { hairs }\end{array}$ & Mexico & $\begin{array}{l}\text { Prickly Pear. There are innu- } \\
\text { merable species of Opuntia- } \\
\text { some of them handsome, but } \\
\text { they are extremely unpleasant } \\
\text { plants to cultivate on account of } \\
\text { their penetrating and almost } \\
\text { poisonous spines. } O \text {. microaasys } \\
\text { is one of the most attractive- } \\
\text { looking, but has to be handled } \\
\text { with great care. The second- } \\
\text { named is not so vicious, and is a } \\
\text { well-known hardy species. }\end{array}$ \\
\hline
\end{tabular}




\begin{tabular}{|c|c|c|c|}
\hline Name. & $\begin{array}{l}\text { Height and } \\
\text { Colour. }\end{array}$ & $\begin{array}{l}\text { Country and } \\
\text { Season under } \\
\text { Glass. }\end{array}$ & General Remarks. \\
\hline Rafinesquii & $\begin{array}{l}\text { Dark- } \\
\text { green flat } \\
\text { stems and } \\
\text { few spines } \\
\text { Fls. } \\
\text { yellow }\end{array}$ & U.S.A. & 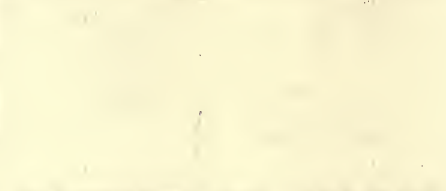 \\
\hline $\begin{array}{l}\text { Phyllocactus Ac- } \\
\text { kermanni }\end{array}$ & $\begin{array}{l}\text { Dwarf } \\
\text { stems } \\
\text { spineless } \\
\text { Fls. rich } \\
\text { full } \\
\text { scarlet }\end{array}$ & Mexico & $\begin{array}{l}\text { Flat-stemmed Cacti. One of the } \\
\text { finest and most easily grown. }\end{array}$ \\
\hline anguliger & $\begin{array}{l}\text { Broadly } \\
\text { angled } \\
\text { stems }\end{array}$ & Mexico & $\begin{array}{l}\text { A handsome and distinct plan } \\
\text { even when not in flower. }\end{array}$ \\
\hline grandis & $\begin{array}{l}\text { Fls. white } \\
\text { Dwarf } \\
\text { Fls. ivory- } \\
\text { white } \\
\text { with pale } \\
\text { yellow } \\
\text { and brown } \\
\text { sepals } \\
6 \text { ins. } \\
\text { across }\end{array}$ & Honduras & $\begin{array}{l}\text { A magnificent species. Its only } \\
\text { fault a too short duration in } \\
\text { flower. Individual blooms open } \\
\text { in the evening and last generally } \\
\text { two days. A well-grown plant } \\
\text { produces many flowers in suc- } \\
\text { cession. }\end{array}$ \\
\hline phyllanthoides & $\begin{array}{l}\text { Dwarf } \\
\text { Fls. } \\
\text { tubular, } \\
\text { bright } \\
\text { pink and } \\
\text { very freely } \\
\text { produced }\end{array}$ & Mexico & $\begin{array}{l}\text { This old species is amongst the } \\
\text { very best, and the fls. are more } \\
\text { lasting than those of most Cacti. } \\
\text { These are four distinct Phyllo- } \\
\text { cacti, but there are numerous } \\
\text { hybrids of garden origin which } \\
\text { are very fine and desirable. }\end{array}$ \\
\hline
\end{tabular}




\section{VARIOUS SUCCULENT PLANTS (NOT CACTI)}

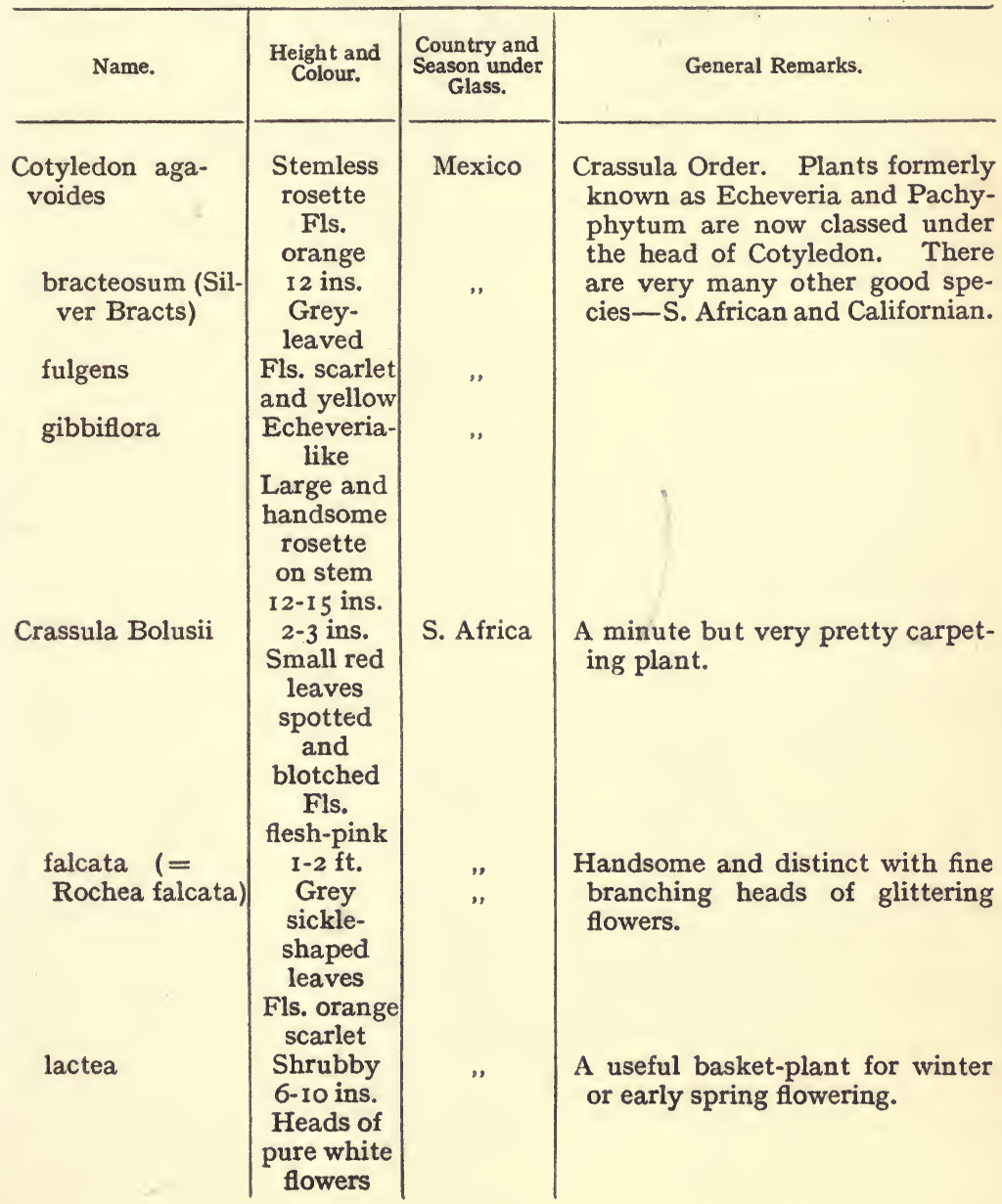




\begin{tabular}{|c|c|c|c|}
\hline Name. & $\begin{array}{l}\text { Height and } \\
\text { Colour. }\end{array}$ & $\begin{array}{l}\text { Country and } \\
\text { Season under } \\
\text { Glass. }\end{array}$ & General Remarks. \\
\hline $\begin{array}{l}\text { Rochea (= Kalo- } \\
\text { santhes) } \\
\text { coccinea } \\
\text { jasminea }\end{array}$ & $\begin{array}{l}\text { Shrubby } \\
\text { I-2 ft. } \\
\text { Fls. } \\
\text { carmine } \\
\text { Dwarf and } \\
\text { decumbent } \\
\text { Flowers } \\
\text { white }\end{array}$ & $\begin{array}{l}\text { Table } \\
\text { Mts. } \\
\text { Summer } \\
\text { S. Africa } \\
\text { Spring }\end{array}$ & $\begin{array}{l}\text { Under this succession of names } \\
\text { we find our old friend Crassula } \\
\text { coccinea which needs no recom- } \\
\text { mendation as it is well known as } \\
\text { one of the most decorative of } \\
\text { greenhouse plants. }\end{array}$ \\
\hline
\end{tabular}




\section{TWENTY-FOUR GOOD SPECIES OF MESEMBRY- ANTHEMUM}

Having carefully grown and studied some I50 species and varieties, the subjoined are given as amongst the best for general cultivation.

Soil. Loam with a plentiful addition of coarse sharp sand or crushed granite.

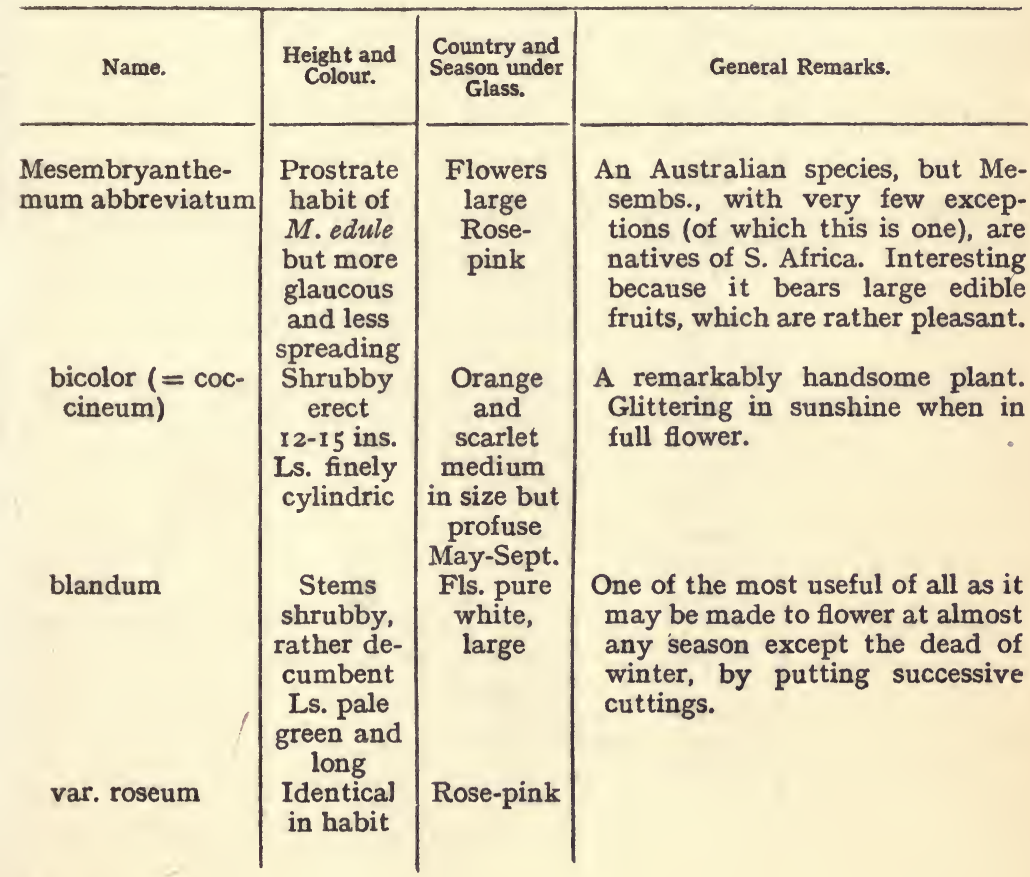




\begin{tabular}{|c|c|c|c|}
\hline Name. & $\begin{array}{l}\text { Height and } \\
\text { Colour. }\end{array}$ & $\begin{array}{l}\text { Country and } \\
\text { Season under } \\
\text { Glass. }\end{array}$ & General Remarks. \\
\hline Cooperi & $\begin{array}{c}\text { Much } \\
\text { branched, } \\
\text { decumbent } \\
\text { 3-4 ins. } \\
\text { Ls. } \\
\text { studded } \\
\text { with } \\
\text { silvery } \\
\text { dots }\end{array}$ & $\begin{array}{l}\text { Fls. } \\
\text { Rosy- } \\
\text { purple } \\
\text { Summer }\end{array}$ & \\
\hline deltoides & $\begin{array}{l}\text { Dwarf } \\
\text { branching } \\
\text { 3-4 ins. } \\
\text { Ls. wedge- } \\
\text { shaped } \\
\text { toothed }\end{array}$ & $\begin{array}{l}\text { Fls. small } \\
\text { pink } \\
\text { Very } \\
\text { sweet } \\
\text { Spring }\end{array}$ & $\begin{array}{l}\text { For permanent rock-work under } \\
\text { glass, this and its allied species } \\
\text { will make excellent carpeting or } \\
\text { overhanging plants. }\end{array}$ \\
\hline densum & $\begin{array}{l}\text { Trailing } \\
\text { stems } \\
3 \text { ins. } \\
\text { Ls. cylin- } \\
\text { dric with } \\
\text { tuft of } \\
\text { hairs at } \\
\text { apex }\end{array}$ & $\begin{array}{l}\text { Flowers } \\
\text { large } \\
\text { Mauve- } \\
\text { purple } \\
\text { June }\end{array}$ & $\begin{array}{l}\text { This belongs to the bearded sec- } \\
\text { tion, and is one of the best. }\end{array}$ \\
\hline , & $\begin{array}{l}\text { Prostrate } \\
\text { spreading } \\
\text { stems } \\
\text { Ls. } \\
\text { 3-angled } \\
\text { dark green }\end{array}$ & $\begin{array}{l}\text { Flowers } \\
\text { very } \\
\text { large } \\
\text { Pale } \\
\text { yellow }\end{array}$ & $\begin{array}{l}\text { Hottentot Fig. This edible sp. } \\
\text { never ripens fruit in England, } \\
\text { though } M \text {. abbreviatum, which } \\
\text { is nearly akin to it, does so in } \\
\text { favourable seasons. }\end{array}$ \\
\hline falciforme & $\begin{array}{l}\text { Shrubby } \\
6 \text {-1 } 2 \text { ins. } \\
\text { Clusters of } \\
\text { very } \\
\text { glaucous } \\
\text { sickle- } \\
\text { shaped } \\
\text { leaves }\end{array}$ & $\begin{array}{l}\text { Fls. large } \\
\text { and hand- } \\
\text { some } \\
\text { Silvery- } \\
\text { pink } \\
\text { April- } \\
\text { June }\end{array}$ & $\begin{array}{l}\text { There are various forms of this } \\
\text { sp., some much more free-bloom- } \\
\text { ing and fine than others. }\end{array}$ \\
\hline formosum & $\begin{array}{l}\text { Dwarf } \\
\text { shrubby } \\
12 \text { ins. } \\
\text { Ls. long } \\
\text { and } \\
\text { 3-angled }\end{array}$ & $\begin{array}{l}\text { Flowers } \\
\text { large } \\
\text { Rose- } \\
\text { pink } \\
\text { with white } \\
\text { centre } \\
\text { Spring }\end{array}$ & $\begin{array}{l}\text { Somewhat like } M \text {. spectabile but } \\
\text { really distinct. }\end{array}$ \\
\hline
\end{tabular}




\begin{tabular}{|c|c|c|c|}
\hline Name. & $\begin{array}{l}\text { Height and } \\
\text { Colour. }\end{array}$ & $\begin{array}{l}\text { Country and } \\
\text { Season under } \\
\text { Glass. }\end{array}$ & General Remarks. \\
\hline glaucum & $\begin{array}{l}12 \text { ins. } \\
\text { Erect } \\
\text { Ls. short } \\
\text { very } \\
\text { glaucous, } \\
\text { 3-angled }\end{array}$ & $\begin{array}{l}\text { Fls. large } \\
\text { Sulphur } \\
\text { with } \\
\text { yellow } \\
\text { centre } \\
\text { March } \\
\text { onwards }\end{array}$ & $\begin{array}{l}\text { A very fine species. Old plants } \\
\text { flower well and the stems bend } \\
\text { down and recurve with age. One } \\
\text { of the hardiest. }\end{array}$ \\
\hline inclaudens & $\begin{array}{l}\text { 6-8 ins. } \\
\text { Branches } \\
\text { spreading } \\
\text { Ls. dark- } \\
\text { green and } \\
\text { angled } \\
\text { Stems red }\end{array}$ & $\begin{array}{l}\text { Fls. } \\
\text { medium- } \\
\text { sized } \\
\text { Pale } \\
\text { mauve } \\
\text { Spring } \\
\text { and } \\
\text { summer }\end{array}$ & $\begin{array}{l}\text { Never closes its flowers, and is } \\
\text { valuable on that account. }\end{array}$ \\
\hline lacerum & $\begin{array}{c}\text { I2-I } 5 \text { ins. } \\
\text { Shrubby } \\
\text { erect stems } \\
\text { Ls. very } \\
\text { glaucous } \\
\text { with } \\
\text { crested } \\
\text { keel }\end{array}$ & $\begin{array}{l}\text { Fls. large } \\
\text { Petals } \\
\text { finely } \\
\text { cut of a } \\
\text { peculiar } \\
\text { shade of } \\
\text { chamois- } \\
\text { pink }\end{array}$ & $\begin{array}{l}\text { Pretty both in foliage and flower, } \\
\text { which, like above, keeps open } \\
\text { after having arrived at maturity. }\end{array}$ \\
\hline linguæforme & $\begin{array}{l}\text { Stemless } \\
\text { depressed } \\
\text { Ls. tongue- } \\
\text { shaped } \\
\text { dark green } \\
\text { and long }\end{array}$ & $\begin{array}{l}\text { Fls. large } \\
\text { solitary } \\
\text { Bright } \\
\text { yellow } \\
\text { July-Sept. }\end{array}$ & $\begin{array}{l}\text { This goes on flowering with each } \\
\text { pair of leaves for some time. }\end{array}$ \\
\hline lunatum & $\begin{array}{l}\text { 9-12 ins. } \\
\text { Shrubby, } \\
\text { branching } \\
\text { Ls. } \\
\text { crescent- } \\
\text { shaped }\end{array}$ & $\begin{array}{l}\text { Fls. small } \\
\text { Pale pink } \\
\text { and very } \\
\text { sweet } \\
\text { Spring }\end{array}$ & A slender pretty plant. \\
\hline micans & $\begin{array}{l}\mathrm{I}-\mathrm{I} \frac{1}{2} \mathrm{ft} . \\
\text { Erect } \\
\text { shrubby } \\
\text { and } \\
\text { slender } \\
\text { Ls. in } \\
\text { clusters } \\
\text { finely } \\
\text { cylindric, } \\
\text { and } \\
\text { glittering }\end{array}$ & $\begin{array}{c}\text { Fls. } \\
\text { medium- } \\
\text { sized } \\
\text { Scarlet } \\
\text { with gold- } \\
\text { en centres } \\
\text { July- } \\
\text { Aug. }\end{array}$ & Brilliant and free flowering. \\
\hline
\end{tabular}




\begin{tabular}{|c|c|c|c|}
\hline Name. & $\begin{array}{l}\text { Height and } \\
\text { Colour. }\end{array}$ & $\begin{array}{l}\text { Country and } \\
\text { Season under } \\
\text { Glass. }\end{array}$ & General Remarks \\
\hline mucronatum & $\begin{array}{l}\text { Dwarf } \\
\text { spreading } \\
\text { shrubby } \\
\text { Ls. deltoid }\end{array}$ & $\begin{array}{l}\text { Fls. rose- } \\
\text { pink } \\
\text { small } \\
\text { Vanilla- } \\
\text { scented } \\
\text { Spring }\end{array}$ & $\begin{array}{l}\text { Very nearly akin to } M \text {. deltoides } \\
\text { (which see) but larger. } M \text {. mu- } \\
\text { vicatum is again almost identical } \\
\text { but the smallest of the three and } \\
\text { more densely crowded. }\end{array}$ \\
\hline polyanthon & $\begin{array}{l}\text { Slender } \\
\text { branching } \\
\text { stems } \\
\text { Ls. } \\
\text { glaucous } \\
\text { finely } \\
\text { cylindric }\end{array}$ & $\begin{array}{c}\text { Fls. bright } \\
\text { purple- } \\
\text { mauve } \\
\text { Small } \\
\text { but } \\
\text { numerous } \\
\text { Spring or } \\
\text { summer }\end{array}$ & $\begin{array}{l}\text { A many-flowered brilliant species, } \\
\text { and one of the most charming. } \\
\text { Cuttings of soft young tops fre- } \\
\text { quently put in give the best } \\
\text { results. }\end{array}$ \\
\hline productum & $\begin{array}{l}\text { 12-1 } 8 \text { ins. } \\
\text { Erect } \\
\text { shrubby } \\
\text { Ls. bright } \\
\text { green } \\
\text { clustered } \\
\text { Stems red }\end{array}$ & $\begin{array}{l}\text { Fls. large } \\
\text { Brilliant } \\
\text { purple } \\
\text { Summer } \\
\text { and } \\
\text { autumn }\end{array}$ & \\
\hline rostratum & $\begin{array}{l}\text { Stemless } \\
3 \text { ins. } \\
\text { 2-cylindric } \\
\text { upright } \\
\text { leaves } \\
\text { gradually } \\
\text { forming } \\
\text { clusters }\end{array}$ & $\begin{array}{l}\text { Fls. } \\
\text { medium- } \\
\text { sized } \\
\text { Lemon- } \\
\text { yellow }\end{array}$ & $\begin{array}{l}\text { Unlike any of the others. Not } \\
\text { showy, but curious. Opens in } \\
\text { the afternoon. }\end{array}$ \\
\hline rubro-cinctum & $\begin{array}{l}\text { Habit of } \\
M . \text { edule } \\
\text { Ls. red- } \\
\text { edged }\end{array}$ & $\begin{array}{l}\text { Fls. very } \\
\text { large } \\
\text { Rose-red }\end{array}$ & $\begin{array}{l}\text { A fine species but not very free- } \\
\text { flowering. }\end{array}$ \\
\hline spectabile & $\begin{array}{l}12 \text { ins. } \\
\text { Flg. stems } \\
\text { erect } \\
\text { Ls. very } \\
\text { glaucous } \\
3 \text {-angled }\end{array}$ & $\begin{array}{l}\text { Fls. } 2 \text { ins. } \\
\text { across } \\
\text { Bright } \\
\text { rose-pink }\end{array}$ & $\begin{array}{l}\text { A good pot-plant for any green- } \\
\text { house, and very free blooming. }\end{array}$ \\
\hline tenuifolium & $\begin{array}{l}\text { Slender } \\
\text { lax } \\
\text { growth } \\
\text { Ls. bright } \\
\text { green } \\
\text { clustered }\end{array}$ & $\begin{array}{l}\text { Fls. } \\
\text { shining } \\
\text { coppery- } \\
\text { red } \\
\text { June- } \\
\text { Sept. }\end{array}$ & $\begin{array}{l}\text { Not very free-flowering but makes } \\
\text { a handsome specimen trained } \\
\text { against a light trellis. Fls. of a } \\
\text { remarkable tint. }\end{array}$ \\
\hline
\end{tabular}




\begin{tabular}{|c|c|c|c|}
\hline Name. & $\begin{array}{l}\text { Height and } \\
=\text { Colour. }\end{array}$ & $\begin{array}{l}\text { Country and } \\
\text { Season under } \\
\text { Glass. }\end{array}$ & General Remarks. \\
\hline tigrinum & $\begin{array}{l}3 \text { ins. } \\
\text { Stemless } \\
\text { clustered } \\
\text { rosettes } \\
\text { Ls. } \\
\text { curiously } \\
\text { ciliated } \\
\text { and } \\
\text { marbled }\end{array}$ & $\begin{array}{l}\text { Fls. } \\
\text { bright } \\
\text { yellow, } \\
\text { large } \\
\text { Opening } \\
\text { after } \\
\text { mid-day } \\
\text { Autumn }\end{array}$ & $\begin{array}{l}\text { "Tiger-chap" of Haworth. There } \\
\text { are several allied species, but } \\
\text { this is the best for an ordinary } \\
\text { collection. }\end{array}$ \\
\hline
\end{tabular}

Cuttings of the soft shoots should frequently be put in as Mesembryanthemums of the shrubby sorts especially, soon grow old and shabby and do not then flower well.

For any one wishing to grow Succulent Plants exclusively, the foregoing lists may be a useful guide in forming the nucleus of a good collection. 



\section{N D E X}

A

Abelia rupestris, $78, \mathbf{1 7 8}$; floribunda, I 85 ; triflora, I 85

Abutilon megapotamicum, I 85 ; vitifolium, 74 , I 85

Acacias, 9, 35, 73, I 85, I 86, I9I

Acanthus latifolius, 46 ; spinosus, I69

Aconite, Winter, 55

Adonis amurensis, 94

Agapanthus, I I ; umbellatus, I6I

Agaves, I 23

Ageratum, 34

Aloes, I 23

Alpine House, plants for flowering in, from January to May, I 45-I 52

Alpine plants for associating with tubers and bulbs in flower from January to May, I 53-I 56

Alstrœmeria pelegrina, alba, I6I

Alstrœmerias, 60, 6I

Anemone coronaria, I 57 ; poppy, I 57 ; stellata, I 57

Anemones, 33, 54, 55

Annual flowers for unheated greenhouse, I07, 108

Annual flowers, tender, for summer and autumn, I I I ; in the cold greenhouse, I I4, I 5 ; and Mrs. Loudon, I 12 , I 13

Anoiganthus breviflorus, I6I Anomatheca cruenta, I63
Anopterus glandulosus, I 86 Aphelexis macrantha, 8I Aquilegia chrysantha, 98; cærulea, 98

Aralia Sieboldi, 46, 169

Aralis albida, 96

Araucaria Bidwilli, I69 ; excelsa, I69

Arctotis aureola, 104 ; arborescens, IO4

Arthropodium cirrhatum, I6I ; paniculatum, 62, I6I

Arums, wintering, I 37

Aucubas, 47

Auriculas from seed, 99

Asparagus umbellatus, 73

Astilbe chinensis,96; japonica, 96

Aster grandiflorus, 102

Asters, China, I I I

Azalea, Ghent, I78 ; indica, I 78 ; mollis, I 78

Azaleas, 33, 81, 82, 83

Azolla filiculoides, 39

\section{B}

BAMBUSA tessellata, I69

Baskets, hanging, Shamrock pea for, $\mathrm{IO}_{3}$

Bauera rubioides, 86, I9I

Begonias, tuberous, I6I

Bell-flower, Peach - leaved, The, in pots, 97,98

Bell-flowers, Italian, Two, 104

Bell-glasses, Use of, I 33

Berberis Darwinii, I78; steno. phylla, I79 
Biennial flowers in the cold greenhouse, 107, 108, II4, II 5

Bletia hyacinthina, I I6

Blight, destroy, 138

Boronias, 9, 35, 192

Bouvardia, 34

Brodiæa uniflora, I 57

Brugmansia sanguinea, I79; suaveolens, I79

Brugmansias, 79

Buddleia Colvillei, 74, 186

Bugloss, bushy, The, 80

Bulbs, half-hardy, I6I; spring, in the unheated green. house, 46 ; Cape, in resting season, I37 ; for unheated greenhouse, 49 ; tubers for associating with Alpine plants in flower from January to May, I53-156; in water and the use of charcoal, I29

Buttercup, Bermuda, 59, 60

\section{C}

CACTI, I6, 35; drip fatal to, 126 ; flat-leaved, 123

Cæsalpinia Gilliesii, I89

Calceolaria violacea, 84

Callas, 6I

Calypso borealis, I I 8

Camellias, 81, 83, 84, I 79

Camellia theifera, I 92

Campanula fragilis, IO4; isophylla alba; Mayi, I04; persicifolia as a pot plant, 97,98

Canna indica, I6I

Cantua buxifolia, 75, I 86

Cape cowslips, 58

Carex japonica, 48

Carnations, The Margherita, I IO ; grenadin, for autumn, 103

Carpenteria californica, 73,74 , I 86

Caryopteris mastacanthus, I 79

Cassia corymbosa, I 79, I 86

Ceanothus azureus, 186
Centaurea ragusina, 48,160

Cereus, night-blowing, I 23 ; speciosissimus, I 21

Cercis Siliquastrum, I 79

Cestrum elegans, 75

Chamæcyparis obtusa, 169; pisifera, I69

Chamæpeuce Casabonæ, II 2 ; diacantha, I I 2

Chamærops humilis, 45 ; excelsa, 45

Charcoal to keep water pure, I 29

Cherry, Winter, $\mathrm{IO}_{2}$ 애

Chimonanthus fragrans, 186

Chionodoxa, 56

Choisya ternata, 78, I80

Chorizemas, 192

Christmas roses, 94, 95

Chrysanthemum serotinum, for autumn, Ior

Chrysanthemums, IOI

Cineraria maritima, 48

Cistus lusitanicus, 180 ; purpureus, I80

Clematis, I I, I 80

Clematises in small pots, 166 ; pruning, I 36

Clethra arborea, 187

Clianthus Dampieri, 85, 86 ; puniceus, 85 , I87

Columbines, Rocky Mountain, The, 97

Conservatory, The, I2, I 3

Construction, some hints on, I 5

Convallaria majalis-Fortin's variety, Victoria variety, I 57

Corbularia monophylla, 39

Coronilla Emerus, 76, 180 ; glauca, 75

Correa bicolor, 86 ; cardinalis, 86

Correas, 9, 35, 192

Corridor, Garden, The, II ; glass, flowers in, 73

Cosmos bipinnatus, I I 2 ;iversifolia, I62

Cowslip, Royal, The, Ioo 
Crassulas, South African, 35

Cratægus monogyna præcox, 76

Crinum Moorei, I I, 64, I62 ; Powelli, I62

Crinums, 35

Crocus Imperati, 56

Croweas, 192

Cupheas, 34

Cupressus funebris glauca, 170

Cuttings, striking, I 34, I 35

Cyclamen, 33, 39 ; Coum, 56 ; europæum, I 57 ; libanoticum, I57; neapolitanum, I 57 ; Persian, 34 ; vernum, 56

Cyclamens, Persian treatment of, I 38

Cypripedium, I 16, I I 8; acaule, I I9; Calceolus, I19; candidum, II9; macranthum, II9 ; pubescens, II9 ; parviflorum, II9; spectabile, I I 8 Cyrtanthus angustifolius, 162 ; lutescens, I62; Macowani, I62; McKenii, I62

Cytisus filipes, 77 ; racemosa, 77

Cytisuses, 180

\section{D}

DAFFoDILS, 24 ; earlier, growing the, 52 ; in pots, 52

Dahlia, Black, The, I04; coccinea, 162; gracilis, 104 ; glabrata, 104

Dahlias for the unheated greenhouse, I04; Mercki, I62 ; Zimapani, I62

Daisies, Paris, I0 5

Daphne Genkwa, 187 ; indica, 75, 192; Dauphini, I 87

Deutzia gracilis, 77 ; Kalmæflora, $18 \mathrm{I}$

Deutzias, I 81 ; pruning, I 36

Desfontainea spinosa, 187

Desmodium pendulifiorum, 73 , 187

Dielytra, 97

Diervilla, 181
Disa grandiflora, I I9, 120

Disas, The, 16, 35, I19; Cape, The, I 16 ,

Doronicums, The, 33, 97

Dracæna australis, 127 ; indivisa, 127

Dracænas, Hardier, The, 127

Dryness, I6; importance of, I 7

E

Echinocacti, I 25

Echinopsis Eyriesii, I 22

Echium callithyrsum, I8I ; fastuosum, 80

Epacris miniata splendens, 86 Epimedium, 96

Erica carnea, 33 ; Cavendishi, 81 ; hyemalis, 86 ; propendens, 86

Eucalyptus globulus, 170

Eugenia buxifolia, 47; ugni, I 70

Eulalia zebrina, 48

Euonymus radicans, 47

Euonymus radicans variegatus, I7 I

\section{F}

Fabiana imbricata, $18 \mathrm{I}$

Farfugium grande, 102

Fern allies, I 77

Ferns, British and foreign, 174, 175, I76; evergreen, native and foreign, 47 ; filmy, New Zealand, 16; syringing, I 38

Flag, Common, The, I 58

Flowers of bulbous plants "blind," 53

Flowering plants, Retarding, by refrigeration, 105

Foliage plants for grouping, 43; hardy for grouping, I69, I70, I7I, I72, I73; silvery, 48

Forget-me-not, the large flowered, 96

Forsythia suspensa, I8I

Freesias, 57 58, 59 
Freesia Leichtlinii, I62; refracta alba, 162

Fremontia californica, 74, I 87

Fritillaria Meleagris, I58; pallidiflora, I58; recurva, I 58

Fritillaries, 56

Fritillary, snake's-head, I 58

Fuchsias, I 8 I

Funkia grandiflora, 47, I7 I ; lancifolia tardiflora, 64, 162 ; sieboldiana, 4I, 172

G

GARDEN-BOOK, Use of, I 39 ; corridor, The, I I ; glass, The, 8 ; winter, The, 73

Gillenia trifoliata, I 82

Gladioli, 35, 60

Gladiolus Colvillei albus, 158 ; Lemoinei, 162 ; nanceianus, 162 ; ramosus, 158 ; Saundersii, 162

Glass, coloured, evil of, 2 I

Glazing, careful, necessity for, I 8

Goodyera pubescens, I I 8

Glory Pea, 85, I 87

Green fly, destroying, I 39

Greenhouse, cold, and routine work in, I 33 ; hardy plants for, 32,33 ; its advantages, I ; healthiness of, 4 ; moderate cost of, 5; management of, 6 ; aspect of the, I 5 ; possibilities of the, I40, I4I ; spring bulbs in, 46 ; working, the, I 3, I40

Grevillea rosmarinifolia, I88 ; thelemanniana, I 88

Groundsel, Cape, ivy-leaved, 47

Grouping, foliage plants for, 43

\section{$\mathrm{H}$}

Hamanthus albiflos, I62; puniceus, 162 ; sanguineus, 162 ; tigrinus, 162
Hard-wooded plants, 17 I ; cutting back, 87 ; some, 8 I

Hawthorns, 76

Heaths, 33, 35,86; watering, I 37

Heating, 23, 24

Hederoma tulipifera, 81

Heliotrope, 34

Helleborus niger, 94

Heuchera sanguinea, 98

Hoheria populnea, I 88

Honeysuckles, I 88, I 89

Hop, Japanese, I I 2

Hovea Celsii, 87, 88

Huntsman's Cup, The, I 19

Hyacinths, 49 ; Roman, 50

Hydrangeas, 182

Hypericum calycinum, 85 ; chinense, 85,182

\section{I}

INSECTICIDES, I 38, I 39

Iris alata, 42 ; bakeriana, 42 ; bolleana, 42 ; chinensis, I63; cristata, I58; Danfordiæ, 42 ; English, The, I 58 ; fimbriata, I63; germanica, I 58 ; Hausknechtii, 42; Heldreichi, 4I ; Histrioides, I58 ; Krelagei, I 58 ; orchioides, 42 ; pumila, I 58 ; reticulata, 42 ; reticulata and cyanea, I 58 ; sindjarensis, 4I, I 58 ; sophenensis, I 58 ; Spanish The, I 59 ; winter, 24

Irises, 39

Irises, The, 53, 54; Xiphioides, I 58 ; Xiphium I 59 Ivy, I I ; German, I 72 Ivies, I 7 I ; small-leaved 47 Ixias, 59,163

$\mathrm{J}$

JASMINES, II

Jasminum nudiflorum, 76 Judas tree, I 79

K

KaLmia latifolia, I 88

Kerria japonica, I 82 
Kew, Himalayan house at, 44 Kniphofia corallina, I 59; Macowani, I 59

Kniphofias, 64

\section{L}

Lachenalia Nelsoni, I63 ; tricolor, I63; luteola, I63; pendula, 60, 163

Lachenalias, 35, 57, 58, 59

Lady-Slippers, Hardy, The, I 8

Lapagerias, 188

Lapeyrousia cruenta, 163

Laurustinus, 76, 184

Libertia formosa, 163

Libonia floribunda, 34

Lilies, 62, 66, 67, 68, 69, 70, 7 I, 72 ; belladonna, 64 ; for pots, I66, 167, I68 ; Guernsey, 62, 63 ; Madonna, 67, 68, 69, 70, 71,72 ; Scarborough, 64, I 38

Lily of the Valley, Forcing, 28, 56 , I 57

Lonicera fragrantissima, I 82

Loniceras, I88, I89

\section{M}

Magnolia stellata, 182

Magnolias, 73

Malus floribunda, 76

Mammillaria lasiacantha, I 26

Mammillarias, 35 , I 25

Mesembryanthemum, 35 ; sowing, I 24, I 25 ; opening of flowers of, I 25

Mesembryanthemum aureum, I 24 ; bicolor, I 24 ; blandum, I 24; glaucum, I24 ; lacerum, I25; micans, I24; polyanthon, I 24 , I 25 ; spectabile, I24; tigrinum, I25; tricolor, II 3

Mignonette, the old-fashioned, I I I
Milla bifora, I 59

Mimulus, shrubby, The, 84 ; glutinosus, 84

Moccasin flower, The, in its wild state, I I 8 , I I9

Muhlenbeckia, 46; complexa, I 7

Myosotis dissitiflora, 96

Myrtle, Box-leaved, 75

Myrtles, I 7 I ; large and small leaved, 47

\section{$\mathrm{N}$}

NANDINA domestica, I 7 I

Narcissi, The, I 59

Narcissus, certain sorts of, 52 ; paper white, 5 I

Nerine, 62, 63, I 37

Nerines corusca, 163 ; Fothergilli, I63 ; pudica, I63 ; sarniensis, 163 ; undulata, 63 , 163

Nerium Oleander, 78

Neriums, 182

Nemesia strumosa, I I I

\section{O}

OleANDER, The, 78

Olearia macrodonta, I 89

Orange-flower, Mexican, I 80

Orchids, bog in pans, II 8; hardy, II 6

Orchis, Bee, I16; Fly, I16 ; foliosa, I I 7, I I 8

Orchises, Terrestrial, difficulties in their culture, I I 7

Origanum Dictamnus, 172

Ornithogalum aureum, I64 ; arabicum, I64 ; nutans, var. boucheanum, I 59

Ornithogalums, 62

Orobus, 33 ; vernus, 96

Othonna cheirifolia, I 72

Oxalis Bowei, I64; cernua, 59, I64; enneaphylla, I64; floribunda, I 59 ; lobata, incarnata, 159 


\section{P}

Palms, Fan, 45 ; hardy, 170

Pancratium illyricum, 164 ; maritimum, 164

Paradisea Liliastrum major, I 59

Parochetus communis, for hanging baskets, IO3

Pea, Shamrock, for hanging baskets, $\mathrm{IO}_{3}$

Peas, Sweet, under glass, I I I

Pelargoniums, 34

Pentstemon Cobæa, I I 4; Murrayanus, II 4

Perennials, autumn, under glass, 101; hardy, for spring, 94

Pernettya mucronata, 183

Phalaris arundinacea variegata, 172

Phyllocacti, I 23

Phyllocactus crenatus, I23; phyllanthoides, 123

Physalis Alkekengi, 103 ; Franchetti, 102

Pieris floribunda, 183

Pimelia decussata, 87

Pink, common white, under glass, I 10

Plantain Lily, The, I 7 I

Plants, greenhouse, suitable and unsuitable, half-hardy, 34 ; hardy for greenhouse, 32, 33; hard-wooded, I9I ; pot, in summer, I30, I 31 , 132; of stiff character, grouping, 127; suitable for flowering in Alpine house from January to May, I45- $^{-}$ I52; pot, time to prune, I 36 ; pot, training and pruning of, 135 ; watering, 137

Plumbago capensis, 189

Poinciana Gilliesii, 74

Polyanthus primrose in the greenhouse, 98

Polygala dalmaisiana, 85

Polygonatum multiflorum, I 72
Pomegranate, The, 79, 183

Poppies, Iceland, The, I 13

Portulacas, The, I 3

Potting-shed, The, 128

Potting, Tools to use in, 130

Primroses in greenhouse, 98

Primula, Chinese, 34; imperialis, 100 ; megaseæfolia, 39 ; Sieboldi in pots, propagation of, 9

Primulas, Alpine, 33

Prunus, 72 ; japonica fl. pl., 76 ; rosea plena, 183 ; sinensis alba plena, 183 ; triloba fl. pl., 183

Punica granata, 79

Pyrethrum uliginosum for autumn, 102

\section{R}

Ranunculus, 54 ; asiaticus, I 59

Red-hot Pokers, 64, I 59

Refrigeration, Retarding flowering plants by, 105

Reineckia carnea variegata, 172

Rhapiolepis japonica, 183

Rhododendron ciliatum, 78 ; dauricum, 87 ; nobleanum, 77 ; racemosum, 78

Rhododendrons, 33, 35, I 84, I 89; hardy, 77 ; Himalayan, 9,73

Ribbon grass, The, 47,172

Richardia æthiopica, I 64

Rock-cress, White, 96

Roscoea purpurea, 164

Roses, 89, 90, 91, 92, 93 ; Tea, II ; pruning, I36

Ruscus racemosus, I 70

S

SALPIGLOSSIS, I I I

Salvia azurea grandiflora, 105 ; coccinea superba, I05; ges- 
neræfolia, I05; Hians, I0; patens, I05; Pitcheri, I05; rutilans, I05; splendens, I05

Salvias, hardier, The, 105

Sarracenia flava, II9; purpurea, II9

Sarracenias, The hybridisation possibilities, I I 9

Saxifraga burseriana major, 39 ; crassifolia as a pot plant, 97

Saxifrages, 33, 39, 40, 4I

Scilla, 56

Seed-sowing, I 34

Senecio Kæmpferi, I 02 ; mikanoides, 47,172 ; maritima, 172

Senna, Scorpion, I80

Shading, 28, 29

Shooting, 20

Shrubs, flowering, 73, I 78, I 79, I $80,181,182,183,184,185$, I86, I87, I88, I89; miscellaneous, for under glass, 78

Sibthorpia europæa variegata, I 73

Snowdrops, 55

Soil for potting, the best, 128 , I 29

Soldanellas, 39, 4 I

Solomon's seal, 46, I 72

Soot-water, making, I 39

Sophora tetraptera, I 89

Sparaxis pulcherrima, 59, 64 ; pendula, I 64

Spiræa Van Houttei, 77, I84

Spiræas as pot plants, 77

Sprekelia formosissima, 164

Spring, Hardy perennials for, 94

Sternbergia fischeriana, 160

Stock all the year round, I IO

Stocks in the unheated greenhouse, I IO ; Ten-week, I IO

Stokesia cyanea, IO2

Structures, flowering shrubs for large, 185

St. John's Wort, 85

Succulent plants, 16 ; for the greenhouse, 121 ; summer treatment of, 126

Swainsonia galegifolia alba, 85

Syringe, Brass, its use in watering, I 38

\section{$\mathrm{T}$}

TEMPERATURE, regulation of, 23

Thistles, Fish-bone, The biennial, I 2

Thorn, Glastonbury, 76

Thrips, destroying, I 39

Tiarella cordifolia, 98

Tomatoes, 28

Tools to use in potting, 130

Tremandra verticillata, 87

Tricyrtis hirta, 103

Trillium grandiflorum, 160

Tropæolum azureum, 61 , I65 ; brachyceras, 6I, 165; tricolorum, I65; tricolorum Jaratti, 6I

Tropæolums, I I I climbing, 6I

Troughs, zinc, for growing plants in, 96

Tubers and bulbs for associating with Alpine plants in flower from January to May, I 53-156; half-hardy, I6I; for unheated greenhouse, 49

Tulipa clusiana, 160 ; fragrans; 160 ; retroflexa, 160

Tulips, dwarf, 50

\section{V}

VACcinium serpens, 190

Vallota purpurea, 64, 138, I65

Veltheimia viridifolia, 62,165

Ventilation, 25, 26, 27

Veronica cupressoides, I73; hulkeana, 74, 184; Hectori, I93; speciosa variegata, 184 
Veronicas, New Zealand, 74 Viburnum plicatum, I84; lucidum, 76

Vine, II

\section{W}

Wallflower, Belvoir Castle, I09; Harbinger, I09

Wallflower, German double, in the unheated greenhouse, and sowing seed of, 109

Wardian-case, value of, I 33

Watering plants, I 37

Weigela hortensis nivea, 75

Watsonia Ardernei, 165; angusta, I65

Watsonias, 62

Winter Sweet, I 86

Wistaria, 76 ; sinensis, I 84

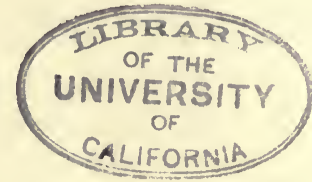

Printed by Ballantyne \& Co. Limited

Tavistock Street, London 




\section{DAY USE}

RETURN TO DESK FROM WHICH BORROWED EIRCULATION DEPARTMENT

This book is due on the last date stamped below, or on the date to which renewed.

Renewed books are subject to immediate recall.

\section{NOV 12197368 \\ HECO ID NOV 9 73.8 AM}

REC. CIR DEC 17 i 979

OCT 161975 OCT 231980 1 iasu

REf fHR dUH 2077

\section{DEC 11979}

KEC. Cir NOV 4. $29: 3$

AEदिंत्र 1979:

LD21-35m-8,'72

(Q4189s10) 476-A-32
General Library

University of California Berkeley 

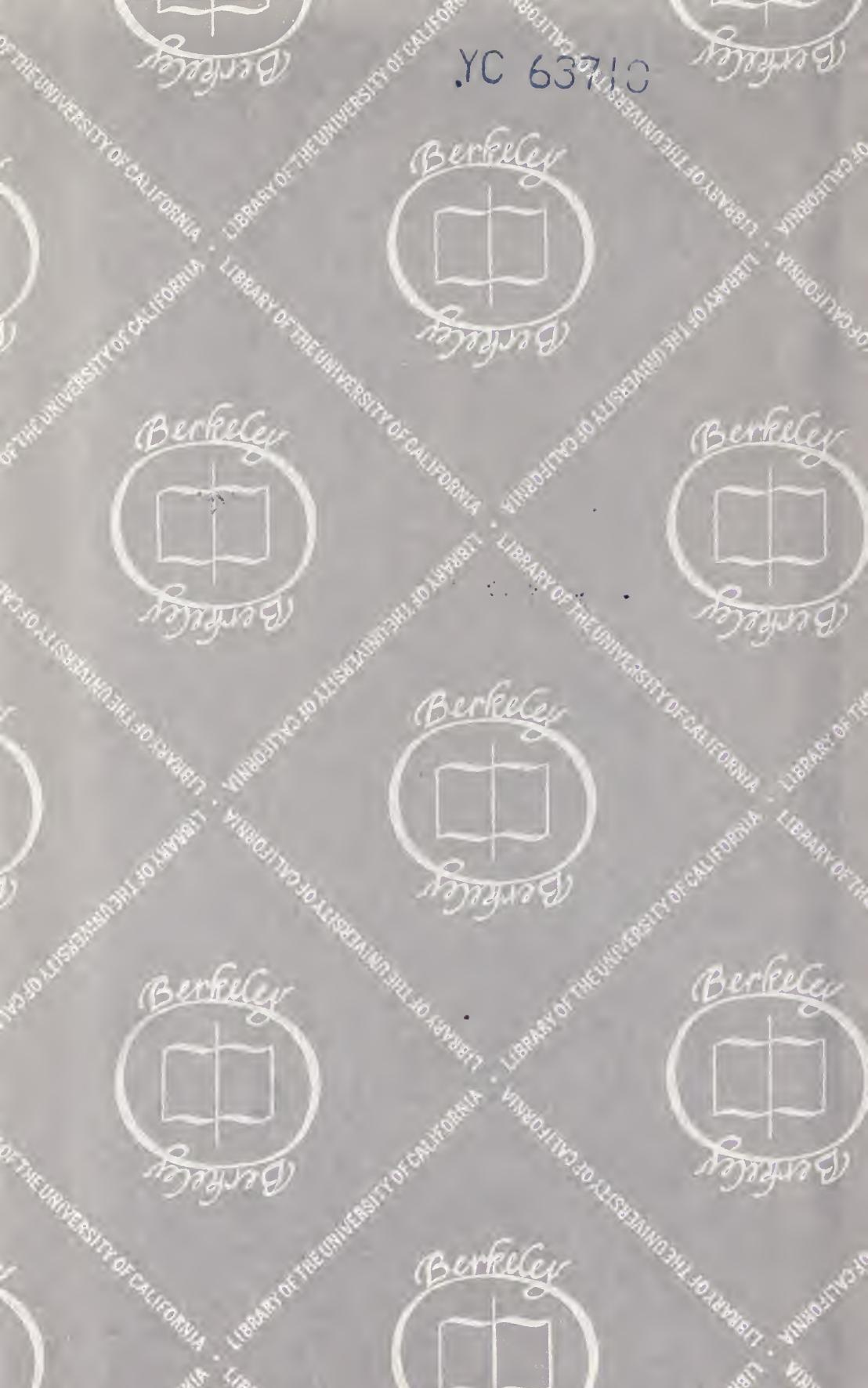
